\title{
MACROINVERTEBRADOS ACUÁTICOS COMO INDICADORES ECOLÓGICOS DE CAMBIOS EN EL USO DEL SUELO EN MALLINES DEL SUDOESTE DE LA PROVINCIA DE RÍO NEGRO
}
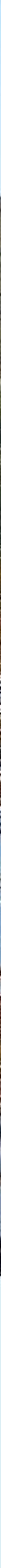

Co-Directora: Dra. Nora Gómez 


\section{Macroinvertebrados acuáticos como indicadores ecológicos de cambios en el uso del suelo en mallines del sudoeste de la Provincia de Río Negro}

Lic. Pablo Antonio Macchi

Trabajo de tesis para optar al título de Doctor en Ciencias Naturales

Directora: Dra. María Laura Miserendino

Co-Directora: Dra. Nora Gómez

Febrero de 2017

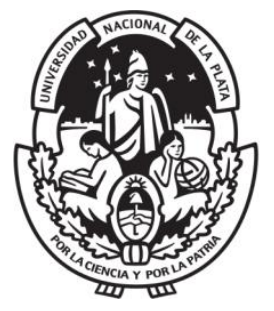

FACULTAD DE CIENCIAS NATURALES Y MUSEO

UNIVERSIDAD NACIONAL DE LA PLATA 
A mi amado Ulises, 


\section{Indice}

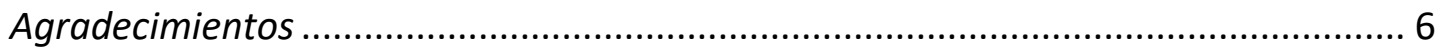

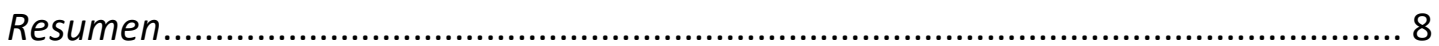

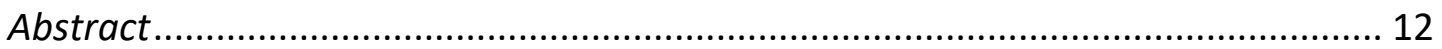

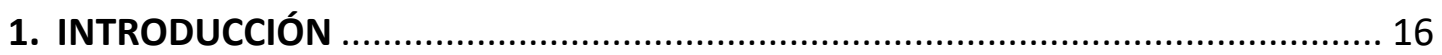

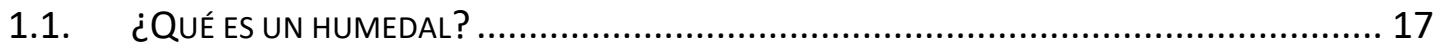

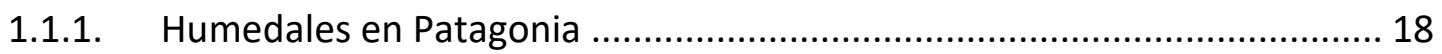

1.2. DINÁMICA Y FUNCIONAMIENTO DE LOS HUMEDALES ............................................... 19

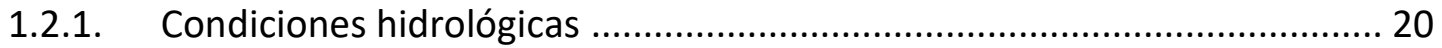

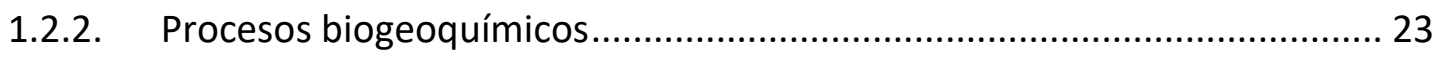

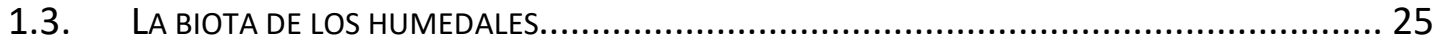

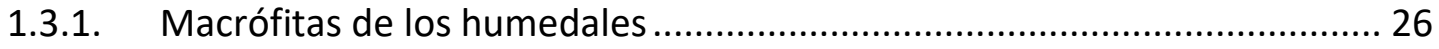

1.3.2. Macroinvertebrados acuáticos de los humedales .................................... 28

1.3.3. Biodiversidad macroinvertebrados en mallines ...................................... 30

1.4. USO DEL SUELO Y DEGRADACIÓN DE LOS HUMEDALES …........................................ 31

1.4.1. Macroinvertebrados acuáticos como bioindicadores ............................... 33

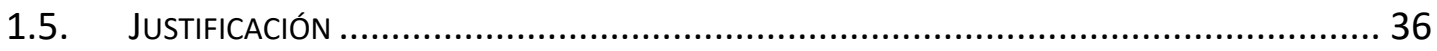

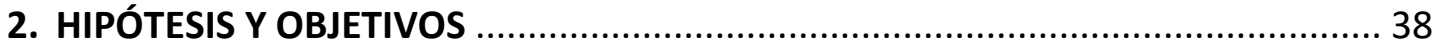

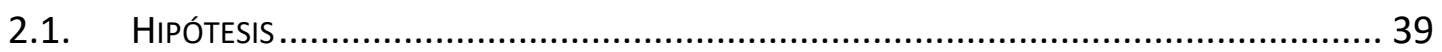

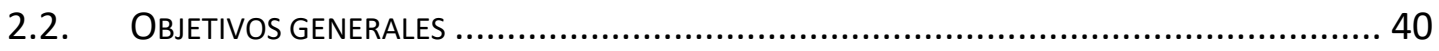

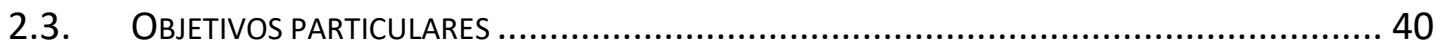

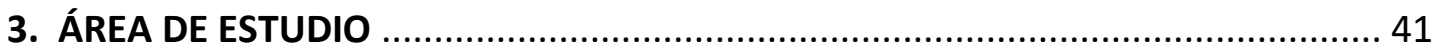

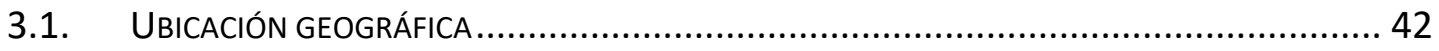

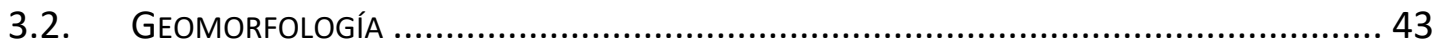

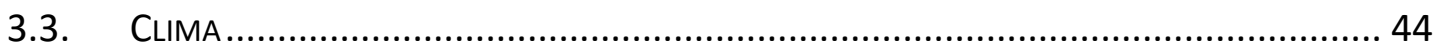

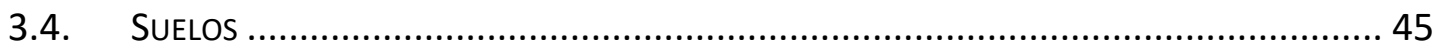

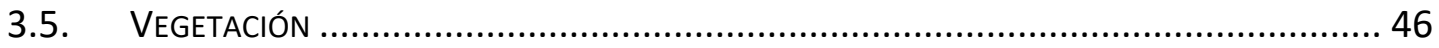

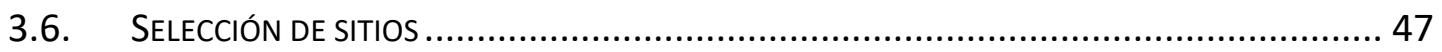

3.7. DESCRIPCIÓN DE LOS MALLINES AGRUPADOS POR DE USO DE SUELO …............................49

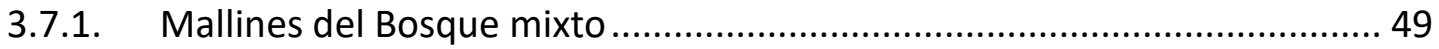




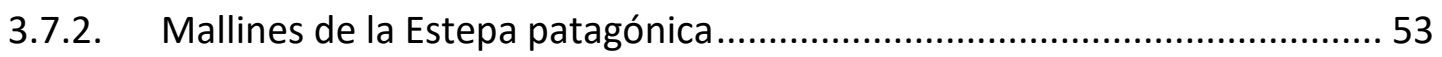

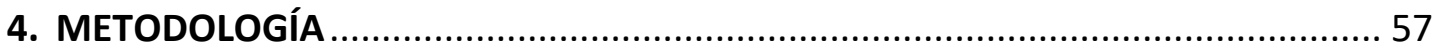

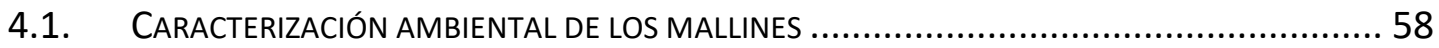

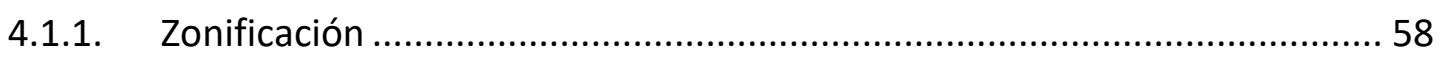

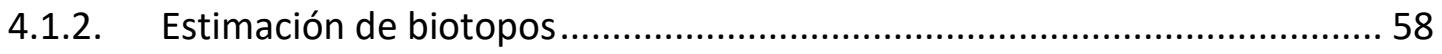

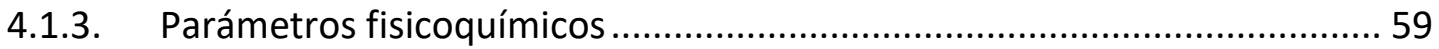

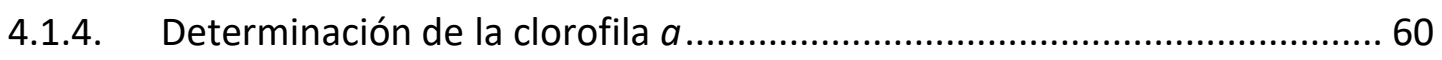

4.1.5. Análisis de nutrientes y estado trófico .....................................................6 60

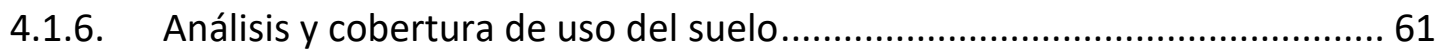

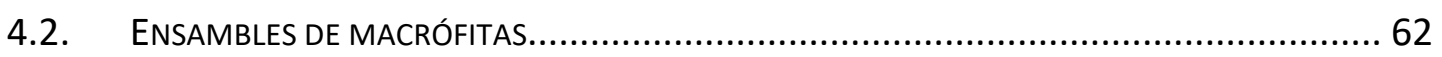

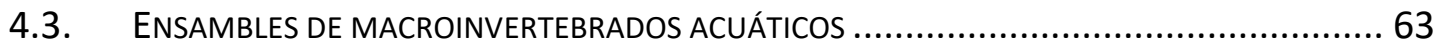

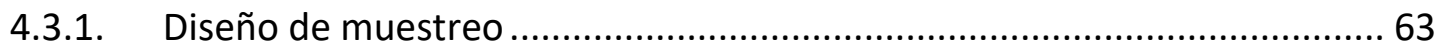

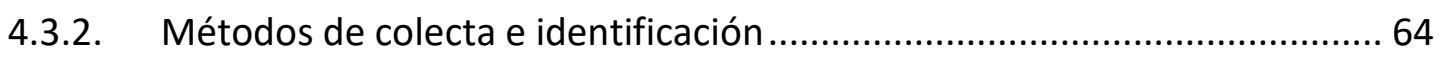

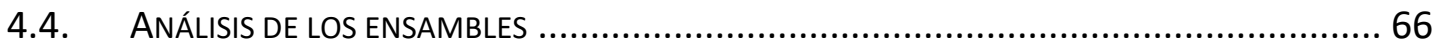

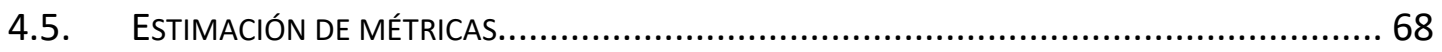

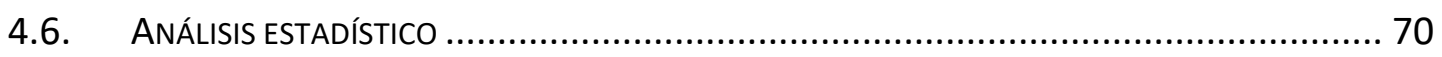

4.6.1. Exploración y comparación de parámetros ambientales y atributos

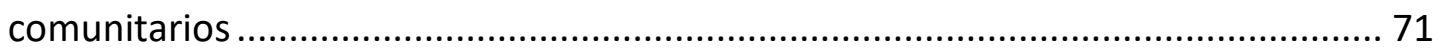

4.6.2. Ordenamiento de mallines según parámetros fisicoquímicos ................... 71

4.6.3. Relaciones especie-ambiente ............................................................. 72

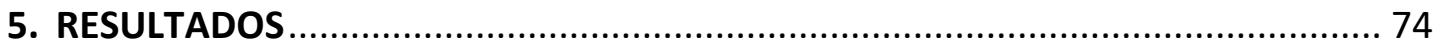

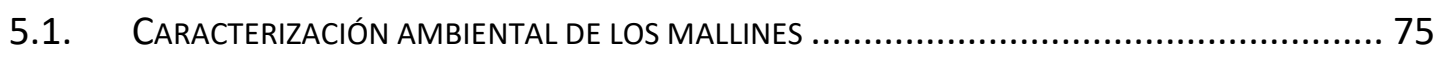

5.1.1. Descripción ambiental según biozona ..................................................... 75

5.1.2. Descripción ambiental por biozona según uso del suelo........................... 90

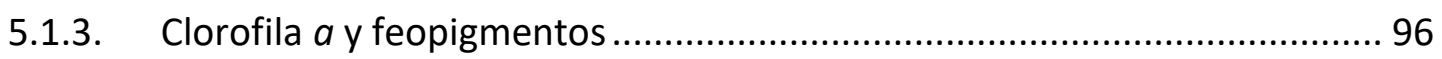

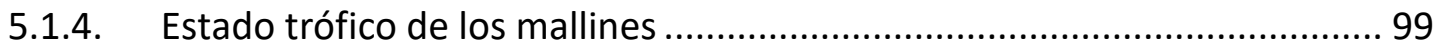

5.1.5. Cobertura de suelo en las áreas de influencia de los mallines ................. 102

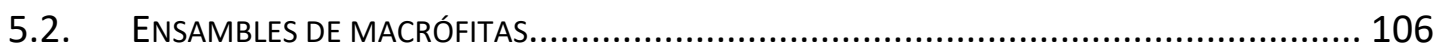

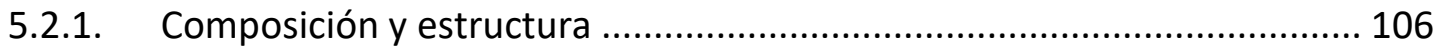

5.3. ENSAMBLES DE MACROINVERTEBRADOS ACUÁTICOS ............................................ 113

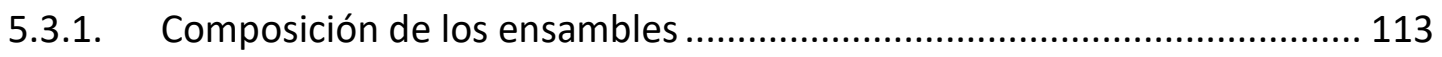

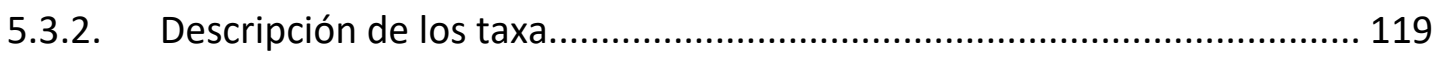


5.3.3. Invertebrados acuáticos de la columna de agua

5.3.4. Macroinvertebrados bentónicos........................................................... 138

5.4. ReLACIONES entre LAS CONDiciones ambientales $Y$ LOS ENSAMBles de

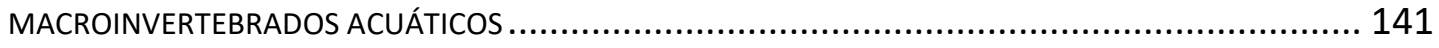

5.5. ANÁLISIS DE MÉTRICAS: INVERTEBRADOS Y RESPUESTA AL USO DEL SUELO ...................... 148

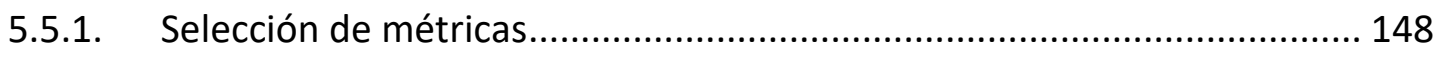

5.5.2. Relación estacional entre las métricas comunitarias y las variaciones ambientales

5.6. INTEGRACIÓN DE MÉTRICAS Y CARACTERÍSTICAS AMBIENTALES: RESPUESTA AL USO DEL SUELO EN MALLINES 158

6. DISCUSIÓN 162

6.1. BIODIVERSIDAD REGIONAL EN MALLINES DE RÍO NEGRO ........................................... 163

6.1.1. Ensambles de macroinverterbados acuáticos ......................................... 163

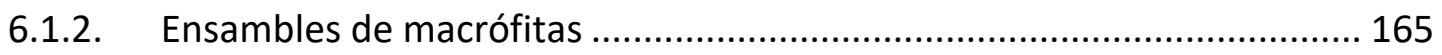

6.1.3. Variaciones de la biodiversidad a escala regional..................................... 166

6.1.4. Efectos locales que afectan a la biodiversidad regional .......................... 167

6.1.5. Estado trófico y su relación con la biodiversidad ................................... 170

6.2. EfECTOS DEL USO DEL SUELO SOBRE LA BIOTA DE MALLINES.................................... 173

6.2.1. Uso urbano y agrícola en mallines de bosque mixto ............................. 173

6.2.2. Uso agrícola en estepa patagónica ....................................................... 177

6.3. MÉtricas PARA El Monitoreo de LA CALIdAd del AGUA EN MALLINES........................ 180

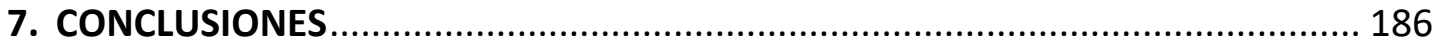

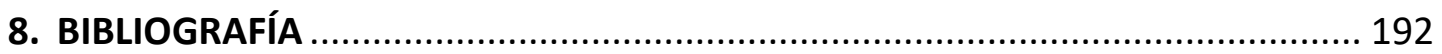




\section{Agradecimientos}

La concreción del presente trabajo de tesis, involucra a muchas personas, que desde diferentes lugares y formas, participaron haciendo su aporte, colaborando en el cierre de esta etapa de mi vida profesional, la que seguramente abrirá otras nuevas.

Agradezco enormemente a mi directora, Dra. María Laura Miserendino, por su compromiso y confianza al involucrarse en este proyecto desde el primer momento en que me salió la beca. Su trabajo ha siempre sido muy inspirador y guía a lo largo de mi formación en Limnología, y su apoyo, dedicación, junto a su visión crítica, fueron fundamentales para que realizará esta tesis. ¡Muchas gracias Laura!

A la Dra. Graciela Calabrese, mi directora de beca, quién sin conocerme, acepto incorporarme a sus proyectos de investigación sobre mallines, sumando a los macroinvertebrados. Su trabajo incansable para la búsqueda de financiación, su aliento permanente, así como su compromiso para encarar cada una de las salidas al campo y las determinaciones de macrófitas, fueron fundamentales para la obtención de los datos. ¡Muchas gracias Graciela!

A la Dra. Nora Gómez, quién durante nuestro primer encuentro en el Taller de Bentos realizado en Cayastá, acepto ser mi codirectora. Su mirada crítica y reflexiva, fueron sumamente importes en el análisis de los resultados, así como su esmero en sus explicaciones ante cada una de mis consulta. iMuchas gracias Nora!

A Ulises, mi motor inspirador diario, itú alegría me contagia!

A Yeny, por entrar en mi vida y mostrarme que exiten otros caminos para ser feliz!

A mis colegas y amigos, Cecilia Brand y Luis Epele, quienes siempre estuvieron ante cada consulta ayudándome y me alentaron en los momentos más difíciles. ¡Gracias amigos! 
A Pamela, por tu aliento para decidirme a tomar la beca e iniciar este doctorado.

Al Dr. Silvio Casadio, codirector de mi beca, por integrarme en el Instituto de Investigación en Paleobiología y Geología de la UNRN, donde continuaré mi trabajo como investigador.

A la Universidad Nacional de Río Negro, por darme la oportunidad de tener una beca de postgrado como docente universitario, que me permitiera crecer profesionalmente.

A todos los Profesores, que a lo largo de mi carrera han aportado en mi formación académica y científica.

A Cristián Diaco y a los alumnos de la carrera de Ingeniería Ambiental de la sede Andina (Bariloche), por su colaboración y acompañamiento en la preparación y ejecución de las laboriosas salidas de campo.

A la Administración de Parques Nacionales, así como también a los propietarios y encargados de los campos, que nos permitieron el acceso a mallines y nos brindaron valiosa información.

Al tribunal evaluador, integrado por la Dra. Mercedes Marchese, la Dra. Alejandra Rumi y el Dr. Ricardo Albariño, quienes con sus observaciones y sugerencias enriquecieron el trabajo final.

Este trabajo de tesis se llevó a cabo con el financiamiento de los Proyectos de Investigación PI-UNRN: Caracterización y evaluación del estado de degradación de los humedales, como base para la gestión sustentable en la región semiárida del sudoeste de la Provincia de Río Negro (PI-UNRN 40-B-050/10); Caracterización ecológica de mallines de la provincia de Río Negro utilizando indicadores biológicos (UNRN PI 40-B-254/12) y Relevamiento y evaluación ambiental de humedales en el ejido de San Carlos de Bariloche (UNRN PI 40-B-359/14). 


\section{Resumen}

Los mallines patagónicos (del mapuche malliñ) son áreas o bajos inundables que se localizan a lo largo del paisaje. Son típicos ecosistemas de humedales, cuya génesis se encuentra asociada a la presencia de agua cerca de la superficie del suelo, constituyendo formaciones netamente diferenciadas de las áreas circundantes, que albergan una rica y variada biodiversidad.

La modificación del paisaje y el uso del suelo debidos a la ganadería, a la agricultura y al avance de la urbanización, han sido las principales causas de la pérdida de la diversidad biológica y de la degradación de los servicios ecosistémicos de los mallines. De esta forma, el objetivo del presente estudio fue determinar qué medidas o estimadores de la comunidad de macroinvertebrados resultan más apropiados para evaluar la degradación ambiental en los mallines patagónicos. Para ello, se seleccionaron 15 mallines en el sudoeste de la Provincia de Río Negro sujetos a diferentes usos del suelo. En el diseño se agruparon los mallines de acuerdo a diferentes categorías de uso $(n=3)$, siendo el agrícola-ganadero y el urbano los de la biozona de bosque mixto y el agrícola-ganadero el asignado en la estepa patagónica, todos se contrastaron con sitios de referencia en su respectiva biozona $(n=3)$. Los mallines fueron visitados en dos periodos, en aguas altas (septiembre 2012) y en aguas bajas (diciembre 2012).

Se zonificó el área de cada uno de los mallines (central, intermedia y periférica) mediante el procesamiento digital de imágenes Landsat multiespectral ETM+ e imágenes de alta resolución espacial (Basemap, ArcGIS de 10.3). Asimismo, utilizando imágenes satelitales actuales (Google Earth 2012 y Basemap de ArcGIS 10.3), se cuantificó la transformación del suelo en la periferia de los cuerpos de agua o áreas inundadas de los mallines (áreas perimetrales a 100 y 500 metros), en las categorías: \% Natural, \% Cuerpos de agua, \% Agrícola, \% Urbano y \% Suelo degradado. En terreno y previo al muestreo en cada sitio, se estimó de forma ocular el porcentaje de cobertura de biotopos, lo que se realizó a partir de una evaluación de la complejidad estructural de los hábitats disponibles para los macroinvertebrados acuáticos (vegetación compleja, vegetación simple, aguas 
someras sin vegetación y aguas profundas sin vegetación). En cada momento de muestreo se registraron in situ los principales parámetros fisicoquímicos del agua (profundidad, temperatura, $\mathrm{pH}$, conductividad eléctrica y oxígeno disuelto) y en el laboratorio se determinaron los principales nutrientes (nitritos + nitratos, amonio, nitrógeno total, fósforo reactivo soluble y fósforo total), la alcalinidad y los sólidos suspendidos totales. Para la estimación de la densidad del fitoplancton, se determinó la concentración de clorofila a en la columna de agua. En la zona central de los mallines se realizó un inventario de macrófitas y se estimó el porcentaje de cobertura mediante el método fitosociológico relevé de Braun-Blanquet.

En cada sitio se colectaron muestras de macroinvertebrados de columna de agua $(n=3)$, utilizando redes de mano (D-frame de $250 \mu \mathrm{m})$ y de sedimentos $(n=3)$ mediante un corer de $12 \mathrm{~cm}$ de diámetro, totalizando $\mathrm{n}=180$ muestras. En laboratorio se realizó la separación de los organismos, los que se identificaron hasta el nivel taxonómico más bajo posible. Con los datos de las abundancias se calculó la riqueza taxonómica, la diversidad de Shannon-Wiener, la equitatividad de Pielou, la densidad y la biomasa de macroinvertebrados acuáticos. Se analizaron los grupos funcionales (desmenuzadores, raspadores, predadores, colectores recolectores, colectores filtradores y picadores herbívoros). Finalmente, se efectuó una evaluación y selección de métricas de macroinvertebrados en relación a su respuesta frente al disturbio asociado al uso del suelo.

Con los datos ambientales de los mallines, según biozona, se realizó un análisis de componentes principales (ACP) para examinar la variación en las características físicas y químicas de los sitios de estudio debidos a los usos del suelo. Para evaluar si existieron diferencias entre las características ambientales de los mallines, según biozonas y según usos del suelo, se realizaron análisis no paramétricos (ANOVA Kruskal Wallis y Mann Whitney U Test). Además, para examinar la relación entre las asociaciones de invertebrados acuáticos o métricos seleccionados y las variables ambientales, se efectuaron análisis de correspondencias canónicas (ACC) o análisis de redundancias (RDA). 
Los resultados del estudio demostraron que los mallines de la Provincia de Río Negro albergan una diversa y abundante biota acuática. Se reconocieron 76 taxa de macrófitas, distribuidas en 22 familias. A escala de paisaje, la mayor diversidad de macrófitas se registró en los mallines de bosque, sin embargo agrupados por uso de suelo, los sitios agrícolas y urbanos presentaron los valores más bajos de riqueza taxonómica y cobertura de nativas, con reducción o ausencia de plantas subemergentes (principalmente Myriophyllum quitense y Potamogeton linguatus).

La comunidad de macroinvertebrados presentó una alta riqueza taxonómica con 145 taxa identificados, distribuidos en 5 Phyla y 65 familias. Dentro de ellos, Chironomidae (Diptera) y Dytiscidae (Coleoptera), en ese orden, constituyeron los taxa más ricos y frecuentes. Al comparar los ensambles de macroinvertebrados acuáticos de la columna de agua respecto de aquellos de los sedimentos, fue notoria la diferencia entre ambas comunidades, hallándose en columna 145 taxa, y en sedimentos una comunidad notablemente pobre totalizando sólo 29 taxa. En términos de densidad y biomasa bentónica, se destacó Oligochaeta principalmente por la presencia de Lumbriculus variegatus y Limnodrilus hoffmeisteri.

A escala de paisaje, la riqueza taxonómica más alta fue documentada en los mallines de bosque mixto, los que congregaron casi el $93 \%$ de los taxa descriptos. La valoración de los atributos estructurales por uso de suelo, mostró ensambles de macroinvertebrados más pobres o simplificados en los sitios disturbados respecto de aquellos de referencia en ambas biozonas.

La calidad del agua reflejó un patrón natural de aumento de $\mathrm{pH}$ y salinidad en consonancia con el gradiente de precipitaciones oeste-este, no obstante se evidenció un destacado aumento significativo en aquellos mallines con mayor disturbio antrópico, debido a la ganadería o a la urbanización. Asimismo, los valores de nutrientes fueron más altos en los mallines impactados, los que presentaron mayor biomasa del fitoplancton y síntomas evidentes de eutrofización.

La alteración antrópica de los mallines fue evidenciada por ocho métricas comunitarias las que fueron validadas por una secuencia de selección, éstas respondieron de igual manera en cada biozona, independientemente de sus 
características particulares debidas al clima y a la geomorfología. Las métricas de riqueza resultaron ser las más sensibles frente al disturbio y entre ellas se destacaron, por responder de acuerdo a lo esperado en términos de correlaciones significativas con los parámetros ambientales: la riqueza taxonómica, el " $\mathrm{n}$ ” de taxa de insectos", el " $n^{\circ}$ de taxa OCD (Odonata- Coleoptera- Diptera)" y el " $n^{\circ}$ de taxa de quironómidos". Entre las métricas de composición y abundancia, el “\% OCD, el “\% de dípteros" y el "\% de quironómidos", también mostraron una respuesta esperada a lo largo del gradiente de disturbio. De esta forma, los valores de estas métricas declinan en mallines, que debido a los usos del suelo, presentaron una mayor degradación de la calidad del agua (aumento de $\mathrm{pH}$, conductividad eléctrica y fósforo reactivo soluble), una fuerte reducción de la complejidad estructural del hábitat (\% de vegetación compleja), dada fundamentalmente por la riqueza y diversidad de macrófitas $y$, una mayor cobertura de suelo degradado (áreas perimetrales a 100 metros). Sólo la métrica de composición el "\% de crustáceos", evidenció una respuesta positiva conforme aumentó el grado de disturbio.

El presente trabajo destaca la vulnerabilidad de los mallines frente a los disturbios antrópicos debidos a los diferentes usos del suelo y el rol de las comunidades de macroinvertebrados como potenciales bioindicadores. La diferente respuesta entre dípteros, particularmente quironómidos, y crustáceos, indica que estos grupos serían apropiados como indicadores de disturbio y podrán ser usados en el diseño de planes de vigilancia y monitoreo ambiental, contribuyendo a una mejor gestión y conservación de los mallines patagónicos. 


\section{Abstract}

Patagonian mallines (from Mapuche malliñ) are wet meadows areas which are widely distributed in the regional landscape. They are typical wetland ecosystems and its genesis is associated with the presence of water near the soil surface, creating clearly differentiated formations in the surrounding areas, which support a rich and varied species assemblages.

The modification of the landscape and land use due to livestock grazing, agriculture and advancing urbanization, have been the main causes of the loss of biodiversity after wetland degradation, with several ecosystem services being affected. Thus, the aim of this study was to determine what measures or estimates of the macroinvertebrate community are more appropriate for assessing the environmental degradation in the Patagonian mallines. In doing so, 15 mallines were chosen in the southwest of the Río Negro Province, subject to different land uses. Mallines were grouped according to different categories of land use $(n=3)$ : agricultural and urban in the biozone of deciduous forest and agricultural for the Patagonian steppe; all were compared with reference sites at their respective biozones $(n=3)$. Each site was visited during two periods, at high water period (September, 2012) and during shallow water period (December, 2012).

The area of each mallin was categorized (central, intermediate and peripheral) by digital image processing multispectral Landsat ETM+ and images of high spatial resolution (Basemap, ArcGIS 10.3). Furthermore, using current satellite images (Google Earth 2012 and Basemap ArcGIS 10.3), the transformation of soil was quantified on the periphery of the water bodies or flooded mallines areas (perimeter areas 100 and 500 meters), in the categories: \% Natural, \% Water bodies, \% Agricultural, \% Urban and \% Degraded land. In the field and before the sampling the percentage of biotopes coverage was visually estimated. This was based on an assessment of the structural complexity of habitats available to the aquatic macroinvertebrates (complex-structured vegetation, simple-structured vegetation, open water and benthic un-vegetated habitat). At each visit, the main physicochemical parameters of water (depth, temperature, $\mathrm{pH}$, conductivity and 
dissolved oxygen) were measured in situ and major nutrients (nitrites + nitrates, ammonium, total nitrogen, soluble reactive phosphorus, total phosphorus), alkalinity and total suspended solids were determined in laboratory. To estimate the density of the phytoplankton, the chlorophyll a concentration in the water column was determined. In the central area of the mallines, a macrophyte inventory was conducted. The coverage of aquatic plant (percentage) was estimated using the Braun-Blanquet relevé method.

At each site, macroinvertebrates were collected in the water column $(n=3)$ with a hand-net (D-frame 250 microns) and in sediment $(n=3)$ using a $12-\mathrm{cm}$ corer, totaling $n=180$ samples. Organism separation was conducted in the laboratory; they were identified to the lowest taxonomic level. Taxa richness, Shannon-Wiener diversity index, Pielou's equitability index, density and biomass of aquatic macroinvertebrates were calculated based on data abundances. Functional feeding groups (shredders, scrapers, predators, collector-gatherers, collector-filters and piercer-herbivores) were also analyzed. Finally, the evaluation and selection of best macroinvertebrate metrics regarding their response to land use disturbance was performed.

A principal component analysis (PCA) was performed to examine the variation in physical and chemical characteristics of the study sites due to land use. In the procedure, environmental data of mallines according to each biozone was employed. To assess differences between the environmental characteristics, according biozones and land use, non-parametric analyses were carried out (Kruskal-Wallis ANOVA and Mann-Whitney $U$ Test). In addition, to examine the relationship between associations of aquatic invertebrate's assemblages of selected metrics, and environmental variables, both, canonical correspondence analysis (PCA) and redundancy analysis (RDA) were conducted.

The results from this study showed that mallines of the Río Negro Province have a diverse and abundant aquatic biota. A total of 76 macrophyte taxa in 22 families were recognized. At a landscape perspective, the greatest diversity of macrophytes was recorded in mallines from the deciduous forest; however, 
grouped by land use, agricultural and urban sites had the lowest taxonomic richness and coverage of native, with reduced or absent submerged plants (mainly Myriophyllum quitense and Potamogeton linguatus).

Macroinvertebrate community showed high taxonomic richness with 145 taxa identified, distributed in 5 Phyla and 65 families. Chironomidae (Diptera) and Dytiscidae (Coleoptera) -in that order- were the richest and most frequent taxa. Comparison of macroinvertebrate assemblages between water column and sediments showed a marked difference at the two communities, totalizing 145 taxa in column, but a remarkable poor community in sediments with only 29 taxa. In terms of density and benthic biomass, just Oligochaeta was highlighted, which was explained by the presence of Lumbriculus variegatus and Limnodrilus hoffmeisteri.

At a landscape scale, the highest taxonomic richness was documented in mallines placed in the deciduous forest, which grouped almost $93 \%$ of the described taxa. The assessment of the structural attributes responses according to land use showed poorer assemblages or simplified macroinvertebrates communities at disturbed sites comparing with references sites, at both forest and steppe biozones.

Water quality reflected a natural pattern of increased $\mathrm{pH}$ and salinity according to the west-east rainfall gradient; however a marked and significant increase was observed in those mallines with more anthropic disturbance due to livestock or urbanization. In addition, the nutrient values were higher at impacted mallines, which showed higher biomass of phytoplankton and clear signs of eutrophication.

Anthropic alteration of mallines was evidenced by eight community metrics which were validated by a sequence of selection. These responded similarly at both biozones, regardless of their particular characteristics due to the climate and geomorphology. Richness metrics proved to be more sensitive to disturbance and among them, the following metrics appeared as more sensitive since they responded according to our expectations in terms of significant correlations with environmental parameters: taxonomic richness, " \% number of insect taxa," \% 
number of OCD (Odonata- Coleoptera- Diptera) taxa" and "number of chironomids taxa". Among composition and abundance metrics, "\% OCD, "\% of dipterans" and "\% chironomids" also showed an expected response along the disturbance gradient. Thus, values of these metrics declined in mallines that, due to land use, showed further degradation of water quality (increased $\mathrm{pH}$, electrical conductivity and soluble reactive phosphorus), a strong reduction in structural complexity of the habitat (\% of complex vegetation), mostly explained by richness and diversity of macrophytes, and a greater coverage of degraded soil (perimeter areas to 100 meters). Only metric composition, the "\% crustaceans", showed a positive response thus, metric values increased as did the degree of disturbance.

This work highlights the vulnerability of mallines facing anthropogenic disturbances resulting from different land uses activities, and evidenced the role of macroinvertebrate communities as potential bioindicators. The different response in dipterans, particularly chironomids, and in crustaceans, indicates that these groups would be appropriate as indicators of disturbance and may be used in the design of look out plans and environmental monitoring, contributing to enhance the management and conservation of the Patagonian mallines. 


\section{INTRODUCCIÓN}

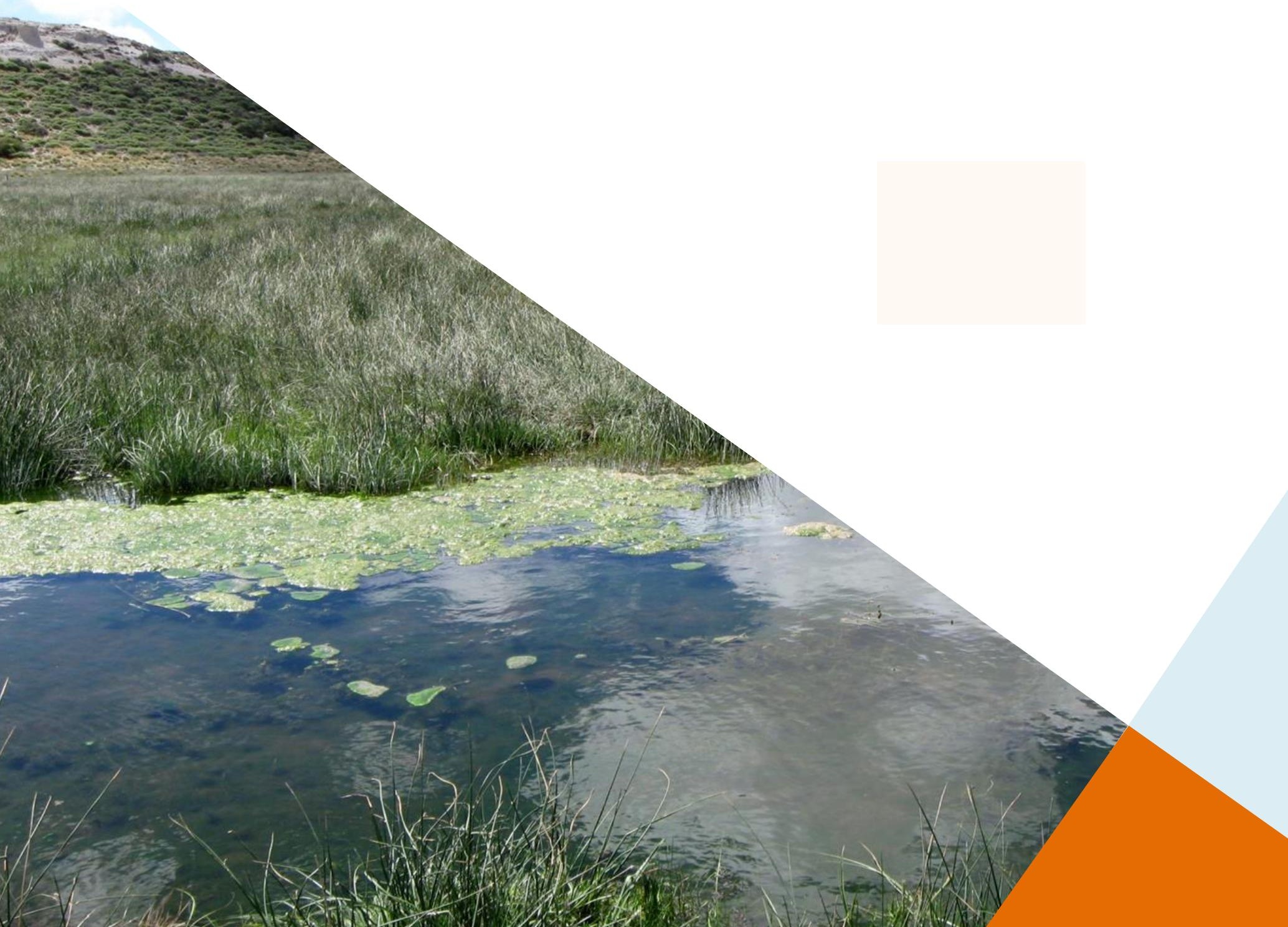




\section{1. ¿QUÉ ES UN HUMEDAL?}

Un humedal es un área de la superficie terrestre que está temporal ó permanentemente inundada, regulada por factores climáticos y en constante interrelación con los seres vivos que la habitan. Engloban a una vasta diversidad de ambientes acuáticos, incluyendo cuerpos de agua temporales, lagunas, turberas, bofedales y zonas litorales de lagos, ríos y mares (www.ramsar.org).

El concepto humedal es relativamente nuevo y abarca una amplia variedad ambientes (National Research Council 1995). Básicamente cualquier ecosistema con aguas someras o suelos saturados, desarrollados bajo condiciones anaeróbicas, cuya vegetación (hidrófitas) es dominada por especies diferentes a las circundantes de zonas altas, es considerado un humedal (van der Valk 2012, Mazzoni y Rabassa 2013).

Los humedales constituyen una interfase o posición de ecotono entre los ecosistemas terrestres y los ecosistemas acuáticos, haciéndolos diferentes de cada uno aunque altamente dependientes de ambos (Bobbink et al. 2007). Están conectados hidrológicamente al agua subterránea y biológicamente, a través del movimiento y desplazamiento de muchos organismos (Mitsch y Gosselink 2007).

Se encuentran entre los ecosistemas más productivos de la Tierra (Merritt y Lawson 1979, Poi de Neiff et al. 2006) y proporcionan innumerables y valiosos servicios que contribuyen al bienestar humano. Estos incluyen fuentes de alimento, abastecimiento y purificación de agua, regulación del clima, regulación de inundaciones, retención de suelo y sedimentos, producción de pasturas, transformación de materiales químicos, biológicos y genéticos, la protección costera, oportunidades de recreación y turismo, entre otras (Malvarez y Bó 2004, Assessment M. E. 2005, Zedler y Kercher 2005, Batzer y Sharitz 2014).

Así como los humedales naturales están declinando en muchas partes del mundo, debido a presiones antrópicas (Gibbs 2000, Daniels y Cumming 2008), otros son continuamente creados para una amplia variedad de propósitos: para mitigar inundaciones (Persson et al. 1999), para retener sedimentos y carbono orgánico 
(Smith et al. 2002, Brainard y Fairchild 2012), para secuestrar y transformar los nutrientes (Brix 1997, Sundaravadivel y Vigneswaran 2001), para interceptar contaminantes tóxicos que arrastra la escorrentía durante las tormentas (Herrmann 2012), para mejorar la biodiversidad (Williams 2006, Oertli et al. 2005, Ruhi et al. 2011, Hassall y Anderson 2015) o para cumplir varios de estos objetivos de forma simultánea (Jurado et al. 2010, Ruhi et al. 2011). Sin embargo, muchas veces la consideración de la construcción de estos humedales no es justificada desde el punto de vista ecológico, ya que se ignora su importante contribución a la biodiversidad y funcionamiento de los ecosistemas a escala de paisaje (Ruhi et al. 2016).

\subsubsection{Humedales en Patagonia}

En la Patagonia Argentina, región caracterizada por un marcado gradiente de precipitaciones oeste-este ( 3.000 a $200 \mathrm{~mm}$ de media anual), se localizan a lo largo del paisaje pequeñas áreas inundables que forman humedales denominados mallines, palabra de origen mapuche para designar tierras pantanosas o bajos anegadizos (Espósito 2003). Ocupan aproximadamente el $5 \%$ de la superficie total de esta región (Iriondo 1989) y se ubican desde la cordillera de los Andes hasta la costa Atlántica.

Los mallines son típicos ecosistemas de humedales con vegetación azonal que forman praderas higrófilas de ciperáceas, juncáceas y gramíneas, cuya génesis se encuentra asociada a la presencia de agua cerca de la superficie del suelo, constituyendo formaciones netamente diferenciadas de las áreas circundantes (Raffaele 1999, Horne et al. 2004, Mazzoni y Rabassa 2013). Constituyen pequeños ecosistemas en áreas muy localizadas del paisaje y relativamente aisladas, o conforman un sistema de humedales más o menos continuos o encadenados que ocupan las líneas de drenaje en sierras y mesetas o en las planicies de inundación de los grandes valles, cauces fluviales, cubetas y depresiones, formando pequeños cuerpos de agua superficial como charcas y lagunas someras (Rabassa y Brandani 1983, Bran et al. 2000, Mazzoni y Vázquez 2004). 


\subsection{DiNÁMICA Y FUNCIONAMIENTO DE LOS HUMEDALES}

Los mallines, así como otros humedales, son ecosistemas complejos cuya dinámica está relacionada con una gran variedad de procesos físicos, químicos y biológicos (Reddy y DeLaune 2008). El clima y la geomorfología definen la formación de un humedal (Euliss et al. 2004), sin embargo su estructura y funcionamiento está regulado principalmente por la hidrología (Malvarez y Bó 2004, Williams 2006), quien a su vez interviene en los procesos fisicoquímicos (suelo - agua), factores que en conjunto controlaran la flora y fauna residente (Mitsch y Gosselink 2007, Batzer y Boix 2016) (Figura 1.1). A su vez la biota ejerce una retroalimentación sobre los componentes de los humedales, controlando la hidrología y química de su ambiente a través de múltiples mecanismos (Mitsch y Gosselink 2007).

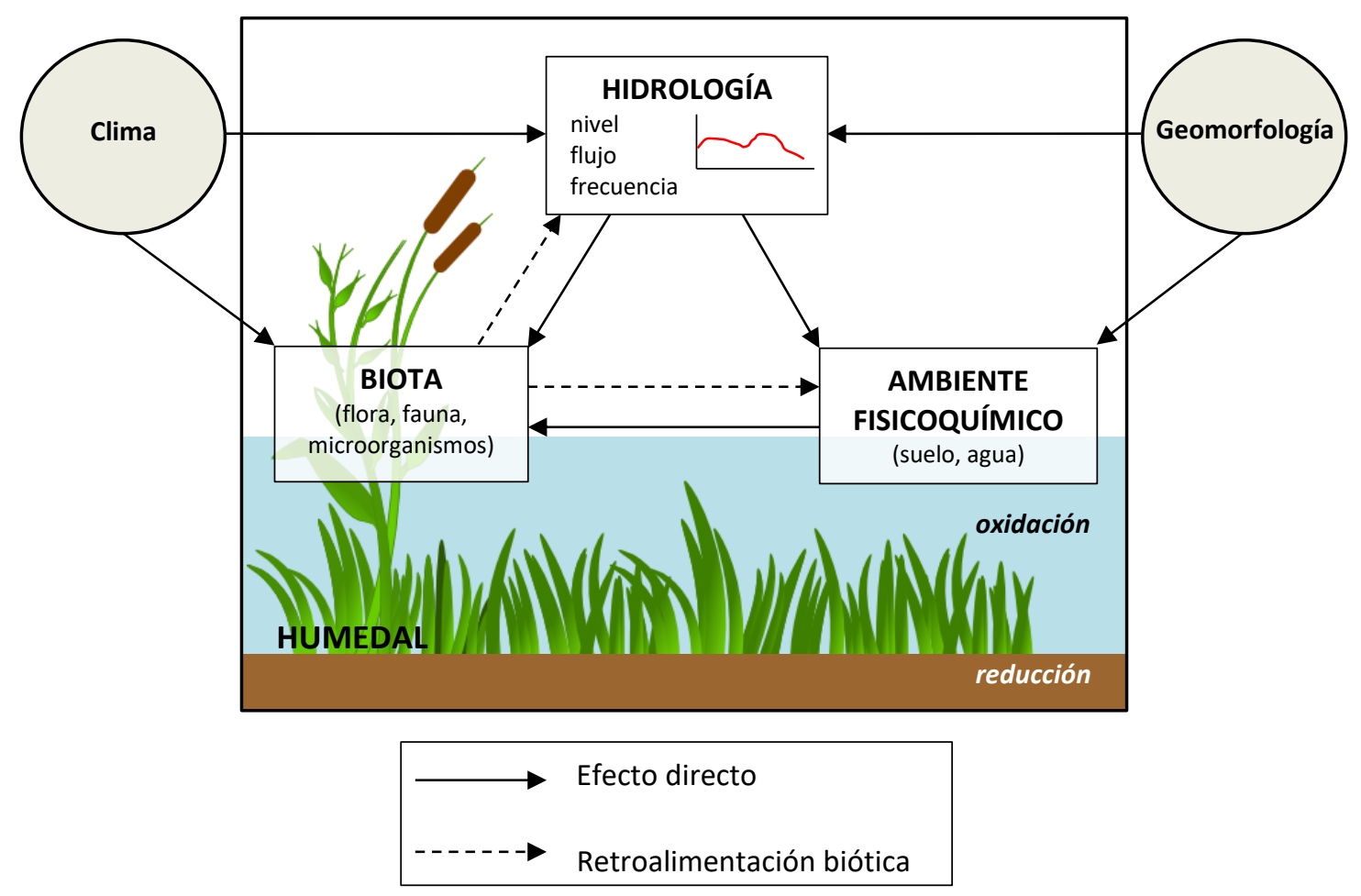

Figura 1.1: Modelo conceptual de la interacción de los tres componentes básicos que regulan en funcionamiento de los humedales: la hidrología, el ambiente fisicoquímico y la biota. Modificado de Mitsch y Gosselink (2007).

El clima regional es el principal factor que determina la magnitud del balance de precipitación- evaporación y, por tanto, la propensión de las aguas para formar humedales (Williams 2006). De esta forma, los humedales son más comunes en 
climas fríos o húmedos que en climas secos (Brinson y Malvárez 2002). En regiones frías existen pocas pérdidas de agua del suelo por una baja evapotranspiración, mientras que en climas húmedos hay una constante recarga debido a las precipitaciones (NRC 1995).

Por otro lado la geomorfología ejerce una fuerte influencia en el movimiento del agua a través del suelo, determinando la existencia y localización del humedal (United States Environmental Protection Agency 2002). La superficie topográfica controla el flujo superficial y subsuperficial (Kolka y Thompson 2006), así como la acumulación del agua en áreas planas o deprimidas del paisaje, tales como cubetas de origen glacial, pisos de valles y cuencas de deflación (Semeniuk y Semeniuk 1995, van der Valk 2012).

En Patagonia, los mallines se distribuyen bajo una amplia variedad de geoformas: laderas o pendientes, ribera de ríos, arroyos y lagos, o en posiciones topográficas deprimidas o planas, siendo éstos los más conspicuos e importantes (Dufiho et al. 1999). En la cordillera y precordillera los mallines se destacan sobre ambientes geomorfológicos glacifluviales, que conforman valles con perfiles en forma de "U", o en ambientes glacilacustres, que constituyen amplias planicies y depresiones (Horne et. al. 2004). Así mismo en el contacto entre distintos niveles de terrazas fluvioglaciales, aparecen mallines "colgados" en las pendientes y suelen extenderse longitudinalmente siguiendo pequeños cursos de agua (Mazzoni y Vázquez 2004).

\subsubsection{Condiciones hidrológicas}

Los humedales difieren de los ambientes terrestres bien drenados y de los sistemas acuáticos de aguas profundas, por su hidrología, la que les imprime características fisicoquímicas particulares (Brinson 1993). Las condiciones hidrológicas son extremadamente importantes en el mantenimiento de la estructura y función de los humedales (Azous y Horner 2000, Jackson et al. 2006). Afectan a diversos factores abióticos, incluyendo la anaerobiosis del suelo, el transporte de solutos y, el reciclado y disponibilidad de nutrientes, los que a su vez determinan el desarrollo de la biota (Mitsch y Gosselink 2007) (Figura 1.1). 
La hidrología de los humedales depende básicamente del balance entre la entrada y salida del agua, la geomorfología y geología de la cuenca, las características del suelo subsuperficial, y las condiciones del agua subterránea (Mitsch y Gosselink 2007).

En Patagonia, la hidrología de los mallines (Figura 1.2) está asociada a zonas de concentración de humedad en el suelo, con un nivel freático alimentado por la precipitación directa más el escurrimiento superficial, subsuperficial y subterráneo proveniente de vastas áreas colindantes, pertenecientes o no a la misma cuenca (Mazzoni y Vázquez 2004, Horne et al. 2004, Mazzoni y Rabassa 2013). En algunos casos existen mallines que, además presentan una conectividad superficial estacional con ríos o lagos (en periodos de crecidas).

En su formación estratigráfica los mallines presentan, a profundidad variable, un estrato de baja conductividad hidráulica relativa que actúa funcionalmente como hidroapoyo, sobre el cual se asientan materiales finos y gruesos de diverso origen que conforman un acuífero o medio saturado, con características freáticas o semiconfinadas (Polla y Horne 1999, Horne et al. 2004) (Figura 1.2).

El aporte hídrico, cualquiera sea su origen, se almacena en ese acuífero libre cuyo nivel freático fluctúa estacionalmente en función del balance entre entradas y salidas de agua al mallín, donde su cauce central funciona como condición de borde del acuífero, fijando el nivel freático a lo largo de su recorrido (Dufilho et al. 1999). Cuando el mallín es recargado lateralmente por los bordes externos o por precipitación directa, el cauce central se transforma en el drenaje del mallín, mientras que durante los períodos de bajante del nivel freático, el cauce puede al menos en algunos tramos, operar como fuente de recarga del acuífero (Dufilho et al. 1999, Horne et al. 2004).

La interacción entre las entradas/salidas de agua subterránea, superficial y atmosférica en los humedales, produce fluctuaciones estacionales en el nivel de agua, que posibilitan la ocurrencia de fases sequía-inundación o permanencia (Figura 1.2). 


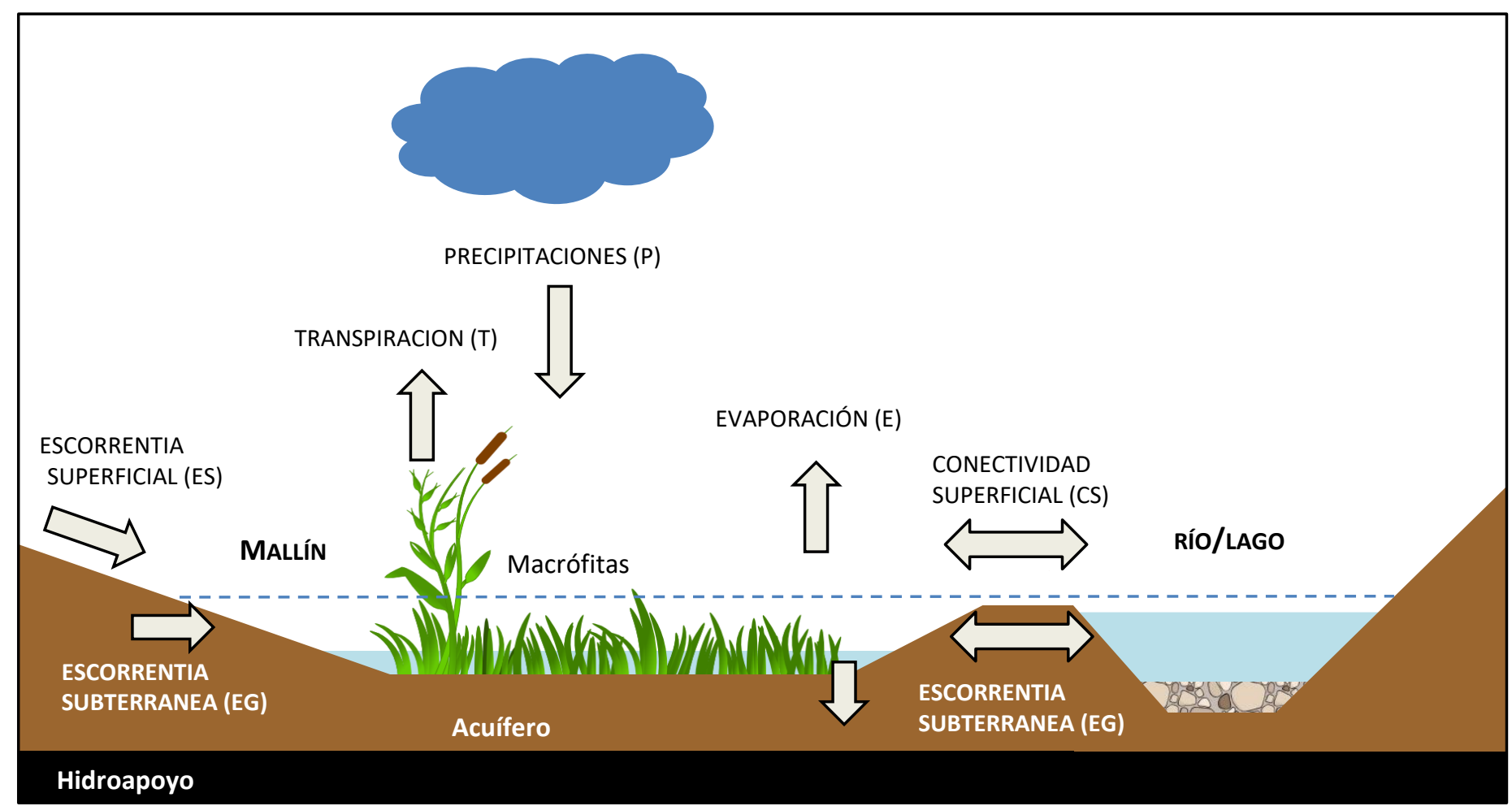

$\mathrm{P}+\mathrm{EG}_{\mathrm{e}}+\mathrm{ES}_{\mathrm{e}}+\mathrm{CS}_{\mathrm{e}}=\mathrm{T}+\mathrm{E}+\mathrm{EG}_{\mathrm{s}}+\mathrm{CS}_{\mathrm{s}}+\Delta \mathrm{V}$

$\mathrm{P}=$ precipitación caída sobre el humedal

$E G=$ Escorrentía subterránea (entrada - salida)

ES = Escorrentía superficial hacia el humedal

T= Transpiración de las plantas

$\mathrm{E}=$ Evaporación del agua

$\mathrm{CR}=$ Conectividad superficial con ríos $\mathrm{o}$ arroyos

$\Delta V=$ Cambio en el volumen de agua (o almacenamiento por unidad de tiempo)

Figura 1.2: Modelo y balance hidrológico general de mallines en Patagonia. 
La interacción entre las entradas/salidas de agua subterránea, superficial y atmosférica en los humedales, produce fluctuaciones estacionales en el nivel de agua, que posibilitan la ocurrencia de fases sequía-inundación o permanencia (Figura 1.2).

El hidroperíodo, patrón estacional del nivel del agua de un humedal (Neiff et al. 2004, Jackson 2006), es el parámetro hidrológico con mayor influencia sobre estos ecosistemas debido a que afecta a las comunidades biológicas y a los procesos ecológicos (Brooks 2000, Euliss et al. 2004, Robson y Clay 2005, Tarr et al. 2005).

El hidroperíodo actúa como factor estructurante de las comunidades de los humedales, afectando a la composición, productividad y reproducción de plantas (Sharitz y Pennings 2006), a la riqueza y la composición de invertebrados (Wiggins et al. 1980, Spencer et al. 1999) y anfibios (Paton y Crouch 2002), así como también a la abundancia, biomasa y éxito reproductivo de ciertas especies (Leeper y Taylor 1998, Brooks 2000).

\subsubsection{Procesos biogeoquímicos}

Las características biogeoquímicas de los humedales son una combinación de transformaciones y procesos de transporte químico, físico y biológico que no comparten con otros ecosistemas (Mitsch y Gosselink 2007). Son ecosistemas únicos como transformadores de materia orgánica, debido principalmente a la dinámica de la matriz suelo-sedimento, cuyo rango puede pasar de fuertemente reducido (anaeróbico) a fuertemente oxidante (aeróbico) (Reddy y DeLaune 2008).

En general, una prolongada inundación en los mallines, ocasiona un ambiente reductor de condiciones anaeróbicas en los sedimentos lo que posibilita las transformaciones de nitrógeno, azufre, fósforo, hierro y manganeso, produciendo en algunos casos compuestos tóxicos, como el sulfuro de hidrógeno, mientras en otros, mediante desnitrificación y metanogénesis, emisiones a la atmósfera de nitrógeno gaseoso y metano. En cambio, la sequía facilita procesos oxidación de la materia orgánica, resultando en un aumento de la disponibilidad de nutrientes para las plantas (van der Valk 2012). De esta forma, la dinámica de los procesos 
biogeoquímicos está fuertemente regulada por las condiciones hidrológicas de estos ecosistemas (Boon 2006) (Figura 1.1).

El centro de la bioquímica en los humedales es la materia orgánica (carbono), aportada por principalmente por el detrito vegetal y, en aquellos intervenidos, por la carga antrópica asociada a un uso agrícola, urbano o industrial (Figura 1.3). Se estima que únicamente el $10 \%$ del carbono de los humedales está en forma de plantas vivas, el resto se encuentra en forma de materia orgánica (van der Valk 2012). El carbono es procesado en dos compartimentos, la columna de agua y el suelo, al que se acoplan otros ciclos de componentes primarios de la materia orgánica: el nitrógeno, el fósforo y el azufre. En estas transformaciones se destacan fundamentalmente comunidades microbianas (bacterias, arqueas y hongos) y sus reacciones fisicoquímicas asociadas, pero también participan del proceso las comunidades del perifiton y los ensambles de invertebrados (Boon, 2006).

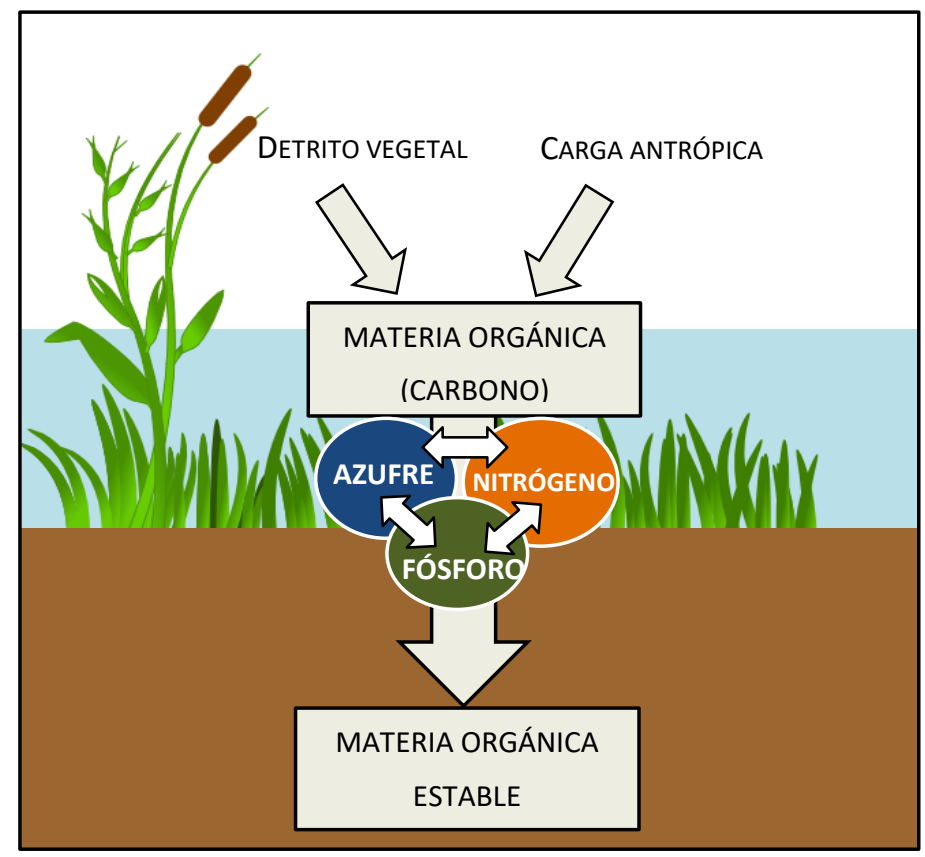

Figura 1.3: Relación entre ciclos biogeoquímicos acoplados y la transformación de la materia orgánica. Modificado de Reddy y DeLaune (2008).

El análisis de los procesos biogeoquímicos permite comprender los efectos que pueden producir, a diferentes escalas, las alteraciones ambientales en los humedales. El ciclo del carbono y nitrógeno son buenos ejemplos de cómo los 
Macchi, P. 2017. Macroinvertebrados acuáticos como indicadores ecológicos de cambios en el uso del suelo en mallines del sudoeste de la Provincia de Río Negro (Dra. María Laura Miserendino - Dra. Nora Gómez)

disturbios pueden generar impactos a nivel local (eutrofización), regional (calidad del agua) y global (emisiones de gases invernadero) (Reddy y De Laune 2008). Incrementos continuos de nutrientes, ya sea de fuentes externas (excretas de ganado, fertilizantes, efluentes cloacales) o internas (a causa de la descomposición de la materia orgánica), podrían ocasionar a futuro, graves impactos en aquellos humedales oligotróficos y sus procesos, modificando sus condiciones originales a eutróficas (Wright et al. 2009).

\subsection{LA BIOTA DE LOS HUMEDALES}

La alta productividad biológica de los humedales y las fuertes presiones de selección sobre la existencia acuática han producido una rica biota asociada únicamente con estos ecosistemas (Gibbs 2000).

Los humedales constituyen mosaicos ambientales dinámicos que proveen una amplia variedad de hábitats para comunidades heterogéneas, contribuyendo significativamente a la biodiversidad regional, ya que frecuentemente contienen especies raras o endémicas de plantas, invertebrados y vertebrados acuáticos (Nicolet et al. 2004, Chimmer et al. 2011, Kadoya et al. 2011). A su vez, estos ambientes han sido reconocidos por su importancia como hábitat crítico de comunidades acuáticas complejas, integradas por especies de invertebrados, peces, anfibios y aves (Canevari et al. 1998, Cussac et al. 2004, Perotti 2005) y actualmente, son reconocidos mundialmente como un punto caliente de la biodiversidad (Céréghino et al. 2014).

El conocimiento de la biota de los humedales y mallines patagónicos es fragmentario y para algunas comunidades aún incipiente (Kutschker et al. 2014), sin embargo sugiere claramente su importancia en el aporte a la biodiversidad de la región. Si bien se cuenta con un cuerpo de información importante sobre las comunidades terrestres de los mallines, la fauna y flora acuática y semiacuática han sido poco estudiadas (Perotti et al. 2005). 


\subsubsection{Macrófitas de los humedales}

La vegetación acuática que crece en los humedales, habitualmente llamada macrófitas, incluye plantas vasculares (angiospermas y helechos), musgos y algas macroscópicas (Brix 1997, Cushing y Allan 2001). Representan un conjunto diverso de especies con variadas adaptaciones y tolerancias ecológicas, cuyos rasgos del ciclo de vida les permiten sobrevivir en suelos saturados o inundados (Epele 2014). De acuerdo a su forma de vida, pueden categorizarse en cuatro grupos: emergentes, subemergentes, hojas flotantes y flotantes libres (Cronk y Fennessy 2016).

Particularmente para la vegetación de los mallines patagónicos Boelke (1957) diferenció tres zonas a lo largo del gradiente hidrológico: (1) La zona central, inundada permanentemente o temporariamente donde prevalecen las macrófitas, principalmente juncáceas y ciperáceas. Por lo general en esta zona siempre se encuentra un cauce que actúa como drenaje del agua y su profundidad está en relación proporcional al estado de conservación de la cuenca (Gandullo y Faggi 2005). (2) La zona intermedia, con la capa freática por debajo de la superficie del suelo la mayor parte del año, es la de mayor producción forrajera, con predominio de poáceas y leguminosas. (3) La zona periférica, influenciada por Stipa spp. (Coirones) y otras especies de la vegetación circundante, constituye un área de frágil equilibrio (Fiorio 1997).

Muchas funciones ecológicas de los humedales son consecuencia directa o indirecta de la presencia de macrófitas (Balcombe et al. 2005, Mitsch y Gosselink 2007), influyen en la estructura física y en las condiciones ambientales de los humedales (Anderson et al. 1999, Schneider et al. 2012), aportan la mayor biomasa y constituyen el componente central de la biogeoquímica de estos ecosistemas, como productores primarios y conductores del ciclo de la materia orgánica (Burks et al. 2006). Participan en procesos de remoción y retención de nutrientes, metales pesados y otros contaminantes (Grace 1999, Engelhardt y Ritchie 2001, Lukács 2009). 
Las macrófitas proveen alimento y hábitat para los invertebrados de los humedales (Murkin et al. 1992, Batzer y Wissinger 1996, King et al. 2000). Su presencia crea microhábitats que difieren en velocidad del agua, intensidad de la luz, temperatura, concentración de oxígeno, etc. (van der Valk 2012), sosteniendo la mayor diversidad y abundancia de invertebrados dentro de los humedales (Batzer y Boix 1999). Anualmente la senescencia de macrófitas emergentes aporta una cantidad considerable de detritos que proveen una importante base trófica para los invertebrados (desmenuzadores), sin embargo, las algas constituyen su principal base primaria de alimentación (colectores, raspadores), debido a que son energéticamente superiores al detrito de plantas vasculares (Batzer y Sharitz 2014).

Por otro lado, el principal factor que determina la composición y estructura de los ensambles de macrófitas es el hidroperíodo (Cronk y Fennessy 2001), pero también son influenciadas por la posición en el paisaje, el sustrato, las concentraciones de nutrientes, el clima, el estrés ambiental y el disturbio, y así como por una variedad de interacciones bióticas como competencia, facilitación y herbivoría (Sharitz y Penning 2006).

Se han realizado numerosas descripciones la estructura y composición florística de los mallines, algunas de ellas asociadas a su uso como forraje para la ganadería (Boelcke 1957, Marcolin et al. 1978, Movia et al. 1982, Bran 1992, Roig 1998, Collantes y Faggi 1999, Gandullo y Schmid 2001, Gandullo y Faggi 2003, entre otras).

En los últimos años se realizaron estudios fitosociológicos de la vegetación de mallines para establecer un sistema sintaxonómico (Gandullo y Faggi 2005) o para analizar la influencia de las variables ambientales (Gaitán et al. 2011). Otros estudios abordaron el rol de las macrófitas en las relaciones elementales, Carbono: Nitrógeno: Fósforo (C:N:P) en humedales patagónicos (Cuassolo et al. 2011, 2012), así como la producción de la materia orgánica disuelta y particulada y su interacción con factores abióticos y bióticos (Cuassolo 2013). Recientemente, Kutschker y otros (2014) realizaron un extenso estudio de la diversidad de macrófitas en 30 mallines de la Provincia de Chubut y los efectos ambientales del pastoreo. 


\subsubsection{Macroinvertebrados acuáticos de los humedales}

Los macroinvertebrados acuáticos, definidos por convención, son aquellos organismos superiores a $1 \mathrm{~mm}$ (Batzer y Boix 2016) e incluyen platelmintos, moluscos, anélidos, ácaros, crustáceos e insectos. Existen alrededor del mundo 40 familias de macroinvertebrados dominantes en estos ecosistemas $(\geq 10 \%$ de ocurrencia), de las cuales 25 corresponden a insectos, los que constituyen el grupo más diverso de los humedales. Entre los insectos se destacan Diptera con ocho familias, Hemiptera con cinco y, Coleoptera y Odonata ambos con cuatro (Batzer y Ruhí 2013).

Los macroinvertebrados son uno de los grupos de organismos más diversos y abundantes de los humedales (Sharitz y Batzer 1999, Paniagua et al. 2010). Participan en el funcionamiento ecológico de los humedales favoreciendo los procesos de descomposición de la materia la orgánica, el ciclo de los nutrientes y la regulación de las comunidades de plantas acuáticas. Ocupan una posición central en las redes tróficas alimentándose de plantas y sus detritos, así como también de algas y son a su vez, consumidos por peces, anfibios, reptiles y aves (Batzer et al. 1999, Silver et al. 2012, Batzer y Boix 2016, Zimmer et al. 2016).

Existen variadas formas de vida de los macroinvertebrados en los humedales que están íntimamente relacionadas con la heterogeneidad de hábitats disponibles. Entre otras, hay formas excavadoras, los hay adheridos sobre rocas o troncos y ramas sumergidas, aferrados a la vegetación flotante o enraizada, nadadores, buceadores planctónicos y patinadores (Merritt y Cummins 1996).

La composición y la estructura de los ensambles de macroinvertebrados presentes en un determinado humedal depende de factores abióticos, como la localización geográfica (Nicolet et al. 2004), el hidroperíodo (Brooks 2000; Euliss et al. 2004, Della Bella et al. 2005, Sim et al. 2013, Kneitel 2014) y la química del agua, así como de factores bióticos como la presencia de macrófitas y peces (McParland y Paszkowski 2006). 
Macchi, P. 2017. Macroinvertebrados acuáticos como indicadores ecológicos de cambios en el uso del suelo en mallines del sudoeste de la Provincia de Río Negro (Dra. María Laura Miserendino - Dra. Nora Gómez)

La localización geográfica, principalmente debida al elemento climático regula la composición comunitaria, como por ejemplo ocurre en regiones frías con marcada estacionalidad, donde la composición de la comunidad puede cambiar en invierno respecto de verano (Silver et al. 2012).

Wissinger (1999) sostiene que diferentes aspectos combinados del hidroperíodo controlan las poblaciones y comunidades de invertebrados acuáticos: (1) Permanencia (permanente; semipermanente, seco algunos años; temporario). (2) Predictibilidad de la sequía - inundación. (3) Fenología (momento estacional) de la sequía - inundación. (4) Duración de las fases secas y fases húmedas (5) Severidad de ambas fases (condiciones extremas de temperatura o desecación).

Los humedales con hidroperíodo corto suelen tener baja diversidad taxonómica de invertebrados acuáticos (Wiggens et al. 1980, Wissinger et al. 2016) y generalmente la riqueza específica y la densidad aumentan de manera acumulativa a medida que éste se prolonga (Schneider y Frost 1996, Wellborn et al. 1996, Vanschoenwinkel et al. 2013, Kneitel 2014). En cambio, cuando presentan un hidroperíodo permanente, los factores de estrés físico tienden a ser de menor importancia respecto a los factores bióticos (Tarr et al. 2005), ya que a medida que aumenta el hidroperíodo, la diversidad y abundancia de los depredadores se incrementa y éstos ejercen una mayor influencia en la estructura de la comunidad de invertebrados (Zimmer et al. 2001, Wiliams 2006, Jara et al. 2013).

La calidad del agua también afecta a las comunidades de macroinvertebrados (Boix et. al. 2016). Las principales variables físicas y químicas que influyen sobre la composición y riqueza específica son la salinidad (Boix et al. 2007, Waterkeyn et al. 2009), la turbidez (Alonso 1998, Ruhí et al. 2016), luz (Mokany et al. 2008), la temperatura (Williams 2006) y la concentración de nutrientes (Balla y Davis 1995, Mlambo 2009). Sin embargo uno de los mayores problemas que enfrentan es la periódica disminución de oxígeno disuelto (Tarr et al. 2005), para lo cual han desarrollado diferentes adaptaciones como cuerpos tubulares que aumentan la relación superficie - volumen facilitando la transferencia de oxígeno (quironómidos y oligoquetos), otros presentan extensiones laterales de su cutícula para aumentar 
Macchi, P. 2017. Macroinvertebrados acuáticos como indicadores ecológicos de cambios en el uso del suelo en mallines del sudoeste de la Provincia de Río Negro (Dra. María Laura Miserendino - Dra. Nora Gómez)

la superficie (larvas de coleópteros de las familias Haliplidae e Hydrophiilidae), unos pueden presentar hemoglobina en su hemolinfa (quironómidos y oligoquetos de la familia Tubificidae) (Resh 2008) y otros simplemente emergen a la superficie del agua para tomar el oxígeno atmosférico (la mayoría de los coleópteros, hemípteros y algunas larvas de dípteros) (Batzer y Boix 2016).

\subsubsection{Biodiversidad de macroinvertebrados en mallines}

Al igual que en otros ambientes acuáticos de Patagonia, los mallines constituyen hábitats con una alta biodiversidad, numerosos endemismos, y son importantes en términos de biomasa de invertebrados (Epele 2014), dando cuenta de su enorme importancia faunística y biogeográfica (Muzón 2002).

En Argentina se han realizado diversos estudios ecológicos de invertebrados acuáticos de humedales (Poi de Neiff y Casco 2003, Montalto y Marchese 2005, Zilli et al. 2008, entre otros), sin embargo en Patagonia el énfasis se ha puesto en las descripciones taxonómicas (Menu-Marque y Balseiro 2000, Paggi y Rodrigues Capítulo 2003, Donato et al. 2009, Pessacq 2009, Pessacq et al. 2011). Recientemente existen algunos estudios enfocados a conocer qué factores ambientales regulan su distribución en los mallines de la región (Perotti et al. 2004, 2005, Epele 2014, Epele y Miserendino 2015).

Particularmente, los insectos acuáticos fueron relevados en humedales y mallines al norte de la Patagonia, en la meseta de Somuncurá y su área de influencia, donde presentaron una alta riqueza específica con representantes pertenecientes a los órdenes Ephemeroptera, Odonata, Hemiptera, Trichoptera, Diptera (familias Ceratopogonidae, Culicidae y Psychodidae) y Coleoptera (Muzón et al. 2005, Muzón et al. 2010). En la Provincia del Chubut se estudiaron ensambles de macroinvertebrados en 30 mallines con distintos niveles de conectividad, documentando una alta riqueza taxonómica de invertebrados acuáticos, donde los órdenes de insectos más diversos fueron Diptera, Coleoptera, Hemiptera y Trichoptera (Epele 2014). Correa-Araneda y otros (2014) analizaron la distribución temporal de macroinvertebrados y su relación con los cambios en el hidroperíodo 
en humedales boscosos de Chile, los que estuvieron dominados por Chironomidae, Oligochaeta y Hyalella araucana (Cunningham). Otros estudios realizados al sur de la Patagonia en mallines y turberas de Tierra del Fuego, mostraron una baja diversidad y abundancia de macroinvertebrados, destacándose entre los insectos acuáticos las familias Corixidae, Dytiscidae y Chironomidae (Burroni 2011). Éstos últimos con representantes de seis géneros (Mercado 2004).

Diversos estudios han puesto el foco en la distribución y rol de los depredadores en la estructuración de las comunidades de invertebrados acuáticos en mallines patagónicos. Jara y otros (2013) determinaron que la riqueza de insectos depredadores esta está dominada por Coleoptera, Hemiptera y Odonata, quienes actúan regulando la estructura de los ensambles de invertebrados acuáticos y a su vez, su abundancia es afectada por el hidroperiodo y la presencia de peces. Por otro lado se estudiaron los efectos de la depredación de hemípteros de la familia Notonectidae (Jara et al. 2012) y del turbelario Mesostoma ehrenbergii (Focke) sobre la composición de invertebrados (Trochine et al. 2008, 2009).

\subsection{USO DEL SUELO Y DEGRADACIÓN DE LOS HUMEDALES}

La modificación del paisaje y el uso del suelo debido a la urbanización, la agricultura, la ganadería, la minería, la desforestación y el remplazo de especies nativas por exóticas con valor comercial, han sido las principales causas de la pérdida y degradación de los humedales y particularmente de los mallines (Ehrenfeld 2000, Brinson y Malvárez 2002, Chimner et al. 2011, Epele y Miserendino 2015).

Diversos estudios muestran la pérdida y reducción de humedales en muchas partes del mundo debido a las acciones antrópicas (Zedler y Kercher 2005, Mitsch y Gosselink 2007, Daniels y Cumming 2008), evidenciando que la biodiversidad dulceacuícola está declinando a una tasa mucho más elevada que la de los ambientes terrestres más afectados (Saunders et al. 2002). Las proyecciones sobre los efectos concomitantes del cambio climático global y de los disturbios sobre humedales son poco alentadoras, dados el carácter acumulativo y el potencial de interacción de tales efectos (Brinson y Malvárez 2002). 
El fenómeno de urbanización es una de las mayores causas de la degradación y pérdida de los humedales (Gibbs 2000, Lee et al. 2006), ya que ejerce una significativa influencia en la composición de las comunidades y en las funciones ecológicas debido a las alteraciones en el balance hidrológico, en la dinámica de los sedimentos y en el ciclo de los nutrientes (Ehrenfeld 2000). Entre las acciones que producen los impactos más significativos se pueden mencionar a la canalización y drenaje de las aguas, a los cambios producidos en la topografía de la cuenca por movimiento de suelos, a la desforestación, al incremento de los contaminantes químicos por efluentes cloacales, al uso recreativo, a la introducción de especies exóticas y a la iluminación artificial (Azous y Horner 2000, Lee et al. 2006, Santos et al. 2009). Particularmente la iluminación de las áreas urbanas en las proximidades de ecosistemas acuáticos altera el comportamiento de dispersión de algunos insectos acuáticos adultos (Eisenbeis et al. 2006) y afecta a la densidad de las poblaciones a través de la pérdida directa de individuos por mortalidad, por falla reproductiva o por cambios en las conductas sexuales (Perkin et al. 2011).

El uso rural de los humedales por actividades agrícolas y ganaderas produce cambios en los procesos ecológicos debido al aumento de la carga de nutrientes, al incremento de los sedimentos finos, a la proliferación de las especies exóticas y a la alteración en el régimen hidrológico (Steiman et al. 2003). Particularmente la acción de la ganadería puede causar impactos directos e indirectos. Entre los directos se incluyen a la presión por el pastoreo de la vegetación acuática, al aporte de nutrientes vía orina y deposiciones fecales y, al pisoteo. Este último, incrementa los procesos erosivos y produce síntomas de sedimentación (Collins et al. 1998, Steiman et al. 2003). Los impactos indirectos incluyen cambios en la composición y estructura de las macrófitas, mayormente inducidas por el aporte de nutrientes y el pastoreo selectivo (Kutschker et al. 2014). Estos impactos pueden ocasionar la eutrofización del sistema y afectar a los niveles tróficos superiores que dependen de esos autótrofos ya sea como hábitat, refugio o alimento, lo que en consecuencia puede disminuir la biodiversidad y la funcionalidad del ecosistema (Kadoya et al. 2011). 


\subsubsection{Macroinvertebrados acuáticos como bioindicadores}

En términos generales la biota acuática cambia su estructura y funcionamiento al modificarse las condiciones ambientales de sus hábitats naturales. De modo que es posible usar algunas características o propiedades estructurales y funcionales de los diferentes niveles de organización biológica para evaluar en forma comparativa el estado de la biota acuática, cuya condición es el reflejo del estado ecológico del sistema (Segnini 2003, Prat et al. 2009). La integridad o estado ecológico de un sistema hidrológico resulta de la interacción de procesos físicos, químicos y biológicos y es una expresión de la calidad de la estructura y el funcionamiento de los ecosistemas acuáticos (Gibson et al. 1996).

En las últimas décadas, se ha estimulado el desarrollo de criterios biológicos que permitan estimar y predecir el efecto de las intervenciones humanas en ellos (Wilcox et al. 2002). Los impactos antropogénicos sobre los humedales son difíciles de detectar y cuantificar utilizando metodologías tradicionales de monitoreo de la calidad de agua y, el desarrollo de procedimientos que posibiliten evaluar y predecir la integridad ecológica de estos cuerpos de agua es de vital importancia (Burton et al. 1999). Actualmente, en Patagonia, existe un gran interés en establecer indicadores que permitan detectar diferentes estados de degradación de los mallines (Raffaelle 1999, Perotti et al. 2005).

El uso de los macroinvertebrados como indicadores del estado ecológico constituye una herramienta útil para detectar alteraciones que se producen en los ecosistemas acuáticos (Barbour et al. 1996, Resh 2008, Summerville et al. 2004, Ocon y Rodrigues Capítulo 2012).

Entre las ventajas que se destacan para el uso de macroinvertebrados como bioindicadores en humedales se pueden mencionar: (1) Están ampliamente distribuidos en muchos tipos de humedales (Batzer et al. 1999, Batzer y Boix 2016). (2) Responden con distinta sensibilidad a diversos factores de estrés ambiental (Barbour et al. 1999, Stuijfzand et al. 2000, Ruhí et al. 2016). (3) La mayoría completa sus ciclos de vida en el humedal por lo que están expuestos directamente 
a factores de estrés físicos, químicos y biológicos (Wiggins et al. 1980). (4) Son importantes en las redes tróficas de la fauna que reside en los humedales (Silver et al. 2012, Batzer y Boix 2016). No obstante su aplicación, a diferencia de los ecosistemas lóticos, ha sido reducida por diversidad de las condiciones hidrogeomorfologicas de estos ecosistemas, que origina condiciones bióticas y abióticas únicas y, por los factores de estrés, que pueden ser muy diferentes de los ríos y arroyos (Adamus y Brandt 1990). De esta forma, dada la amplia variedad de humedales y la especificidad propia del sitio y sus condiciones, no existe un enfoque único y estándar para el uso de macroinvertebrados como bioindicadores de humedales (Ruhí et al. 2016). Por ello muchos autores han resaltado que los estudios integrados serían los más apropiados (Walker 1992, Rosenfeld 2002), estableciendo índices específicos de integridad ecológica de los humedales sobre la base de comunidades locales de macroinvertebrados (Ruhí et al. 2016).

A nivel mundial existen diversos ejemplos de la aplicación de métricas comunitarias de macroinvertebrados como indicadores de la integridad ecológica de los humedales. En California del Norte (Lunde y Resh 2012) se determinaron las mejores ocho métricas indicadoras del disturbio en humedales: de abundancia relativa (Ephemeroptera, Odonata, Trichoptera, Tanypodinae, Chironomidae, Oligochaeta y Coleoptera) y de grupos funcionales (raspadores y depredadores). Especialmente en relación a los impactos de aguas residuales y aguas pluviales, para la región de Los Grandes Lagos, Cooper y Uzarki (2016) encontraron que las variaciones de las abundancias de tres taxa (Ephemeroptera, Isopoda y Trichoptera) y cuatro grupos funcionales (depredadores, colectores-filtradores, colectoresrecolectores y raspadores), constituyen métricas óptimas para evaluar estos humedales. Otros estudios determinaron que la riqueza específica y la abundancia relativa del grupo EOT (Ephemeroptera, Odonata y Trichoptera) disminuye con al aumento de la turbidez por efectos de los sedimentos en suspensión (Gleason et al. 2003, Stewart y Downing 2008).

En los humedales mediterráneos semiáridos de España, la proporción de Coleoptera, Hemiptera y la riqueza específica macroinvertebrados acuáticos fueron 
incluidos en un índice de integridad ecológica para humedales sometidos a factores de estrés hídrico, aumento de nutrientes y fluctuaciones de salinidad (Ortega et al. 2004). Otros índices propuestos para evaluar los humedales en ese país se basaron, por un lado en la sensibilidad de crustáceos (Copepoda, Ostracoda y Cladocera) y en la riqueza insectos (Quintana et al. 2015) y por otro, en la familia Chironomidae, que respondió a las causas de la eutrofización (incremento de nutrientes) y a sus síntomas. En India, Sharma y Rawat (2009) estudiaron durante un año cuatro sectores en un humedal del Himalaya Central, concluyendo que el aumento de la turbidez y sólidos disueltos totales produce una disminución significativa de la densidad de invertebrados. La eutrofización y el aumento de los sólidos suspendidos en humedales de Irán produjo cambios en la riqueza taxonómica, diversidad y, en las abundancias de Coleoptera y Chironomidae (Ahmadi et al. 2011). Humedales de Etiopía, sujetos a disturbios hidrológicos y agrícolas, fueron categorizados por la riqueza de macroinvertebrados, taxa indicadores y tolerantes, en un índice propuesto por Yimer y Mengistou (2010). El análisis de la diversidad y la abundancia de Odonata y la riqueza de macroinvertebrados en humedales de Japón, permitió evidenciar las alteraciones en el ecotono tierra-agua y en la disponibilidad del hábitat acuático generalmente producidas por el acción de ganado en áreas agrícolas y, por las canalizaciones y dragado en áreas urbanas (Kadoya et al. 2011).

Para América del Sur, Villagrán-Mella y otros (2006) recomendaron la utilización de invertebrados acuáticos de humedales en Chile como indicadores de degradación en sitios urbanos. En Minas Gerais en el sur de Brasil, se desarrolló un índice multimétrico para evaluar las presiones antrópicas sobre los humedales, donde se incluyeron 4 métricas: riqueza de Ephemeroptera, puntuación media de taxa tolerantes, abundancia de Odonata y abundancia de depredadores (Macedo et al. 2016). En Patagonia, un conjunto de siete métricas que incluyen medidas de riqueza, abundancia, biomasa y grupos funcionales, describieron, consistentemente y con precisión, los efectos del pastoreo de ganado en mallines de la Provincia de Chubut. Los indicadores más destacados fueron la riqueza taxonómica, el número 
Macchi, P. 2017. Macroinvertebrados acuáticos como indicadores ecológicos de cambios en el uso del suelo en mallines del sudoeste de la Provincia de Río Negro (Dra. María Laura Miserendino - Dra. Nora Gómez)

de familias de insectos, el porcentaje de Ephemeroptera, Odonata, Trichoptera y el porcentaje del taxón dominante (Epele y Miserendino 2015).

\subsection{JUSTIFICACIÓN}

En Patagonia, diversas actividades humanas han impactado, en diferentes grados, sobre los ecosistemas acuáticos: la ganadería extensiva, la agricultura y el uso de plaguicidas, la forestación y la extracción de madera, y el crecimiento de las urbanizaciones (Miserendino 2005, Miserendino y Brand 2009, Brand y Miserendino 2011, Miserendino et al. 2011, Macchi et al. 2012).

Históricamente, los mallines patagónicos han sustentado la economía regional basada en la ganadería debido a que representan los ambientes de mayor productividad forrajera, la cual es entre 4 y 20 veces mayor comparada con la de la vegetación circundante (Bonvissuto y Somlo 1998, Gaitán et al. 2011). Si bien la variabilidad de la productividad es muy grande, dependiendo del tipo de mallín y ubicación dentro del mismo, la disponibilidad de humedad y forraje durante todo el año, expone a estos sitios a una mayor presión de pastoreo y pisoteo, con su consecuente degradación (del Valle et al. 1998). El uso y el manejo inadecuado de los mallines han provocado el deterioro de la vegetación y del suelo, así como la pérdida de la diversidad biológica transformándolos en focos de degradación intensa (Mazzoni y Vazquéz 2004).

Así mismo el crecimiento sostenido y desordenado de grandes ciudades cordilleranas como Bariloche, El Bolsón y San Martín de los Andes han generado, con sus intervenciones, destacadas transformaciones y presiones ambientales sobre mallines. Drenaje, canalizaciones, loteos, construcción de viviendas, vertido de efluentes y basura, introducción de especies exóticas, han sido los mayores impactos que han sido sometidos estos ecosistemas (Pereyra 2007, Horne et al. 2004, Macchi 2008).

En los últimos años diversos estudios han abordado el efecto de las actividades humanas en ríos y arroyos de Patagonia debidos a los diferentes usos del suelo (Miserendino y Pizzolón 2004, Miserendino 2009, Miserendino y Masi 
Macchi, P. 2017. Macroinvertebrados acuáticos como indicadores ecológicos de cambios en el uso del suelo en mallines del sudoeste de la Provincia de Río Negro (Dra. María Laura Miserendino - Dra. Nora Gómez)

2010 Miserendino et al. 2011). Sin embargo estudios sobre macroinvertebrados de mallines y su aplicación como indicadores biológicos son muy escasos (Miserendino y Epele 2009).

La utilización de los macroinvertebrados acuáticos como indicadores de cambios en el uso del suelo permitiría un diagnóstico rápido y eficaz, que posibilite ajustar las medidas correctoras necesarias para que el uso de los mallines sea sustentable en el tiempo, posibilitando una gestión adecuada de estos ecosistemas. Por otro lado, la caracterización del estado ecológico actual servirá de línea de base para el conocimiento de la biodiversidad local y regional de los mallines. 


\section{HIPÓTESIS Y OBJETIVOS}

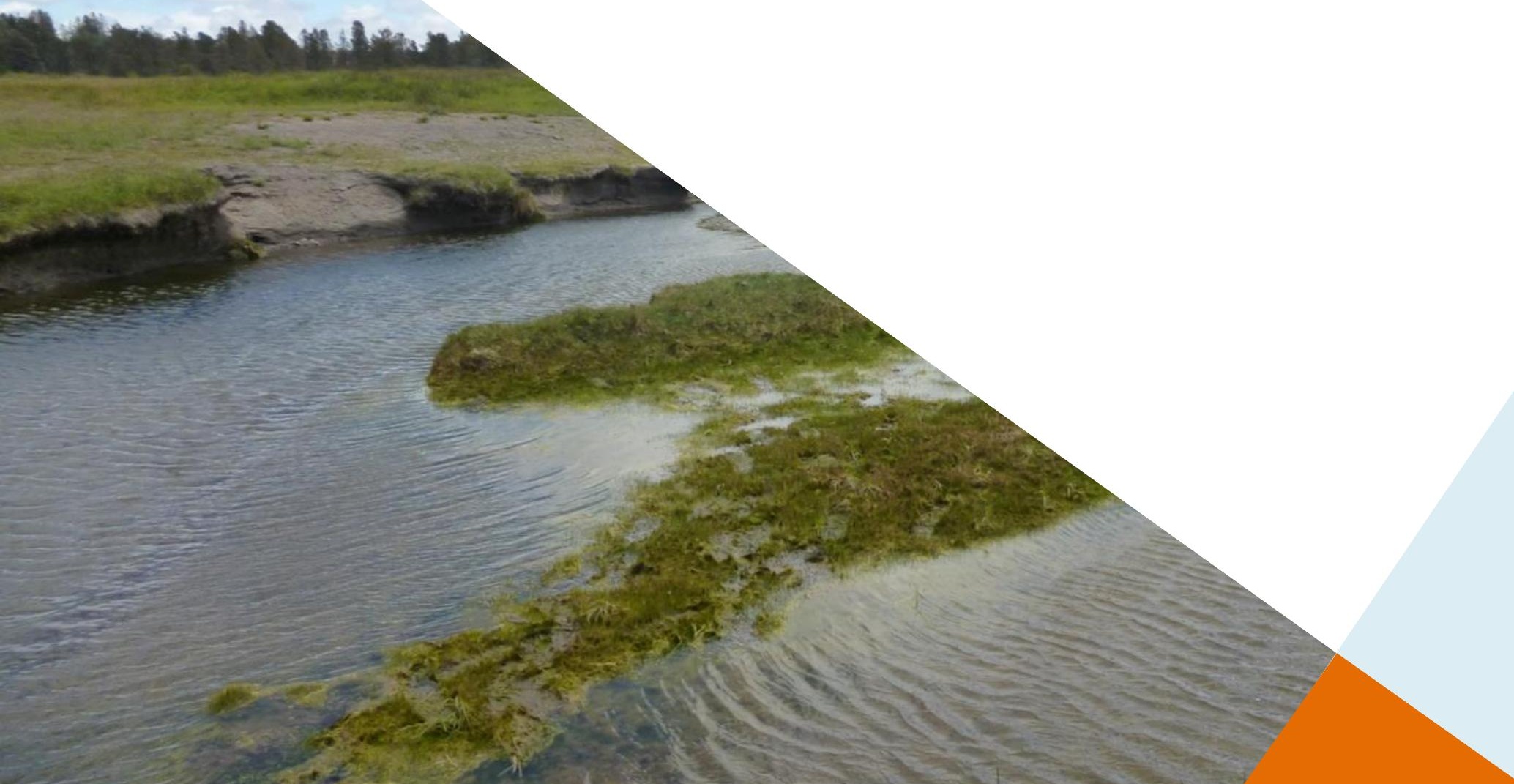




\subsection{HIPÓTESIS}

El deterioro ambiental de los mallines del sudoeste de la Provincia de Río Negro, ocasionado por los cambios en el uso del suelo, principalmente agrícola y urbano, altera la composición y estructura de las asociaciones de macroinvertebrados. Por lo tanto, la magnitud de estas alteraciones determinará cambios en el estado ecológico de estos ecosistemas.

\subsection{PREDICCIONES}

A. La conductividad eléctrica y la concentración de nutrientes serán mayores en mallines sometidos a uso agrícola o urbano.

B. La riqueza y diversidad de macroinvertebrados acuáticos será menor en mallines sometidos a uso agrícola o urbano.

C. La complejidad estrutural del hábitat disponible para macroinvertebrados se reducirá en mallines sometidos a uso agrícola o urbano. 


\subsection{OBJETIVOS GENERALES}

- Evaluar el estado ecológico de mallines en el sudoeste de la Provincia de Río Negro, sometidos a diferentes usos del suelo utilizando atributos de las comunidades de macroinvertebrados.

- Determinar medidas o estimadores de la comunidad de macroinvertebrados que resulten más apropiados para evaluar los impactos ambientales debidos al uso del suelo en los mallines bajo estudio.

\subsection{OBJetivos PARTICULARES}

- Describir y analizar las características físicas, químicas y biológicas de 15 mallines de bosque mixto y estepa patagónica.

- Caracterizar el hábitat de los ensambles de macroinvertebrados a través de la descripción de las asociaciones de macrófitas.

- Analizar la estructura y dinámica de las comunidades de macroinvertebrados en mallines y establecer sus relaciones con las variables ambientales y el uso del suelo.

- Comparar los ensambles de macroinvertebrados entre mallines de bosque mixto y estepa patagónica.

- Contribuir al conocimiento de la biodiversidad de macroinvertebrados de mallines. 


\section{3. ÁREA DE ESTUDIO}

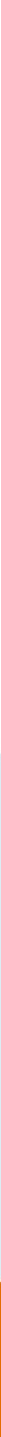


Macchi, P. 2017. Macroinvertebrados acuáticos como indicadores ecológicos de cambios en el uso del suelo en mallines del sudoeste de la Provincia de Río Negro (Dra. María Laura Miserendino - Dra. Nora Gómez)

\subsection{UBICACIÓN GEOGRÁFICA}

La Patagonia Argentina se extiende desde el sur de los ríos Barrancas y Colorado, hasta el extremo sur del continente y está delimitada en el oeste por la Cordillera de los Andes y en el este por el océano Atlántico. Esta región cubre aproximadamente un tercio de la superficie total de la Argentina continental y se extiende, en latitud, desde los $36^{\circ} \mathrm{S}$ hasta los $55^{\circ} \mathrm{S}$. El área de estudio se localizó en el sudoeste de la Provincia de Río Negro entre las longitudes $71^{\circ} 50^{\prime}-70^{\circ} 30^{\prime} \mathrm{O}$ y las latitudes $41^{\circ}$ - $41^{\circ} 30^{\prime} \mathrm{S}$ (Figura 3.1.). La misma comprendió dos biozonas bien definidas, bosque mixto y estepa patagónica (Paruelo et al. 1998a).

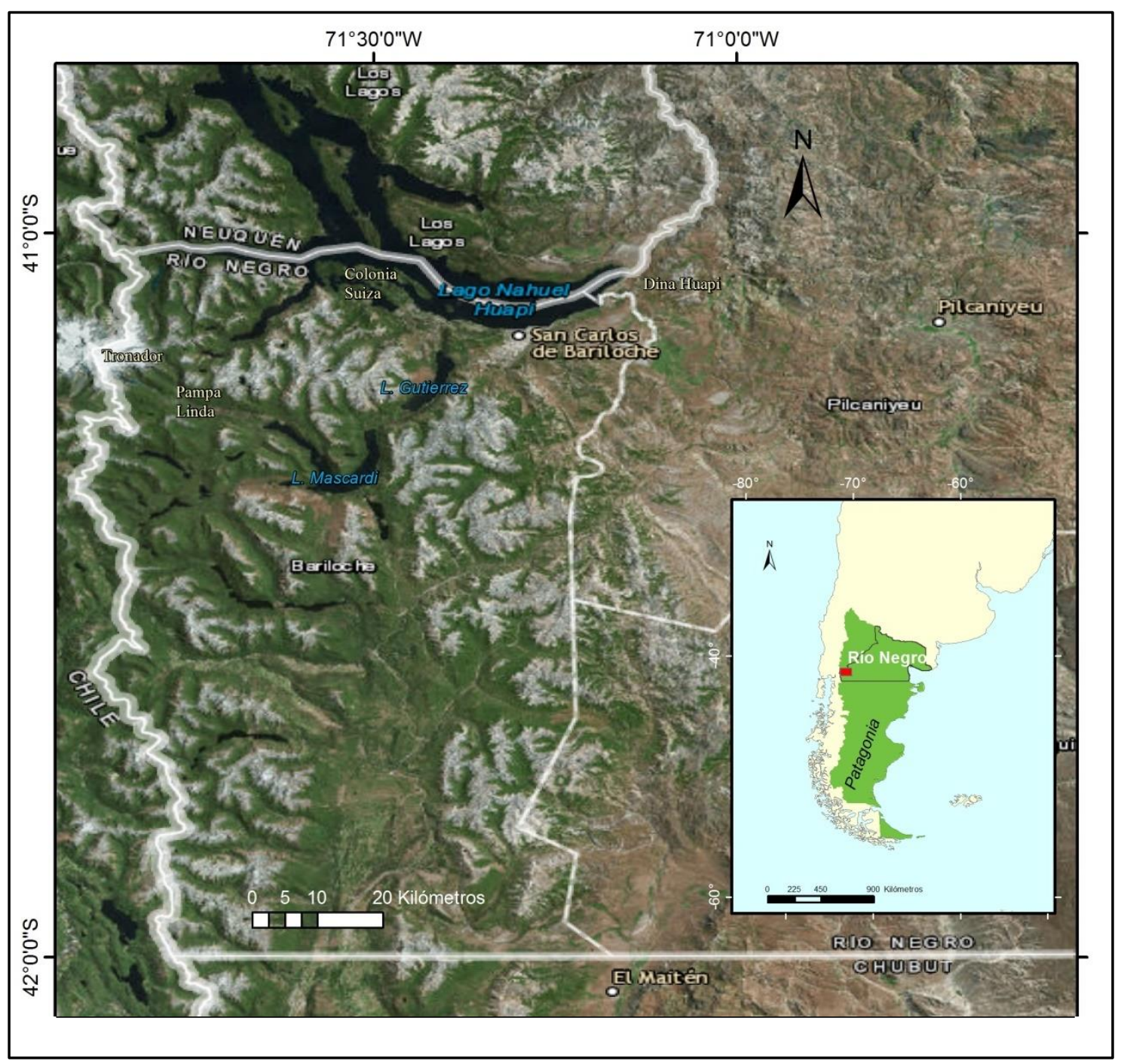

Figura 3.1: Localización geográfica del área de estudio en el SO de la Provincia de Río Negro. 


\subsection{GEOMORFOLOGÍA}

La geomorfología de la región está marcada fundamentalmente por la Cordillera de los Andes. Esta formación se produjo por elevación de la corteza terrestre a fines del periodo Terciario, como consecuencia de la presión de la placa tectónica del Pacífico (Aguirre 1985).

El ambiente geomorfológico cordillerano, al oeste de la ciudad de San Carlos de Bariloche se caracteriza por presentar una serranía de bloques con relieve juvenil por glaciación (González Díaz y Malagnino 1984). La estructuración en bloques y láminas tectónicas durante la deformación ándica originó una serie de bloques orientados en sentido $\mathrm{N}-\mathrm{S}$, con algunas fallas de rumbo E-O, lo que condicionó la forma del drenaje, dando como resultado un diseño angular (Giacosa y Heredia 2001). Como consecuencia de esa estructura, en el área se presentan una serie de serranías de aproximadamente rumbo norte, con alturas que oscilan entre 2400 y 700 msnm, con algunos sectores más elevados, como la zona del cerro Tronador (más de $3500 \mathrm{msnm}$ ). Este paisaje, originariamente tectónico, fue intensamente modificado por la acción de los hielos durante las diferentes glaciaciones, conformando un paisaje compuesto y complejo, representado por amplios valles glaciarios, morenas de diferentes tipos, terrazas y planicies glacifluviales o glacilacustres y, formas erosivas de escalas intermedias. En estas planicies y valles heterogéneos, cuyo piso se encuentra a cotas superiores a $700 \mathrm{msnm}$, se localizan humedales o mallines.

Hacia el este de Bariloche, en la zona menos afectada por las glaciaciones, el modelado del paisaje es de tipo poligenético (González Díaz y Malagnino 1984), formando un relieve a partir de rocas terciarias afectadas por glaciaciones antiguas, materializada en la presencia de bloques erráticos, acumulaciones de till y rasgos de abrasión. En las proximidades de la localidad de Dina Huapi, los mallines están asentados sobre geoformas, gobernadas por morenas y procesos erosivosdeposicionales glaciarios. En cambio hacia el este, en las cercanías de Pilcaniyeu, aparece un relieve estructural en rocas plegadas de origen terciario, en una 
Macchi, P. 2017. Macroinvertebrados acuáticos como indicadores ecológicos de cambios en el uso del suelo en mallines del sudoeste de la Provincia de Río Negro (Dra. María Laura Miserendino - Dra. Nora Gómez)

formación de bajos y mallines, rodeados por cañadones y pendientes aluviocoluviales, con zonas de pedimentos.

\subsection{CLIMA}

La ubicación geográfica de la región determina que la mayor parte del territorio este dominado fundamentalmente por masas de aire originadas en el Pacífico (Paruelo et. al. 2005). El sistema de circulación atmosférica originado por la interacción del anticiclón del Pacífico y la faja de baja presión del círculo polar antártico, da lugar a los vientos de dirección oeste (Muñoz y Garay 1985). La ubicación e intensidad de estos centros de presión no sólo controlan el régimen de los vientos, sino que también inciden sobre los regímenes de precipitación y temperatura (Paruelo et al. 1998b).

Por otro lado, la cordillera de los Andes juega un papel central como determinante en el clima patagónico. La distribución N-S de la cordillera, genera una fuerte barrera orográfica para las masas de aire húmedas provenientes del océano Pacífico. Estas masas de aire descargan su humedad en las laderas occidentales de los Andes y, al descender sobre vertiente oriental, se calientan y se secan determinado un marcado gradiente de precipitaciones O-E en la región (Barros et al. 1979). Por ejemplo entre Pampa Linda (2000 mm anuales) y Pilcaniyeu (300 mm anuales), cuya distancia lineal es cercana a 90 kilómetros, las precipitaciones disminuyen en el orden de $16-18 \mathrm{~mm}$ por kilómetro. En tanto los meses de otoño-invierno concentran la mayor cantidad de lluvias, ocasionando un fuerte déficit hídrico estival (Paruelo et al. 1998b).

Las temperaturas medias anuales en el área varían entre 5 y $15^{\circ} \mathrm{C}$, con una amplitud térmica (diaria y anual) que se incrementa notoriamente hacia el este (Pereyra 2007). Sin embargo los fuertes vientos del oeste modifican la sensación térmica, produciendo un efecto enfriante con veranos más frescos.

De acuerdo a las características hídricas y térmicas de la región, a medida que la deficiencia de agua, con respecto a la evapotranspiración potencial se incrementa, el clima aumenta en aridez. De esta forma el clima de la región varia de 
Macchi, P. 2017. Macroinvertebrados acuáticos como indicadores ecológicos de cambios en el uso del suelo en mallines del sudoeste de la Provincia de Río Negro (Dra. María Laura Miserendino - Dra. Nora Gómez)

perhúmedo microternal en el límite oeste (bosque mixto), a seco subhúmedo y semiárido hacia el este (estepa patagónica) (Godagnone y Bran 2009).

\subsection{SUELOS}

El marcado gradiente climático en sentido O-E ha condicionado la evolución de los suelos en Patagonia, imprimiendo características diferenciales en sus propiedades (Colmet Daage et al. 1988). Acorde con las características climáticas, el régimen de humedad de los suelos es, en general: údico en la zona cordillerana y arídico en la zona extrandina.

La dominancia de vientos predominantes del oeste ha producido una distribución de material volcánico sobre la región, determinando que la mayor parte de los suelos de la porción más occidental sean derivados de cenizas volcánicas. Estos suelos poseen una serie de propiedades particulares (elevada capacidad de retención de humedad, baja densidad aparente, alta capacidad de retención de fosfato, alto contenido de carbono orgánico) que los diferencian de los suelos originados a partir de otros materiales (Gaitan y López 2007).

En los mallines de bosque, la interacción entre un régimen de humedad ácuico con la deposición de cenizas volcánicas y sedimentos glacigénicos ha resultado en la formación de suelos Molisoles con un horizonte superficial muy oscuro, de texturas medias, con abundante materia orgánica, rico en bases y con una alta capacidad de adsorción aniónica, lo que determina la retención de fosfatos (Calabrese et al. 2012). Presentan poca diferenciación de horizontes y la capa freática se encuentra a los $50 \mathrm{~cm}$ de profundidad (Godagnone y Bran 2009).

En cambio en los mallines de estepa, el suelo es una consecuencia de aportes aluviales y coluviales, arrastrados por el agua y con alto componente de materia orgánica. En planicies aluviales se desarrollan Entisoles, de textura arenosa, de color pardo oscuro, con moderada alcalinidad y salinidad (Godagnone y Bran 2009). Estos cambios en la química de los suelos, se relacionan con los aportes de sales derivadas del lavado de rocas sedimentarias, los que también aportan material arcilloso. 
Macchi, P. 2017. Macroinvertebrados acuáticos como indicadores ecológicos de cambios en el uso del suelo en mallines del sudoeste de la Provincia de Río Negro (Dra. María Laura Miserendino - Dra. Nora Gómez)

En algunos sectores de mallines, tanto de bosque como de estepa, se destaca la presencia de suelos Histosoles, únicos francamente orgánicos con valores superiores al $20 \%$ de materia orgánica y con ligera acidez. Poseen condiciones de drenaje restringido y se encuentran casi completamente saturados de agua la mayor parte del año. En su sección vertical se aprecian horizontes con un elevado tenor de fibras vegetales con diferentes grados de descomposición provenientes de la acumulación de juncáceas y ciperáceas (Ferrer et al. 2006).

\subsection{VEGETACIÓN}

La biozona de bosque mixto, localizada a lo largo de un gradiente de precipitaciones O-E (3000-600 mm anuales), coincide en gran parte con la Provincia Fitogeográfica Subantártica (Godagnone y Bran 2009).

La vegetación está caracterizada por las fisonomías de bosque y matorral. En el primero sobresalen árboles de hoja perenne (Austrocedrus chilensis (D. Don) y Nothofagus dombeyi (Mirb.) Oerst.) y caducifolios (N. pumilio Poepp. \& Endl. Krasser y $N$. antárctica (G. Forst.) Oerst.). En el estrato arbustivo las especies más comunes son Chusquea culeou E. Desv., que suele formar cerrados cañaverales, varias especies del género Berberis, Lomatia hirsuta (Ruiz \& Pav.) R.T. Penn. y Schinus patagonicus (Phil.) I.M. Johnst. La cobertura de la vegetación oscila entre 80-100\% (del Valle 2003).

La estepa patagónica, que se caracteriza por un marcado déficit hídrico, es la biozona más extensa en la región Patagónica, abarcando aproximadamente un 75$85 \%$ de su superficie. La vegetación responde, fisonómica y florísticamente, a la Provincia Fitogeográfica Patagónica (Calabrese et al. 2012). Predomina una estepa de arbustos bajos y gramineas. Entre los primeros los más comunes son: Mulinum spinosum (Cav.) Pers., Senecio bracteolatus (Hook. \& Arn.), Berberis heterophylla K.Koch y Tetraglochin alatum (Gillies ex Hook. \& Arn.) Kuntze. Entre las segundas Papostipa speciosa (Trin. \& Rupr.) Romasch., P. humilis (Cav.) Romasch., Poa ligularis Nees ex Steud. y Festuca pallescens (St.-Yves) Parodi. Acompañan otras gramíneas (Bromus setifolius J. Presl, Hordeum comosum J. Presl) y hierbas. 
Macchi, P. 2017. Macroinvertebrados acuáticos como indicadores ecológicos de cambios en el uso del suelo en mallines del sudoeste de la Provincia de Río Negro (Dra. María Laura Miserendino - Dra. Nora Gómez)

Como vegetación azonal, de distribución local y asociada a las condiciones del sustrato, se encuentran las praderas de hidrófitas de juncáceas, ciperáceas y gramíneas que cubren densamente, bajos y mallines, en ambas biozonas.

\subsection{SELECCIÓN DE SITIOS}

Para la selección de los sitios se realizó una tipificación de los mallines dentro de categorías en cuanto a los tipos de uso de suelo: referencia, urbano y rural. Con ello se intentó minimizar la variación dentro de los grupos y maximizar la varianza entre grupos. En una primera clasificación se identificaron mallines de referencia, es decir aquellos prístinos o menos disturbados, cuyos valores en sus atributos y condiciones ambientales permitieran identificar una condición de referencia. Para la selección de sitios posiblemente disturbados, agrícolas o urbanos, se tuvo en cuenta el uso histórico y actual de los mallines y, su cuenca hidrológica.

En la biozona de bosque mixto se seleccionaron nueve mallines, agrupados en tres categorías, referencia $(n=3)$, rural $(n=3)$ y urbano $(n=3)$, éstos últimos localizados en la ciudad de San Carlos de Bariloche. En cambio en la biozona de estepa patagónica, se eligieron seis mallines, distribuidos en dos categorías, referencia $(n=3)$ y rural $(n=3)$.

Los mallines seleccionados, en el sudoeste de la Provincia de Río Negro, se distribuyeron a lo largo de un gradiente de precipitaciones (2000 $\mathrm{mm}$ a $300 \mathrm{~mm}$ ) cuya distancia lineal equivale a aproximadamente 92 kilómetros (Figura 3.2; Tabla 3.1).

Las precipitaciones junto con la geomorfología definen el hidroperíodo de los humedales. En el bosque predominaron los mallines con hidroperíodo permanente a semipermanente, solo la Laguna Fantasma fue temporaria, con una duración de 910 meses, entre otoño y mediados de verano. En la estepa, todos los mallines fueron semipermanentes a temporarios, con hidroperíodos que oscilan entre los 810 meses de fase húmeda y con inviernos que pueden congelar la superficie de los cuerpos de agua (Tabla 3.1). 


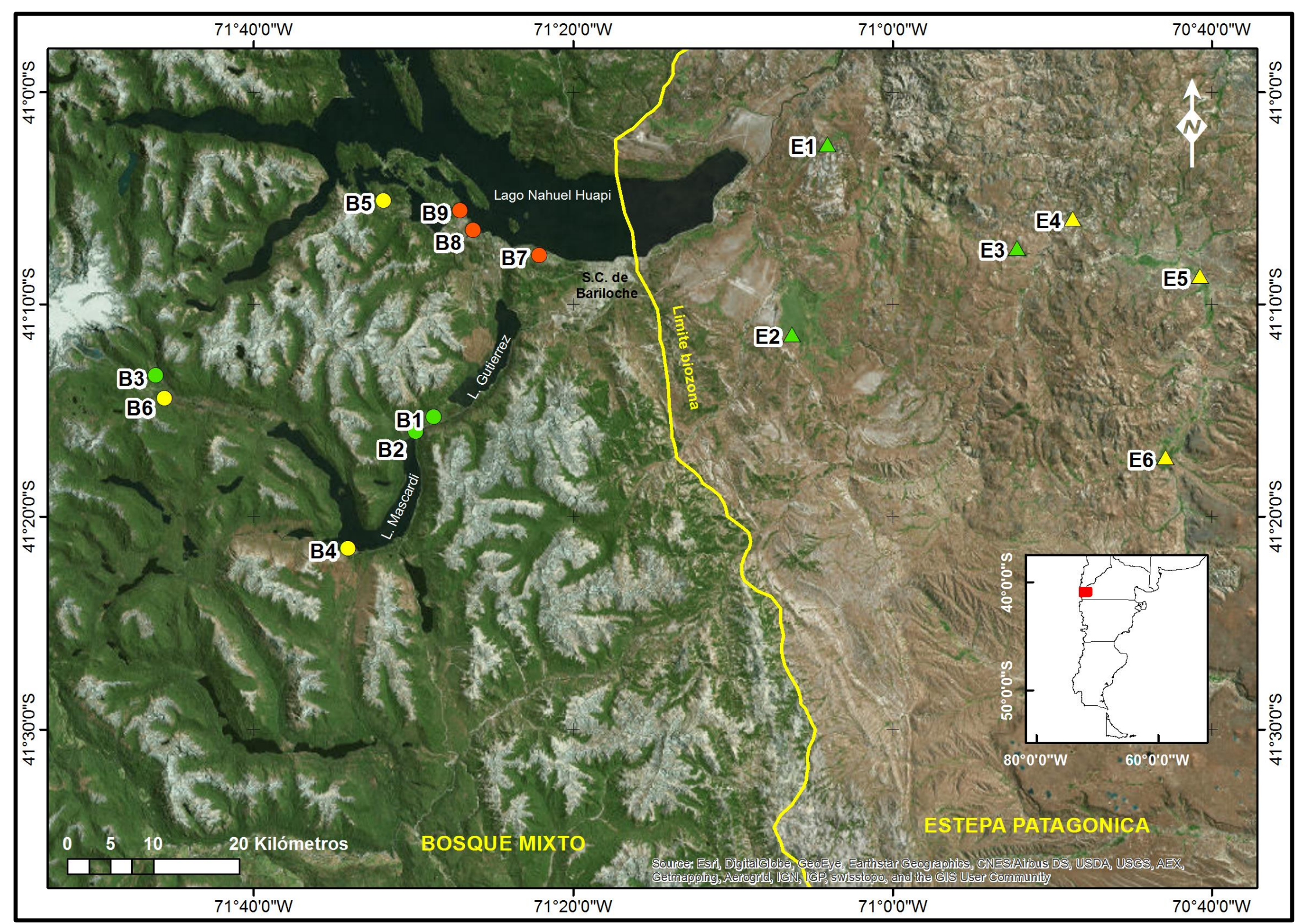

Figura 3.2: Localización geográfica de los 15 humedales muestreados en ambas biozonas en el SO de la Provincia de Río Negro durante septiembre y diciembre de 2012. Los nombres de los mallines asociados a sus respectivos códigos se consignan en la tabla 3.1. Colores uso del suelo: verde referencia; amarillo agrícola; rojo urbano. 
Tabla 3.1. Características descriptivas de los 15 mallines muestreados, localizados en el SO de la Provincia de Río Negro, nombre asignado, código, uso de suelo (R: referencia; A: agrícola; U: urbano), latitud, longitud, altitud, hidroperíodo y precipitaciones medias mensuales obtenidas a partir de isoyetas históricas. Fuente INTA. *datos suministrados por la estancia (Septiembre - Diciembre de 2012).

\begin{tabular}{|c|c|c|c|c|c|c|c|c|}
\hline & 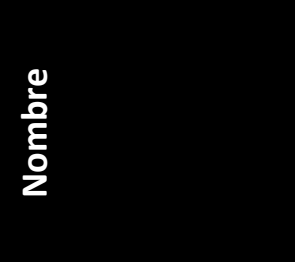 & $\begin{array}{l}\circ \\
\frac{.0}{70} \\
0\end{array}$ & 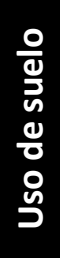 & 总 & 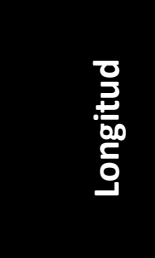 & 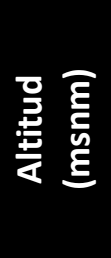 & 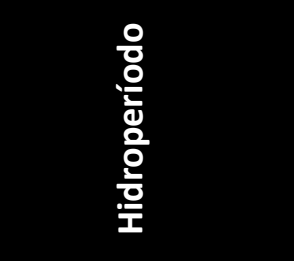 & 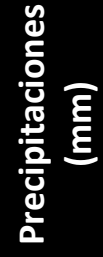 \\
\hline \multirow{9}{*}{ 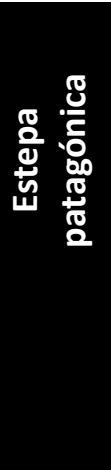 } & Ea. San Ramón & E1 & $\mathrm{R}$ & $-41.040^{\circ}$ & $-71.067^{\circ}$ & 1026 & Semipermanente & $578^{*}$ \\
\hline & Ea. El Cóndor & E2 & $\mathrm{R}$ & $-41.191^{\circ}$ & $-71.106^{\circ}$ & 798 & Semipermanente & $694 *$ \\
\hline & Ea. Pto. Moreno & E3 & $\mathrm{R}$ & $-41.122^{\circ}$ & $-70.869^{\circ}$ & 983 & Semipermanente & $348 *$ \\
\hline & Ea. Dominguez & E4 & $A$ & $-41.098^{\circ}$ & $-70.812^{\circ}$ & 957 & Semipermanente & 300 \\
\hline & Ea. Pilcañeu & E5 & $A$ & $-41.144^{\circ}$ & $-70.678^{\circ}$ & 979 & Permanente & $264^{*}$ \\
\hline & Ea. Rayhuao & E6 & $A$ & $-41.285^{\circ}$ & $-70.709^{\circ}$ & 1042 & Permanente & $476^{*}$ \\
\hline & Vereertbrugghen & B1 & $\mathrm{R}$ & $-41.258^{\circ}$ & $-71.480^{\circ}$ & 828 & Permanente & 1700 \\
\hline & Muelle viejo & B2 & $\mathrm{R}$ & $-41.267^{\circ}$ & $-71.497^{\circ}$ & 817 & Permanente & 1800 \\
\hline & La Turbina & B3 & $\mathrm{R}$ & $-41.221^{\circ}$ & $-71.770^{\circ}$ & 849 & Semipermanente & 2000 \\
\hline \multirow{6}{*}{ 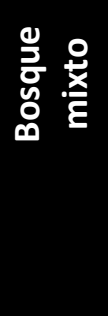 } & Playa Negra & B4 & $A$ & $-41.358^{\circ}$ & $-71.568^{\circ}$ & 800 & Semipermanente & 1800 \\
\hline & Cretón & B5 & $A$ & $-41.084^{\circ}$ & $-71.533^{\circ}$ & 788 & Permanente & 1700 \\
\hline & Pampa Linda & B6 & $A$ & $-41.239^{\circ}$ & $-71.760^{\circ}$ & 857 & Permanente & 2000 \\
\hline & $\mathrm{Km} 5$ & B7 & $U$ & $-41.127^{\circ}$ & $-71.368^{\circ}$ & 827 & Permanente & 1200 \\
\hline & $\mathrm{Km} 12$ & B8 & $U$ & $-41.107^{\circ}$ & $-71.435^{\circ}$ & 771 & Semipermanente & 1100 \\
\hline & Lag. Fantasma & B9 & $U$ & $-41.093^{\circ}$ & $-71.451^{\circ}$ & 779 & Temporario & 1100 \\
\hline
\end{tabular}

\subsection{DESCRIPCIÓN DE LOS MALLINES AGRUPADOS POR DE USO DE SUELO}

\subsubsection{Mallines en el Bosque mixto}

Los mallines de seleccionados de referencia en la biozona de bosque mixto se localizan al sur de la ciudad de San Carlos de Bariloche, en las áreas del Parque Nacional Nahuel Huapí, Lago Gutiérrez, Lago Mascardi y Tronador. 
El mallín Vereertbrugghen (B1), que pertenece a la estancia del mismo nombre, tiene una superficie de aproximadamente 93 hectáreas y se asienta en una planicie glacilacustre (828 msnm), con pendiente hacia el Lago Gutiérrez. El agua que drena el mallín, en dirección S-E, surge de una red de vertientes localizadas en el extremo sur del mismo y fueron canalizadas para obtener una mayor cobertura de pasturas. Si bien la estancia hace un uso agrícola-ganadero del humedal, la zona de las vertientes se encuentra protegida del acceso de los animales, por tal motivo fue seleccionada como sitio de referencia en el diseño.

El mallín Muelle Viejo (B2), de tan sólo 4 hectáreas, ocupa parte de una pequeña planicie glacilacustre, en el extremo norte del Lago Mascardi. Al igual que el mallín Vereertbrugghen, las aguas que escurren por el mallín surgen de diversas vertientes localizadas al norte y al este de la planicie, formando pequeños canales de drenaje N-S y áreas inundadas. Este humedal no presentó rastros o evidencias de pastoreo.

Finalmente, el otro mallín seleccionado como de referencia fue La Turbina (B3), está localizado en la zona Tronador del Parque Nacional Nahuel Huapí, a solo un kilómetro al norte del área recreativa Pampa Linda. Presenta una superficie de algo más de 100 hectáreas y ocupa un amplio valle glaciario a 849 msnm, originado por la erosión y posterior retroceso de los actuales glaciares Castaño Overo y Los Alerces, situados en la ladera oriental del Cerro Tronador. Por el fondo del valle y recostado hacia el este, escurre el arroyo Castaño Overo, cuyas aguas drenan, en parte por una planicie originando un extenso mallín. Este humedal tiene un uso ganadero ocasional debido al pastoreo de caballos pertenecientes a los guardaparques de la seccional Pampa Linda.

Los mallines de uso agrícola se localizan, al igual que los de referencia, en el Parque Nacional Nahuel Huapí.

Playa Negra (B4), es un mallín lindero a la margen suroeste del Lago Mascardi, sólo separado por el camino que une Pampa Linda con la Ruta Nacional 40. Probablemente antes de la construcción del camino, el área constituía un humedal 
somero conectado superficialmente con el lago. Actualmente el agua que recibe el mallín proviene del deshielo de los cerros linderos, pero básicamente de los flujos de agua subterránea con el Lago Mascardi. Presenta una superficie de 10 hectáreas y es pastoreado por ganado, principalmente caballos, ovejas y cabras de pobladores del lugar.

El mallín Cretón (B5), cuya superficie es aproximadamente 115 hectáreas, se sitúa en área de la ruta conocida como Circuito Chico, al oeste de Colonia Suiza. El escalonamiento estructural y la posterior erosión glacial, produjo una zona deprimida y chata mayormente ocupada por el mallín. Las incipientes vías de drenaje naturales fueron profundizadas artificialmente, existiendo una canalización que sale desde la parte central del mallín para alimentar un canal principal que se dirige hacia el noroeste del Lago Moreno, facilitando el escurrimiento superficial del área. Estas obras definieron un sector occidental, donde el mallín ha dejado de ser funcional y un sector oriental, que permanece inundado la mayor parte del año. En las zonas intermedias y periféricas del sector oriental del mallín, existe un continuo pastoreo de caballos, vacas, ovejas y cabras que han inducido la formación de suelo desnudo favoreciendo procesos erosivos (Alonso et al. 2010).

El último de los mallines de este uso, es la laguna Pampa Linda (B6), localizada en un sector deprimido de depósitos morénicos (857 msnm), en el sudoeste del valle de origen glaciario por el que escurre el río Manso Superior. Este pequeño mallín de sólo dos hectáreas, recibe aguas de deshielo y lluvias, y su uso agrícola esta dado básicamente por el pastoreo de ganado vacuno.

Los mallines urbanos que se seleccionaron para el presente estudio, se ubicaron dentro ejido de San Carlos de Bariloche. Estos mallines, así como otros humedales urbanos, se encuentran protegidos por la legislación municipal. De acuerdo a la Carta Orgánica, en su capítulo Humedales, Art. 185 - La Municipalidad protege y regula el uso racional de los humedales (mallines) dentro del ejido, favoreciendo el mantenimiento de los mismos en su estado natural. 
El Mallín KM 5 (B7), se localiza en el faldeo norte del cerro Otto (827 msnm) en el Barrio Rayen Mapú, a tan sólo 5 kilómetros del centro de la ciudad. El suelo que ocupa este humedal se encuentra prácticamente urbanizado, solo se preservan las áreas anegadas y con afloramiento de agua permanente, que ocupan menos de dos hectáreas (Figura 3.4.5). Incluso sobre sus tierras está construida la estación del teleférico, que conecta con la confitería del mencionado cerro.

El ambiente geomorfológico en el que se inserta el mallín $\mathrm{KM} \mathrm{5,} \mathrm{se} \mathrm{asocia} \mathrm{las}$ pendientes de la ladera del cerro Otto, con la presencia de cauces efímeros y con una importante cobertura detrítica, depósitos morénicos y afloramientos de rocas intensamente meteorizadas y diaclasadas. El área experimenta casi todos los años, aluviones que afectan numerosas viviendas, debidos a los flujos e inundaciones se producen en los cañadones que tienen sus nacientes en el cerro Otto. Diversos factores influyen en su ocurrencia, como las altas pendientes de sus cabeceras (más de $30^{\circ}$ ), la deforestación intensa, el alto grado de intervención antrópica, la impermeabilización del suelo y la cobertura de las pendientes con material grueso poco consolidado (till y aluvio-coluvial) suprayacente al sustrato rocoso. Al insumirse el agua en el till muy permeable, favorecido por la deforestación y el excedente agua por uso domiciliario, esta llega al sustrato rocoso y ahí se desplaza en forma subsuperficial a favor de la pendiente quitando sustentación al material suprayacente, favoreciendo su deslizamiento pendiente abajo (Pereyra 2007).

Otro de los mallines urbanos seleccionados está localizado en el KM 12 (B8) de la avenida Bustillo, a 771 msnm. Este mallín formaba parte una ingresión muy somera del lago Nahuel Huapí antes de que se construya la mencionada avenida. Constituye un bajo anegado que recibe agua de precipitaciones y escorrentía subsuperficial del faldeo norte del cerro Catedral, pero además presenta conexión subterránea con el lago. El mallín, que posee una superficie de 17 hectáreas, tiene un hidroperíodo semipermanente, secándose ocasionalmente durante el verano.

Históricamente, las presiones urbanas sobre el mallín KM 12 han sido muy intensas, parte de las tierras son aún utilizadas para el pastoreo de caballos y vacas, otras fueron rellenadas para la construcción de viviendas, comercios e incluso 
industrias (dos cervecerías). La mayoría de estas construcciones y las del área periférica, poseen lechos nitrificantes como sistemas de tratamiento de efluentes cloacales domiciliarios, que aportan una gran carga de nutrientes y bacterias. Parte de este impacto se refleja en la playa de Bahia Serena, que recibe naturalmente el drenaje subterráneo del mallín. Esta playa, balneario municipal habilitado, es periódicamente denunciada por la alta contaminación bacteriológica.

Finalmente, el último de los mallines urbanos fue la Laguna Fantasma (B9), que se sitúa al oeste de la ciudad de San Carlos de Bariloche, en el Barrio Tres Lagos, en el kilómetro 15 de la avenida Bustillo. Localizado a 779 msnm, el mallín tiene una superficie de algo más de una hectárea y su geomorfología presenta un relieve cóncavo, inmerso en un paisaje erosivo glaciario como morenas de fondo. Dependiendo del régimen de lluvias otoñales, su hidroperíodo temporario, puede durar entre 9 y 10 meses.

Actualmente este humedal se encuentra protegido por Ordenanza Municipal ( $\left.\mathrm{N}^{\circ} 332-\mathrm{CM}-94\right)$ como área intangible, cuyo objetivo principal es la preservación de especies de distribución restringida y su diversidad genética. Sin embargo, el mallín ha sufrido deterioros propios de un ambiente urbano, como vuelco de efluentes residuales, contaminación por vertidos domésticos e infiltración de lechos nitrificantes, extracción de plantas y leña, entre otros.

\subsubsection{Mallines en la Estepa patagónica}

Los mallines seleccionados en la biozona de estepa patagónica se localizaron al este de la ciudad de San Carlos de Bariloche, dentro de un gradiente de precipitaciones entre 700-270 mm (Tabla 3.1).

Los usos del suelo en esta biozona, son casi exclusivamente agrícolaganaderos, donde la principal actividad pecuaria es la cría extensiva de ganado ovino y bovino. Por lo tanto, para la selección de los sitios de referencia se buscó a aquellos sitios con mejores prácticas de manejo, las que incluyen, sectorización en cuadros de pasturas, rotación de ganado entre cuadros para la recuperación de la vegetación, baja intensidad de carga ganadera, baja o nula intervención en cuerpos 
de agua para la canalización y drenaje, así como aplicación de medidas para la protección de los mismos. De esta forma los tres mallines tipificados en la categoría de referencia fueron Ea. San Ramón, Ea. Perito Moreno y Ea. El Cóndor.

El mallín perteneciente a la estancia San Ramón (E1), se localiza al noreste de la localidad de Dina Huapi, a sólo 10 kilómetros por la ruta nacional 23 (Figura 3.6). La superficie del mallín es de aproximadamente 360 hectáreas y se encuentra a 1026 msnm. Presenta un paisaje plano-cóncavo, rodeado de sierras y colinas bajas, redondeadas. El material originario de los suelos es de origen glaciar cubierto de sedimentos aluviales. El hidroperíodo es semipermanente y agua aflora en superficie en forma de pequeñas charcas en la zona central del mallín. De acuerdo a Calabrese y otros (2012), el área central de mallín, cercana a los cuerpos de agua, presenta suelos húmedos a mojados en todo el perfil, de textura franco-limosa, con abundante contenido de materia orgánica en los horizontes superiores (>20\%) y con síntomas de hidromorfismo. El pH es levemente ácido $(5,8-6,5)$, sin presencia de sales ni de álcalis (CE $<50 \mu \mathrm{S} / \mathrm{cm}$ ), el drenaje general es muy pobre. El uso del mallín es ganadero vacuno, sin embargo no se registran signos de degradación en el suelo por sobrepastoreo, cuya cobertura vegetal es del 100\% (Calabrese et al. 2012).

Otro de los mallines de referencia, es el que se encuentra dentro de la estancia Perito Moreno (E3) (Figura 3.2). Ubicado a 30 kilómetros de Dina Huapi por la RN23, presenta una superficie de 115 hectáreas. Al igual que el mallín de la estancia San Ramón, la geomorfología es plano-concava, con sedimentos aluviales como material originario de los suelos. La presencia de agua en superficie es semipermanente, con sequia ocasional. En el sector central del mallín el suelo es profundo $(>1,50 \mathrm{~m})$, generalmente de mojado a empapado, con textura francolimosa y materia orgánica abundante en horizontes superiores (>10\%). El pH es cercano a la neutralidad $(6,4-7,2)$ y la conductividad eléctrica es $50 \mu \mathrm{S} / \mathrm{cm}$ (Calabrese et al. 2012). El uso del mallín es ganadero vacuno y no se registran síntomas de degradación (Calabrese et al. 2012).

Finalmente, el mallín de la estancia el Cóndor (E2) fue otro de los elegidos de referencia (Figura 3.2). Esta localizado en las cercanías del aeropuerto internacional 
de Bariloche, a una altitud de 798 msnm. Con una superficie de 1870 hectáreas, constituye uno de los mayores mallines de la Patagonia. Ocupa una amplia planicie glacifluvial, conocida como Pampa de Nahuel Huapi, que debido a su morfología y extensión, presenta en diversos sectores, afloramientos, flujos y/o acumulaciones de agua en superficie. En general, el hidroperíodo es temporario a semipermanente dependiendo del cuerpo de agua. El uso del mallín es para pastoreo de ganado vacuno y ovino principalmente.

En cuanto a los mallines categorizados como de uso agrícola, debido básicamente al pastoreo intensivo ganadero y/o con una importante intervención de obras hidráulicas sobre los cuerpos de agua, estuvieron localizados en el departamento de Pilcaniyeu, al este de San Carlos de Bariloche.

El Mallín Domínguez (E4), ocupa una extensión de 48 hectáreas, en una planicie estructural lávica rodeada de sierras y mesetas (Figura 3.2). El agua superficial que drena por el mallín se acumula en pequeños cuerpos de agua que han sido canalizados para ampliar el área de pasturas. Su hidroperíodo es semipermanente con periodo de sequía ocasional. El suelo en el área central se presenta comúnmente mojado a empapado, posee textura franco-limosa, $\mathrm{pH}$ levemente básico $(\mathrm{pH} \mathrm{7-7,4)} \mathrm{y} \mathrm{conductividad} \mathrm{eléctrica} \mathrm{superior} \mathrm{a} 100 \mu \mathrm{S} / \mathrm{cm}$. Existe una alta carga de ganado vacuno y caballar, así como signos evidentes de degradación y erosión de suelo en algunos sectores del mallín (Calabrese et al. 2012).

El mallín de la estancia Pilcañeu (E5) ocupa un amplio bajo de 911 hectáreas, que se extiende hasta las proximidades de la localidad de Pilcaniyeu. Esta zona de bajos está rodeada de cañadones y pendientes aluvio-coluviales, con un área de pedimentos superficiales de erosión y cubiertas sedimentarias delgadas y discontinuas

A los largo de este amplio mallín fluyen las aguas del arroyo, permanente y de régimen nival, Pilcaniyeu. Para aprovechar el agua de deshielo y retrasar su escurrimiento, casi toda la extensión del arroyo que atraviesa el mallín (10 Km) fue 
disectado, con la construcción de pequeños diques que embalsan el agua y garantizan su provisión durante casi todo el año. De esta forma, se originan una serie de pequeños cuerpos de agua lenticos, conectados entre sí mediante el flujo de agua subterránea. Estas obras hidráulicas constituyen reservorios que permiten distribuir, mediante canalizaciones, el agua a otras partes del mallín. Con respecto al suelo, en la zona central del mallín presenta una textura franco-limosa a franco arcillosa, con moderada cantidad de materia orgánica en horizontes superiores (4-5 $\%), \mathrm{pH}$ moderadamente alcalino $(8,4-9,4)$ y alta conductividad eléctrica $(209-457$ $\mu \mathrm{S} / \mathrm{cm})$. La cobertura de vegetación en el área es de $60-80 \%$, con manchones de suelo desnudo, evidenciado signos de erosión y sobrepastoreo (Calabrese et al. 2012).

Por último, el mallín de la estancia Rayhuao (E6) se encuentra a 20 kilómetros aguas arriba de la Ea. Pilcañeu, en una planicie por la que escurre el arroyo Pilcaniyeu. Este humedal tiene una superficie de aproximadamente 500 hectáreas y se localiza a 1049 msnm. La geomorfología es de un ambiente de abanico aluvial y bajada, con superficies de erosión inclinadas, de pendientes de pocos grados y cubiertas sedimentarias delgadas y discontinuas. La hidrología del mallín, es similar al anterior, parte del agua que recibe proviene de la infiltración en las laderas de los cerros contiguos, que aflora en la parte central del mallín, y otra parte del almacenamiento en reservorios a lo largo del cauce del arroyo mediante la construcción de diques, de manera similar a lo realizado en la Ea. Pilcañeu. El mallín es básicamente utilizado para el pastoreo intensivo de ganado vacuno y ovino. 


\section{METODOLOGÍA}

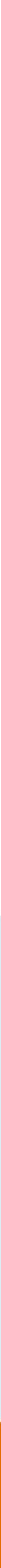




\subsection{CARACterización AMBiental De los MALLINES}

\subsubsection{Zonificación}

Para zonificar el área de los mallines (central, intermedia y periférica) se utilizaron imágenes Landsat multiespectral ETM+ (30x30, 11/10/2012). Con las imágenes se realizó un procesamiento digital, que incluyó realce de histogramas, combinaciones de bandas, índice verde NDVI (Normalizad Difference Vegetation Index) y transformación Tasseled Cap, que permitieron identificar los diferentes sectores en los mallines. Posteriormente se generó, de manera supervisada, una firma espectral de zonificación de mallines y se realizó una clasificación por el método paralelepípedo (Gaitán et al. 2009). Finalmente, la información obtenida de cada mallín fue convertida a vector y terminada de digitalizar con ayuda de imágenes de alta resolución espacial (Basemap, ArcGIS). Los programas utilizados fueron ENVI 5.1 y ArcGIS 10.3.

\subsubsection{Estimación de biotopos}

Dentro de cada humedal se estimó de forma ocular, el porcentaje de cobertura de biotopos, a partir de una evaluación de la complejidad estructural de los hábitats disponibles para los invertebrados acuáticos (Bird 2012). La calidad y cantidad de los biotopos son fundamentales para la estructuración de las comunidades de macroinvertebrados (Dickens y Graham 2002, Bird y Day 2014) y sus cambios pueden afectar a su composición y abundancia (Hill 2004, De Klerk y Wepener 2011).

Los tipos de biotopos evaluados en cada mallín fueron (MPCA 2007, Mlambo et al. 2011, Bird 2012): A. Vegetación compleja (conformado por ensambles de macrófitas pertenecientes a distintos tipos biológicos, sumergidas y emergentes, arraigadas o no arraigadas); B. Vegetación simple (conformado por ensambles de macrófitas únicamente arraigadas y emergentes de la superficie del agua); C. Aguas someras (hábitat sin vegetación, con una profundidad máxima de $30 \mathrm{~cm}$ ); D. Aguas profundas (hábitat sin vegetación, con una profundidad superior a los $30 \mathrm{~cm}$ ). El 
porcentaje de cobertura de los tipos biotopos en cada mallín se estimó cualitativamente en campo, durante ambos periodos de muestreo.

\subsubsection{Parámetros fisicoquímicos}

Se determinaron diversos parámetros fisicoquímicos para caracterizar la calidad del agua de los mallines y sus variaciones asociadas al uso del suelo y la estacionalidad. Para ello se midió in situ en cada cuerpo de agua y período de muestreo $(n=30)$ :

- Temperatura $\left({ }^{\circ} \mathrm{C}\right)$, con sonda multiparámetro OAKTON PCS Testr 35

- $\quad$ pH, con sonda multiparámetro OAKTON PCS Testr 35

- Conductividad ( $\mu \mathrm{S} . \mathrm{cm}-1)$, con sonda multiparámetro OAKTON PCS Testr 35

- Oxígeno disuelto (mg/L),con oxímetro YSI Pro 20

- Profundidad máxima (m), con varilla graduada (precisión $1 \mathrm{~cm}$ )

Asimismo en campo, se tomaron muestras de agua $(2000 \mathrm{ml})$, las que se refrigeraron inmediatamente $\left(4^{\circ} \mathrm{C}\right)$ para su posterior análisis en el laboratorio. Para la determinación de sustancias disueltas, las muestras fueron previamente filtradas utilizando filtros de Acetato de Celulosa de 0,45 $\mu \mathrm{m}$. De las muestras se determinaron:

- Fósforo total ( $\mu \mathrm{g} / \mathrm{L})$ : por digestión ácida y reducción del complejo fosfomolíbdico con ácido ascórbico (Golterman et al. 1978).

- Fósforo reactivo soluble $(\mu \mathrm{g} / \mathrm{L})$ : método colorimétrico por reacción con Molibdato de amonio, ácido sulfúrico diluido, ácido ascórbico y tartrato antimonio de potasio (Método del Ácido Ascórbico (424-F Standard Methods) (APHA 2001). Las lecturas se realizaron con espectrofotómetro Agilent 8452, a una longitud de onda de $885 \mathrm{~nm}$.

- Nitrógeno total ( $\mu \mathrm{g} / \mathrm{L}$ ): digestión (Grasshoff et al. 2009) y valoración de $\mathrm{NO}_{3}+\mathrm{NO}_{2}$ por reducción en columna de cadmio y diazotización (APHA 2001).

- Amonio ( $\mu \mathrm{g} / \mathrm{L})$ : método del azul-indofenol (Mackereth et al. 1978). La lectura se realizó con un espectrofotómetro Hewlett Packard modelo 8452A a una longitud de onda de $640 \mathrm{~nm}$. 
- Nitratos-nitritos $(\mu \mathrm{g} / \mathrm{L})$ : método colorimétrico por reacción con naftiletilendiamina y sulfanilamida (Método de reducción en columna de cadmio, 418-F Standard Methods) (APHA 2001). Previo a la coloración, la muestra atravesó una columna reductora de cobre-cadmio. La lectura se realizó con autoanalizador "AA1 SEAL Autoanalyzer" a una longitud de onda de $540 \mathrm{~nm}$.

- Solidos suspendidos totales ( $\mu \mathrm{g} / \mathrm{L})$ : diferencia entre peso final e inicial en filtros secados a peso constante en estufa a una temperatura entre 103-105 ${ }^{\circ} \mathrm{C}$ durante cuatro horas. Los filtros utilizados fueron 934AH Whatman (APHA 2001).

- Alcalinidad: titulación (mg/L) (APHA 2001).

\subsubsection{Determinación de la clorofila $a$}

Para la estimación de la densidad del fitoplancton en cada mallín y momento de muestreo, se determinó la concentración de clorofila $a$ en la columna de agua. Se colectaron entre 2-5 litros de agua en diferentes puntos de cada mallín. Luego, se filtraron en el campo utilizando una bomba de vacío, un portafiltros y filtros Whatman GF/F (Gómez et al. 2011). Los filtros se conservaron en viales refrigerados a $4^{\circ} \mathrm{C}$ y en la oscuridad hasta su análisis en laboratorio. La extracción de los pigmentos se realizó con acetona al $90 \%$ y se determinó la concentración de la clorofila a leyendo la muestra a longitudes de onda de 664, 647, 630 y $750 \mathrm{~nm}$. Las medidas de cada longitud de onda fueron corregidas mediante sustracción de la lectura a $750 \mathrm{~nm}$ sobre las absorciones de 664, 647 y $630 \mathrm{~nm}$ (APHA 2001). Los valores de clorofila a fueron expresados en $\mathrm{mg} / \mathrm{L}$ (Wetzel y Likens 1991).

\subsubsection{Análisis de nutrientes y estado trófico}

Se exploraron las proporciones NT:NP (nitrógeno total: fósforo total) y NID:PT (nitrógeno inorgánico disuelto: fósforo total), para establecer qué nutriente podría limitar el desarrollo del fitoplancton en los mallines. Sakamoto (1966) propone que la biomasa de fitoplancton es limitada por el nitrógeno cuando NT:PT $<10$ y, por el fósforo cuando TN:TP > 17. En cuanto la proporción NID:PT, según Bergström 
(2010), valores < 2,2 el nitrógeno es limitante, en cambio valores $>2,2$ el fósforo es limitante.

Por otro lado se evaluó el estado trófico de los mallines aplicando el Índice de Estado Trófico (TSI, por sus siglas en inglés) propuesto por Carlson (1977) y modificado por Aizaki et al. (1981). Este índice fue calculado a partir de la concentración de la clorofila a $\left(\mathrm{TSI}_{\mathrm{CL}}\right)$ y la concentración de del fósforo total (TSI $\left.\mathrm{PT}\right)$, mediante las siguientes ecuaciones:

$$
\begin{gathered}
T S I(C l)=10 x\left(2,46+\frac{\ln (C l)}{\ln 2,5}\right) \\
T S I(P T)=10 x\left(2,46+\frac{6,71+1,15 \ln (P T)}{\ln 2,5}\right)
\end{gathered}
$$

donde:

$\mathrm{Cl}$ : concentración de clorofila $a$ en $\mathrm{mg} \cdot \mathrm{m}^{-3}$

PT: concentración de PT en mg. $\mathrm{m}^{-3}$

De acuerdo a los valores que alcanza el TSI se pueden diferenciar tres categorías (Carlson 1977): oligotrófico (TSI < 30), mesotrófico (TSI > $30-<60$ ), eutrófico (TSI > $60)$.

\subsubsection{Análisis y cobertura de uso del suelo}

El análisis del uso del suelo de los mallines y la cuantificación de su transformación se realizó en diferentes instancias. En primer lugar se realizó una revisión bibliográfica de publicaciones y búsqueda de documentos en el INTA Bariloche, en la Biblioteca del Centro Regional Universitario Bariloche (Universidad Nacional del Comahue) y en la Intendencia del Parque Nacional Nahuel Huapí. Así mismo la información fue ampliada con visitas y recolección de datos en campo, entrevistas a administradores de las estancias, para describir el uso histórico y actual de los mallines teniendo en cuenta su fisonomía, producción de forraje, el manejo y tipo de ganado, las modificaciones hidráulicas como canalizaciones, dragado, impermeabilizaciones y construcción de diques, entre otras. 
En una segunda instancia se cuantificó la transformación del suelo en la periferia de los cuerpos de agua o áreas inundadas, dentro de las categorías (Bird 2012 y 2013, López et al. 2013): \% Natural, cubierta de vegetación natural sin transformación o uso determinado; \% Cuerpos de agua, áreas ocupadas por lagunas, lagos o ríos en la proximidad de los humedales; \% Agrícola, suelo intervenido por actividades agrícolas ganaderas; \% Urbano, área destinada a uso urbano que incluye viviendas, industrias, obras viales; \% Suelo degradado, cubierta de suelo desnudo o escasamente colonizado mayormente por vegetación exótica.

La cuantificación de la cobertura superficial de cada categoría de uso de suelo se realizó tomando áreas perimetrales de 100 y 500 metros desde los cuerpos de agua o áreas inundables más frecuentes en la zona central de los mallines. Para ello se utilizaron imágenes satelitales actuales (Google Earth 2012 y Basemap de ArcGIS), procesando los datos y digitalizando la información con el programa ArcGIS 10.3. Finalmente, los resultados obtenidos fueron verificados en campo con el uso de GPS (ETREX Garmin).

\subsection{ENSAMBLES DE MACRÓFITAS}

La descripción de composición y estructura de los ensambles de macrófitas se realizó en la zona central de los mallines, incluyendo sus cuerpos de agua, mediante el método fitosociológico relevé de Braun-Blanquet (Muller-Dombois y Ellenberg 1974, Braun-Blanquet 1979). El relevamiento fue realizado únicamente en diciembre de 2012, en coincidencia con la época de mayor crecimiento de la vegetación (Utrilla et al. 2008).

En primer lugar se realizó una fotointerpretación, localizando los sitios de relevamiento en áreas representativas en la zona central de los mallines. Posteriormente, en campo, los inventarios florísticos se realizaron en parcelas de 50 y $100 \mathrm{~m}^{2}$, en "stands" florística y estructuralmente homogéneos (Gandullo y Faggi 2005). En cada censo se registraron las especies y su respectiva abundancia y dominancia, expresada en porcentaje de cobertura, de acuerdo a Mueller-Dombois y Ellenberg (1974). Para cada especie se determinó su forma de vida, de acuerdo 
con la tipología de Sculthorpe (1967) en: emergentes (plantas enraizadas, morfológicamente adaptadas para crecer en sustratos pantanosos o sumergidos), flotantes enraizadas (plantas enraizadas al sustrato con hojas flotantes), subemeregentes (plantas con el tejido fotosintético completamente sumergido) y flotantes libres (plantas que flotan en superficie con poca o ninguna raíz) y, su origen en: nativa, endémica o exótica.

Así mismo se extrajeron muestras de la vegetación y se confeccionó un herbario de mallines, que se encuentra depositado Instituto de Recursos Naturales, Agroecología y Desarrollo Rural de la sede Andina de la Universidad Nacional de Río Negro. La nomenclatura de las plantas está de acuerdo al Catálogo de las Plantas Vasculares del Conosur (Zuloaga et al. 2008).

\subsection{ENSAMBLES DE MACROINVERTEBRADOS ACUÁTICOS}

\subsubsection{Diseño de muestreo}

Los mallines sometidos a similares usos de suelo en una misma región fueron considerados casos en los modelos $(n=3$ ) (Miserendino et al. 2011, Brand y Miserendino 2011). En cada uno de los 15 mallines seleccionados, agrupados por biozona y uso de suelo, se tomaron muestras de invertebrados acuáticos en los sedimentos $(n=3)$ y en la columna de agua $(n=3)$, que incluyó a los organismos de vida libre y asociados a las macrófitas. Con el objetivo de analizar la variación temporal, cada uno de los sitios fue visitado en dos oportunidades durante el año hidrológico: aguas altas, en época de lluvias y deshielo (septiembre de 2012), y aguas bajas, durante el estiaje (fines de diciembre de 2012) (Tabla 4.1). 
Tabla 4.1: Diseño de muestreo de invertebrados acuáticos en 15 mallines del So de la Provincia de Río Negro (septiembre - diciembre de 2012).

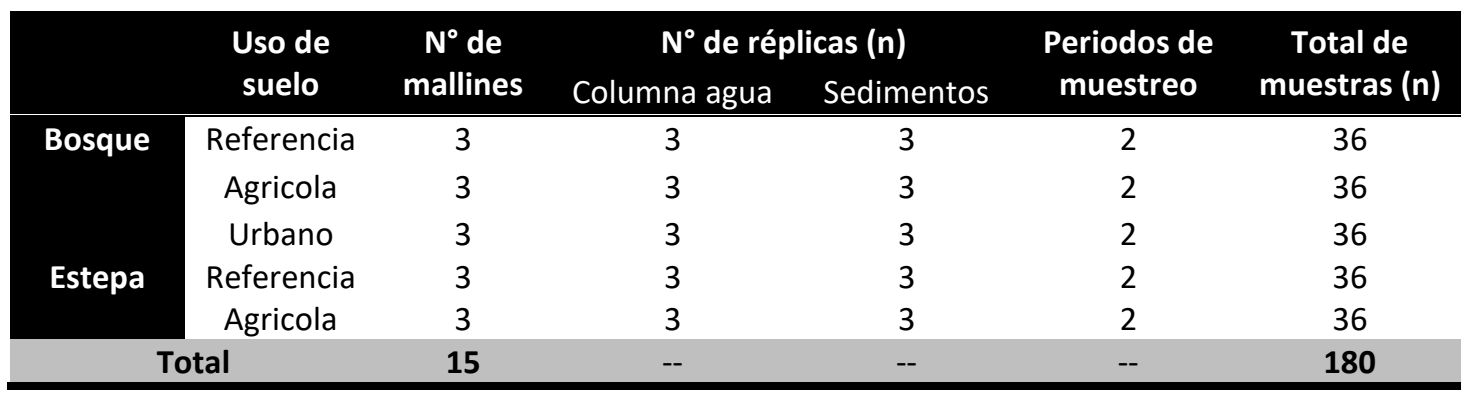

\subsubsection{Métodos de colecta e identificación}

En la columna de agua los invertebrados fueron colectados con una red marco tipo D-frame $250 \mu \mathrm{m}$ de tamaño de poro (Figura 4.1), según el método multihábitat (Barbour et al. 2006, Hering et al. 2006). Cada réplica tomada con este tipo de muestreador constó de cuatro movimientos de red distribuidos a largo de una transecta que incluyó a cada biotopo presente de manera proporcional a su extensión en el humedal. Las muestras se almacenaron en recipientes plásticos (500 $\mathrm{cm}^{3}$ ), previamente rotulados y se fijaron in situ con formaldehído al $5 \%(\mathrm{v} / \mathrm{v})$. Teniendo en cuenta el área de abertura de la red D-frame (radio $20 \mathrm{~cm}$ ) y la distancia recorrida dentro del agua (2 metros), las densidades de invertebrados se expresaron como ind. $\mathrm{m}^{-3}$ (Bolduc y Afton 2003, Balcombe et al. 2005, Hornung y Foote 2006).

Los invertebrados bentónicos se colectaron con un corer modificado de $12 \mathrm{~cm}$ de diámetro (Figura 4.1). El muestreo consistió en hundir el muestreador en los sedimentos hasta una profundidad de entre $10-20 \mathrm{~cm}$ dependiendo de la compactación del sustrato (Tall et al. 2008). Los sedimentos extraídos se almacenaron en bolsas plásticas de alta densidad, previamente rotuladas y se fijaron in situ con formaldehído al $10 \%(\mathrm{v} / \mathrm{v})$. A partir de la altura de los sedimentos extraídos y el diámetro del corer, las densidades de invertebrados bentónicos se expresaron como ind. $\mathrm{m}^{-3}$. 


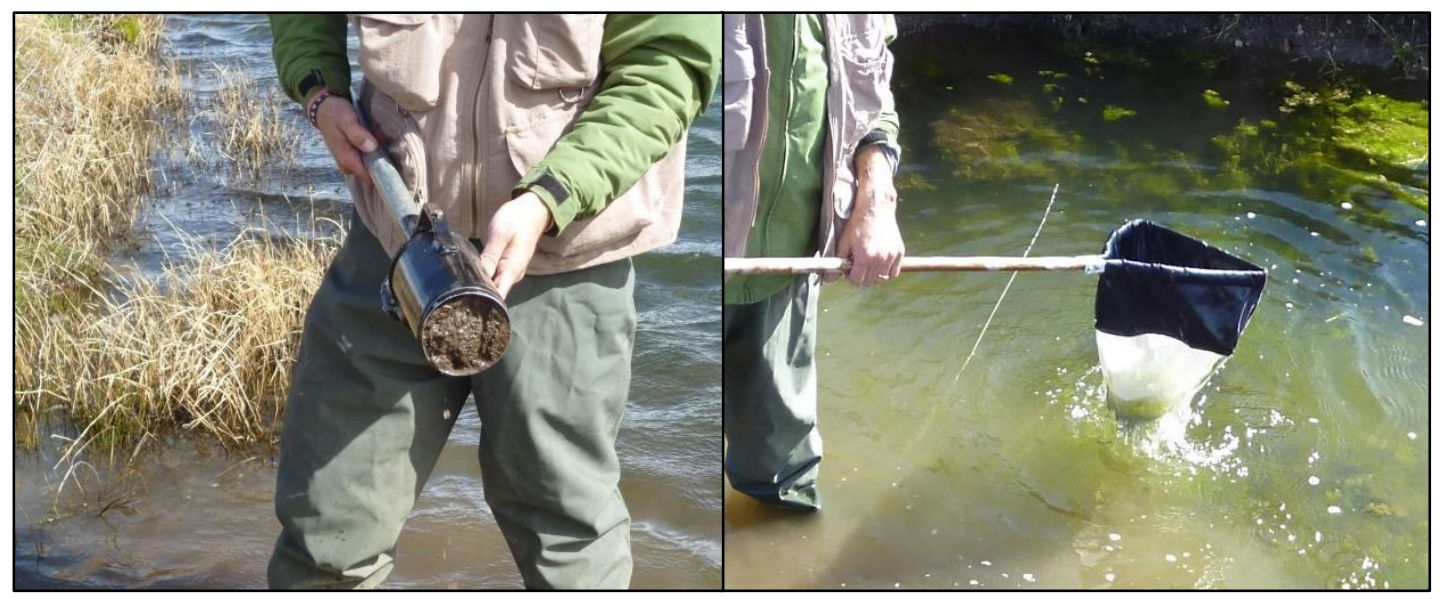

Figura 4.1: Métodos de colecta de macroinvertebrados. Izq: corer de $12 \mathrm{~cm}$ de diametro para bentos. Der: Red marco tipo D-frame para columna de agua.

En laboratorio se realizó la separación de los organismos de las muestras de columna de agua y de sedimentos se realizó mediante el lavado de las muestras en una serie de tamices de $2000 \mu \mathrm{m}, 1000 \mu \mathrm{m}, 500 \mu \mathrm{m}$ y $250 \mu \mathrm{m}$ (Rodríguez Capitulo et al. 2009). Los organismos se conservaron en frascos, rotulados por sitio y preservados en alcohol al $70 \%$.

La identificación y recuento de los invertebrados se realizó bajo estereomicroscopio y microscopio óptico utilizando claves regionales y publicaciones (Bachmann 1981, Wygodzinsky y Coscarón 1989, Wiederholm 1989, Rodríguez Capítulo 1992, Lopretto y Tell 1995, Archangelsky 1997, Muzón y Von Ellenrieder 1997, Cranston 2000, Epler 2001, Fernández y Domínguez 2001, Oliva et al. 2002, Heckman 2006, Michat y Archangelsky 2007, Heckman 2008, Michat et al. 2008, Alarie et al. 2009, Domínguez y Fernández 2009, Libonatti et al. 2011, Muzón et al. 2014). Los invertebrados fueron identificados hasta menor nivel taxonómico posible, y debido a que no todos pudieron ser determinados a nivel de especie, los valores de riqueza y diversidad se refirieron como riqueza y diversidad taxonómica. 
Asimismo, los invertebrados fueron clasificados en seis grupos funcionales tróficos desmenuzadores, raspadores, predadores, colectores recolectores, colectores filtradores y picadores herbívoros de acuerdo a Merritt y Cummins (1996). Para la asignación de las categorías de los grupos funcionales se utilizó bibliografía específica (Merritt y Cummins 1996, Lopretto y Tell 1995, Miserendino 2007).

\subsection{ANÁLISIS DE LOS ENSAMBLES}

Para la sistematización de los datos se confeccionó, con cada una de las réplicas, un inventario taxonómico de macrófitas y macroinvertebrados de columna de agua y bentónicos.

Con el inventario de macrófitas se calculó, por sitio y por uso de suelo según biozona, la riqueza taxonómica media y acumulada, la abundancia relativa de cada especie y el porcentaje de cobertura de plantas nativas y exóticas.

Con los datos de macroinvertebrados se determinó la riqueza taxonómica media y acumulada, así como la densidad media (inv. $\mathrm{m}^{-3}$ ) y la biomasa media $\left(\mathrm{mg} \cdot \mathrm{m}^{-3}\right.$ ) por sitio y por uso de suelo en cada biozona. La biomasa seca de los invertebrados se calculó a partir de regresiones largo-peso disponibles (Benke et al. 1999, Miserendino 2001, Miyasaka et al. 2008, Epele 2014, Rivera-Usme et al. 2015).

Para analizar la estructura de los ensambles de macroinvertebrados, se aplicó el índice de diversidad de Shannon-Wiener y el índice de equitatividad de Pielou.

El Índice de Shannon- Wiener, derivado de la teoría de información como una medida de la entropía, refleja la heterogeneidad de una comunidad sobre la base de dos factores: el número de especies presentes y su abundancia relativa (Pla 2006). Mide el grado promedio de incertidumbre en predecir a que especie pertenecerá un individuo escogido al azar de una comunidad (Magurran 1988, Ravera 2001). Asume que los individuos son seleccionados al azar y que todas las especies están representadas en la muestra. 


$$
H^{\prime}=-\sum_{i=1}^{S} p i \cdot \ln p i
$$

donde:

$\mathrm{H}^{\prime}=$ índice de Shannon- Wiener (nats.inv ${ }^{-1}$, nats por sus siglas en ingles natural digits). $p i=$ proporción del taxa $i$ en la muestra, dada por $i / n i$, donde $n i=n^{\circ}$ de individuos del taxa $i$.

$\mathrm{S}=\mathrm{n}^{\circ}$ de taxa en la muestra.

Adquiere valores entre cero, cuando hay una sola especie, y el logaritmo de $\mathrm{S}$ (número de especies), cuando todas las especies están representadas por el mismo número de individuos (Moreno 2001).

El índice de equitatividad de Pielou mide la proporción de la diversidad observada con relación a la máxima diversidad. Es decir, analiza con qué grado de igualdad están representadas las especies presentes en una muestra. Cuando las abundancias de una muestra son similares, el valor arrojado por el índice es máximo, mientras que cuando son muy diferentes el valor del índice se acerca a cero (Magurran 1988).

$$
J^{\prime}=\frac{H^{\prime}}{\ln S}
$$

donde:

J'=índice de Pielou

$H^{\prime}=$ índice de Shannon-Wiener

$\mathrm{S}=\mathrm{n}^{\circ}$ de taxa en la muestra

Finalmente, para el análisis de la estructura trófica de los ensambles de invertebrados acuáticos, con los datos de grupos funcionales, se calculó la densidad media (inv. $\mathrm{m}^{-3}$ ) y la biomasa seca media $\left(\mathrm{mg} \cdot \mathrm{m}^{-3}\right)$ por sitio y por uso de suelo según biozona. 


\subsection{ESTIMACIÓN DE MÉTRICAS}

La utilización de macroinvertebrados como indicadores a nivel de comunidad requiere, metodológicamente, la transformación de los datos (presencia o abundancia de los diferentes taxa) en métricas (Prat et al. 2009). La mayor parte de las métricas simples aplicadas en el estudio de los macroinvertebrados utilizan como factor clave la tolerancia de los diferentes taxa a una perturbación determinada. De este modo la relación entre el número de organismos tolerantes a las perturbaciones y los intolerantes a ella son un recurso habitual en las métricas usadas (Bonada et al. 2006).

Para analizar el posible efecto de diferentes usos del suelo y la calidad del agua sobre los ensambles de invertebrados acuáticos se calcularon 152 métricas simples, que miden atributos de las comunidades como riqueza, diversidad, composición, abundancia, tolerancia/intolerancia y estructura trófica. En la tabla 4.2 se presentan algunas de las métricas estimadas y sus probables respuestas al disturbio, en este caso las distintas prácticas o usos del suelo y su variación respecto a los valores de estas métricas en los sitios de referencia (Barbour et al. 1996, Tangen et al. 2003, Miserendino 2009, Prat et al. 2009, Bird 2014, Epele y Miserendino 2015, Poulton et al. 2015).

Las métricas con rangos bajos, o con la mayoría de los valores idénticos, son incapaces de diferenciar los sitios más perturbados respecto de aquellos de referencia (Whittier et al. 2007, Stoddard et al. 2008). Por lo tanto, se eliminaron las métricas de riqueza con rango $<5$, métricas porcentuales con rango de $<10 \%$, y las métricas con $>80 \%$ de los valores iguales a cero (Klemm et al. 2003, Macedo et al. 2016).

Para evaluar el nivel de apartamiento de cada uno de los métricos entre los sitios de referencia y los disturbados, se utilizó la metodología propuesta por Barbour et al. (1996), que evalúa la sensibilidad de métricos mediante la valoración de medianas y rangos intercuartiles (Figura 4.2). 
Tabla 4.2: Algunas de las métricas estimadas y sus probables respuestas al disturbio o cambios en el uso del suelo en humedales.

\begin{tabular}{|c|c|c|}
\hline Medida & Métrica & $\begin{array}{c}\text { Respuesta } \\
\text { esperada al } \\
\text { disturbio }\end{array}$ \\
\hline $\begin{array}{l}\text { Riqueza y } \\
\text { diversidad }\end{array}$ & $\begin{array}{l}\text { № total de taxa } \\
\text { № de familias de insectos } \\
\text { № de órdenes de invertebrados no insectos } \\
\text { № de taxa de insectos } \\
\text { № de géneros de coleópteros } \\
\text { № de taxa de crustáceos } \\
\text { № de taxa de gasterópodos } \\
\text { Índice de Shannon y Wiener } \\
\text { Índice de Pielou }\end{array}$ & $\begin{array}{l}\text { Disminuye } \\
\text { Disminuye } \\
\text { Aumenta } \\
\text { Disminuye } \\
\text { Aumenta } \\
\text { Disminuye } \\
\text { Disminuye } \\
\text { Disminuye } \\
\text { Disminuye }\end{array}$ \\
\hline $\begin{array}{l}\text { Composición y } \\
\text { abundancia }\end{array}$ & $\begin{array}{l}\text { \% de efemerópteros } \\
\% \text { de tricópteros } \\
\% \text { de dípteros } \\
\% \text { de quironómidos } \\
\% \text { de gasterópodos } \\
\% \text { de oligoquetos } \\
\% \text { de crustáceos } \\
\% \text { de anfípodos } \\
\% \text { de ditíscidos } \\
\% \text { de oligoquetos } \\
\% \text { EOT (Efemerópteros, odonatos y tricópteros) } \\
\% \text { OCD (Odonatos, coleópteros y dípteros) } \\
\text { Abundancia de efemerópteros } \\
\text { Abundancia de tricopteros } \\
\text { Abundancia de odonatos } \\
\text { Abundancia de anfípodos } \\
\text { Abundancia de quironómidos }\end{array}$ & $\begin{array}{l}\text { Disminuye } \\
\text { Disminuye } \\
\text { Aumenta } \\
\text { Aumenta } \\
\text { Disminuye } \\
\text { Aumenta } \\
\text { Aumenta } \\
\text { Aumenta } \\
\text { Aumenta } \\
\text { Aumenta } \\
\text { Disminuye } \\
\text { Disminuye } \\
\text { Disminuye } \\
\text { Disminuye } \\
\text { Disminuye } \\
\text { Aumenta } \\
\text { Aumenta }\end{array}$ \\
\hline $\begin{array}{l}\text { Tolerancia/ } \\
\text { Intolerancia }\end{array}$ & $\begin{array}{l}\text { Índice de Simpson } \\
\text { Densidad } \\
\text { EOT } \\
\text { OCD }\end{array}$ & $\begin{array}{l}\text { Aumenta } \\
\text { Aumenta } \\
\text { Disminuye } \\
\text { Disminuye }\end{array}$ \\
\hline $\begin{array}{l}\text { Características } \\
\text { tróficas }\end{array}$ & $\begin{array}{l}\text { \% Predadores } \\
\% \text { Colectores } \\
\% \text { Filtradores } \\
\% \text { Raspadores } \\
\% \text { Fragmentadores }\end{array}$ & $\begin{array}{l}\text { Variable } \\
\text { Disminuye } \\
\text { Disminuye } \\
\text { Disminuye } \\
\text { Variable }\end{array}$ \\
\hline
\end{tabular}


3 puntos: Sin superposición de rangos intercuartiles.

\section{2 puntos: baja superposición de rangos} intercuartiles, pero las medianas están fuera de la superposición.

1 punto: moderada superposición de rangos intercuartiles, pero las medianas están fuera de la superposición.

0 punto: a. mucha superposición de rangos intercuartiles. b. ambas medianas se superponen con los rangos intercuartiles.
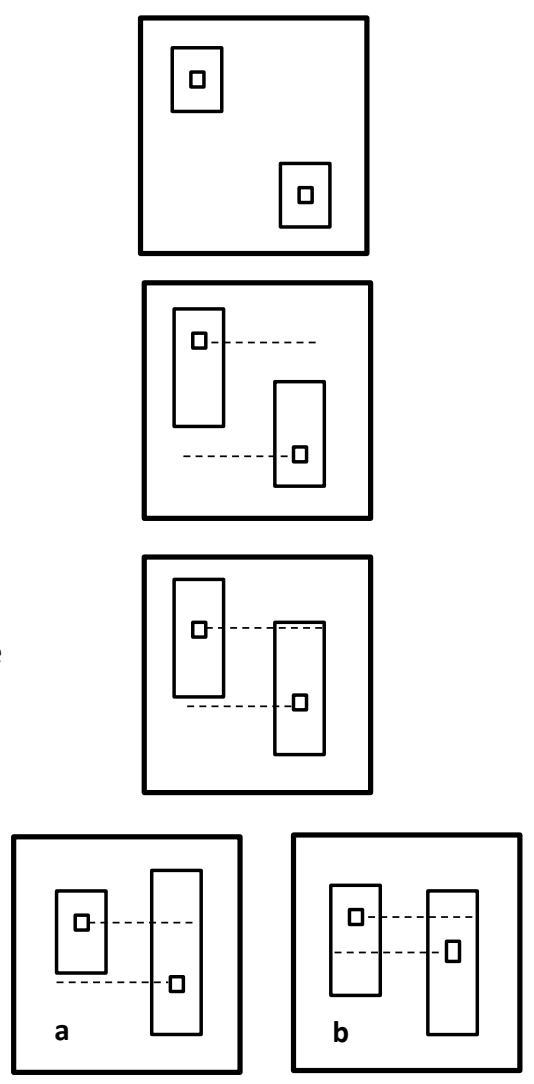

Figura 4.2: Esquema que resume el criterio utilizado para evaluar la sensibilidad de los métricos. Los cuadrados pequeños representan las medianas; las cajas son los rangos intercuartiles (25\%75\%). Figura modificada de Barbour et al. 1996.

De este modo, los métricos se juzgaron asignando alguno de los cuatro valores posibles y sólo se conservaron aquellos que mostraron las mejores respuestas frente al disturbio, representado por el grado de apartamiento (poder de discriminación de tipo 3 y 2).

\subsection{ANÁLISIS ESTADÍSTICO}

La descripción, análisis y evaluación de los datos obtenidos se realizó mediante la aplicación de métodos estadísticos univariados y multivariados, efectuando, cuando fue necesario una verificación de la normalidad y homogeneidad de la varianza mediante el test de Shapiro-Wilk y la prueba de Levene (Ellison y Gotelli 2004). 


\subsubsection{Exploración y comparación de parámetros ambientales y atributos comunitarios}

Para analizar del grado de asociación entre dos o más variables, se realizó un análisis correlación no paramétrica de Spearman (Sokal y Rohlf 1995) relacionando las métricas comunitarias seleccionadas para cada biozona con las variables ambientales. Para estos procedimientos se utilizó el programa InfoStat (Di Renzo et al. 2014).

Para evaluar si existieron diferencias en los parámetros ambientales de los mallines comparando, por un lado biozonas y por el otro, usos de suelo, se aplicaron modelos no paramétricos por rangos de ANOVA test de Kruskal-Wallis (Ludwing y Reynolds 1988) para grupos (usos de suelo en mallines de bosque), seguidos de test (Tukey test $p<0,05$ ) cuando dichas diferencias fueron significativas (Sokal y Rohlf 1995) o, el test de Mann-Whitney para pares de comparaciones (biozonas, usos de suelo en mallines de estepa, estacionalidad) (Ludwing y Reynolds 1988).

Similar análisis se realizó para examinar las diferencias de los atributos comunitarios (riqueza taxonómica, diversidad, densidad, biomasa, grupos funcionales) entre biozonas y entre usos de suelo. Adicionalmente los muestreos estacionales fueron usados para mejorar la significación de los análisis en las comparaciones, lo cual es aceptable en orden de contrastar múltiples muestras independientes (Sokal y Rohlf 1995).

\subsubsection{Ordenamiento de mallines según parámetros fisicoquímicos}

Por otro lado, para reducir el número de variables y analizar posibles gradientes ambientales en el ordenamiento de los mallines en cada biozona, se realizó un análisis de componentes principales (ACP) con los datos previamente transformados como log $(x+1)$ (excepto $\mathrm{pH})$. De esta manera se examinó la variación en las características fisicoquímicas de los sitios en las áreas estudiadas y permitió agruparlos en función de los usos de suelo. El ACP es un método de ruptura o particionamiento de una matriz de similitud, la que se representa en un set de ejes 
ortogonales dado que es un modelo linear. Este método es muy útil para detectar estructura en las relaciones de las variables analizadas (Ludwing y Reynolds 1988). Para estos procedimientos se utilizó el programa InfoStat (Di Renzo et al. 2014).

\subsubsection{Relaciones especie-ambiente}

Las relaciones entre los sitios de muestreo en los mallines, variables ambientales y abundancia de macroinvertebrados fueron evaluadas mediante modelos de análisis directo de gradientes (programa CANOCO 4.0. Número de serie: 6009).

Previo al ordenamiento se analizó si el comportamiento de las especies era mejor explicado por métodos lineares o unimodales (ter Braak y Smilauer 1998) y se utilizaron alternativamente análisis de redundancias o de correspondencias canónicas. Estos métodos permiten identificar la base ambiental que determina o afecta la distribución de la comunidad, combinando ordenación y regresión (ter Braak 1986, Leps y Smilauer 2003).

Para examinar las relaciones entre las asociaciones de macroinvertebrados, variables ambientales y mallines en un análisis temporal, se realizaron dos análisis de correspondencias canónicas (ACC). En un primer ACC se exploraron en nueve mallines de la biozona de bosque mixto, las relaciones entre las variables ambientales y los ensambles de invertebrados acuáticos en dos momentos de muestreo (septiembre y diciembre de 2012). En el segundo ACC se hizo lo propio, pero con los seis mallines de la biozona de estepa patagónica. En estos análisis temporales se empleó la media de las abundancias de cada uno de los taxa en las tres réplicas obtenidas en cada sitio y fecha de muestreo. En el modelo se incluyeron inicialmente todos los descriptores ambientales de los mallines, como parámetros fisicoquímicos, biológicos (clorofila $a$ y feopigmentos) y porcentaje de cobertura de biotopos. Sin embargo aquellas variables que evidenciaron covariación (factor de inflación >10) fueron removidas y el análisis final fue realizado sobre las variables ambientales remanentes (ter Braak y Smilauer 1999). Todos los análisis multivariados se realizaron sobre matrices estandarizadas, es decir las variables 
ambientales (exceptuando $\mathrm{pH}$, clorofila $a$ y feopigmentos) y los datos de densidad de especie se transformaron como el $\log (x+1)$.

Con los ACC obtenidos, se extrajeron los dos primeros ejes y se graficaron dos biplot, uno que incluyó el ordenamiento mallines según fecha de muestreo junto con las variables ambientales seleccionadas y otro, con el ordenamiento de las especies y las mismas variables ambientales seleccionadas. La significación de los ejes obtenidos se evaluó mediante la prueba de Monte-Carlo (9999 permutaciones). Éste es un test de permutaciones que permite determinar la significación estadística de la relación entre las especies y el total del grupo de variables ambientales medidas. El enfoque del test se basa en un remuestreo aleatorio donde se admiten la mayor cantidad de permutaciones posibles. En el programa CANOCO, ya sea en análisis de redundancias como de correspondencias canónicas, permite establecer la significación (valor de $p$ ) tanto del primer eje como de todos los ejes en los ordenamientos realizados. (ter Braak y Smilauer 1998).

Para evaluar la respuesta de las métricas comunitarias en el ordenamiento de los mallines respecto al uso del suelo y las variables ambientales, se realizó un análisis de redundancias canónicas (RDA). La elección de este análisis multivariado se debió a que se observó que los patrones de abundancia mostraron una tendencia lineal más que unimodal, evidenciadas por el largo del gradiente (ter Braak y Smilauer 1998). En el análisis se utilizaron las medias de las métricas en cada mallín $(n=6)$, que fueron seleccionadas y compartidas en ambas biozonas. Así mismo se incluyeron los descriptores ambientales, como parámetros fisicoquímicos, biológicos (clorofila a y feopigmentos), porcentaje de cobertura de biotopos y cobertura de uso de suelo. Previo al análisis, todas las variables (excepto $\mathrm{pH}$, clorofila $a$ y feopigmentos) y métricas se transformaron logarítmicamente (log $(x+1)$ ). Las variables ambientales fuertemente correlacionadas (factor de inflación $>10$ ) se eliminaron en un análisis inicial. La significación de los ejes obtenidos se determinó mediante el test de Monte Carlo (9999 permutaciones) (ter Braak y Smilauer 1999). 


\section{RESULTADOS}




\subsection{CARACTERIZACIÓN AMBIENTAL DE LOS MALLINES}

\subsubsection{Descripción ambiental según biozona}

La zonificación de los mallines (central, intermedia y periférica), de acuerdo a la microtopografía y la vegetación, permitió identificar el gradiente hídrico en cada uno de ellos (Figuras 5.1 a 5.8) y dimensionar las áreas más frecuentemente inundables (Tabla 5.1).

Los mallines de estepa, a pesar de poseer mayores superficies, presentaron una menor proporción de zona central respecto de aquellos de bosque. En esta zona, que incluye a los cuerpos de aguas permanentes o semipermanentes y es caracterizada por la abundancia de juncáceas y ciperáceas, la menor cobertura se registró en Ea. Domínguez, con sólo 3,3 \% de la superficie total del mallín, y la mayor cobertura en Laguna Fantasma, con más de $63 \%$, sin embargo en el resto de los mallines $(n=14)$ la zona central no superó el $22 \%$ de su superficie total (Tabla 5.1).

La zona intermedia, con menor tensión de humedad en el suelo y caracterizada por mayor abundancia de poáceas y leguminosas, representó la mayor superficie relativa de los mallines, particularmente en los localizados en estepa. Los valores oscilaron entre 20,5 \%, en Km 5, y 62 \%, en Ea. El Cóndor.

Finalmente, la zona periférica, con mayor influencia de la vegetación aledaña a los mallines, presentó coberturas relativas entre 26,5- $74 \% \quad(n=14)$ cuyos extremos se localizaron en Playa Negra y Km 5 respectivamente (Tabla 5.1).

Los cuerpos de agua presentes en los mallines, de acuerdo a su morfología constituyeron pequeñas charcas (Ea. San Ramón, Ea. El Cóndor, Km 5, Km 12, Playa Negra) con profundidades máximas menores a $1 \mathrm{~m}$, lagunas someras con profundidades mayores a 1,5 m (Fantasma, Cretón, Pampa Linda) o arroyuelos y canales de drenaje de baja pendiente, de escasa profundidad (Ea. Pilcañeu, Ea. Rayhuao, Muelle viejo y La Turbina) (Tabla 5.2) 
Macchi, Pablo. 2017. Macroinvertebrados acuáticos como indicadores ecológicos de cambios en el uso del suelo en mallines del sudoeste de la Provincia de Río Negro (Dra. María Laura Miserendino - Dra. Nora Gómez)

Tabla 5.1: Superficie total y zonificación de los mallines, en zonas central, intermedia y periférica, expresadas en superficie relativa porcentual. Uso del suelo: $\mathrm{R}$ referencia; A agrícola; $U$ urbano.SO de la Provincia de Río Negro.

\begin{tabular}{|c|c|c|c|c|c|c|c|}
\hline 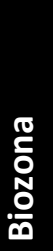 & 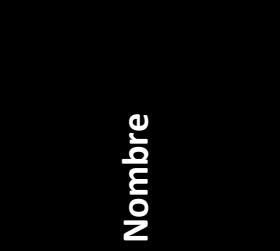 & $\begin{array}{l}\circ \\
\frac{0}{80} \\
\frac{8}{8}\end{array}$ & 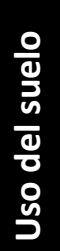 & 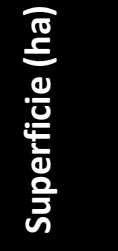 & 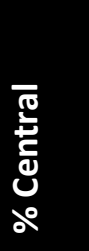 & 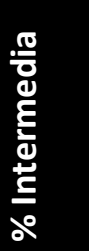 & 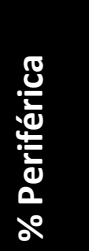 \\
\hline \multirow{6}{*}{ 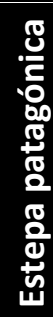 } & Ea. San Ramón & E1 & $\mathrm{R}$ & 364,9 & 18,2 & 39,3 & 42,5 \\
\hline & Ea. El Cóndor & E2 & $\mathrm{R}$ & 1872,1 & 10,4 & 62,0 & 37,6 \\
\hline & Ea. Pto. Moreno & E3 & $\mathrm{R}$ & 114,2 & 9,2 & 59,0 & 31,8 \\
\hline & Ea. Domínguez & E4 & $A$ & 48,5 & 3,3 & 51,3 & 45,4 \\
\hline & Ea. Pilcañeu & E5 & A & 911,2 & 9,5 & 40,0 & 50,5 \\
\hline & Ea. Rayhuao & E6 & $A$ & 501,5 & 5,6 & 53,7 & 40,7 \\
\hline \multirow{9}{*}{ 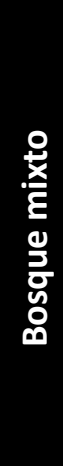 } & Vereertbrugghen & B1 & $\mathrm{R}$ & 92,6 & 17,8 & 42,6 & 39,6 \\
\hline & Muelle viejo & B2 & $\mathrm{R}$ & 3,7 & 15,5 & 40,0 & 44,5 \\
\hline & La Turbina & B3 & $\mathrm{R}$ & 101,5 & 11,4 & 48,4 & 40,3 \\
\hline & Playa Negra & B4 & $A$ & 10,5 & 18,9 & 54,6 & 26,5 \\
\hline & Cretón & B5 & $A$ & 115,6 & 12,6 & 37,1 & 50,3 \\
\hline & Pampa Linda & B6 & $A$ & 2,1 & 21,3 & 42,2 & 36,5 \\
\hline & Km 5 & B7 & $U$ & 1,9 & 5,5 & 20,5 & 74,0 \\
\hline & Km 12 & B8 & $U$ & 17,2 & 14,1 & 42,5 & 43,4 \\
\hline & Lag. Fantasma & B9 & $U$ & 1 & 63,2 & 32,9 & 4,0 \\
\hline
\end{tabular}

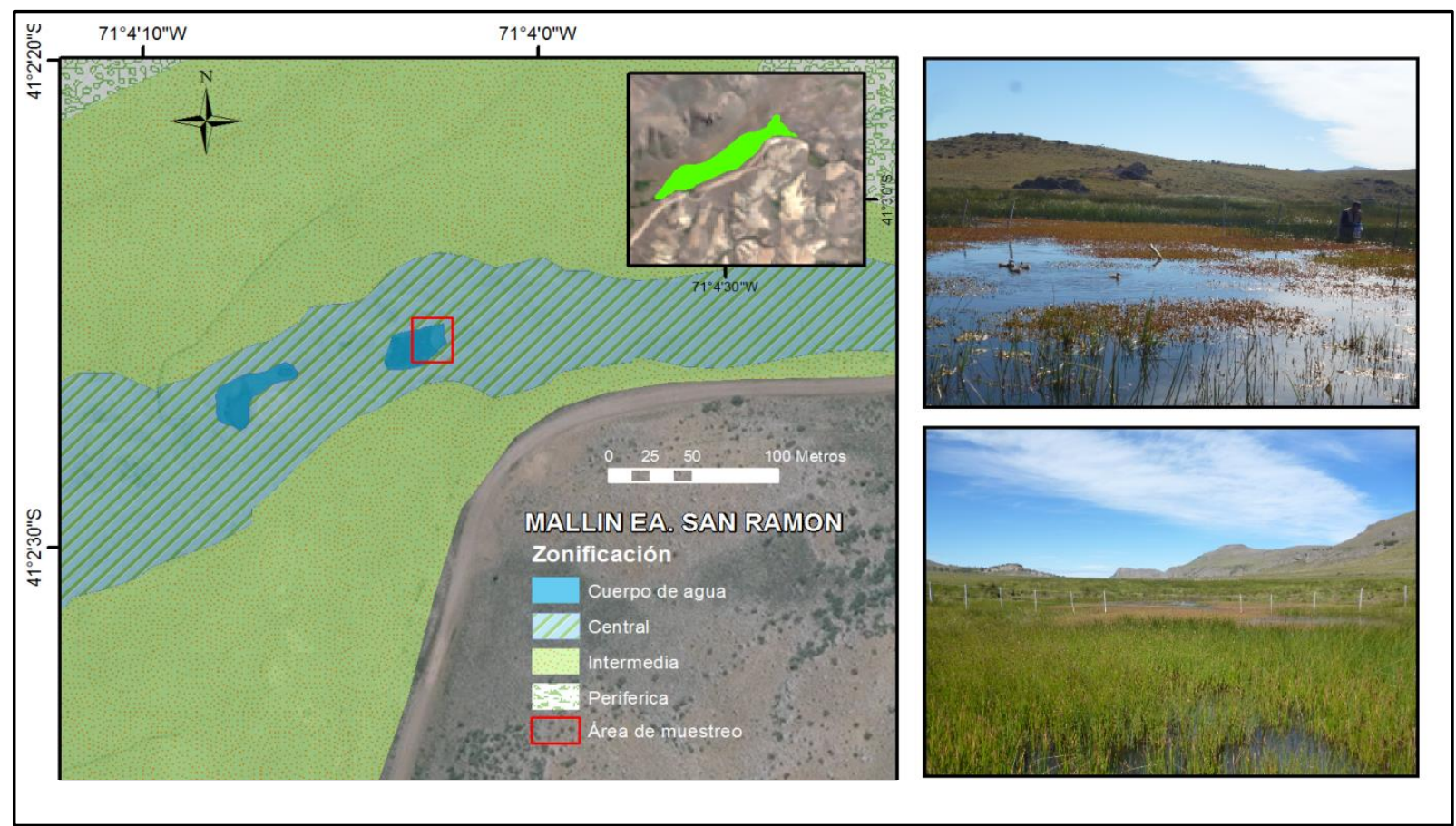

Figura 5.1: Zonificación de los mallines seleccionados en la biozona de estepa patagónica en el SO de la Provincia de Río Negro. Mallín Ea. San Ramón. 

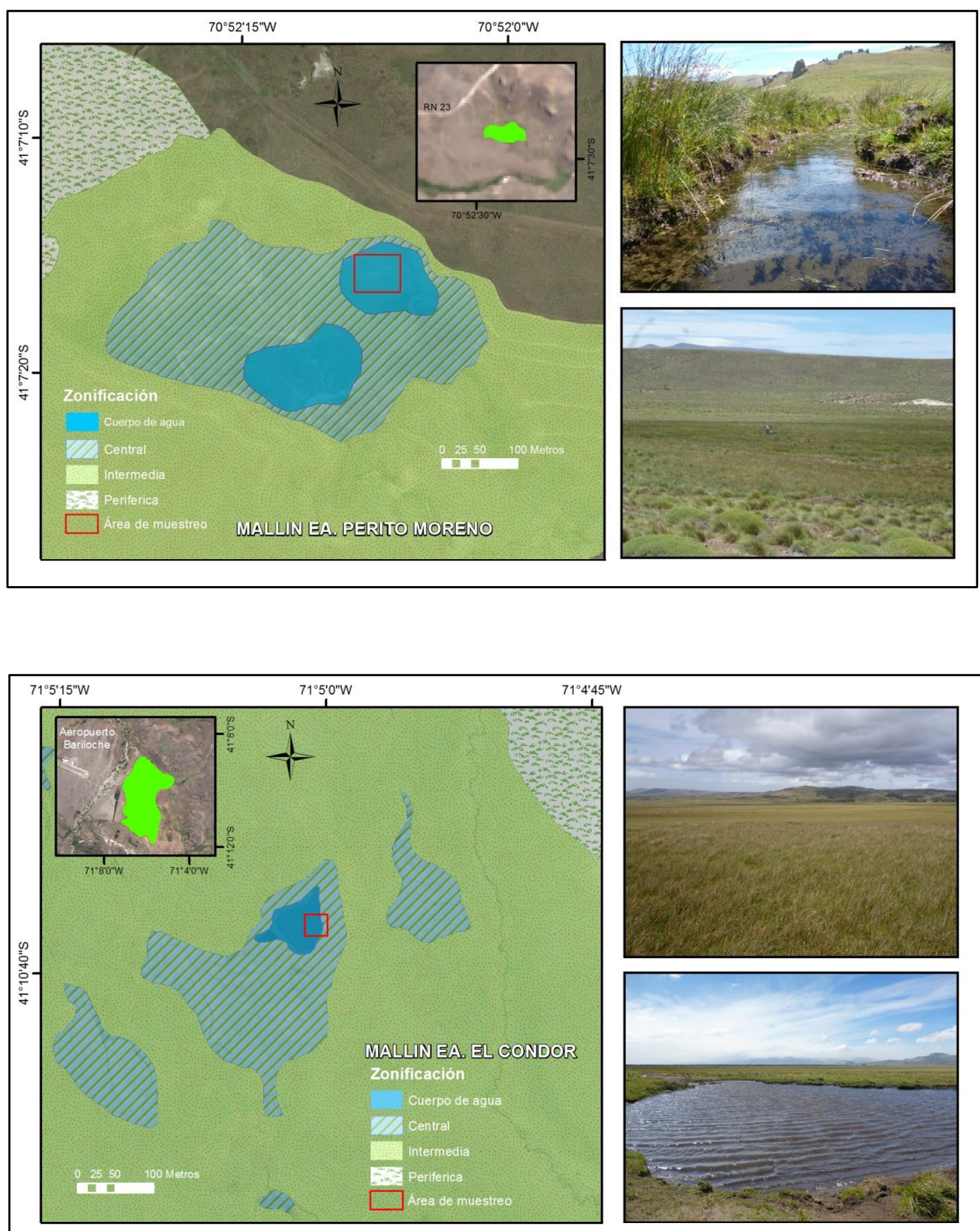

Figura 5.2: Zonificación de los mallines seleccionados en la biozona de estepa patagónica en el SO de la Provincia de Río Negro. Arriba: Ea. Perito Moreno. Abajo: Ea. El Cóndor. 

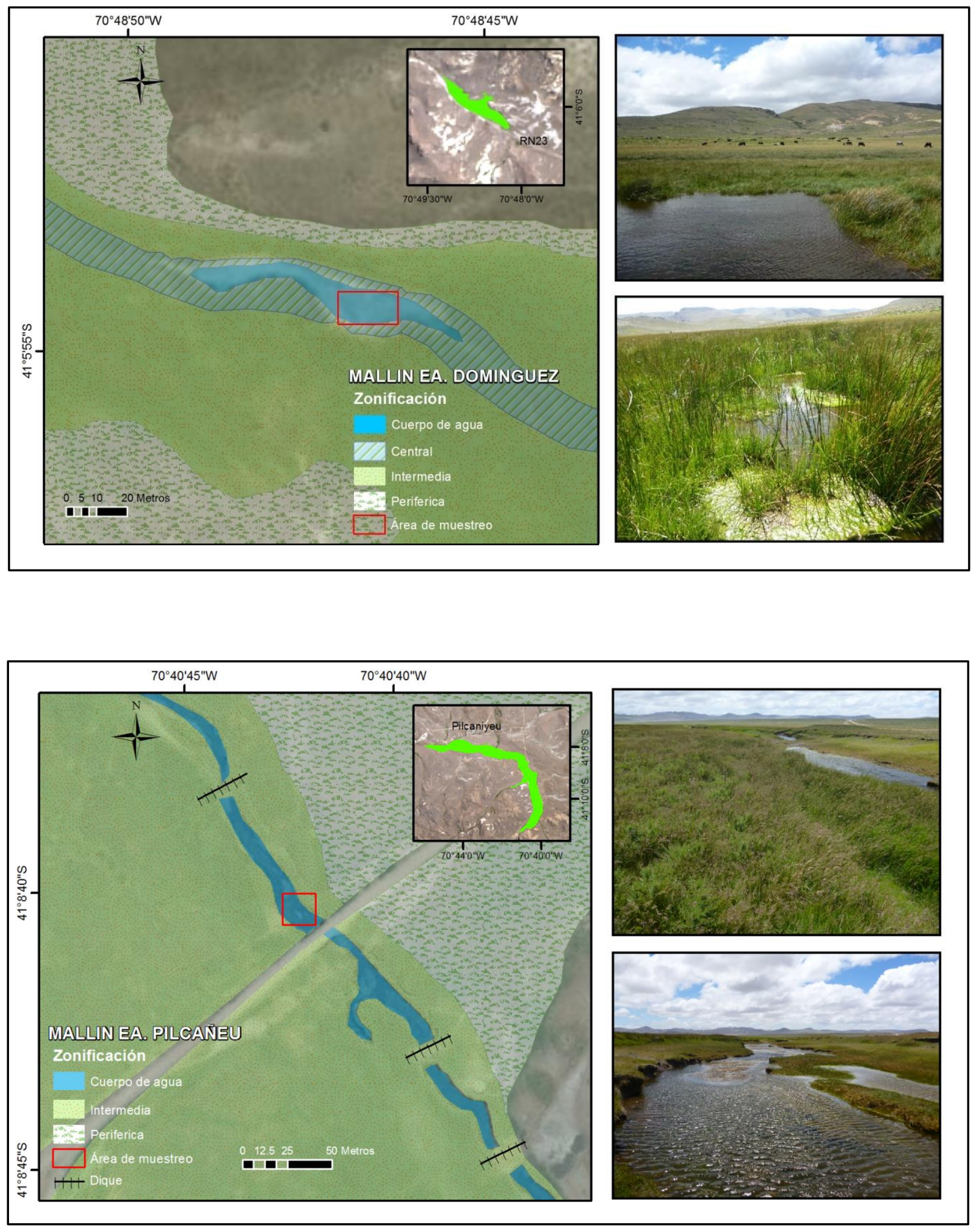

Figura 5.3: Zonificación de los mallines seleccionados en la biozona de estepa patagónica en el SO de la Provincia de Río Negro. Arriba: Ea. Domínguez. Abajo: Ea. Pilcañeu. 

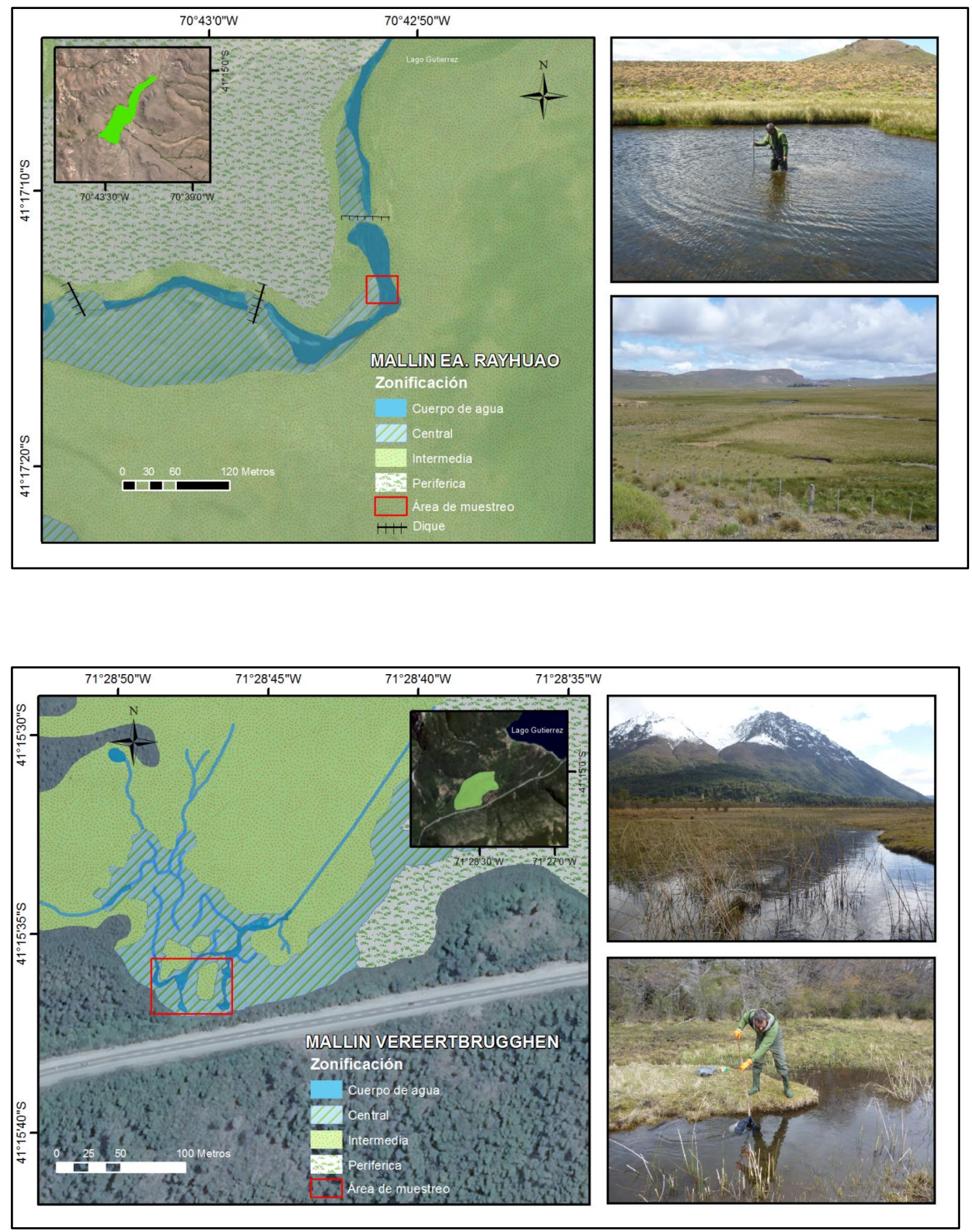

Figura 5.4: Zonificación de los mallines seleccionados en el SO de la Provincia de Río Negro. Arriba: Ea. Rauhuao. Abajo: Ea. Vereetbrugghen. 

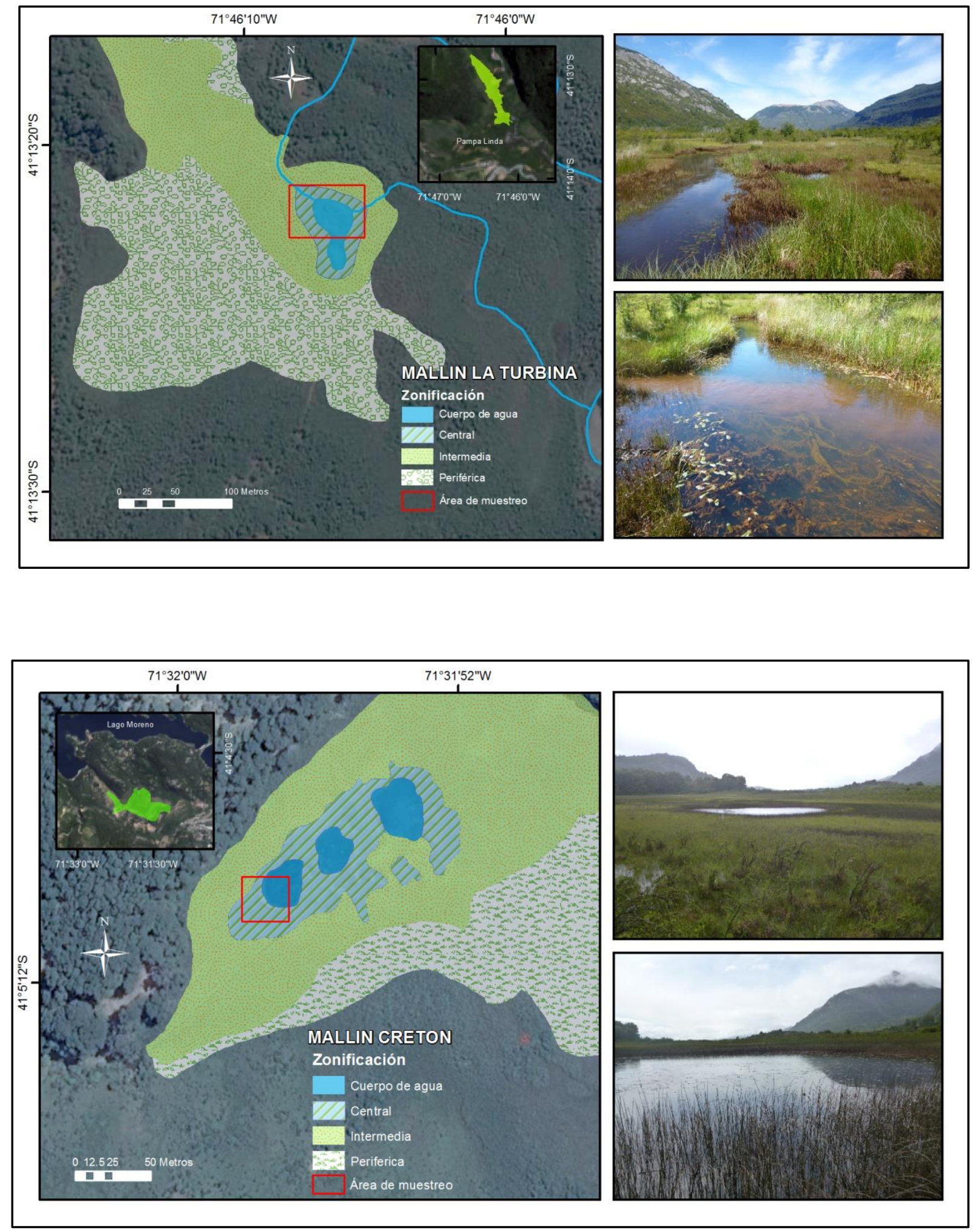

Figura 5.5: Zonificación de los mallines seleccionados en la biozona de bosque mixto en el SO de la Provincia de Río Negro. Arriba: La Turbina. Abajo: Cretón. 

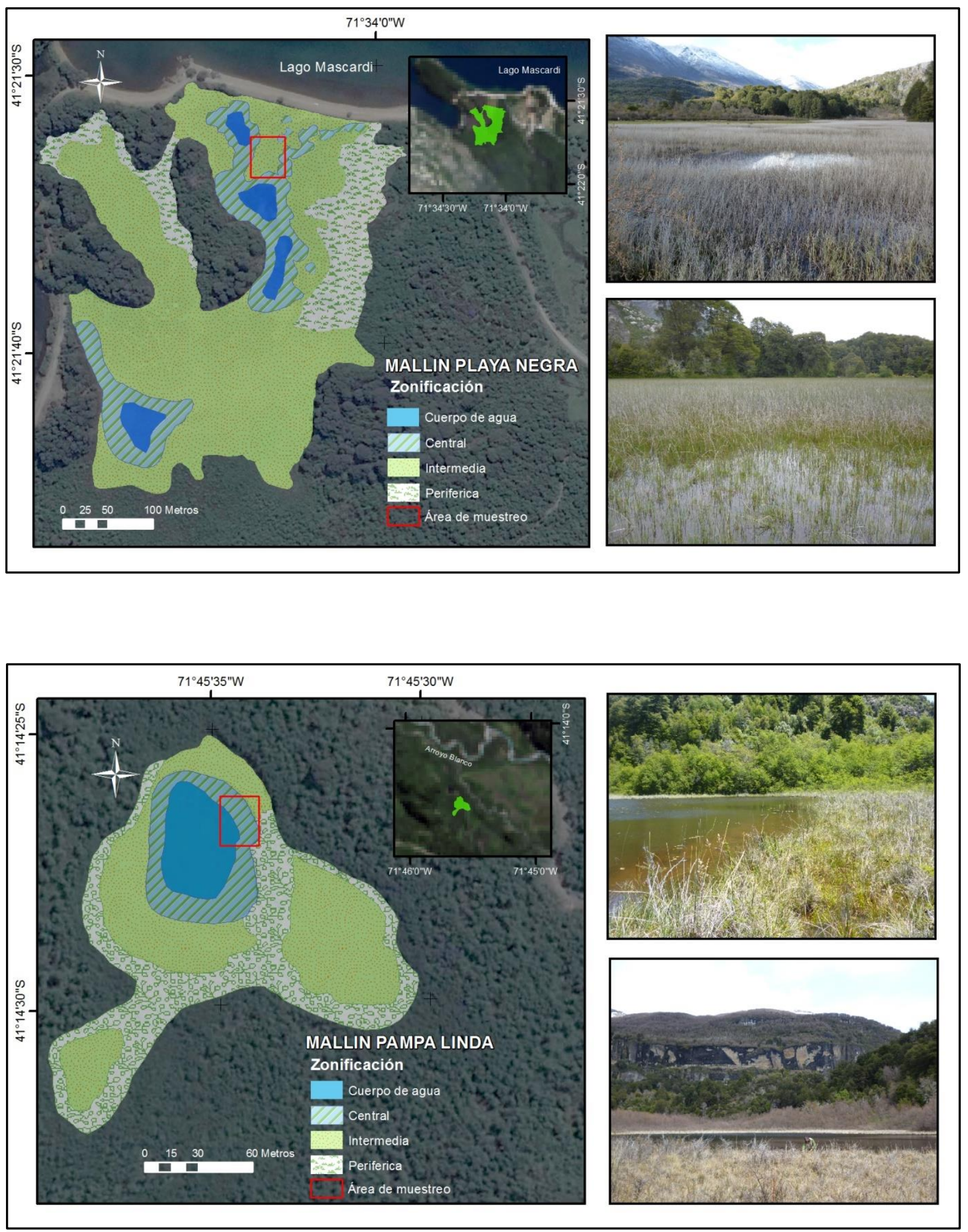

Figura 5.6: Zonificación de los mallines seleccionados en la biozona de bosque mixto en el so de la Provincia de Río Negro. Arriba: Playa Negra. Abajo: Pampa Linda. 

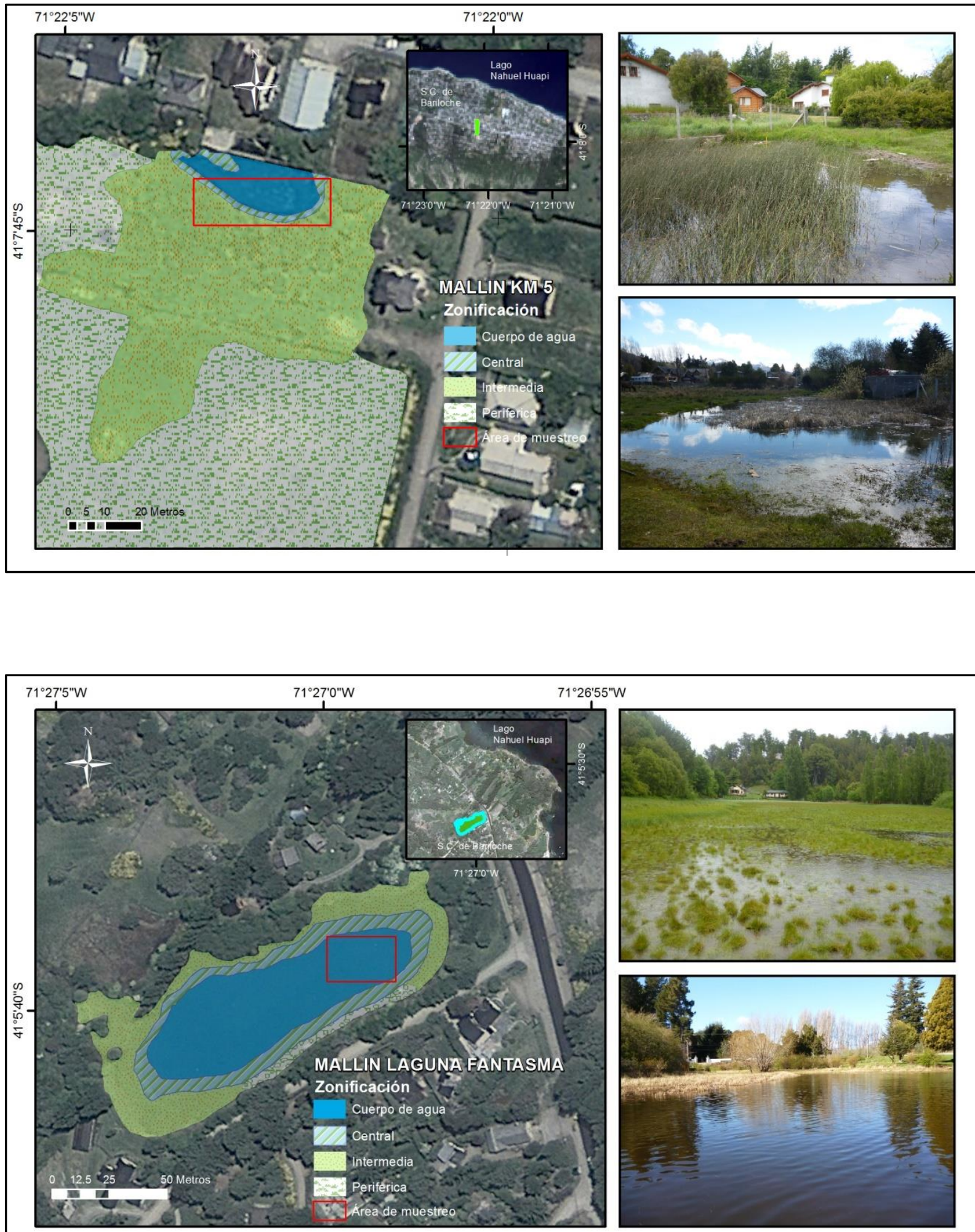

Figura 5.7: Zonificación de los mallines seleccionados en la biozona de bosque patagónico en el SO de la Provincia de Río Negro. Arriba: Km 5 (Teleférico). Abajo: Laguna Fantasma. 

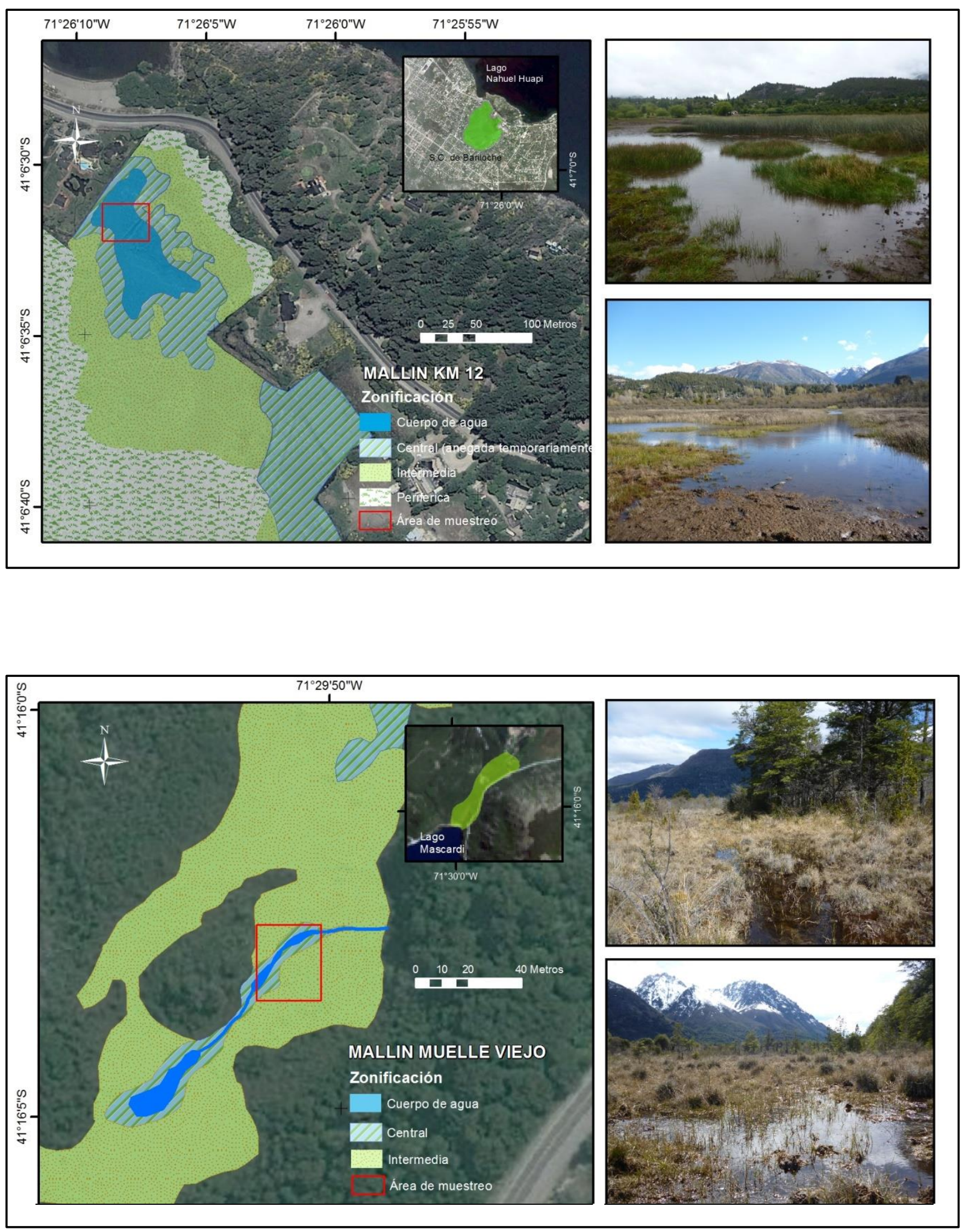

Figura 5.8: Zonificación de los mallines seleccionados en la biozona de bosque patagónico en el SO de la Provincia de Río Negro. Arriba: Km 12. Abajo: Muelle viejo. 
Tabla 5.2: Valores de profundidad máxima, área mojada y biotopos según biozona registrados en 15 mallines en el SO de la Provincia de Rio Negro. Uso: del suelo: R: referencia; A: agrícola; U: urbano. Muestreo: a: aguas altas (septiembre 2012). b: aguas bajas (diciembre 2012). Porcentajes de cobertura de biotopos presentes: \%VC vegetación compleja, \%VS vegetación simple, \% AS aguas someras $(<30 \mathrm{~cm})$, AP aguas profundas $(>30 \mathrm{~cm})$.

\begin{tabular}{|c|c|c|c|c|c|c|c|c|c|}
\hline 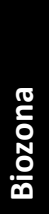 & 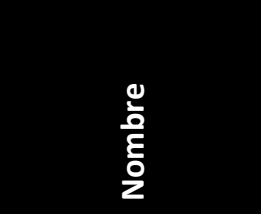 & $\begin{array}{l}\text { 웅 } \\
\text { 응 }\end{array}$ & 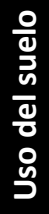 & 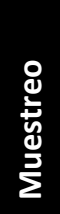 & 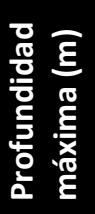 & $\frac{y}{x^{0}}$ & $\underset{d^{0}}{s}$ & $\frac{y}{d}$ & $\frac{\stackrel{\alpha}{\alpha}}{\partial}$ \\
\hline \multirow{10}{*}{ 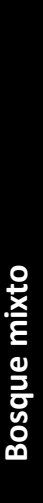 } & \multirow[t]{2}{*}{ Vereertbrugghen } & \multirow[t]{2}{*}{ B1 } & \multirow[t]{2}{*}{$\mathrm{R}$} & $a$ & 0,68 & 20 & 30 & 50 & 0 \\
\hline & & & & $b$ & 0,89 & 40 & 50 & 10 & 0 \\
\hline & \multirow[t]{2}{*}{ Muelle viejo } & \multirow[t]{2}{*}{ B2 } & \multirow[t]{2}{*}{$\mathrm{R}$} & a & 0,12 & 30 & 50 & 20 & 0 \\
\hline & & & & $b$ & 0,15 & 60 & 20 & 20 & 0 \\
\hline & \multirow[t]{2}{*}{ La Turbina } & \multirow[t]{2}{*}{ B3 } & \multirow[t]{2}{*}{$\mathrm{R}$} & a & 0,68 & 30 & 40 & 30 & 0 \\
\hline & & & & $b$ & 0,73 & 70 & 20 & 10 & 0 \\
\hline & \multirow[t]{2}{*}{ Playa Negra } & \multirow[t]{2}{*}{ B4 } & \multirow[t]{2}{*}{$A$} & a & 0,45 & 30 & 70 & 0 & 0 \\
\hline & & & & $b$ & 0,34 & 50 & 50 & 0 & 0 \\
\hline & \multirow[t]{2}{*}{ Cretón } & \multirow[t]{2}{*}{ B5 } & \multirow[t]{2}{*}{$A$} & a & 0,79 & 10 & 85 & 0 & 5 \\
\hline & & & & $b$ & 1,3 & 30 & 65 & 0 & 5 \\
\hline & \multirow[t]{2}{*}{ Lag. Pampa Linda } & \multirow[t]{2}{*}{ B6 } & \multirow[t]{2}{*}{ A } & a & 1,45 & 5 & 60 & 0 & 35 \\
\hline & & & & $b$ & 1,6 & 5 & 30 & 0 & 65 \\
\hline & \multirow[t]{2}{*}{ Km 5} & \multirow[t]{2}{*}{ B7 } & \multirow[t]{2}{*}{$\mathrm{R}$} & a & 0,87 & 0 & 60 & 40 & 0 \\
\hline & & & & $b$ & 0,7 & 0 & 70 & 30 & 0 \\
\hline & \multirow[t]{2}{*}{ Km 12} & \multirow[t]{2}{*}{ B8 } & \multirow[t]{2}{*}{$\mathrm{R}$} & a & 0,4 & 0 & 80 & 20 & 0 \\
\hline & & & & $b$ & 0,39 & 0 & 90 & 10 & 0 \\
\hline & \multirow[t]{2}{*}{ Lag. Fantasma } & \multirow[t]{2}{*}{ B9 } & \multirow[t]{2}{*}{$\mathrm{R}$} & a & 1,12 & 0 & 60 & 40 & 0 \\
\hline & & & & $b$ & 0,27 & 0 & 100 & 0 & 0 \\
\hline & Ea. San Ramón & E1 & $\mathrm{R}$ & a & 0,68 & 40 & 60 & 0 & 0 \\
\hline & & & & $b$ & 0,52 & 70 & 30 & 0 & 0 \\
\hline 8 & Ea. El Cóndor & E2 & $\mathrm{R}$ & a & 0,11 & 15 & 60 & 25 & 0 \\
\hline . & & & & $b$ & 0,25 & 15 & 70 & 15 & 0 \\
\hline 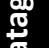 & Ea. Pto. Moreno & E3 & $\mathrm{R}$ & a & 1,35 & 10 & 40 & 40 & 0 \\
\hline$\pi$ & & & & $b$ & 0,25 & 40 & 25 & 35 & 0 \\
\hline$\frac{0}{d j}$ & Ea. Domínguez & E4 & A & a & 0,35 & 20 & 70 & 10 & 0 \\
\hline 4 & & & & $b$ & 0,2 & 30 & 70 & 0 & 0 \\
\hline & Ea. Pilcañeu & E5 & $A$ & a & 1,08 & 10 & 30 & 0 & 60 \\
\hline & & & & $b$ & 0,33 & 30 & 50 & 0 & 20 \\
\hline & Ea. Rayhuao & E6 & $A$ & a & 1,5 & 0 & 30 & 10 & 60 \\
\hline & & & & $b$ & 0,87 & 0 & 50 & 30 & 20 \\
\hline & Lag. Fantasma & B9 & $\mathrm{R}$ & a & 1,12 & 0 & 60 & 40 & 0 \\
\hline & & & & $b$ & 0,27 & 0 & 100 & 0 & 0 \\
\hline
\end{tabular}


En los mallines de estudio se diferenciaron cuatro tipos de biotopos principales a partir de la complejidad estructural de sus hábitats: A. Vegetación compleja (conformado por ensambles de macrófitas pertenecientes a distintos tipos biológicos, sumergidas y emergentes, arraigadas o no arraigadas, que incluyó especies como Myriophyllum quitense, Potamogeton linguatus, Callitriche spp. y/o Veronica anagallis-aquatica, algas pertenecientes a los géneros Zignema, Spirogyra y/o Cladophora junto a vegetación emergente de las familias Juncaceae y/o Ciperaceae); B. Vegetación simple (conformado por ensambles de macrófitas únicamente arraigadas y emergentes de la superficie del agua, constituidas por diversas especies de juncáceas del género Juncus spp. y/o ciperáceas como Schoenoplectus californicus, Carex spp. y Eleocharis spp. entre las más frecuentes); C. Aguas someras (hábitat sin vegetación, con una profundidad máxima de $30 \mathrm{~cm}$ ); D. Aguas profundas (hábitat sin vegetación, con una profundidad superior a los 30 cm) (Tabla 5.2; Figura 5.9).

De los cuatro biotopos identificados, sólo tres de ellos se registraron como máximo en cada uno de los mallines. En la estepa patagónica, el porcentaje del biotopo representado por vegetación compleja (\% VC) se destacó en el mallín Ea. San Ramón con una cobertura media de 55 \%, en tanto estuvo ausente en Ea. Rayhuao. En mallines de bosque el \% VC estuvo presente en Playa Negra, Muelle viejo y La Turbina con valores medios superiores al $40 \%$, desapareciendo en los mallines urbanos Km 12 y Laguna Fantasma, donde no se registraron macrófitas sumergidas. El biotopo vegetación simple (\% VS), fue el único presente en todos los mallines de ambas biozonas, con coberturas que oscilaron entre $25 \%$ en Ea. Perito Moreno y 85 \% en $\mathrm{Km} 12$. Respecto al biotopo aguas someras (\% AS), el valor más alto fue observado en Ea. Perito Moreno con $40 \%$ de cobertura en aguas altas, en el resto de los mallines donde estuvo representado, sus coberturas fueron menores a $30 \%$. Por último aguas profundas (\% AP) presentó altas contribuciones en Pampa Linda y en las estancias Rayhuao y Pilcañeu. 


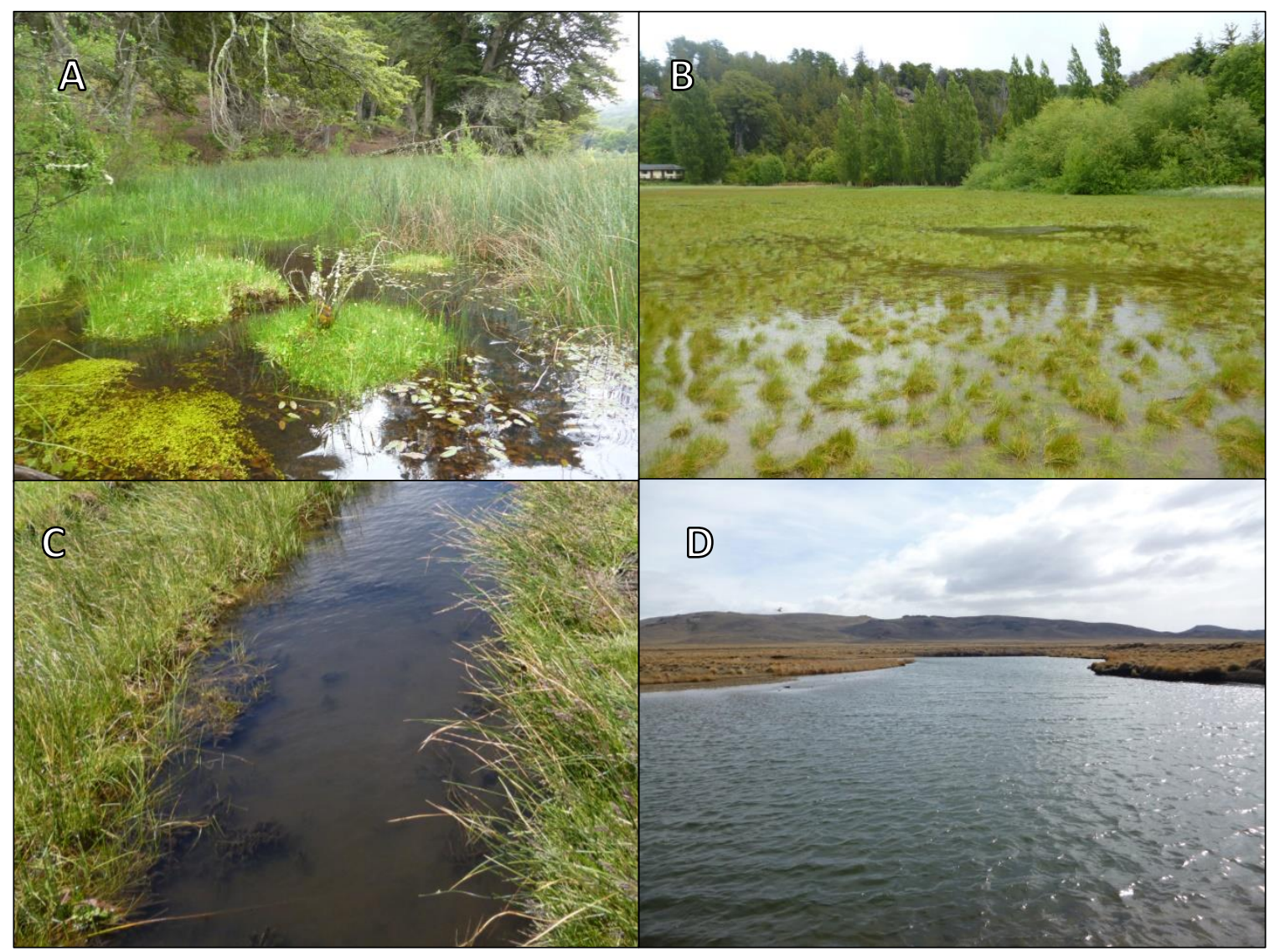

Figura 5.9: Biotopos identificados en los mallines según la complejidad estructural del hábitat, en el SO de la Provincia de Río Negro (sep. - dic. de 2012). A. Vegetación compleja en Cretón (B5); B. Vegetación simple en Laguna Fantasma (B4); C. Aguas someras sin vegetación en Ea. Perito Moreno; D. Aguas profundas sin vegetación en Ea. Rayhuao.

En la tabla 5.3. se detallan los resultados de los parámetros fisicoquímicos del agua, medidos en campo y aquellos determinados en laboratorio, tanto en mallines de estepa patagónica como en aquellos de bosque mixto.

La temperatura del agua de no presentó una variación significativa (Mann Whitney $p=0,458$ ) entre ambas biozonas, pero sí se observó una marcada estacionalidad. Los valores más bajos se registraron en primavera con $4^{\circ} \mathrm{C}$ en Ea. Domínguez (estepa) y los más altos en verano con $23,6^{\circ} \mathrm{C}$ en La Turbina (bosque) (Tabla 5.3). Las concentraciones de oxígeno disuelto, tampoco presentaron diferencias entre las dos biozonas, aunque los valores medios más bajos fueron registrados durante la época estival en los mallines de estepa Ea. San Ramón (2,21 $\mathrm{mg} / \mathrm{L})$ y Ea. Perito Moreno $(3,17 \mathrm{mg} / \mathrm{L})$. 
Tabla 5.3: Valores de las variables fisicoquímicas del agua determinadas en cada uno de los mallines muestreados en el boxque mixto según fecha de muestreo. a: septiembre de 2012 b: diciembre de 2012. Uso del suelo: R: referencia; A: agrícola; U: urbano. SO de la Provincia de Río Negro.

\begin{tabular}{|c|c|c|c|c|c|c|c|c|c|c|c|c|c|c|c|c|c|}
\hline 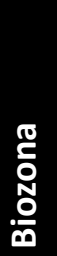 & $\begin{array}{l}\frac{d}{\alpha} \\
\text { हू } \\
z\end{array}$ & 웅 & $\begin{array}{l}\frac{0}{0} \\
\frac{0}{3} \\
\frac{0}{0} \\
\text { ப̆ } \\
\frac{0}{3}\end{array}$ & 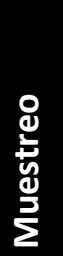 & 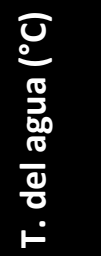 & $\frac{\tilde{g}}{\frac{5}{2}}$ & $\frac{\vec{F}}{\underline{\xi}}$ & $\begin{array}{l}\mathbf{O} \\
\dot{\mathrm{J}} \\
\dot{H} \\
\dot{0}\end{array}$ & 플 & $\frac{\sqrt{2}}{\frac{20}{2}}$ & 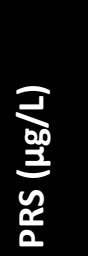 & $\frac{\sqrt{2}}{\frac{60}{2}}$ & 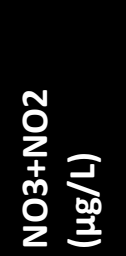 & $\frac{2}{\frac{200}{2}}$ & $\frac{\sum_{0}^{2}}{\frac{0}{2}}$ & 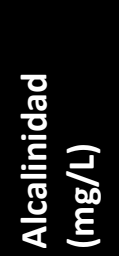 & $\frac{\sum_{00}^{0}}{\frac{5}{5}}$ \\
\hline \multirow{18}{*}{ 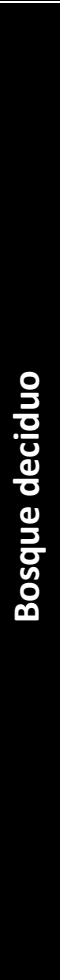 } & \multirow[t]{2}{*}{ Vereertbrugghen } & \multirow[t]{2}{*}{ B1 } & \multirow[t]{2}{*}{$\bar{R}$} & 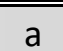 & 9,2 & 86,5 & 10,96 & 102,9 & 7,61 & 41,6 & 2,6 & 142,9 & 2,7 & 2,9 & $\overline{5,6}$ & 20,5 & $\bar{~} 17,8$ \\
\hline & & & & $b$ & 11,3 & 69 & 10,17 & 102,4 & 7,94 & 18,6 & 1,4 & 50 & 11,4 & 7,4 & 18,8 & 13 & 1 \\
\hline & \multirow[t]{2}{*}{ Muelle viejo } & \multirow[t]{2}{*}{ B2 } & \multirow[t]{2}{*}{$\mathrm{R}$} & $a$ & 12,2 & 166,5 & 7,22 & 85,6 & 8,89 & 18,1 & 2,3 & 48 & 13,1 & 3,7 & 16,8 & 74,5 & 7,1 \\
\hline & & & & $b$ & 13,1 & 168,5 & 10,21 & 102,6 & 8,8 & 27,6 & 2 & 45 & 4,4 & 8,6 & 13 & 33 & 6,7 \\
\hline & \multirow[t]{2}{*}{ La Turbina } & \multirow[t]{2}{*}{ B3 } & \multirow[t]{2}{*}{$\mathrm{R}$} & $a$ & 15,5 & 42,3 & 7,46 & 82,8 & 7,32 & 26,2 & 1,3 & 89,6 & 3,6 & 2,5 & 6,1 & 13 & 4,3 \\
\hline & & & & $b$ & 23,6 & 56,8 & 6,1 & 80,6 & 7,02 & 29,5 & 2,9 & 116,9 & 12 & 8,6 & 20,6 & 13 & 3,9 \\
\hline & \multirow[t]{2}{*}{ Playa Negra } & \multirow[t]{2}{*}{ B4 } & \multirow[t]{2}{*}{$A$} & $\mathrm{a}$ & 8,1 & 52,3 & 4,32 & 41,5 & 7,16 & 35,1 & 3,3 & 311,4 & 4,1 & 2,5 & 6,6 & 13 & 10,2 \\
\hline & & & & $b$ & 10,7 & 64 & 5,17 & 52,1 & 6,86 & 26 & 1,4 & 458 & 4 & 14 & 18 & 12,5 & 4,8 \\
\hline & \multirow[t]{2}{*}{ Cretón } & \multirow[t]{2}{*}{ B5 } & \multirow[t]{2}{*}{$A$} & a & 9,4 & 127 & 8,14 & 75,6 & 7,78 & 23,5 & 1,3 & 96,3 & 11,1 & 3,6 & 14,7 & 31 & 4,3 \\
\hline & & & & $b$ & 13,4 & 124,6 & 4,84 & 50,2 & 7,19 & 27,9 & 1,9 & 390,6 & 1,5 & 6,6 & 8,1 & 26,5 & 4,1 \\
\hline & \multirow[t]{2}{*}{ Lag. Pampa Linda } & \multirow[t]{2}{*}{ B6 } & \multirow[t]{2}{*}{$A$} & a & 10,2 & 50,8 & 9,52 & 93,4 & 8,01 & 24,2 & 1,3 & 142,9 & 4,1 & 2,5 & 6,6 & 12 & 1,6 \\
\hline & & & & $b$ & 16,5 & 77,7 & 7,13 & 81,5 & 7,76 & 31,1 & 3,1 & 217,1 & 17,1 & 7,4 & 24,5 & 16 & 8,1 \\
\hline & \multirow[t]{2}{*}{$\mathrm{Km} 5$} & \multirow[t]{2}{*}{$\mathrm{B} 7$} & \multirow[t]{2}{*}{$U$} & a & 16,9 & 180,7 & 12,41 & 129,4 & 7,52 & 50,8 & 2,5 & 767 & 369,1 & 16,7 & 385,8 & 67 & 5,7 \\
\hline & & & & $b$ & 18,2 & 196,5 & 6,24 & 73,2 & 7,28 & 143,3 & 5,9 & 658 & 10,1 & 14 & 24,1 & 34,5 & 29,4 \\
\hline & \multirow[t]{2}{*}{$\mathrm{Km} 12$} & \multirow[t]{2}{*}{ B8 } & \multirow[t]{2}{*}{$U$} & a & 16,9 & 204 & 8,2 & 77,4 & 8,51 & 78,3 & 1,6 & 1539,5 & 6,3 & 75,1 & 81,4 & 88 & 21,1 \\
\hline & & & & $b$ & 14,6 & 139,2 & 6,32 & 70,1 & 6,94 & 249,7 & 4,5 & 1665,2 & 282,1 & 413,4 & 695,5 & 14 & 97,3 \\
\hline & \multirow[t]{2}{*}{ Lag. Fantasma } & \multirow[t]{2}{*}{ B9 } & \multirow[t]{2}{*}{$U$} & a & 13,9 & 130,5 & 4,56 & 49,2 & 7,43 & 73,9 & 2 & 423,9 & 3,6 & 17,3 & 20,9 & 34 & 8,6 \\
\hline & & & & $b$ & 16,1 & 166,3 & 8,62 & 101,4 & 9 & 59,3 & 2,6 & 898 & 5,5 & 17,3 & 22,8 & 36 & 6,7 \\
\hline
\end{tabular}

CE: conductividad eléctrica; OD: oxígeno disuelto; \% Sat. $\mathrm{O}_{2}$ : porcentaje de saturación de oxígeno; $\mathrm{PT}$ : fósforo total; $\mathrm{PRS}$ : fósforo reactivo soluble; $\mathrm{NO}_{3}+\mathrm{NO}_{2}$ nitratos+nitritos; $\mathrm{NH}_{4}$ : amonio; NID: nitrógeno inorgánico disuelto; SST: sólidos suspendidos totales. 
Tabla 5.3 (continuación): Valores de las variables fisicoquímicas del agua determinadas en cada uno de los mallines muestreados en la estepa patagónica según fecha de muestreo. a: septiembre de 2012 b: diciembre de 2012. Uso del suelo: R: referencia; A: agrícola; U: urbano. SO de la Provincia de Río Negro.

\begin{tabular}{|c|c|c|c|c|c|c|c|c|c|c|c|c|c|c|c|c|c|}
\hline 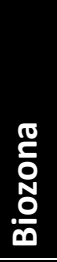 & $\begin{array}{l}\frac{1}{\alpha} \\
\text { है } \\
\frac{0}{2}\end{array}$ & 웅 & $\begin{array}{l}\frac{0}{0} \\
\frac{0}{3} \\
\frac{0}{0} \\
\circ \\
0 \\
\frac{0}{2}\end{array}$ & 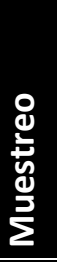 & 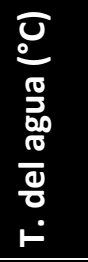 & $\frac{\bar{E}}{\frac{E}{3}}$ & 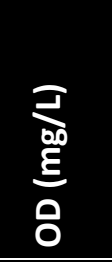 & $\begin{array}{l}0 \\
\dot{H} \\
\dot{H} \\
0\end{array}$ & 플 & $\frac{\sum_{0}^{2}}{\stackrel{5}{2}}$ & $\frac{P}{\frac{p}{0}}$ & $\frac{\sum_{00}^{2}}{\frac{5}{2}}$ & 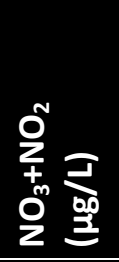 & $\begin{array}{l}\underset{5}{2} \\
\frac{5}{2} \\
\frac{1}{2}\end{array}$ & $\begin{array}{l}\frac{2}{20} \\
\frac{0}{2} \\
\frac{0}{2}\end{array}$ & 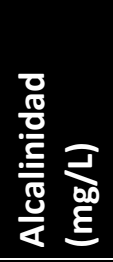 & $\frac{2}{\frac{5}{5}}$ \\
\hline \multirow{12}{*}{ 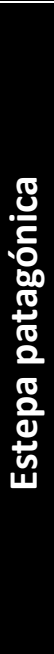 } & \multirow[t]{2}{*}{ Ea. San Ramón } & \multirow[t]{2}{*}{ E1 } & \multirow[t]{2}{*}{$\mathrm{R}$} & $\mathrm{a}$ & 8,6 & 251 & 8,98 & 86,8 & 8,51 & 172 & 6,4 & 740,5 & 4,1 & 12,3 & 16,4 & 63,5 & 14,5 \\
\hline & & & & $b$ & 10,3 & 229 & 2,21 & 22,1 & 7,11 & 151,4 & 21,5 & 1261,9 & 5,1 & 30 & 35,1 & 70 & 22,1 \\
\hline & \multirow[t]{2}{*}{ Ea. El Cóndor } & \multirow[t]{2}{*}{ E2 } & \multirow[t]{2}{*}{$\mathrm{R}$} & $a$ & 10,2 & 103 & 10,12 & 102,1 & 8,46 & 375 & 157,1 & 753,9 & 1,8 & 4 & 5,8 & 23,5 & 40,5 \\
\hline & & & & $b$ & 20 & 93,4 & 7,16 & 88,9 & 8,38 & 171,7 & 6,4 & 771,4 & 42 & 36,2 & 78,2 & 20 & 46,7 \\
\hline & \multirow{4}{*}{$\begin{array}{l}\text { Ea. Pto. } \\
\text { Moreno } \\
\text { Ea. Domínguez }\end{array}$} & \multirow[t]{2}{*}{ E3 } & \multirow[t]{2}{*}{$\mathrm{R}$} & a & 9,7 & 163,2 & 9,84 & 95,4 & 8,25 & 92 & 31,2 & 167,4 & 17 & 14,4 & 31,4 & 30 & 1,9 \\
\hline & & & & $b$ & 17,6 & 199,7 & 3,17 & 35,5 & 8,55 & 104 & 47,9 & 223,3 & 11,1 & 9,5 & 20,6 & 42 & 3 \\
\hline & & \multirow[t]{2}{*}{ E4 } & \multirow[t]{2}{*}{$A$} & a & 4 & 477 & 8,91 & 76,1 & 7,91 & 156,3 & 62 & 488,3 & 3,8 & 24,6 & 28,4 & 105 & 10 \\
\hline & & & & $b$ & 19,8 & 279 & 10,71 & 136,2 & 8,59 & 74,2 & 7,6 & 410,5 & 1,8 & 31,2 & 33 & 61,8 & 30,9 \\
\hline & \multirow[t]{2}{*}{ Ea. Pilcañeu } & \multirow[t]{2}{*}{ E5 } & \multirow[t]{2}{*}{$A$} & a & 9,7 & 228 & 10,4 & 103,8 & 8,51 & 104,6 & 21,6 & 296,4 & 3,2 & 14,8 & 18 & 48 & 12,5 \\
\hline & & & & $b$ & 17,9 & 299 & 11,7 & 132,1 & 9,21 & 76,2 & 18,3 & 510 & 3 & 11,9 & 14,9 & 68 & 33,4 \\
\hline & \multirow[t]{2}{*}{ Ea. Rayhuao } & \multirow[t]{2}{*}{ E6 } & \multirow[t]{2}{*}{$A$} & $\mathrm{a}$ & 9,5 & 153 & 10,82 & 105,5 & 8,69 & 96,1 & 29,8 & 162,6 & 4,1 & 10,8 & 14,9 & 30 & 2,8 \\
\hline & & & & $b$ & 12,7 & 170,7 & 9,08 & 95,2 & 9,22 & 65,4 & 8,2 & 351,9 & 6,9 & 9 & 15,9 & 35 & 32,4 \\
\hline
\end{tabular}

$\mathrm{CE}$ : conductividad eléctrica; $\mathrm{OD}$ : oxígeno disuelto; \% $\mathrm{Sat}_{2} \mathrm{O}_{2}$ : porcentaje de saturación de oxígeno; $\mathrm{PT}$ : fósforo total; $\mathrm{PRS}$ : fósforo reactivo soluble; $\mathrm{NO}_{3}+\mathrm{NO}_{2}$ : nitratos+nitritos; $\mathrm{NH}_{4}$ : amonio; NID: nitrógeno inorgánico disuelto; SST: sólidos suspendidos totales. 
En cuanto al $\mathrm{pH}$, las diferencias entre los mallines de ambas biozonas fueron significativas (Mann Whitney $p=0,0076$ ). Los mallines de la estepa exhibieron aguas alcalinas, con valores extremos en Ea. Pilcañeu $(9,21)$ y Ea. Rayhuao $(9,22)$. En cambio aquellos de bosque, mostraron valores cercanos a la neutralidad o fueron levemente alcalinos (Tabla 5.3; Figura 5.10).

La conductividad eléctrica (CE) del agua y la concentración de sólidos suspendidos totales de los mallines de estepa, también fue significativamente mayor que aquellos localizados en el bosque (Mann Whitney $p=0,002$ y $p=0,04$ respectivamente). La CE media en la biozona de estepa fue $220,50 \mu \mathrm{S} / \mathrm{cm}(\mathrm{n}=12)$, con un máximo de $477 \mu \mathrm{S} / \mathrm{cm}$ en Ea. Domínguez, y en el bosque $116,84 \mu \mathrm{S} / \mathrm{cm}$ ( $n=18$ ), con un mínimo de 42,3 $\mu \mathrm{S} / \mathrm{cm}$ en La Turbina (Tabla 5.3; Figura 5.10).

Entre los mallines, también existió un amplio rango de variación entre la concentración de nutrientes y su fracción biodisponible. El fósforo reactivo soluble representó entre el $2 \%$ y $46 \%$ del fósforo total $(1,3 \mu \mathrm{g} / \mathrm{L}$ a $157,1 \mu \mathrm{g} / \mathrm{L})$ y el nitrógeno inorgánico disponible constituyó entre el $1 \%$ y $50 \%$ del nitrógeno total presente en la columna de agua $(5,6 \mu \mathrm{g} / \mathrm{L}$ a $385,5 \mu \mathrm{g} / \mathrm{L})$ (Tabla 5.3; Figura 5.10).

La comparación por biozona y particularmente para el fósforo, mostró que los mallines de estepa presentaron concentraciones significativamente superiores de fósforo total (PT) (Mann Whitney $p=0,001$ ) y fósforo reactivo soluble (PRS) (Mann Whitney $p<0,001)$ en comparación a los de bosque. En la mayoría de sitios se registraron bajos valores de PT $(<105 \mu \mathrm{g} / \mathrm{L} \mathrm{n}=23)$ y de PRS $(<9 \mu \mathrm{g} / \mathrm{L}, \mathrm{n}=22)$, con máximos en Ea. Cóndor (PT: $375 \mu \mathrm{g} / \mathrm{L}$; PRS 157,1 $\mu \mathrm{g} / \mathrm{L}$ ). En el caso del nitrógeno total y del nitrógeno inorgánico disuelto no existieron diferencias significativas para ninguno de sus estados químicos entre ambas biozonas (Mann Whitney: NT $\left.\mathrm{p}=0,175 ; \mathrm{NO}_{3}+\mathrm{NO}_{2} \mathrm{p}=0,279 ; \mathrm{NH}_{4} \mathrm{p}=0,068\right)$. La mayoría de las concentraciones de nitrato-nitrito estuvieron por debajo de $17,10 \mu \mathrm{g} / \mathrm{L}(\mathrm{n}=27)$, con registros extremos superiores a $280 \mu \mathrm{g} / \mathrm{L}$ hallados en los mallines de $\mathrm{Km} 12$ y Km 5. El amonio también presentó bajas concentraciones, muchas de las cuales fueron menores a 17,3 $\mathrm{\mu g} / \mathrm{L}$ $(\mathrm{n}=24)$, salvo en $\mathrm{Km} \mathrm{12}$, donde se se registró un valor de $413,40 \mu \mathrm{g} / \mathrm{L}$ durante el muestreo estival (Tabla 5.3; Figura 5.10). 
Oxígeno disuelto $(\mathrm{mg} / \mathrm{L})$

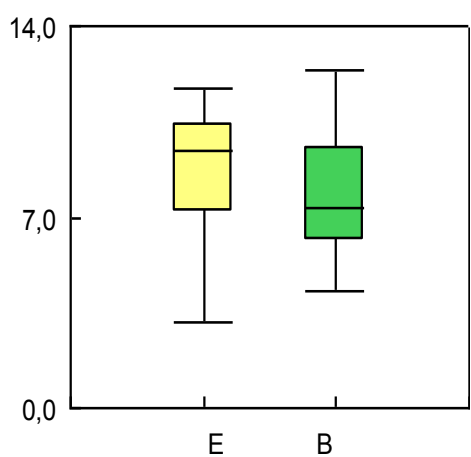

Amonio $(\mu \mathrm{g} / \mathrm{L})$

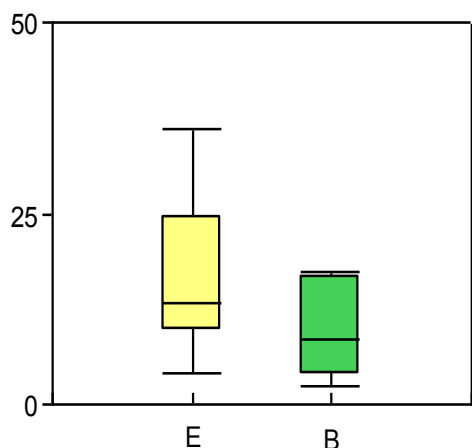

$\mathrm{pH}$

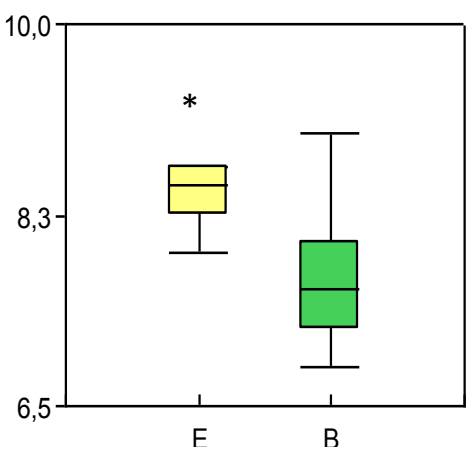

Fósforo reactivo soluble $(\mu \mathrm{g} / \mathrm{L})$

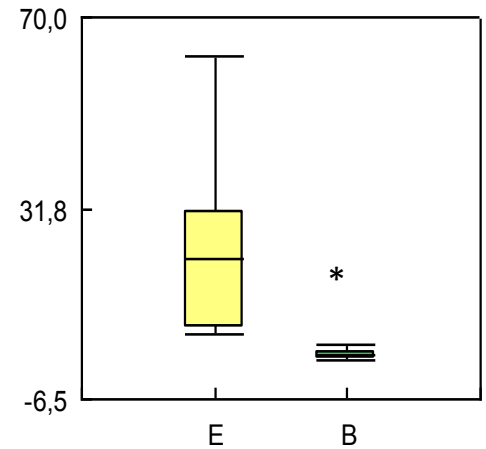

Conductividad eléctrica $(\mu \mathrm{S} / \mathrm{cm})$

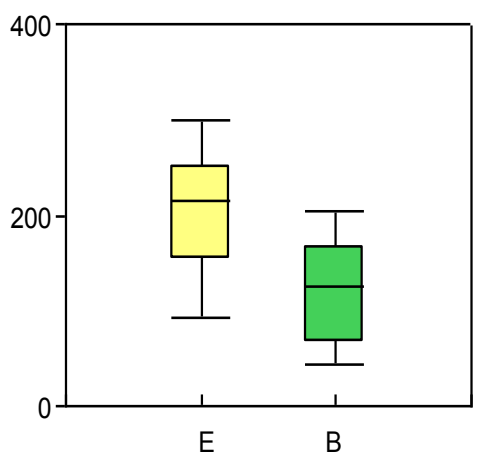

Nitrato +nitrito $(\mu \mathrm{g} / \mathrm{L})$

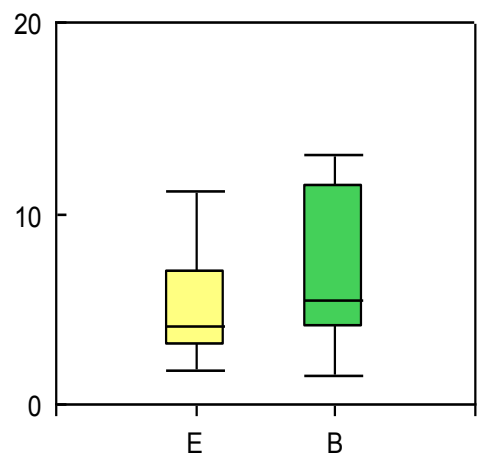

Figura 5.10: Comparación de la distribución de los valores de las principales variables fisicoquímicas determinadas en los 15 mallines para ambos momentos de muestreo según biozonas en el SO de la Provincia de Río Negro. E: estepa patagónica $(n=12)$; B: bosque mixto $(n=18)$. Cajas intercuartiles (2575\%), línea: mediana, barras: máximos y mínimos, sin consignar valores extremos. Asterisco indica diferencias significativas $p<0,05$ según el análisis no paramétrico de Mann-Whitney.

\subsubsection{Descripción ambiental por biozona según uso del suelo}

Dado que los mallines pertenecen a biozonas diferentes, las características ambientales derivadas del uso del suelo se analizan y comparan por biozona en forma independiente, basadas en los valores medios de las variables documentadas.

Para la biozona de bosque mixto, el análisis de componentes principales (ACP) mostró una buena separación entre los mallines, según el uso del suelo y sus características ambientales (Figura 5.11). Los dos primeros componentes explicaron el $86 \%$ de la variabilidad, relacionada con las precipitaciones, el oxígeno disuelto (OD) y los nutrientes. El primer eje, que explicó el 66,9 \%, definió un gradiente 
gobernado por las precipitaciones medias anuales, la conductividad eléctrica (CE) y las concentraciones de los sólidos suspendidos totales (SST), nitrógeno total (NT) y fósforo total (PT). En tanto el segundo eje, que capturó el 19,1 \% de la varianza, ordenó a los mallines según la concentración de OD.

Los mallines asociados a un uso del suelo urbano (círculos rojos) $\mathrm{Km} 5$ (B7), Km 12 (B8) y la Laguna Fantasma (B9) se ubicaron sobre el lado positivo de la componente 1 , definiéndose un gradiente de enriquecimiento de nutrientes y de CE. Sobre el lado negativo de la componente 1 se agruparon los mallines de uso agrícola (círculos amarillos) y los de referencia (círculos verdes), con menor degradación, explicada por menores concentraciones de nutrientes, SST y CE. A su vez este componente separó a los mallines localizados a lo largo de un gradiente de precipitaciones (según medias anuales). Por otro lado, aquellos mallines que presentaron mayores niveles de OD como Muelle Viejo (B2), Ea. Vereertbrugghen (B1) y Km5 (B7) quedaron localizados en el extremo positivo de la componente 2.

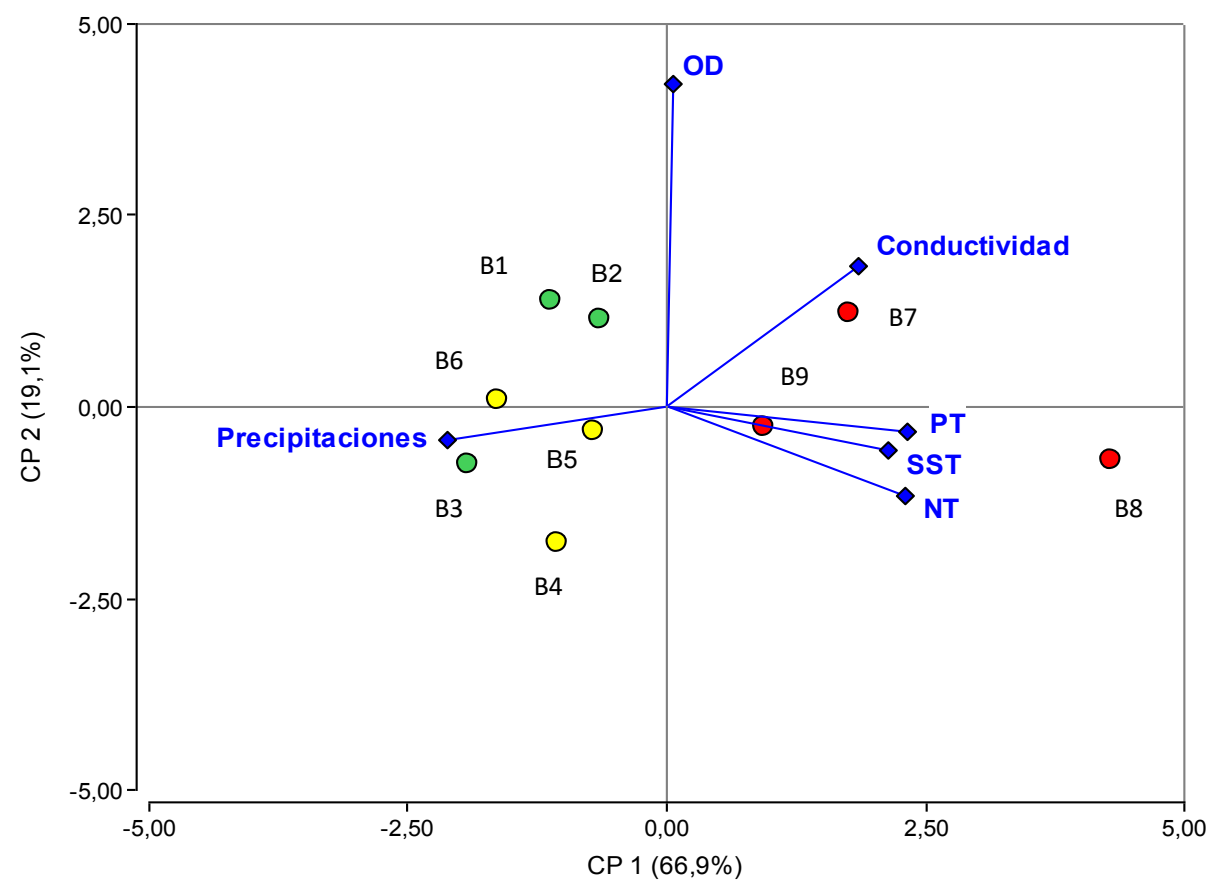

Figura 5.11: Ordenamiento de los sitios de acuerdo al ACP, basado en variables ambientales en 9 mallines del bosque mixto en la Provincia de Río Negro (septiembre y diciembre de 2012). Uso de suelo de mallines: círculo verde: referencia, círculo amarillo: agrícola; círculo rojo: urbano. Los nombres completos de los sitios se consignan en la Tabla 5.1. 
Este ordenamiento permitió validar el agrupamiento de los mallines según el nivel de degradación debido al uso de suelo, separando principalmente los localizados en áreas urbanas, respecto de aquellos de uso agrícola y de referencia, los que presentaron mejores condiciones ambientales.

El análisis comparativo (ANOVA no paramétrico de Kruskal-Wallis) de las principales características fisicoquímicas en relación al uso del suelo urbano, agrícola y de referencia en la biozona de bosque mixto, evidenciaron una notable diferenciación entre los de uso urbano respecto de las otras categorias (Figura 5.12).

Conductividad eléctrica $(\mu \mathrm{S} / \mathrm{cm})$

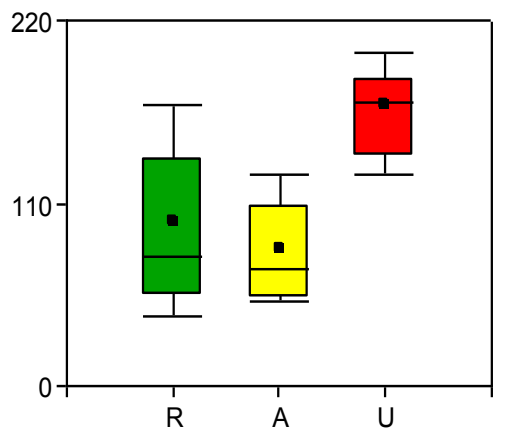

Fósforo total $(\mu \mathrm{g} / \mathrm{L})$

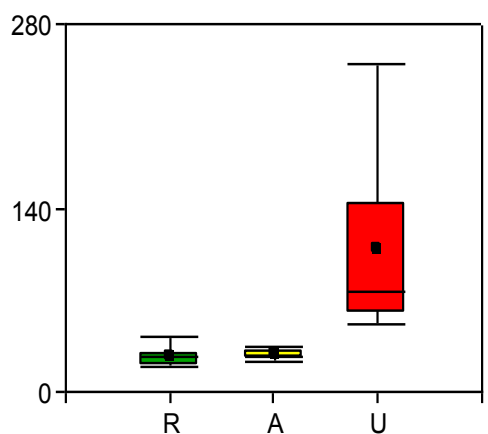

Alcalinidad $(\mathrm{mg} / \mathrm{L})$

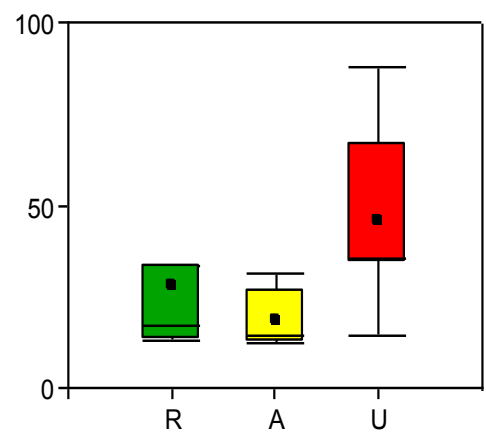

Nitrógeno total $(\mu \mathrm{g} / \mathrm{L})$

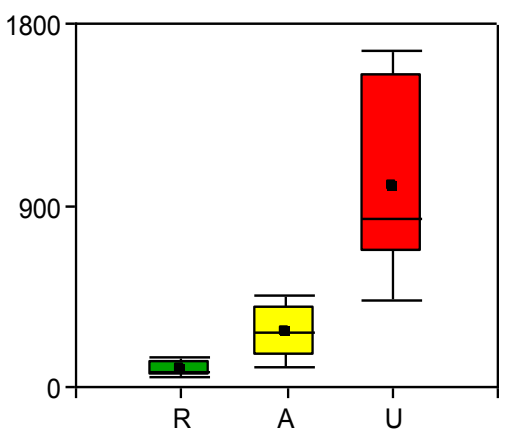

SST (mg/L)

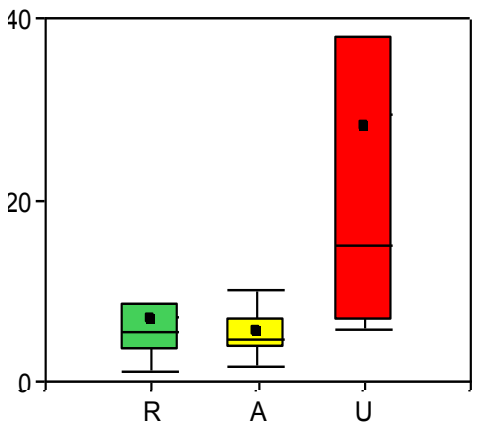

Oxígeno disuelto $(\mathrm{mg} / \mathrm{L})$

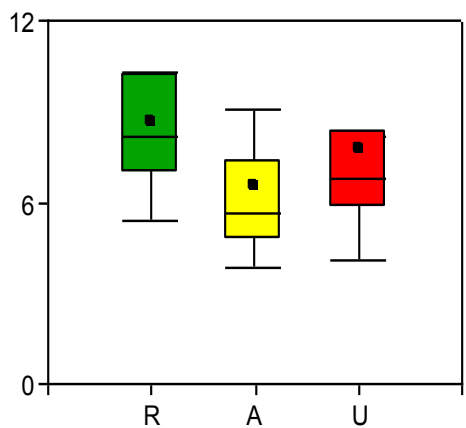

Figura 5.12: Comparación de la distribución de los valores de las principales variables fisicoquímicas determinadas para los nueve sitios de muestreo en la biozona de bosque en el sudoeste de la Provincia de Río Negro. Valores medios de dos momentos de muestreo (septiembre 2012 - diciembre 2012). Usos: R, referencia; A, agrícola y U, urbanos. Cajas intercuartiles (25-75\%), cuadrado negro: media; línea: mediana, barras: máximos y mínimos, sin consignar valores extremos. 
La conductividad eléctrica en los mallines urbanos se duplicó significativamente respecto del resto de los sitios $(p=0,015)$. Lo mismo ocurrió con la alcalinidad, donde en sitios urbanos fue significativamente mayor $(p=0,035)$ respecto de aquellos de uso agrícola y de referencia. En tanto el pH mostró aguas neutras a levemente alcalinas en todos los usos, con valores medios comprendidos entre 7,46 $\pm 0,45$ (agrícola) y 8,68 $\pm 0,77$ (referencia) y el oxígeno disuelto, no mostró variaciones significativas $(p=0,244)$ en función a los usos, con concentraciones medias entre 6,52 $\pm 2,07 \mathrm{mg} / \mathrm{L}$ (agrícola) a 8,69 $\pm 2 \mathrm{mg} / \mathrm{L}$ (referencia).

Por otro lado, las concentraciones de nutrientes también evidenciaron una clara degradación de la calidad del agua en los mallines urbanos. La concentración de fósforo total, nitrógeno total y nitrógeno inorgánico disuelto fueron significativamente superiores en el uso urbano, respecto del agrícola y de referencia $(p<0,05)$, los que a su vez entre ambos no mostraron diferencias. Finalmente, y si bien las diferencias no fueron estadísticamente significativas $(p=0,071)$, fue notable la concentración media de los sólidos suspendidos totales $(28,13 \pm 35,15 \mathrm{mg} / \mathrm{L})$ en los mallines urbanos respecto de los otros usos (referencia: $6,8 \pm 5,82 \mathrm{mg} / \mathrm{L} \mathrm{-}$ agrícola: 5,52 $\pm 3,1 \mathrm{mg} / \mathrm{L})$.

En la biozona de estepa patagónica, el ACC mostró una buena separación entre los mallines agrícola-ganaderos, con mayor intensidad de pastoreo y alta intervención en manejo hídrico (círculos amarillos), respecto de los agrícolas seleccionados como de referencia por llevar a cabo una moderada intervención hídrica y menor presión ganadera (Figura 5.13). Los dos primeros componentes explicaron el $87,1 \%$ de la variabilidad, relacionada con la conductividad eléctrica y las concentraciones de sólidos suspendidos totales y nutrientes. El primer factor, que explicó el 56,1 \%, definió un gradiente que estuvo determinado por las concentraciones de fósforo total (PT) y nitratos-nitritos $\left(\mathrm{NO}_{3}-\mathrm{NO}_{2}\right)$, así como por la conductividad eléctrica (CE). En tanto el segundo factor, que explicó el 27,1 \%, estuvo gobernado principalmente por el oxígeno disuelto (OD) y la concentración de sólidos suspendidos totales (SST). Sin embargo el patrón de separación fue inverso al esperado, esto es, los mallines sometidos a un uso de suelo agrícola con 
escasa intervención antrópica en los cuerpos de agua se asociaron sobre el eje positivo de la componente 1 mostrando mayores concentraciones de nutrientes, principalmente en Ea. El Cóndor (E2). En cambio, en el lado negativo de esa componente se agruparon los mallines con alta presión ganadera y manejo hídrico, con mayores valores de CE y menores concentraciones de nutrientes (Ea. Rayhuao, Ea. Domínguez y Ea. Pilcañeu). Sobre la componente 2, los mallines se distribuyeron a lo largo de un gradiente conformado por el OD y los SST, donde a valores positivos se asociaron los sitios con mayor intensidad de pastoreo, salvo la Ea. El Cóndor.

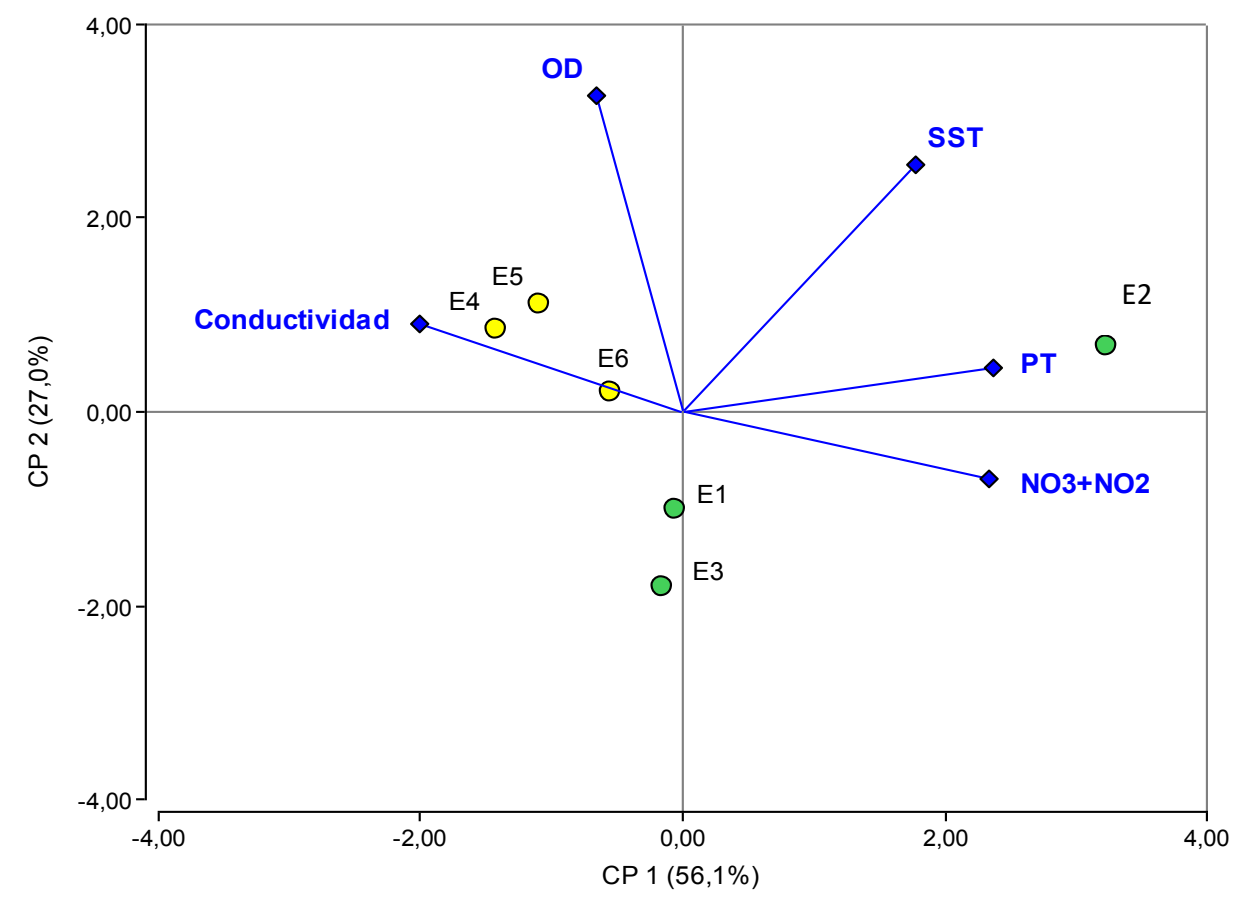

Figura 5.13: Ordenamiento de los sitios de acuerdo al ACP, basado en variables ambientales en 6 mallines de la estepa patagónica en la Provincia de Río Negro, Argentina (septiembre y diciembre de 2012). Uso de suelo de mallines: círculo verde: referencia; círculo amarillo: agrícola. Los nombres completos de los sitios se consignan en la Tabla 5.1.

El ordenamiento logrado por el ACC en la biozona de la estepa, permitió separar a los mallines agrícolas sometidos a una alta presión ganadera con mayores prácticas de manejo hídrico (Ea. Dominguez, Ea. Rayhuao y Ea. Pilcañeu), respecto de aquellos agrícolas de moderada o baja presión de pastoreo y escasas prácticas de riego y drenaje (Ea. Perito Moreno, Ea. El Cóndor y Ea. San Ramón). 
El análisis comparativo (no paramétrico de Mann-Whitney) de las principales variables ambientales en los mallines de estepa, agrupados por uso y manejo suelo (Figura 5.14) mostraron valores promedios de conductividad eléctrica más altos en los sitios con mayor presión ganadera $(267,78 \pm 117,52 \mu \mathrm{S} / \mathrm{cm}$ agrícola; 173,22 $\pm 65,21 \mu \mathrm{S} / \mathrm{cm}$ referencia), pero no se registraron diferencias estadísticamente significativas $(p=0,179)$.

Conductividad eléctrica $(\mu \mathrm{S} / \mathrm{cm})$

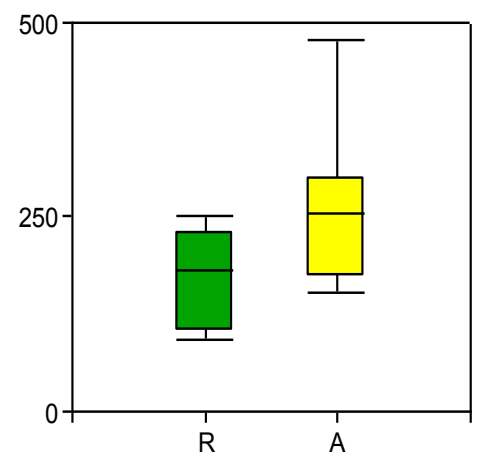

Fósforo total $(\mu \mathrm{g} / \mathrm{L})$

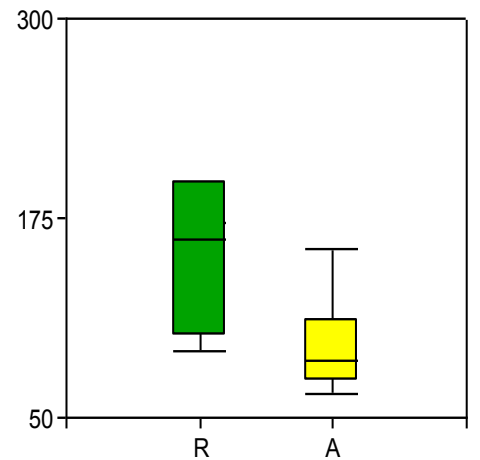

Oxígeno disuelto $(\mathrm{mg} / \mathrm{L})$

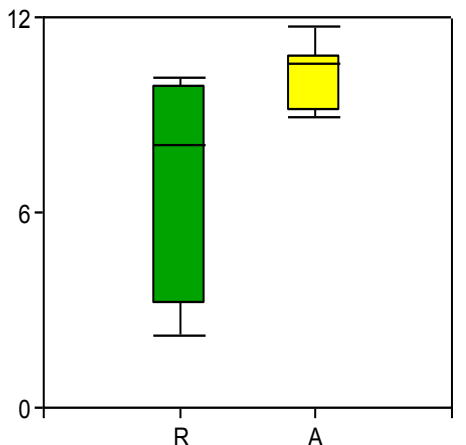

Nitrógeno total $(\mu \mathrm{g} / \mathrm{L})$

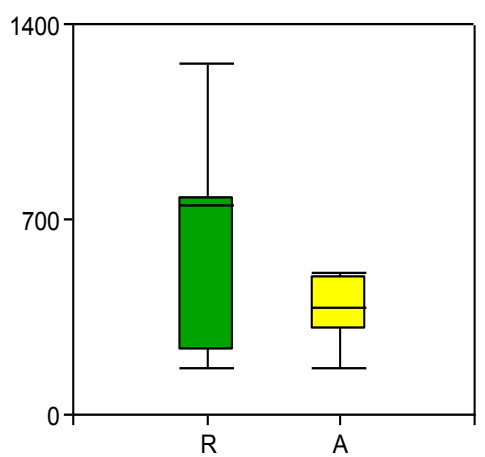

Nitritos-nitratos $(\mu \mathrm{g} / \mathrm{L})$

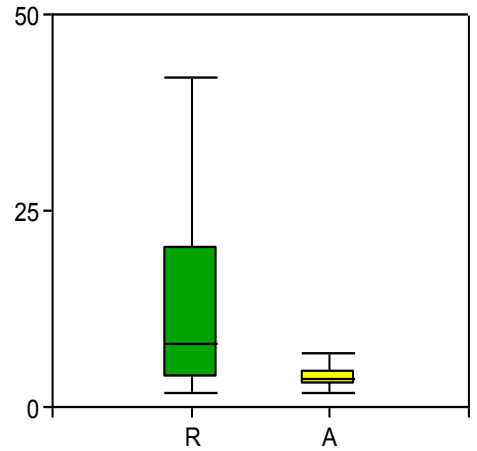

Alcalinidad (mg/L)

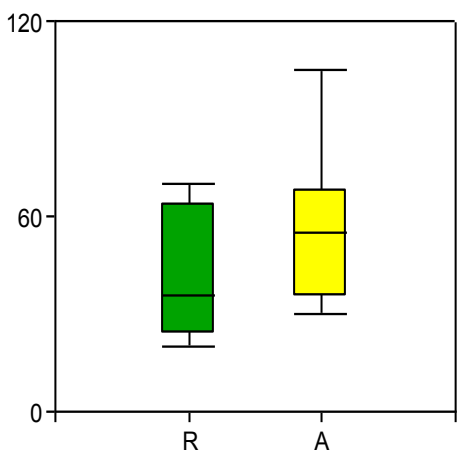

Figura 5.14: Comparación de la distribución de los valores de las principales variables fisicoquímicas determinadas para los 6 sitios de muestreo en la biozona de estepa en el sudoeste de la Provincia de Río Negro, Cordillera Patagónica (Argentina). Valores medios de dos momentos de muestreo (septiembre 2012 - diciembre 2012). Usos: R, referencia; A, agrícola. Cajas intercuartiles (25-75\%), cuadrado negro: media; línea: mediana, barras: máximos y mínimos, sin consignar valores extremos. 
El pH medio indicó aguas alcalinas en todos los casos $(>8,33)$ y aunque la alcalinidad fue más alta en los mallines más impactados, las diferencias tampoco fueron significativas (Mann-Whitney $p=0,329$ ). Las concentraciones de oxígeno disuelto evidenciaron valores significativamente más altos $(p=0,041)$ y cercanos a la saturación en los mallines con mayor actividad ganadera e intervenidos con obras de canalización y drenaje $(10,27 \pm 1,08 \mathrm{mg} / \mathrm{L}$ agrícola; 6,91 $\pm 3,44 \mathrm{mg} / \mathrm{L}$ referencia). En relación a los nutrientes, las mayores concentraciones fueron encontradas en los mallines de referencia aunque sólo existieron diferencias significativas en las concentraciones de fósforo total $(93,8 \pm 32,90 \mathrm{mg} / \mathrm{L}$ agrícola; $177,68 \pm 102,4 \mathrm{mg} / \mathrm{L}$ referencia; $p=0,041$ ) (Figura 5.14).

\subsubsection{Clorofila a y feopigmentos}

La concentración de la clorofila $a(\mathrm{chl}-a)$ del fitoplancton estuvo comprendida en un rango de $0,25 \mu \mathrm{g} / \mathrm{L}-32,50 \mu \mathrm{g} / \mathrm{L}(\mathrm{n}=30)$. El valor mínimo correspondió al mallín de bosque Muelle Viejo y el máximo a la Ea. El Cóndor localizado en la estepa. Sin embargo la mayoría de las concentraciones estuvieron por debajo de 5,41 $\mu \mathrm{g} / \mathrm{L}$ ( $n=23)$ (Tabla 5.4).

La comparación de las concentraciones de chl- $a$ en ambas biozonas no mostró diferencias significativas (Mann-Whitney $p=0,421$ ). Pero cuando el análisis se realizó por uso del suelo dentro de cada biozona, los mallines de bosque urbanos presentaron una concentración media de chl-a ocho veces superior $(9,57 \pm 8,34$ $\mu \mathrm{g} / \mathrm{L})$, respecto de los agrícolas $(1,13 \pm 0,52 \mu \mathrm{g} / \mathrm{L})$ y de referencia $(1,29 \pm 2,03 \mu \mathrm{g} / \mathrm{L})$, evidenciando diferencias significativas (Kruskal-Wallis $p=0,007$ ) (Figura 5.15). En la estepa patagónica la clorofila a no presentó diferencias estadísticamente significativas (Mann-Whitney $p=0,484$ ) entre ambos usos, sin embargo en los mallines de uso agrícola, drenados por arroyuelos y canalizaciones, la concentración media de clorofila a fue 1,73 $\pm 1,17 \mu \mathrm{g} / \mathrm{L}$, casi cuatro veces menor a la registrada en los mallines de referencia, cuya media fue 9,29 $\pm 12,84 \mu \mathrm{g} / \mathrm{L}$ (Figura 5.15). 
Tabla 5.4: Valores de clorofila $a$ y feopigmentos, junto a las relaciones N:P (nitrógeno total: fósforo total), NID:P (nitrógeno inorgánico disuelto: fósforo total), $\mathrm{TSI}_{\mathrm{Cl}}$ (índice trófico de Carlson clorofila $a$ ) e TSI $_{\mathrm{PT}}$ (índice trófico de Carlson fósforo total) de la columna de agua en los 15 mallines, según fecha de muestreo. a: septiembre de 2012 b: diciembre de 2012. Uso del suelo: R: referencia; A: agrícola; U: urbano. SO de la Provincia de Río Negro.

\begin{tabular}{|c|c|c|c|c|c|c|c|c|c|c|}
\hline 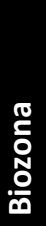 & $\begin{array}{l}\text { d } \\
\text { हू } \\
\text { 을 }\end{array}$ & $\frac{\circ}{\frac{0}{8}}$ & 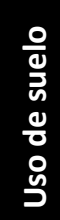 & 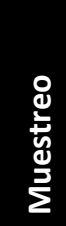 & $\begin{array}{l}0 \\
\frac{0}{5} \\
\text { ᄅ } \\
\frac{0}{0} \\
\frac{0}{0}\end{array}$ & 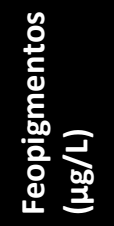 & $\frac{0}{z}$ & $\frac{0}{2}$ & $\frac{\bar{x}}{\bar{n}}$ & $\frac{5}{\bar{n}}$ \\
\hline \multirow{12}{*}{ 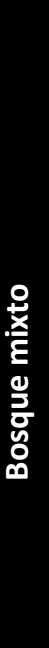 } & \multirow[t]{2}{*}{ Vereertbrugghen } & \multirow[t]{2}{*}{ B1 } & \multirow[t]{2}{*}{$\mathrm{R}$} & $a$ & 5,41 & 2,735 & 3,435 & 0,135 & 47,16 & 57,94 \\
\hline & & & & $b$ & 0,389 & 0,417 & 2,688 & 1,011 & 21,33 & 46,32 \\
\hline & \multirow[t]{2}{*}{ Muelle viejo } & \multirow[t]{2}{*}{ B2 } & \multirow[t]{2}{*}{$\mathrm{R}$} & a & 0,359 & 0,199 & 2,652 & 0,928 & 20,55 & 45,93 \\
\hline & & & & $b$ & 0,249 & 0,204 & 1,63 & 0,471 & 16,97 & 52,02 \\
\hline & \multirow[t]{2}{*}{ La Turbina } & \multirow[t]{2}{*}{ B3 } & \multirow[t]{2}{*}{$\mathrm{R}$} & a & 0,432 & 0,15 & 3,42 & 0,233 & 22,36 & 51,27 \\
\hline & & & & $b$ & 0,884 & 0,996 & 3,963 & 0,698 & 29,39 & 52,98 \\
\hline & \multirow[t]{2}{*}{ Playa Negra } & \multirow[t]{2}{*}{ B4 } & \multirow[t]{2}{*}{$A$} & a & 0,897 & 0,638 & 8,872 & 0,188 & 29,53 & 55,48 \\
\hline & & & & $b$ & 1,03 & 0,993 & 17,62 & 0,692 & 30,89 & 51,15 \\
\hline & \multirow[t]{2}{*}{ Cretón } & \multirow[t]{2}{*}{ B5 } & \multirow[t]{2}{*}{$A$} & a & 0,498 & 0,217 & 4,098 & 0,626 & 23,77 & 49,7 \\
\hline & & & & $b$ & 0,831 & 1,007 & 14 & 0,29 & 28,78 & 52,17 \\
\hline & \multirow{2}{*}{$\begin{array}{l}\text { Lag. Pampa } \\
\text { Linda }\end{array}$} & \multirow[t]{2}{*}{ B6 } & \multirow[t]{2}{*}{$A$} & $a$ & 1,832 & 0,262 & 5,905 & 0,273 & 36,54 & 50,12 \\
\hline & & & & $b$ & 1,666 & 0,756 & 6,981 & 0,788 & 35,61 & 53,74 \\
\hline & \multirow[t]{2}{*}{$\mathrm{Km} 5$} & \multirow[t]{2}{*}{ B7 } & \multirow[t]{2}{*}{ U } & a & 12,06 & 4,299 & 15,1 & 7,594 & 55,02 & 60,82 \\
\hline & & & & $b$ & 10,02 & 20,96 & 4,592 & 0,168 & 53,21 & 75,78 \\
\hline & \multirow[t]{2}{*}{$\mathrm{Km} 12$} & \multirow[t]{2}{*}{ B8 } & \multirow[t]{2}{*}{ U } & a & 2,143 & 2,323 & 19,66 & 1,04 & 38,08 & 67,06 \\
\hline & & & & $b$ & 26,61 & 17,55 & 6,669 & 2,785 & 62,79 & 83,79 \\
\hline & \multirow[t]{2}{*}{ Lag. Fantasma } & \multirow[t]{2}{*}{ B9 } & \multirow[t]{2}{*}{ U } & $a$ & 4,934 & 1,555 & 5,736 & 0,283 & 46,26 & 66,23 \\
\hline & & & & $b$ & 1,675 & 3,098 & 15,14 & 0,384 & 35,66 & 63,05 \\
\hline & Ea. San Ramón & E1 & $\mathrm{R}$ & $a$ & 3,335 & 1,737 & 4,305 & 0,095 & 42,42 & 78,41 \\
\hline & & & & $b$ & 16,45 & 3,685 & 8,335 & 0,232 & 58,07 & 76,57 \\
\hline & Ea. El Cóndor & E2 & $\mathrm{R}$ & a & 32,5 & 10,77 & 2,01 & 0,015 & 64,75 & 89,66 \\
\hline (8) & & & & $b$ & 1,794 & 3,753 & 4,493 & 0,455 & 36,33 & 78,39 \\
\hline & Ea. Pto. Moreno & E3 & $\mathrm{R}$ & a & 0,529 & 0,212 & 1,82 & 0,341 & 24,35 & 69,39 \\
\hline$\frac{1}{20}$ & & & & $b$ & 1,146 & 0,93 & 2,147 & 0,198 & 31,94 & 71,15 \\
\hline & Ea. Domínguez & E4 & A & $a$ & 0,336 & 0,501 & 3,124 & 0,182 & 19,91 & 77,03 \\
\hline & & & & $b$ & 1,538 & 3,157 & 5,532 & 0,445 & 34,82 & 66,28 \\
\hline & Ea. Pilcañeu & E5 & A & $a$ & 3,813 & 1,185 & 2,834 & 0,172 & 43,73 & 71,24 \\
\hline & & & & $b$ & 1,321 & 0,493 & 6,693 & 0,196 & 33,33 & 66,67 \\
\hline & Ea. Rayhuao & E6 & $A$ & $a$ & 2,153 & 0,401 & 1,692 & 0,155 & 38,12 & 70,02 \\
\hline & & & & $b$ & 1,234 & 0,834 & 5,381 & 0,243 & 32,66 & 64,46 \\
\hline
\end{tabular}


Bosque Mixto

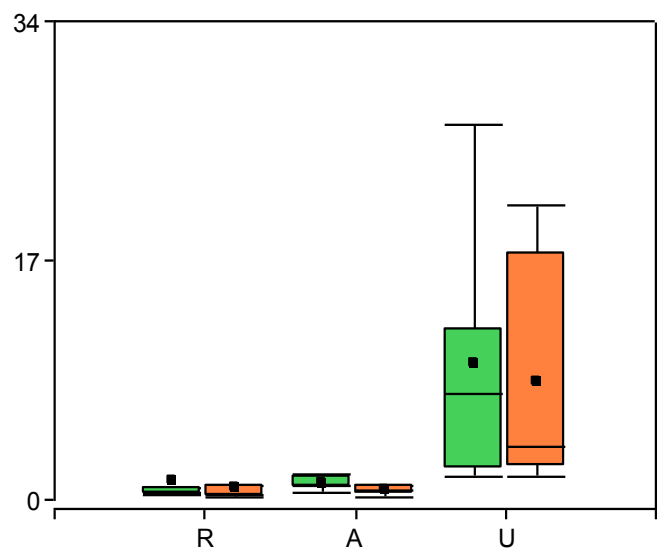

Estepa Patagónica

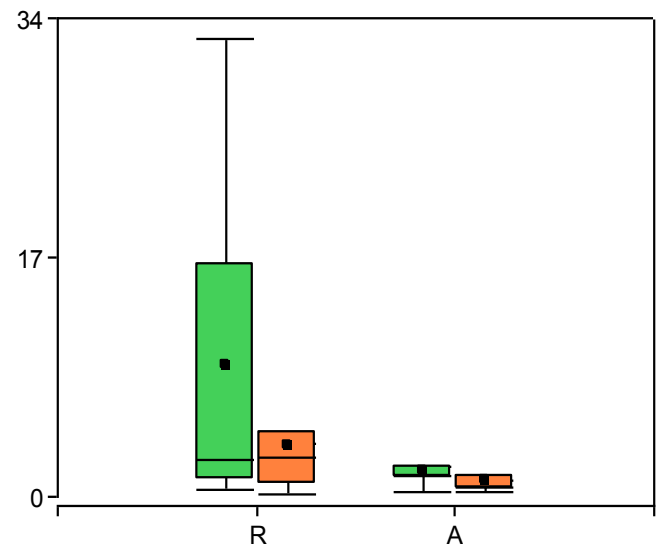

Figura 5.15: Comparación de la distribución de los valores medios de la clorofila $a$ (cajas verdes) y feopigmentos (cajas naranjas) determinados en cada uno de los mallines en dos momentos de muestreo (septiembre 2012 - diciembre 2012) en el SO de la Provincia de Río Negro y agrupados según uso de suelo en cada biozona (bosque $n=18$; estepa $n=12$ ) Usos: $R$, referencia; $A$, agrícola; $U$, urbanos. Cajas: intercuartiles (25-75\%), cuadrado negro: media; línea: mediana, barras: máximos y mínimos.

En cuanto a la clorofila detrítica, medida a partir los feopigmentos, la concentración osciló dentro de un rango de 0,15 $\mu \mathrm{g} / \mathrm{L}-20,96 \mu \mathrm{g} / \mathrm{L}(\mathrm{n}=30)$. Sin embargo la mayoría de las concentraciones estuvieron por debajo de 4,30 $\mathrm{\mu g} / \mathrm{L}$ ( $\mathrm{n}=27)$. La concentración mínima fue encontrada en La Turbina y la máxima en Km 5, ambos mallines de bosque. El contraste de la concentración de los feopigmentos entre mallines de las biozonas de bosque y estepa (con valors medios 3,24 $\pm 5,97$ $\mu \mathrm{g} / \mathrm{L}$ y $2,30 \pm 2,96 \mu \mathrm{g} / \mathrm{L}$ respectivamente) no mostró diferencias significativas (MannWhitney $p=0,611$ ). Sin embargo al comparar por uso de suelo en cada biozona, se observaron diferencias significativas (Kruskal-Wallis $p=0,005$ ) en los mallines de bosque localizados en áreas urbanas, con una concentración media de 8,3 $\pm 7,6 \mu \mathrm{g} / \mathrm{L}$ frente a las detectadas en los mallines agrícolas $(0,65 \pm 0,34 \mu \mathrm{g} / \mathrm{L})$ y de referencia $(0,78 \pm 0,64 \mu \mathrm{g} / \mathrm{L})$. En la estepa, las concentraciones de feopigmentos fueron también significativamente más altas en los mallines de referencia $(3,52 \pm 3,83$ $\mu \mathrm{g} / \mathrm{L})$, respecto de los agrícolas $(1,09 \pm 1,05 \mu \mathrm{g} / \mathrm{L})$. Particularmente se encontró un valor extremo, con una concentración de 10,77 $\mu \mathrm{g} / \mathrm{L}$ en Ea. El Cóndor durante el muestreo realizado en aguas altas. 


\subsubsection{Estado trófico de los mallines}

La relación entre la biomasa del fitoplancton, medida a través de la concentración de la chl- $a$, y las concentraciones de nutrientes mostraron algunas correlaciones positivas (tabla 5.5). Tanto el $\mathrm{NH}_{4}(p=0,0437)$, NT $(p=0,0001)$ y PT $(p=0,0004)$ explicaron significativamente el aumento en la biomasa del fitoplancton en los mallines muestreados.

Tabla 5.5: Correlación de Spearman entre la clorofila $a$ y los principales nutrientes durante el estudio $(n=30)$. SO de la Provincia de Río Negro. En negrita se indican valores significativos $p$-valor<0,05.

\begin{tabular}{|c|c|c|}
\hline & Clorofila a & $p$-valor \\
\hline $\mathbf{N H}_{4}$ & 0,37 & 0,0437 \\
\hline $\mathrm{NO} 3+\mathrm{NO}_{2}$ & $-0,05$ & 0,7961 \\
\hline NT & 0,64 & 0,0001 \\
\hline PRS & 0,28 & 0,1346 \\
\hline PT & 0,6 & 0,0004 \\
\hline NT:PT & 0,29 & 0,1123 \\
\hline NID:PT & $-0,26$ & 0,1662 \\
\hline
\end{tabular}

$\mathrm{NH}_{4}$ : amonio; $\mathrm{NO}_{3}+\mathrm{NO}_{2}$ : nitratos +nitritos; $\mathrm{NT}$ : nitrógeno total; PRS: fósforo reactivo soluble PT: fósforo total; N:P (nitrógeno total: fósforo total), NID:P (nitrógeno inorgánico disuelto: fósforo total).

La proporción de NT:PT en los cuerpos de agua fluctuó entre 2 y 18 (Tabla 5.4). En todos los mallines, salvo Playa Negra (B4) y KM 12 (B8) durante el período de aguas bajas, la relación presentó valores entre 17-10 $(n=7)$ o valores menores de diez ( $n=22$ ) (Figura 5.16). Un análisis por biozona mostró que los mallines de bosque presentaron una mayor relación NT:PT y, estadísticamente significativa, respecto de aquellos de estepa (Mann-Whitney $p=0,049$ ).

Otro indicador que evalua la respuesta de la chl- $a$ en aguas superficiales es la relación NID:PT, cuyos valores se encontraron dentro del rango 0,02 y 7,59 (Tabla 5.4). Casi todos los mallines en ambos periodos de muestreo $(n=28)$ presentaron 
relaciones menores a 2,2. Nuevamente, al comparar por biozonas, los mallines de bosque mostraron una relación significativamente superior de NID:PT, respecto de los de estepa (Mann-Whitney $p=0,004$ ) (Figura 5.16).
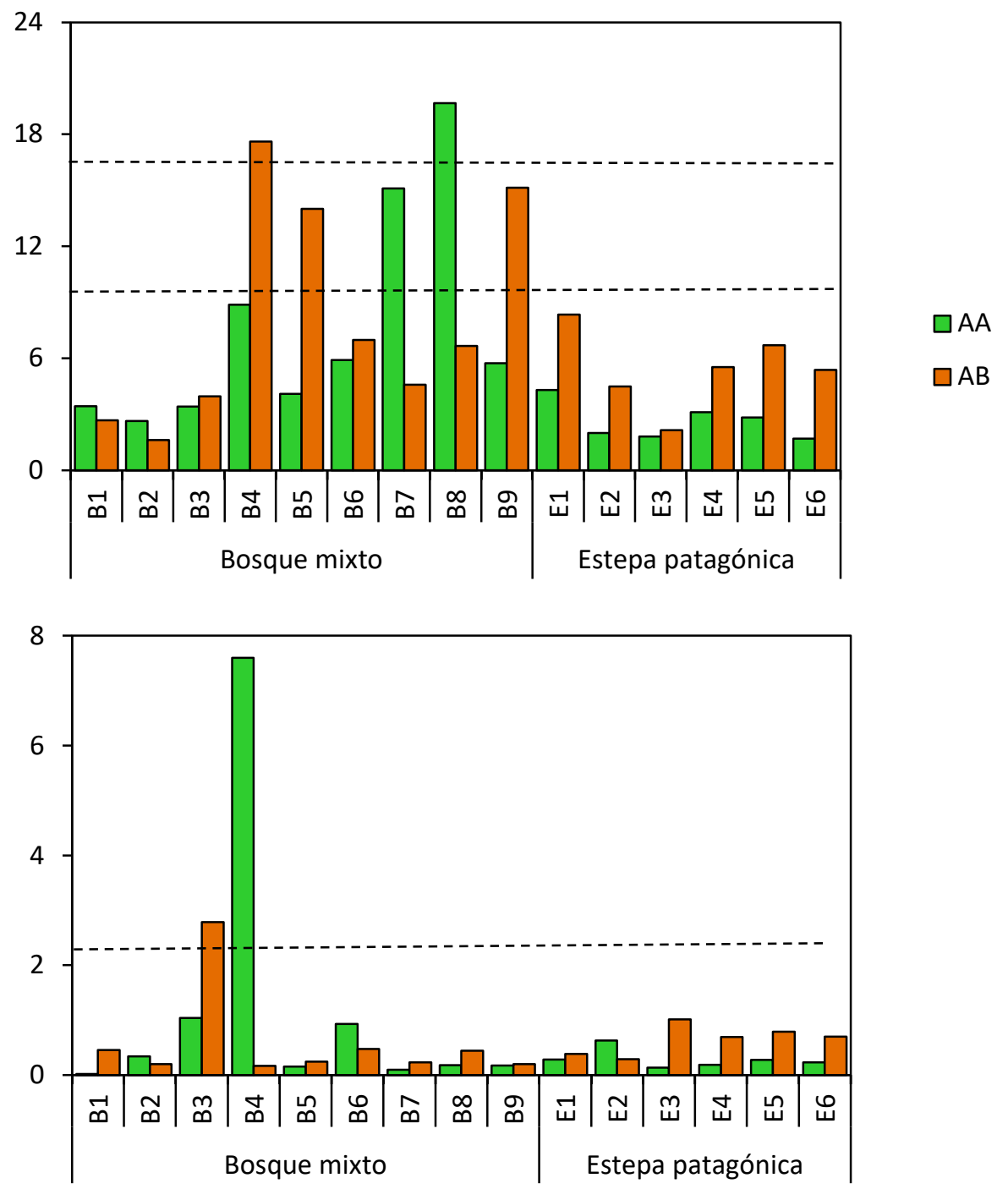

Figura 5.16: Distribución de los valores de las proporciones N:P (nitrógeno total: fósforo total) (Arriba) y NID:PT (nitrógeno orgánico disuelto: fósforo total) (Abajo) para cada uno de los mallines en dos momentos de muestreo (AA:septiembre de 2012 - AB:diciembre de 2012). Rangos líneas punteadas: para N:P <10 N limitante; entre 10-17 N y P limitantes; > 17 P limitante (Sakamoto 1966). Para NID:P <2,2 N limitante; > 2,2 fósforo limitante (Bergström 2010). 
Finalmente se determinó el estado trófico de los mallines ulizando los valores de los indices de Carlson $\mathrm{TSI}_{\mathrm{CL}}$ y $\mathrm{TSI}_{\mathrm{PT}}$. De acuerdo al primero, en la estepa prevalecieron los estados mesotróficos $(n=9)$, donde sólo Ea. El Cóndor fue clasificado como eutrófico durante el muestreo de aguas altas. En tanto en los mallines de bosque, los estados tróficos según el $\mathrm{TSI}_{\mathrm{CL}}$, variaron igualmente entre oligotrófficos $(n=8)$ y mesotróficos $(n=9)$, salvo KM 12, que para el estiaje fue clasificado como eutrófico (Figura 5.17).
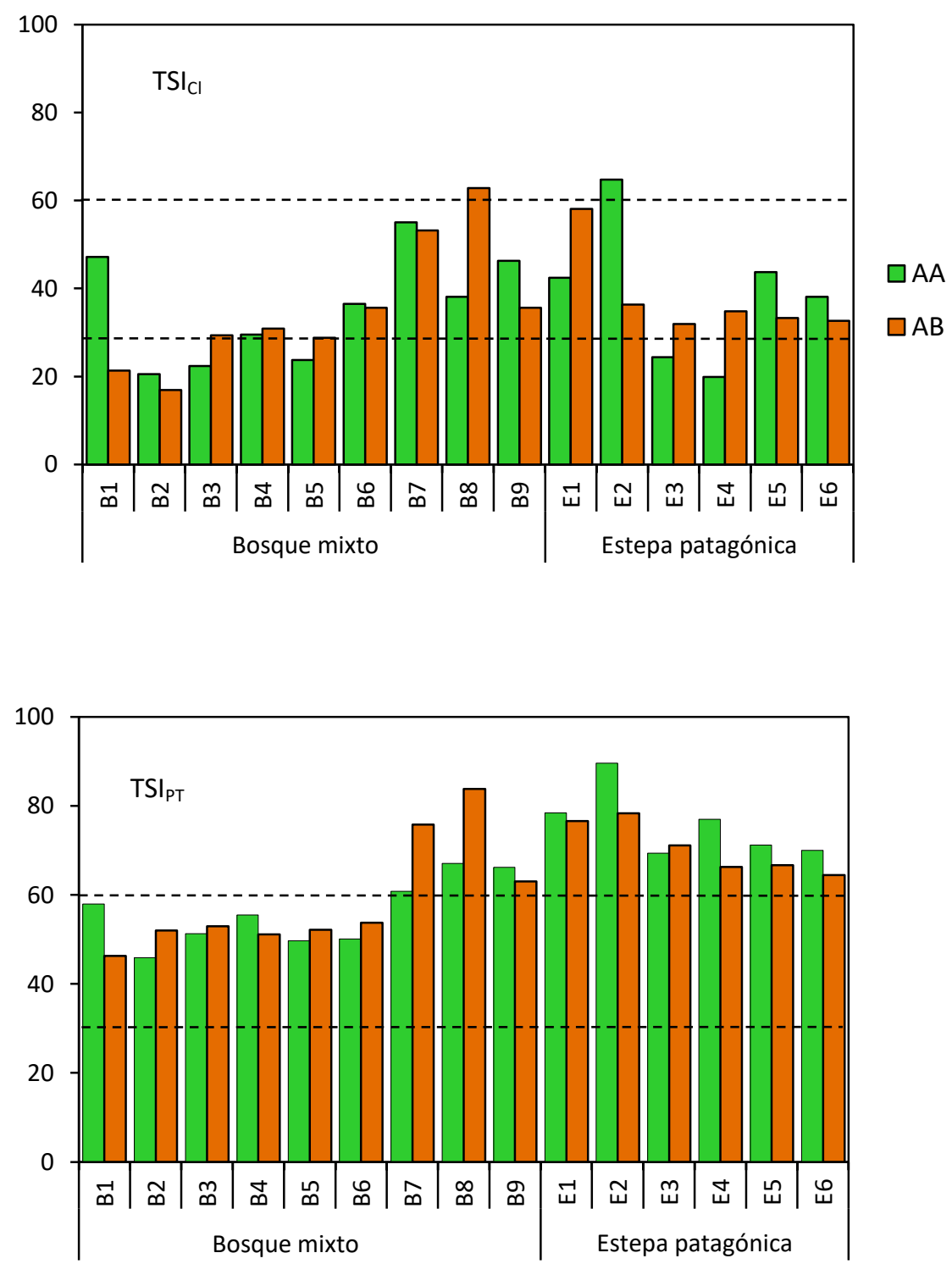

Figura 5.17: Valores del $\mathrm{TSI}_{\mathrm{CI}}$ (índice de estado trófico de Carlson clorofila $a$ ) y $\mathrm{TSI}_{\mathrm{PT}}$ (índice de estado trófico de Carlson fósforo total) calculado para 15 mallines, en muestreos de aguas altas, barras verdes (septiembre 2012) y aguas bajas, barras naranjas (diciembre de 2012). Líneas punteadas negras: Rangos TSICl <30 oligotrófico; 30-60 mesotrófico; > 60 eutrófico. 
El evaluar el estado trófico utilizando el $\mathrm{TSI}_{\mathrm{PT}}$, en la estepa todos los mallines fueron categorizados como eutróficos tanto para aguas altas como bajas. En cambio, en el bosque los valores indicaron estados mesotróficos, salvo los mallines urbanos que para ambos periodos de muestreo, fueron clasificados como eutróficos (Figura 5.17).

\subsubsection{Cobertura de suelo en las áreas de influencia de los mallines}

El resultado del análisis SIG de la cobertura de suelo y los respectivos porcentajes identificados para cada categoría, tomando dos tipos de áreas perimetrales (100 m y 500 m; Figura 5.18) adyacentes al agua superficial de los mallines, se muestra en la tabla 5.6.

En la biozona de bosque mixto, para un área periférica de 100 metros, y agrupando los mallines según las tres tipologías de uso (Figura 5.19), se observó una notable reducción del porcentaje de cobertura de suelo natural (\% Natural), que incluye praderas de juncáceas, ciperáceas y poáceas, junto a bosques de Nothofagus, en los sitios de referencia respecto de los agrícolas (medias $75 \%$ a 48 $\%$ respectivamente), llegando incluso a desaparecer en aquellos de uso urbano. En el mallín La Turbina, el \% Natural representó alrededor de $85 \%$ y en Muelle Viejo constituyó el $100 \%$ del área adyacente al mallín. En contraste la cobertura de suelo agrícola (\% Agrícola), como era de esperar, fue mayor en mallines destinados a este uso (media 45 \%). En los mallines Playa Negra y Cretón, el área agrícola aportó entre $35-63 \%$ de la cobertura a 100 metros. Respecto a la cobertura de suelo degradado (\% Suelo degradado), la mayor contribución se observó hacia los mallines con mayor intervención antrópica, con un valor máximo de 23,1 \% en el humedal Km 12. Por último la cobertura de suelo urbano (\% Urbano), presentaron una alta cobertura (media $75 \%$ ) en los mallines localizados en la ciudad de San Carlos de Bariloche respecto de los otros tipos de usos. 
Tabla 5.5: Porcentaje relativo por categorías de la cobertura de la tierra en áreas perimetrales de 100 y 500 metros de distancia medida desde los cuerpos de agua de los mallines. Uso del suelo: R referencia; A: agrícola; U: urbano. SO de la Provincia de Río Negro (septiembre - diciembre de 2012).

\begin{tabular}{|c|c|c|c|c|c|c|c|c|c|}
\hline & $\begin{array}{l}\text { ॥ } \\
\text { है } \\
\text { 일 }\end{array}$ & $\begin{array}{l}\circ \\
\stackrel{\circ}{\circ} \\
0 \\
0\end{array}$ & 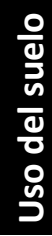 & 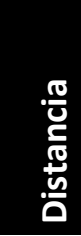 & 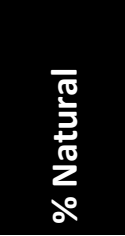 & 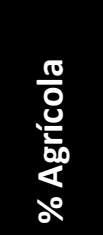 & $\begin{array}{l}\frac{0}{7} \\
\frac{8}{5} \\
\frac{0}{5} \\
\text { de }\end{array}$ & 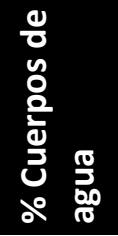 & 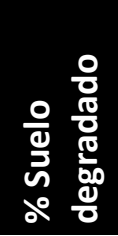 \\
\hline \multirow{16}{*}{ 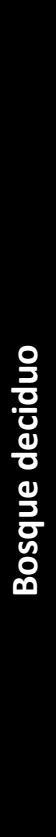 } & \multirow[t]{2}{*}{ Vereertbrugghen } & \multirow[t]{2}{*}{ B1 } & \multirow[t]{2}{*}{$\mathrm{R}$} & 100 & 39,66 & 57,83 & 2,52 & & \\
\hline & & & & 500 & 55,63 & 31,61 & 1,79 & 0,05 & 10,92 \\
\hline & \multirow[t]{2}{*}{ Muelle viejo } & \multirow[t]{2}{*}{ B2 } & \multirow[t]{2}{*}{$\mathrm{R}$} & 100 & 100,00 & & & & \\
\hline & & & & 500 & 82,96 & 1,53 & 1,66 & 13,85 & \\
\hline & \multirow[t]{2}{*}{ La Turbina } & \multirow[t]{2}{*}{ B3 } & \multirow[t]{2}{*}{$\mathrm{R}$} & 100 & 85,74 & 14,26 & & & \\
\hline & & & & 500 & 93,14 & 2,32 & & 4,54 & \\
\hline & \multirow[t]{2}{*}{ Playa Negra } & \multirow[t]{2}{*}{ B4 } & \multirow[t]{2}{*}{ A } & 100 & 40,37 & 35,00 & & 18,82 & 5,81 \\
\hline & & & & 500 & 46,51 & 11,54 & & 39,17 & 2,77 \\
\hline & \multirow[t]{2}{*}{ Cretón } & \multirow[t]{2}{*}{ B5 } & \multirow[t]{2}{*}{$A$} & 100 & 30,43 & 63,01 & & & 6,56 \\
\hline & & & & 500 & 38,57 & 45,39 & & 0,47 & 15,57 \\
\hline & \multirow{2}{*}{$\begin{array}{l}\text { Lag. Pampa } \\
\text { Linda }\end{array}$} & \multirow[t]{2}{*}{ B6 } & \multirow[t]{2}{*}{$A$} & 100 & 75,02 & 24,98 & & 0,00 & 0,00 \\
\hline & & & & 500 & 91,51 & 4,09 & 1,12 & & 2,13 \\
\hline & \multirow[t]{2}{*}{ Km 5} & \multirow[t]{2}{*}{ B7 } & \multirow[t]{2}{*}{$U$} & 100 & & 11,18 & 86,61 & & 2,20 \\
\hline & & & & 500 & & 0,60 & 88,47 & & 10,93 \\
\hline & \multirow[t]{2}{*}{$\mathrm{Km} 12$} & \multirow[t]{2}{*}{ B8 } & \multirow[t]{2}{*}{ U } & 100 & & 6,85 & 66,57 & 3,39 & 23,19 \\
\hline & & & & 500 & & 4,19 & 57,94 & 27,91 & 9,96 \\
\hline & \multirow[t]{2}{*}{ Lag. Fantasma } & \multirow[t]{2}{*}{ B9 } & \multirow[t]{2}{*}{$U$} & 100 & 9,00 & 2,13 & 73,32 & & 15,56 \\
\hline & & & & 500 & 14,26 & 3,06 & 68,51 & 10,48 & 3,69 \\
\hline & \multirow[t]{2}{*}{ Ea. San Ramón } & E1 & $\mathrm{R}$ & 100 & & 96,68 & & & 1,36 \\
\hline & & & & 500 & 33,83 & 44,06 & 1,46 & & 20,64 \\
\hline & Ea. El Cóndor & E2 & $\mathrm{R}$ & 100 & 39,63 & 57,33 & & & 3,04 \\
\hline 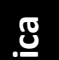 & & & & 500 & 36,52 & 60,28 & 0,97 & 0,26 & 1,98 \\
\hline 品 & Ea. Pto. Moreno & E3 & $\mathrm{R}$ & 100 & 11,31 & 88,69 & & & 11,31 \\
\hline$\stackrel{00}{\stackrel{0}{*}}$ & & & & 500 & 78,39 & 19,28 & 0,24 & & 2,09 \\
\hline$\frac{10}{8}$ & Ea. Dominguez & E4 & $A$ & 100 & 37,45 & 47,67 & 0 & 14,88 & 14,88 \\
\hline$\frac{0}{9}$ & & & & 500 & 63,05 & 23,72 & 1,17 & & 12,06 \\
\hline 5 & Ea. Pilcañeu & E5 & $A$ & 100 & 0 & 77,38 & 1,76 & 1,74 & 17,34 \\
\hline & & & & 500 & 4,95 & 45,49 & 6,27 & 1,27 & 42,01 \\
\hline & Ea. Rayhuao & E6 & $A$ & 100 & 27,48 & 11,2 & 2,1 & 2,20 & 59,22 \\
\hline & & & & 500 & 13,24 & 38,36 & & 1,85 & 46,55 \\
\hline
\end{tabular}



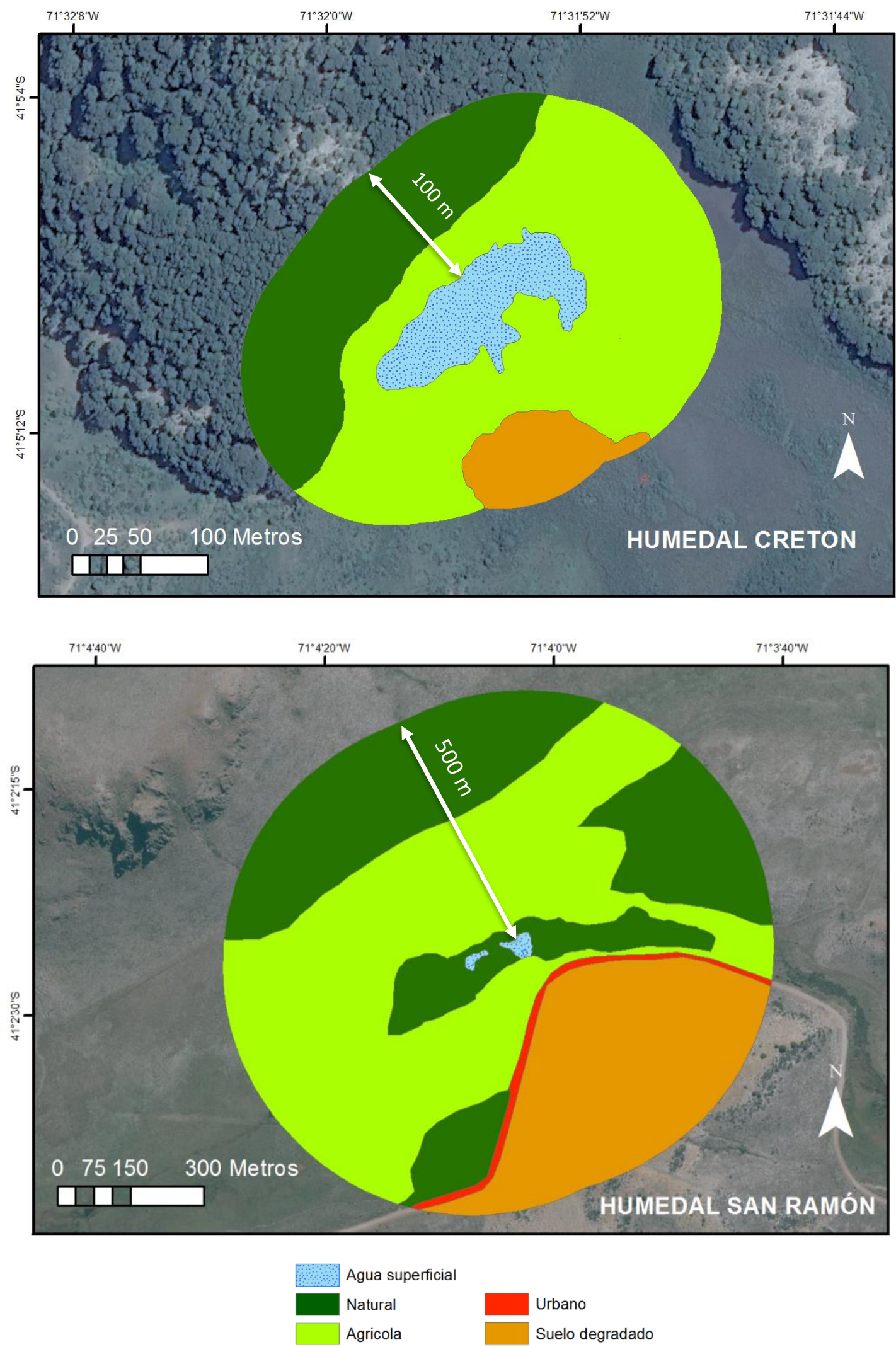

Figura 5.18: Estimación del porcentaje de cobertura de suelo en áreas perimetrales al cuerpo de agua superficial de los mallines en el SO de la Provincia de Río Negro (septiembre-diciembre de 2012). Arriba: Mallín Cretón: cobertura del uso del suelo en área perimetral de 100 m. Abajo: Mallín Ea. San Ramón: cobertura del uso del suelo en área perimetral de $500 \mathrm{~m}$. 
El análisis espacial las coberturas de suelo a 500 metros en mallines de bosque, no evidenció diferencias respecto de las áreas tomadas a 100 metros (Figura 5.19), salvo la reducción relativa del \% Agrícola, con el consecuente aumento del \% Natural, debido a una mayor contribución del bosque circundante al considerar una mayor distancia periférica desde el agua superficial de los mallines. Otro aspecto a destacar fue el aumento de la representatividad de la cobertura de cuerpos de agua exteriores (\% Cuerpos de agua), debido a la proximidad de varios mallines a grandes lagos como el Nahuel Huapi, Gutiérrez y Mascardi.

En el mismo análisis, pero agrupando los mallines según su uso, se observó una notable reducción del \% Agrícola en distancias a 100 metros en los sitios de mayor presión ganadera respecto de aquellos de referencia (medias 45 y $80 \%$ respectivamente) (Figura 5.19). En contraposición el \% Suelo degradado, con evidentes signos de sobrepastoreo, procesos erosivos y baja cobertura de vegetación, fue superior en mallines de uso agrícola, con valores medios mayores a $30 \%$, en ambas superficies perimetrales analizadas. En los mallines de las estancias Pilcañeu y Rayhuao se registraron las mayores coberturas relativas de suelo degradado, con valores superiores a $42 \%$ (Tabla 5.6). Finalmente, el aporte de $\%$ Natural fue variable para cada uso y área considerada (100 ó 500 metros), pero al igual de lo observado para el bosque mixto, su representatividad relativa fue mayor en áreas de 500 metros, más alejadas del agua superficial de los mallines. Por otro lado el \% Urbano fue escaso y bajo, solo representado por caminos rurales y algunos puestos o cascos de estancias. Es de destacar que todos los mallines de estepa presentaron únicamente praderas pastoreadas con mayor o menor grado de intensidad, a diferencia de algunos mallines de bosque donde además, existieron praderas con esporádica o nula presencia de ganado. 


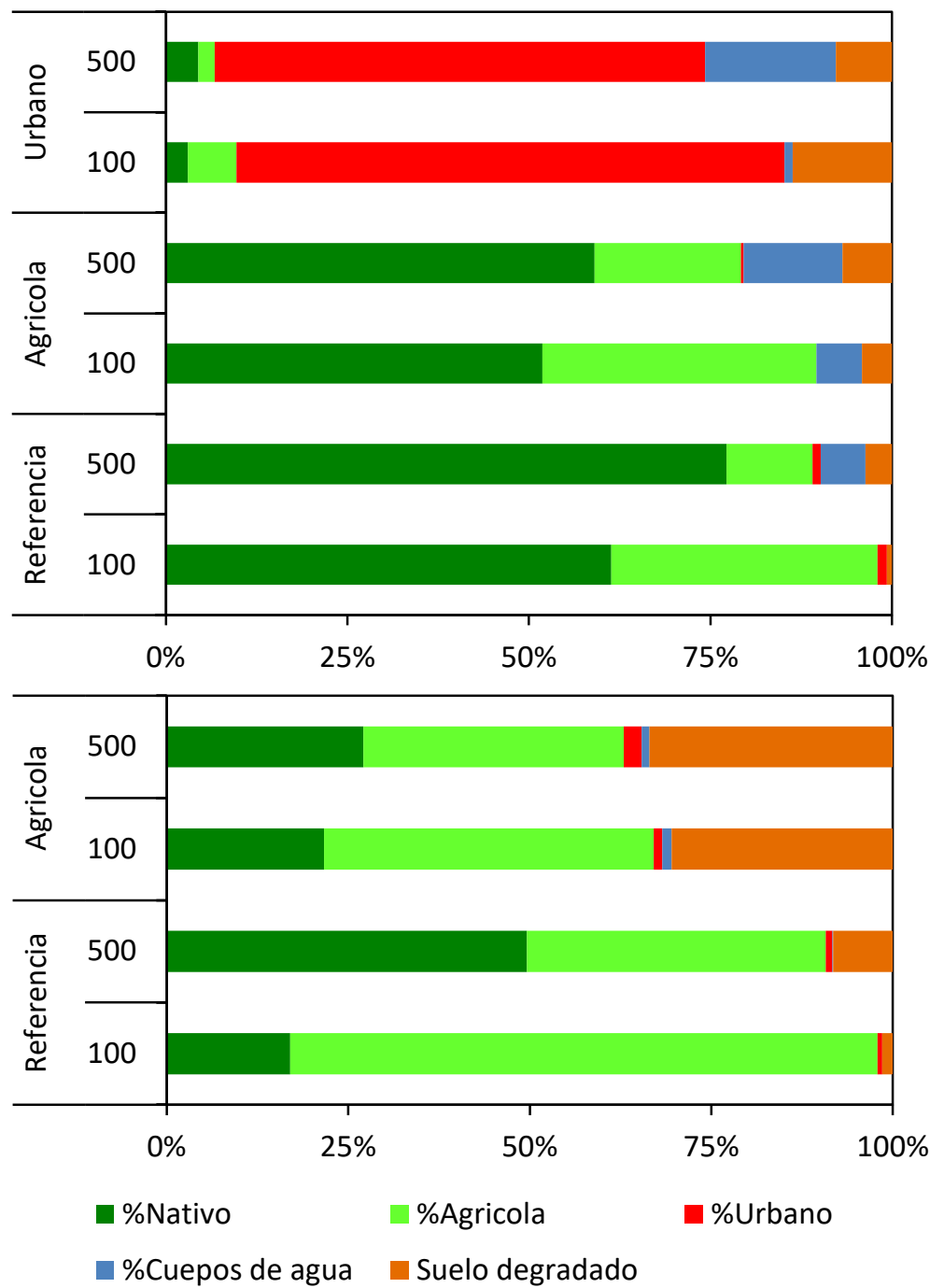

Figura 5.19: Porcentajes de cobertura de uso de la tierra en áreas perimetrales a 100 y 500 metros de los cuerpos de agua de los mallines. Arriba: bosque mixto; abajo: estepa patagónica. SO de la Provincia de Río Negro (septiembre- diciembre de 2012).

\subsection{ENSAMBLES DE MACRÓFITAS}

\subsubsection{Composición y estructura}

El ensamble de macrófitos de los mallines estuvo constituido por 76 taxa distribuidos en 22 familias, de las cuales las más representativas, en términos de riqueza específica, fueron Cyperaceae (14), Poaceae (12) y Juncaceae (9). Del total de especies determinadas, 47 fueron nativas (62\%), 7 de ellas endémicas de Patagonia y, 29 (39\%) exóticas (Tabla 5.7). Las especies emergentes o palustres más frecuentes en los mallines fueron Juncus balticus $(n=15)$, Carex gayana $(n=14)$ y Festuca pallecens $(\mathrm{n}=11)$. Entre los hidrófitos subemergentes sobresalieron 
Callitriche lechleri $(n=8)$, Veronica anagallis-aquatica $(n=5)$, Myriophyllum quitense $(n=4)$ junto a las algas filamentosas Zignema sp. y Spirogyra sp. $(n=6)$. Particularmente, en mallines de bosque, se destacó Potamogeton linguatus $(n=5)$, planta acuática de hojas flotantes. Por último, entre las plantas exóticas con alta frecuencia de aparición estuvieron Taraxacum officinale $(n=12)$ y Poa pratensis $(n=10)$, esta última de alto valor forrajero.

Tabla 5.7: Inventario florístico de 15 mallines en el SO de la Provincia de Río Negro (septiembre diciembre de 2012). Se consigna: origen (O): Nat: nativa; End: endémica; Exot: exótica; Cos: cosmopolita; forma de vida (FV): Em: emergente; Sub: subemergente y biozona (BZ): B: bosque mixto; E: estepa patagónica.

\section{Taxa}

\section{Zygnemataceae}

Zignema sp.

Spirogyra sp.

Characeae

Nitella sp.

Bryofyta spp.

Blechnaceae

Blechnum penna-marina (Poir.) Kuhn

\section{Apiaceae}

Azorella trifurcata (Gaertn.) Pers.

Lilaeopsis macloviana (Gand.) A. W. Hill

\section{Asteraceae}

Cirsium vulgare (Savi) Ten.

Matricaria inodora L.

Matricaria recutita $\mathrm{L}$.

Taraxacum officinale Weber ex F.H. Wigg.

Xanthium spinosum $\mathrm{L}$.

\section{Brassicaceae}

Cardamine variabilis Phil.

Nasturtium officiale W.T. Aiton

\section{Callitrichaceae}

Callitriche lechleri (Hegelm.) Fassett

Callitriche truncata Guss.

$\begin{array}{ll}\text { Sub } & \text { B } \\ \text { Sub } & B / E\end{array}$

Sub B

Em B/E

Cos

Em

B

End Em $E$

Nat Sub B

Exo Em $\quad B / E$

Exo Em E

Exo Em E

Exo Em B/E

Nat Em E

End $\quad$ Em $\quad B / E$

Exo Sub E

End Sub $B / E$


Tabla 5.7: Continuación

\section{Taxa}

O

$\mathbf{F V}$

BZ

Campanulaceae

Lobelia oligophylla (Wedd.) Lammers

Nat

Em

E

Caryophyllaceae

Arenaria serpens Kunth

Nat

Em

B

Cyperaceae

Carex aematorrhyncha (Phil.) Kük.

Carex distenta Kunze ex Kunth

End

Em

B

Carex excelsa Poepp. ex Kunth

Nat

Em B

Carex gayana E. Desv.

Nat

Em B

Carex niederleiniana Boeck.

Nat

Em

B/E

Carex subantarctica Speg.

End

Em

B

Eleocharis macrostachya Britton

Nat

Em

$B / E$

Eleocharis melanomphala C.B. Clarke

Eleocharis melanostachys (d'Urv.) C.B. Clarke

Nat

Em

B

Eleocharis pachycarpa E. Desv.

Nat

Em

B/E

Eleocharis pseudoalbibracteata S. González y Guagl.

End

Em

B

Schoenoplectus californicus (C.A. Mey.) Soják

End

Em

$B / E$

Nat

Em

$B / E$

Schoenus rhynchosporoides (Steud.) Kük.

Nat

Em

B

Uncinia phleoides (Cav.) Pers.

End

Em

B

Fabaceae

Medicago lupulina $\mathrm{L}$.

Nat

Em

B

Trifolium repens $\mathrm{L}$.

Exo

Em

E

Geraniaceae

Erodium cicutarium (L.) L'Hér. ex Aiton

Exo

Em

B/E

Haloragaceae

Myriophyllum quitense Kunth

Exo

Em

B/E

Juncaceae

Juncus balticus Willd.

Nat

Sub

$B / E$

Juncus bufonius L.

Nat

Em

B/E

Juncus burkartii Barros

Nat

Em

B

End

Em

B

Juncus diemii Barros

End

Em

B

Juncus effusus $\mathrm{L}$.

Nat

Em

B

Juncus lesueurii Bol.

Nat

Em

B

Juncus pallescens Lam.

Nat

$\mathrm{Em}$

B/E

Juncus sp.

Em

B

Juncus stipulatus Nees

Nat

Em

B

Juncaginaceae

Triglochin palustris L.

Nat

Em

E 


\section{Lamiaceae}

Prunella vulgaris L.

Mentha aquatica L.

Plantaginaceae

Plantago lanceolata L.

Plantago major L.

\section{Poaceae}

Agrostis stolonifera $\mathrm{L}$.

Alopecurus pratensis L.

Bromus unilionioides Kunth

Distichlis australis (Speg.) Villamil

Distichlis spicata (L.) Greene

Glyceria multiflora Steud.

Festuca pallescens (St.-Yves) Parodi

Holcus lanatus L.

Hordeum comosum J. Presl

Pappostipa speciosa (Trin. \& Rupr.) Romasch.

Poa lanuginosa Poir.

Poa pratensis $\mathrm{L}$.

\section{Polygonaceae}

Rumex acetosella L.

Rumex crispus L.

\section{Potamogetonaceae}

Potamogeton linguatus Hagstr.

Stuckenia striata (Ruiz y Pav.) Holub

\section{Ranunculaceae}

Caltha appendiculata Pers.

Halerpestes cymbalaria (Pursh) Greene

Ranunculus hydrophilus Gaudich.

Ranunculus peduncularis Sm.

\section{Rosaceae}

Acaena splendens Hook. \& Arn.

Acaena magellanica (Lam.) Vahl

Potentilla anserina $\mathrm{L}$.

\section{Scrophulariaceae}

Mimulus glabratus Kunth

Veronica anagallis-aquatica $\mathrm{L}$.

Verbascum thapsus L.

$\begin{array}{lll}\text { Exo } & \text { Em } & B \\ \text { Exo } & \text { Em } & B\end{array}$

Exo

Em

B/E

Exo

Em

$B / E$

Exo

Em

E

Exo

Em

B/E

Nat

$\mathrm{Em}$

B

End

Em

E

Nat

Em

E

Nat

$\mathrm{Em}$

B

End

Em

$B / E$

Exo

Em

B/E

Nat

Em

$\mathrm{E}$

Nat

Em

$B / E$

Nat

Em

$B / E$

Exo

Em

B/E

Exo

Em

$B / E$

Exo

Em

B/E

End

$\mathrm{Fl}-\mathrm{H}$

B

Nat

Sub

B

End

Em

$B / E$

Nat

Em

B/E

End

Em

B

End

Em

B

End $\quad \mathrm{Em} \quad \mathrm{B} / \mathrm{E}$

Nat Em B/E

Exo

$\mathrm{Em}$

$B / E$

Nat

Em

E

Nat Sub

$B / E$

Exo

$B / E$ 
El análisis de los atributos de la comunidad de macrófitos mostró una mayor riqueza específica acumulada en mallines de bosque (65), respecto de los de estepa (47). En la biozona de bosque la riqueza osciló entre 8 (Laguna Fantasma) y 39 especies (La turbina), mientras que en la estepa el rango estuvo entre 12 (Ea. Rayhuao) y 26 taxa (Ea. San Ramón) (Figura 5.20). La cobertura de macrófitas en la zona central los mallines de estepa analizados estuvo dominada básicamente por cuatro especies Juncus balticus, Carex gayana, Eleocharis pseudoalbibracteata y Myriophyllum quitense, las que en conjunto sumaron entre $78-95 \%$ de la cobertura florística total en cada sitio (Figura 5.21). En cambio en el bosque mixto la composición florística de las especies más abundantes fue más heterogénea. Las ciperáceas Eleocharis pachycarpa y E. melanostachis, junto a J.balticus constituyeron las macrófitas más comunes en estos mallines, con una cobertura máxima cercana al $45 \%$. Schoenoplectus californicus contribuyó con un poco más del $50 \%$ en $\mathrm{Km} 12$ (B8) y las exóticas Potentilla anserina y Holcus lanatus presentaron altas coberturas en los mallines urbanos, 27\% en Laguna Fantasma (B9) y $41 \%$ en $\mathrm{Km} \mathrm{5}$, respectivamente (Figura 5.21).

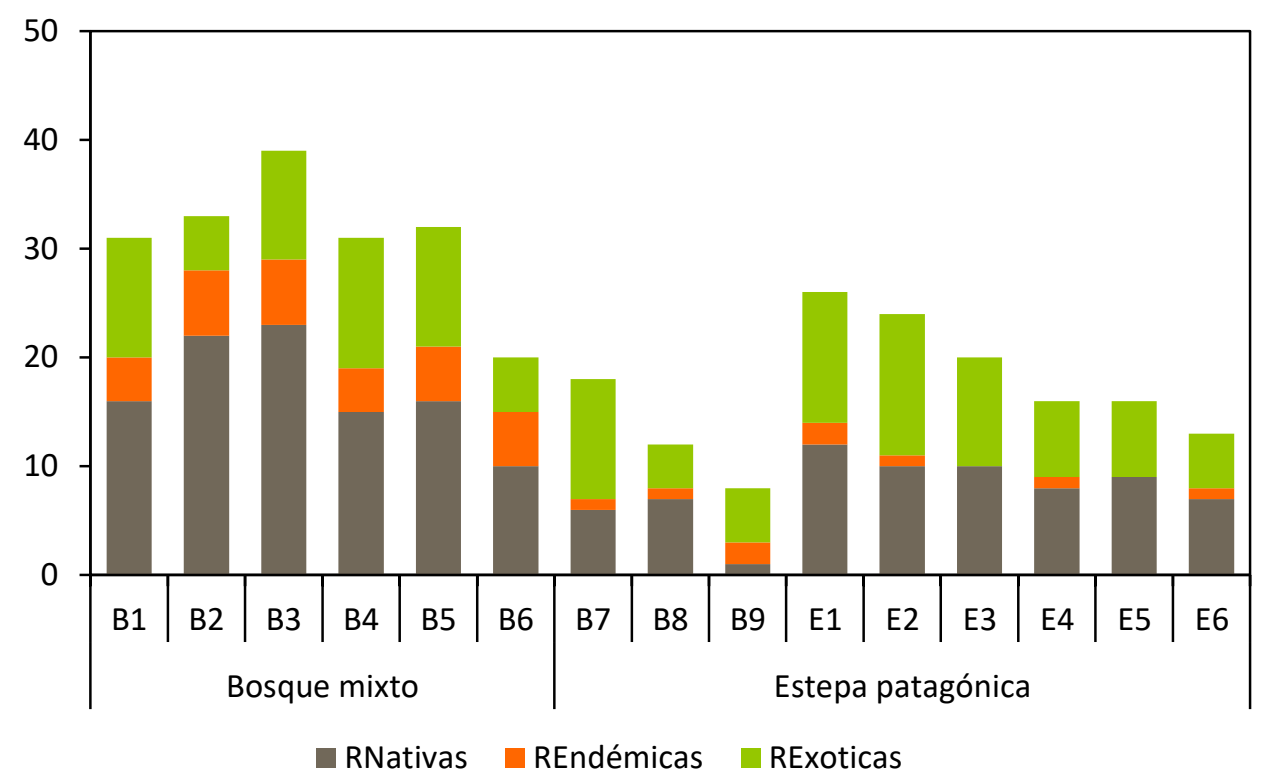

Figura 5.20: Representación de la riqueza de macrófitos de acuerdo a su origen en 15 mallines de estepa y bosque, sometidos a diferentes usos de suelo, de la Provincia de Río Negro. Códigos de sitios en tabla 5.1. 

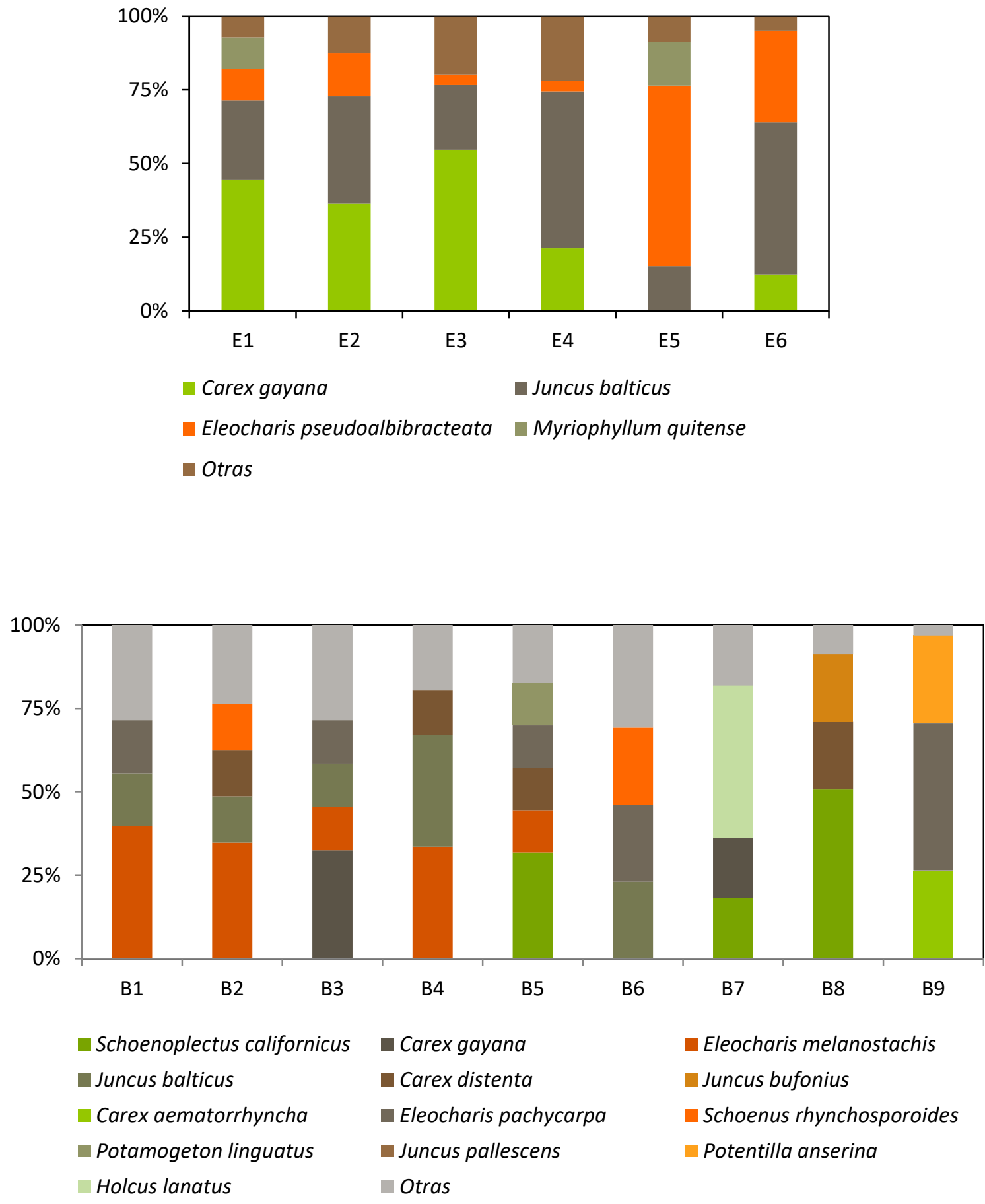

Figura 5.21: Representación de la cobertura relativa porcentual de especies de macrófitas registrados en la zona central de mallines en el SO de la Provincia de Río Negro (septiembre- diciembre de 2012). Arriba: Mallines de estepa patagónica. Abajo: Mallines de bosque mixto. 
Al agrupar los atributos que caracterizan la estructura de la comunidad de macrófitos según el uso del suelo (Tabla 5.8), se observó en la estepa patagónica que los sitios de referencia presentaron mayor riqueza específica, incluso separando la riqueza en nativas y exóticas, aunque las diferencias no fueron estadísticamente significativas (Mann-Whitney $p>0,05$ ) y, una composición de la cobertura relativa (nativa o exótica) muy similar en ambos tipos de usos. No ocurrió lo mismo al comparar entre los usos en mallines de bosque mixto, donde la riqueza específica, junto a la particular de nativas y endémicas, fue tres veces superior en los sitios de referencia respecto de los urbanos (Kruskal-Wallis, $p<0,05$ ). Los mallines de uso agrícola presentaron valores intermedios de riqueza, al compararlos con los otros usos, salvo la riqueza de exóticas que fue levemente superior, aunque la diferencia no fue significativa (Kruskal-Wallis, $p>0,05$ ). En cuanto a la composición de los tipos de cobertura, aunque se observó una disminución del aporte de nativas con el consecuente aumento de las exóticas hacia los usos de mayor distubio, las diferencias no fueron significativas (Kruskal-Wallis, $p>0,05$ ).

Tabla 5.8: Valores medios y desvío estándar de los atributos estructurales de la comunidad de macrófitos en los mallines muestreados agrupados según la biozona y el uso de suelo ( $n=3$ ) en el NO de la Provincia de Río Negro. En negrita consigna el valor significativo ( $p$-valor) según el análisis ANOVA no paramétrico de Kruskal Wallis (bosque) y Mann Whitney (estepa).

\begin{tabular}{lrrr|rrrr}
\multicolumn{3}{c}{} & \multicolumn{3}{c}{ ESTEPA PATAGONICA } & & \multicolumn{3}{c}{ BOSQUE MIXTO } \\
& Referencia & Agrícola & $\boldsymbol{p}$ & Referencia & Agrícola & Urbano & $\boldsymbol{p}$ \\
& & & & & & & \\
\hline RE & $23,33 \pm 3,06$ & $15 \pm 1,73$ & 0,1 & $\mathbf{3 4 , 3 3}$ & 27,67 & $\mathbf{1 2 , 6 7}$ & $\mathbf{0 , 0 1 4}$ \\
RN & $10,67 \pm 1,15$ & $8 \pm 1,00$ & 0,1 & $\mathbf{2 0 , 3 3}$ & 13,67 & $\mathbf{4 , 6 7}$ & $\mathbf{0 , 0 0 7}$ \\
REn & $1,00 \pm 1,00$ & $0,67 \pm 0,58$ & $>0,99$ & $\mathbf{5 , 3 3}$ & 4,67 & $\mathbf{1 , 3 3}$ & $\mathbf{0 , 0 3 3}$ \\
REx & $11,67 \pm 1,53$ & $6,33 \pm 1,15$ & 0,1 & 8,67 & 9,33 & 6,67 & 0,421 \\
\% N & $92 \pm 4$ & $93 \pm 4$ & $>0,99$ & 94 & 89 & 72 & 0,721 \\
\% Ex & $8 \pm 4$ & $7 \pm 4$ & $>0,99$ & 6 & 11 & 28 & 0,721 \\
\hline
\end{tabular}

RE: riqueza específica; RN: riqueza de nativas; RE: riqueza de endémicas; REx: riqueza de exóticas; \% N: porcentaje de cobertura de nativas; \% Ex: porcentaje de cobertura de exóticas. 


\subsection{ENSAMBLES DE MACROINVERTEBRADOS ACUÁTICOS}

\subsubsection{Composición de los ensambles}

La comunidad de macroinvertebrados acuáticos de los mallines estuvo constituida por 145 taxa correspondientes a los Phyla Cnidaria (1), Platyhelminthes (2), Annelida (16), Mollusca (6) y Arthropoda (120) (Tabla 5.9). Los taxa con mayor riqueza taxonómica fueron los Diptera (56), Coleoptera (20), Odonata (12) y Hemiptera (9) (Tabla 5.9). Particularmente dentro de Diptera, la familia Chironomidae fue la mejor representada con 33 géneros, correspondiendo al 23\% de la riqueza taxonómica total determinada en los mallines estudiados.

Tabla 5.9: Inventario de invertebrados acuáticos registrados en 15 mallines en el SO de la Provincia de Río Negro (septiembre y diciembre de 2012). Se consignan: códigos de analisis multivariados (CO); grupos funcionales asignados (GF): P: predador; CR: colector recolector; F: filtrador; Ra: raspadores; De: desmenuzadores; P-H: succionadores-herbívoros; biozona (BZ): B: bosque mixto; E: estepa patagónica; y hábitat $(\mathrm{H})$. C: columna de agua; B: bentónico.

\section{TAXA}

\section{CO $\quad$ GF $\quad$ BZ $\quad$ H}

\section{Cnidaria}

Hydrozoa

\section{Plathyhelminthes}

Hydra sp.

Hyd P B $\quad$ C

Turbellaria

Tricladida

Girardia sp.

Gir P B C

Neorhabdocoela

\begin{tabular}{lllll} 
Mesostoma ehrenbergii (Focke) & MeE & $\mathrm{P}$ & $\mathrm{B}$ & $\mathrm{C} / \mathrm{B}$ \\
\hline
\end{tabular}

\section{Annelida}

Oligochaeta

Enchytraeidae
Enchytraeidae sp.
Naididae
Chaetogaster diaphanus (Gruithuisen)
Dero sp.
Nais communis (Piguet)
Nais sp1
Nais sp2
Pristina osborni (Walton)
Stephensoniana sp.

$\begin{array}{cccc}\text { Enc } & \text { CR } & \text { B/E } & \text { C } \\ \text { ChD } & \text { P } & \text { B/E } & \text { C/B } \\ \text { Der } & \text { CR } & \text { B/E } & \text { C/B } \\ \text { NaC } & \text { CR } & \text { B/E } & \text { C/B } \\ \text { Na1 } & \text { CR } & \text { B/E } & \text { C/B } \\ \text { Na2 } & \text { CR } & \text { E } & \text { C } \\ \text { PrO } & \text { CR } & \text { B/E } & \text { C/B } \\ \text { Ste } & \text { CR } & \text { B } & \text { C }\end{array}$




\section{TAXA}

Naidiae

Aulodrilus limnobius (Bretscher)

Limnodrilus hoffmeisteri (Claparede)

Tubifex tubifex (Müller)

Lumbriculidae

Lumbriculus variegatus (Muller)

Hirudinea

Glossiphoniidae

Helobdella hyallina (Ringuelet)

Helobdella michaelseni (Blanchard)

Helobdella simplex (Moore)

Theromyzon propinquum (Ringuelet)

\section{CO GF BZ H}

AuL CR B C/B

$\mathrm{LiH} \quad \mathrm{CR} \quad \mathrm{B} \quad \mathrm{C} / \mathrm{B}$

TUT CR B C/B

LuV CR B/E C/B

$\begin{array}{ccccc}\text { Glossiphoniidae } & & & \\ \text { Helobdella hyallina (Ringuelet) } & \text { HeH } & \text { P } & \text { B } \\ \text { Helobdella michaelseni (Blanchard) } & \text { HeM } & \text { P } & \text { B/E } & \text { C/B } \\ \text { Helobdella simplex (Moore) } & \text { HeS } & \text { P } & \text { B/E } & \text { C } \\ \text { Theromyzon propinquum (Ringuelet) } & \text { ThP } & \text { P } & \text { E } & \text { C/B }\end{array}$

\section{Mollusca}

Gastropoda

Physidae

Physa sp.

Phy $\mathrm{R}$ B $\mathrm{C}$

Lymnaeidae

Lymnaea viatrix (d'Orbigny)

LyV R B/E C/B

Chilinedae

Chilina dombeiana (Bruguiere)

CDo R B C/B

Planorbidae

Biomphalaria peregrina (d'Orbigny)

Cochliopidae

Heleobia hatcheri (Pilsbry)

BiP R B/E C/B

Hha R B C

Bivalvia

Sphaeridae

Muscullium sp.

Sph F B/E C/B

\section{Arthropoda}

\section{Crustacea}

Branchiopoda

Cladocera

Cladocera spp.

Maxillopoda

Copepoda

Copepoda spp.

Parabroteas sarsi (Mrázek)

Ostracoda

Ostracoda spp.

Cla F B/E C

Isopoda spp.

$\begin{array}{cccc}\text { Cop } & \text { F } & \text { B/E } & \text { C/B } \\ \text { PaS } & \text { P } & \text { B } & \text { C } \\ \text { Ost } & \text { F } & \text { B/E } & \text { C/B } \\ \text { Isp } & \text { CR } & \text { B } & \text { C }\end{array}$


Tabla 5.9: Continuación

\section{TAXA}

\section{CO GF BZ H}

Malacostraca

Amphipoda

Hyalella curvispina (Shoemaker) HyC $\quad$ CR $\quad$ B $\quad$ C/B

Hyalella patagonica (Cunningham) HyP $\quad$ CR $\quad$ B/E $\quad$ C

Cheliceriformes

Hydracarina spp. Hna $P$ B/E C

Oribatidae

$\begin{array}{llllll}\text { Hydrozetes sp. } & \mathrm{Hdr} & \mathrm{P} & \mathrm{B} & \mathrm{C}\end{array}$

\begin{tabular}{l} 
Hexapoda \\
$\begin{array}{l}\text { Collembola } \\
\text { Isotomidae spp. }\end{array}$ Iso CR $B / E \quad C$ \\
\hline
\end{tabular}

\begin{tabular}{|c|c|c|c|c|}
\hline \multicolumn{5}{|l|}{ Ephemeroptera } \\
\hline \multicolumn{5}{|l|}{ Baetidae } \\
\hline Andesiops peruvianus (Ulmer) & $A n P$ & $\mathrm{Ra}$ & B & $\mathrm{C}$ \\
\hline \multicolumn{5}{|l|}{ Leptophlebiidae } \\
\hline Nousia sp. & Nou & CR & B & $\mathrm{C}$ \\
\hline \multicolumn{5}{|l|}{ Odonata } \\
\hline \multicolumn{5}{|l|}{ Coenagrionidae } \\
\hline Andinagrion peterseni (Ris) & Ape & $P$ & $B / E$ & $\mathrm{C}$ \\
\hline Andinagrion sp. & And & $\mathrm{P}$ & B & C \\
\hline Cyanallagma interruptum (Selys) & Cyl & $P$ & $B / E$ & C \\
\hline Lestes undulatus Say & LeU & $P$ & B & $\mathrm{C}$ \\
\hline Oxyagrion rubidum (Rambur) & OxR & $P$ & $E$ & $\mathrm{C}$ \\
\hline \multicolumn{5}{|l|}{ Libellulidae } \\
\hline Erythrodiplax connata (Burmeister) & $\mathrm{ErC}$ & $P$ & B & $\mathrm{C}$ \\
\hline Erythrodiplax nigricans (Rambur) & ErN & $P$ & B & $\mathrm{C}$ \\
\hline Sympetrum villosum Ris & SyV & $P$ & B & $\mathrm{C}$ \\
\hline \multicolumn{5}{|l|}{ Corduliidae } \\
\hline Gomphomacromia paradoxa Brauer & GoP & $P$ & B & C \\
\hline \multicolumn{5}{|l|}{ Aeshnidae } \\
\hline Rhionaeschna absoluta (Calvert) & RhA & $P$ & B & $\mathrm{C}$ \\
\hline Rhionaeschna variegata (Fabricius) & RhV & $P$ & $B / E$ & $\mathrm{C}$ \\
\hline Rhionaeschna sp. & Rhi & $\mathrm{P}$ & $\mathrm{B} / \mathrm{E}$ & $\mathrm{C}$ \\
\hline \multicolumn{5}{|l|}{ Plecoptera } \\
\hline \multicolumn{5}{|l|}{ Notonemouridae } \\
\hline Udamocercia sp. & Uda & $\mathrm{CR}$ & B & $\mathrm{C}$ \\
\hline \multicolumn{5}{|l|}{ Grypopterygidae } \\
\hline Claudioperla tigrina (Klapálek) & CIT & $\mathrm{Ra}$ & B & $\mathrm{C}$ \\
\hline Limnoperla jaffuelli (Navás) & LiJ & $\mathrm{Ra}$ & B & $\mathrm{C}$ \\
\hline
\end{tabular}




\section{TAXA}

CO GF BZ H

Hemiptera

Notonectidae

Notonecta vereertbruggheni Hungerford

$\begin{array}{llll}\text { Nvi } & P & B / E & C \\ \text { NoV } & P & B / E & C\end{array}$

Notonecta virescens Blanchard

Corixidae

Ectemnostega (Ectemnostega) quadrata

(Signoret)

EcQ S-H B/E C

Sigara (Tropocorixa) santiagiensis (Hungerford)

SiS S-H B/E C

Trichocorixa sp.

Tri S-H B $\quad$ C

Hydrometridae

Hydrometra argentina Berg.

HyA P B C

Mesoveliidae

Mesovelia mulsanti White

MeM P B C

Belostomatidae

Belostoma bifoveolatum Spinola

BeB P B/E C

Saldidae

Saldula sp.

Sal $\quad \mathrm{P} \quad \mathrm{B} / \mathrm{E} \quad \mathrm{C}$

\section{Coleoptera}

Dytiscidae

Desmopachria punctatissima (Zimmermann)

Laccophilus sp.

Laccornellus lugubris (Aube)

Lancetes sp1

Lancetes sp2

Liodessus patagonicus (Zimmermann)

Rhantus antarcticus (Trémouilles)

Rhantus signatus (Fabricius)

Haliplidae

Haliplus subseriatus (Zimmermann)

Hydrophilidae

Berosus chalcocephalus

Enochrus sp.

Paracymus sp.

Tropisternus setiger (Germar)*

$\begin{array}{cccc}\text { DeP } & \mathrm{P} & \mathrm{B} / \mathrm{E} & \mathrm{C} \\ \text { Lac } & \mathrm{P} & \mathrm{B} & \mathrm{C} \\ \text { LaL } & \mathrm{P} & \mathrm{B} / \mathrm{E} & \mathrm{C} \\ \text { La1 } & \mathrm{P} & \mathrm{B} / \mathrm{E} & \mathrm{C} \\ \text { La2 } & \mathrm{P} & \mathrm{B} / \mathrm{E} & \mathrm{C} \\ \text { LiP } & \mathrm{P} & \mathrm{B} / \mathrm{E} & \mathrm{C} \\ \text { Rhn } & \mathrm{P} & \mathrm{B} / \mathrm{E} & \mathrm{C} \\ \text { RhS } & \mathrm{P} & \mathrm{B} / \mathrm{E} & \mathrm{C} \\ & & & \\ \text { HaS } & \mathrm{S}-\mathrm{H} & \mathrm{B} / \mathrm{E} & \mathrm{C} \\ & & & \\ \text { Ver } & \mathrm{CR} & \mathrm{E} & \mathrm{C} \\ \text { Eno } & \mathrm{CR} & \mathrm{B} / \mathrm{E} & \mathrm{C} \\ \text { Par } & \mathrm{CR} & \mathrm{B} & \mathrm{C} \\ \text { TrS } & \mathrm{CR} & \mathrm{B} / \mathrm{E} & \mathrm{C} \\ & & & \\ \text { Gym } & \mathrm{Ra} & \mathrm{B} / \mathrm{E} & \mathrm{C} \\ & & & \\ \text { Cyp } & \mathrm{Ra} & \mathrm{B} & \mathrm{C} \\ \text { Pri } & \mathrm{Ra} & \mathrm{B} & \mathrm{C} \\ & & & \\ \text { Het } & \mathrm{P} & \mathrm{B} & \mathrm{C}\end{array}$

Heterocerus sp. 


\section{TAXA}

Carabidae

Carabidae sp.

Staphylinidae

Thinobius sp.

Curculionidae

Curculionidae sp.

Diptera

Ceratopogonidae

Bezzia sp.

Culicoides sp.

Dasyhelea sp.

Chironomidae

Chironominae

Chironomus sp.

Parachironomus sp.

Paratanytarsus sp.

Paratendipes sp.

Polypedilum sp.

Rheotanytarsus sp.

Riethia sp.

Tanytarsus sp.

Orthocladinae

Botryocladius sp.1

Botryocladius sp.2

Bryophaenocladius sp.

Corynoneura sp1

Corynoneura sp2

Cricotopus sp1

Cricotopus sp2

Cricotopus sp3

Diploclaudius sp.

Eukiefferiella sp.

Limnophyes sp1

Limnophyes sp2

Orthocladinii sp.

Parapsectrocladius sp.

Paratrichoclaudius sp1

Paratrichoclaudius sp2

Pseudosmittia sp.
CO GF BZ H

$\begin{array}{cccc}\text { Car } & \text { P } & \text { B } & \text { C } \\ \text { Thi } & \text { P } & \text { B } & \text { C } \\ \text { Cur } & \text { S-H } & \text { E } & \text { C }\end{array}$

$\begin{array}{cccc}\text { Bez } & \mathrm{P} & \mathrm{B} & \mathrm{C} \\ \text { Cul } & \mathrm{P} & \mathrm{B} & \mathrm{C} \\ \text { Das } & \mathrm{P} & \mathrm{B} / \mathrm{E} & \mathrm{C} / \mathrm{B}\end{array}$

Chi CR B/E C

Pah CR B/E C/B

Pat $C R \quad E \quad C$

Pdi CR B C

Pol CR B/E C

Rhe $F$ E $C$

Rie $C R \quad B \quad C / B$

Tan $F \quad B / E \quad C / B$

Bor CR B C

Bor CR B C

Bry CR B C

Co1 CR E C

$\mathrm{Co} 2 \mathrm{CR}$ B $\mathrm{C}$

Cr1 CR B/E C

$\mathrm{Cr} 2 \quad \mathrm{CR} \quad \mathrm{B} / \mathrm{E} \quad \mathrm{C}$

$\mathrm{Cr} 3 \quad \mathrm{CR} \quad \mathrm{B} \quad \mathrm{C}$

Dip CR B C

Euk $C R \quad B / E \quad C$

Li1 CR B/E C/B

Li2 CR B/E C

Ort CR B/E C

Pap CR B/E C

Pa1 CR B C

Pa2 CR E C/B

Pse CR B/E $C$ 
Tabla 5.9: Continuación

\section{TAXA}

Podonominae

Podonomus sp1

Podonomus sp2

Parochlus sp.

Tanypodynae

Ablabesmyia sp.

Alotanypus sp.

Apsectrotanypus sp.

Labrundinia sp.

Larsia sp.

Culicidae

Ochlerotatus albifasciatus

Dixidae

Dixidae sp.

Dolichopodidae

Dolichopodidae sp.

Empididae

Empididae sp1

Empididae sp2

Ephydridae

Ephydridae sp1

Ephydridae sp2

Ephydridae sp3

Muscidae

Muscidae sp.

Psychodidae

Psychodidae sp.

Sarcophagidae

Sarcophagidae sp.

Sciomyzidae

Sciomyzidae sp1

Sciomyzidae sp2

Tabanidae

Tabanus sp.

Tipulidae

Tipulidae sp.

Simulidae

Gigantodax antarcticus (Bigot)

Gigantodax brophyi (Edward)

Gigantodax marginalis (Edward)

Gigantodax sp.

Simulium sp.

\section{CO GF BZ H}

$\begin{array}{cccc}\text { Po1 } & \text { CR } & \text { B/E } & \text { C } \\ \text { Po2 } & \text { CR } & \text { B/E } & \text { C } \\ \text { Pch } & \text { CR } & \text { B } & C\end{array}$

Abl P B/E C/B

Alo $P \quad B / E \quad C / B$

Aps $P$ B $C$

Lab P B/E C

Lar $\mathrm{P} \quad \mathrm{B} / \mathrm{E} \quad \mathrm{C}$

Aed $F \quad B \quad C$

Dix $\quad P \quad B \quad C$

Dol CR B/E C

Em1 P B C/B

Em2 $P$ E $C$

Ep1 CR B/E C

Ep2 CR B C

Ep3 CR B/E C

Mus $P \quad B / E \quad C$

Psy CR B C

Sar CR B C

Sc1 $\mathrm{P} \quad \mathrm{B} / \mathrm{E} \quad \mathrm{C}$

Sc2 $P$ B $\quad$ C/B

Tab P E C

Tip $\mathrm{P} \quad \mathrm{B} / \mathrm{E} \quad \mathrm{C}$

GiM $F \quad B \quad C$

GiB $F \quad B \quad C$

GiA $F \quad B \quad C$

Gig $F \quad B \quad C$

Sim $F \quad B \quad C$


Tabla 5.9: Continuación

\section{TAXA}

$\begin{array}{llll}\text { CO } & \text { GF } & \text { BZ } & \text { H }\end{array}$

Trichoptera

Polycentropodidae

Polycentropus $s p$.

Limnephilidae

Verger limnophilus (Schmid)

Verger sp.

Leptoceridae

Brachisetodes sp.

Sericostomidae

Parasericostoma ovale (Schmid)

Hydroptilidae

Metrichia neotropicalis (Schmid)

Oxyethira bidentata (Mosely)

Lepidoptera

Crambidae

Crambinae sp.

$\begin{array}{lll}\text { Cra Ra B } & \text { C }\end{array}$

\subsubsection{Descripción de los taxa}

El Phylum Platyhelminthes se caracterizó por la presencia de dos especies Girardia sp. y Mesostoma ehrenbergii únicamente en mallines de bosque. Esté ultimo llegó a presentar una densidad media de 100 ind. $\mathrm{m}^{-3}$ en la Laguna Fantasma, aunque la biomasa de ambas fue poco representativa.

Dentro del Phylum Annelida, Oligochaeta con 12 taxa, tuvo una destacada representación en los mallines de las dos biozonas. Lumbriculus variegatus y Chaetogaster diaphanus (Figura 5.22) fueron las especies con mayor frecuencia, detectando su presencia en 9 y 12 mallines respectivamente. Aunque $C$. diaphanus fue el único oligoqueto en superar valores medios de 200 ind. $\mathrm{m}^{-3}$, L. variegatus junto a Limnodrilus hoffmeisteri fueron las especies con mayor contribución a la biomasa seca de los oligoquetos, con valores, en algunos casos, superiores a 150 $\mathrm{mg} \cdot \mathrm{m}^{-3}$. En cuanto a Hirudinea, solo cuatro especies estuvieron presentes y de ellas, 
Helobdella michaelseni y $\mathrm{H}$. simplex, fueron las más frecuentes, aunque con bajos valores de densidad.

El Phylum Mollusca estuvo representado por seis especies, de las cuales Lymnaea viatrix y Biomphalaria peregrina (ambas Gastropoda) junto a Muscullium sp. (Bivalvia) fueron las más frecuentes en mallines distribuidos en ambas biozonas. Las dos primeras superaron valores de densidad media de 100 ind. $\mathrm{m}^{-3}$ y fueron, junto a Chilina dombeiana y Physa sp. (Figura 5.22), las de mayor contribución al peso seco, con valores medios, en algunos casos, mayores a $500 \mathrm{mg} \cdot \mathrm{m}^{-3}$.

Crustacea constituyó uno de los taxa con mayor contribución en términos de densidad, tanto en mallines de estepa como de bosque. En los humedales de estepa los ensambles estuvieron representados por una alta frecuencia y abundancia de Cladocera, Ostracoda y Copepoda, con una densidad media de hasta 1000 ind. $\mathrm{m}^{-3}$, sin embargo dadas sus pequeñas tallas, su aporte a la biomasa fue bajo. En cambio en los mallines de bosque, prevalecieron ensambles con mayor participación en densidad de Hyalella curvispina, H. patagonica y Parabroteas sarsi (Figura 5.22), este último mostró un pico de abundancia en la Laguna Fantasma durante el muestreo de primavera (3120 ind. $\mathrm{m}^{-3}$ ). Las mayores tallas de estas especies, junto con su alta densidad, contribuyeron con más de 30\% de la biomasa seca en mallines de bosque.

Dentro de los insectos, Diptera constituyó el orden con mayor aporte a la riqueza y densidad de los ensambles de invertebrados en ambas biozonas. Tres taxones fueron los más frecuentes Tanytarsus sp. ( $n=13)$, Alotanypus sp. $(n=11)$ y Limnophyes sp.1 ( $n=10)$, todos de la familia Chironomidae. En los mallines de estepa 30 taxones representaron a este orden, sobresaliendo Paratrichoclaudius sp.2 (Chironomidae) como taxón exclusivo de esta región y con altos valores de densidad cercanos a 1500 ind. $\mathrm{m}^{-3}$. En cambio en el bosque, la riqueza fue mayor con 50 taxones, de los cuales se destacaron por su mayor densidad, los quironómidos Parapsectrocladius sp. y Paratrichoclaudius sp.1, junto a los simúlidos Gigantodax marginalis y $G$. antarcticus, estos últimos solo en aquellos mallines con aguas corrientes como La Turbina, Ea. Berenbrijen y Muelle viejo. La contribución relativa 
en biomasa de los dípteros no fue importante y sólo representó porcentajes menores al $10 \%$ del peso seco en ambas biozonas

El orden Odonata estuvo muy bien representado con un total de 12 taxa identificados. Si bien la densidad de este orden fue baja, se destacaron particularmente Erythrodiplax connata y Rhionaeschna variegata (Figura 5.22) por presentar valores medios superiores a 60 ind.m-3, aunque la mayoría de esos individuos se encontraron en sus primeros estadios larvales. En cuanto a la biomasa seca, su contribución fue mayor que la densidad, debido a que las náyades de Cyanallagma interruptum y sobre todo los últimos estadios de Rhionaeschna spp. son relativamente más grandes que otros invertebrados.

Otro orden muy representativo de los mallines fue Hemiptera con nueve taxa. Notonecta virescens (Notonectidae) (Figura 5.22) y Sigara santiagiensis (Corixidae) fueron las especies registradas con mayor frecuencia, detectándose en seis mallines en ambas biozonas, aunque la mayor densidad media se registró en la estepa con 170 ind. $\mathrm{m}^{-3}$ y 130 ind. $\mathrm{m}^{-3}$ respectivamente. En tanto en términos de biomasa seca, además de las especies anteriores, se destacó, por su mayor tamaño, Belostoma bifoveolatum (Figura 5.22) principalmente en mallines de bosque.

El orden Coleoptera fue uno de los más diversos, con 20 taxa, sin embargo en ninguno de los ambientes registraron valores considerables que contribuyeran en densidad o biomasa seca, salvo Tropisternus setiger (Figura 5.22) que, en el mallín Ea. San Ramón, presentó valores medios superiores a los $100 \mathrm{mg} \cdot \mathrm{m}^{-3}$. Esta última especie junto a aquellas del género Lancetes (Figura 5.22), fueron las más frecuentes, apareciendo en diez y nueve mallines respectivamente.

Finalmente otro orden destacado, principalmente en los mallines de bosque fue Trichoptera. Si bien, se registraron siete taxa, sólo aquellos del género Verger (Figura 5.22), exclusivos en la biozona de bosque, representaron importantes aportes a la densidad y biomasa seca, por sus grandes tallas. Así, de este género, en la Laguna Fantasma, se registraron valores medios de abundancia mayores a 400 ind. $\mathrm{m}^{-3}$ con un aporte de biomasa medias de casi $2000 \mathrm{mg} \cdot \mathrm{m}^{-3}$. 


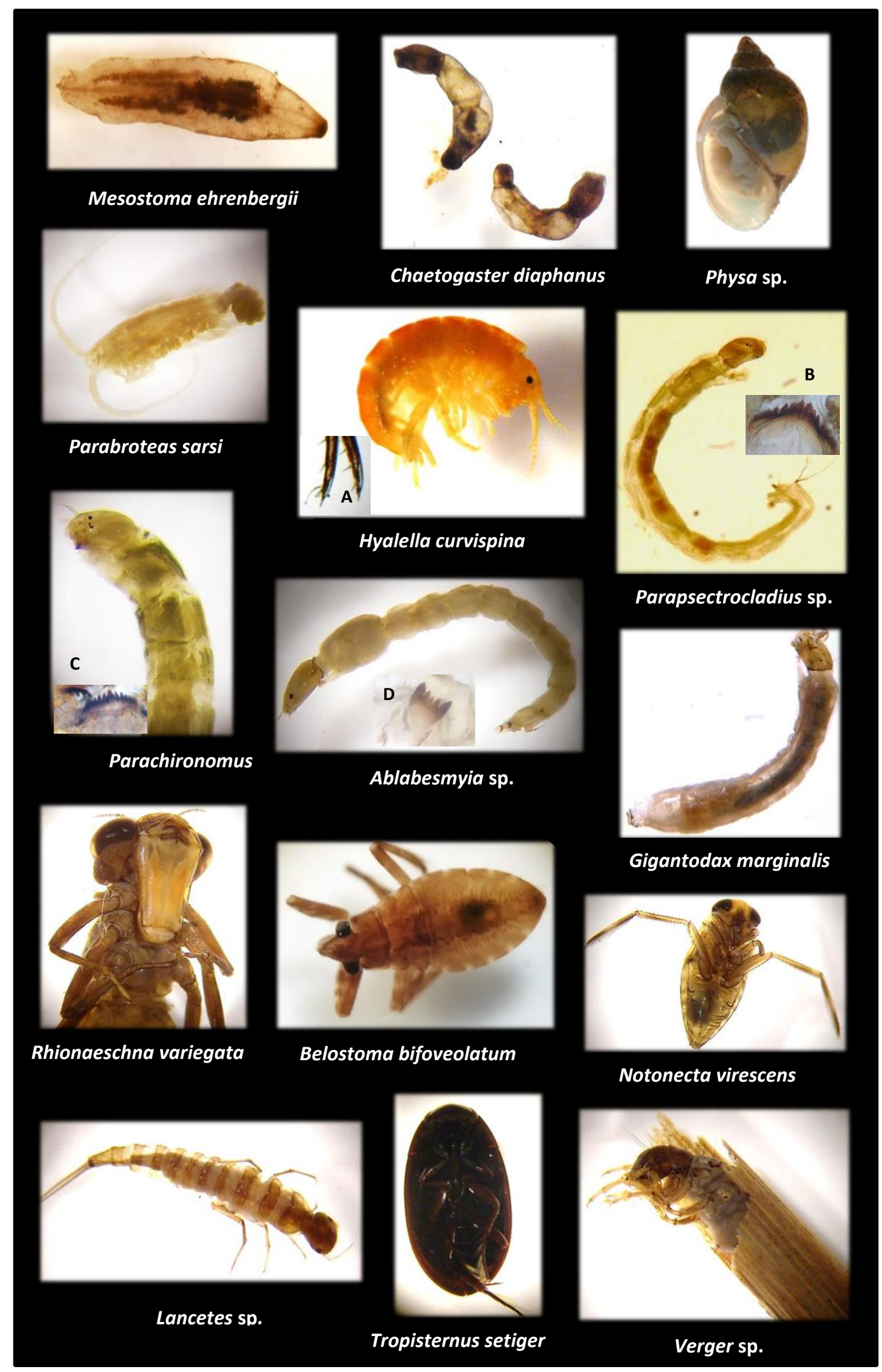

Figura 5.22: Fotografías obtenidas con un estereomicroscopio de taxa de invertebrados acuáticos colectados en mallines en el SO de la Provincia de Río Negro (septiembre y diciembre 2012). Fotografías bajo microscopio óptico. Letras blancas: nombre científico. Letras negras: A: uropodo con espina curva; B y C: mentón; D: lígula. 


\subsubsection{Invertebrados acuáticos de la columna de agua}

\subsubsection{Atributos estructurales de los ensambles}

En el análisis de la estructura comunitaria (Tabla 5.10), la riqueza taxonómica acumulada de cada humedal mostró valores mínimos en las estancias Pilcañeu y Rayhuao con 17 y 20 taxa respectivamente y máximos en los mallines Ea. Vereertbrugghen y La Turbina con 48 y 56 taxa respectivamente.

Tabla 5.10: Valores de atributos comunitarios de invertebrados acuáticos de columna de agua $(n=6)$ : Riqueza taxonómica acumulada, densidad, biomasa seca, diversidad de Shannon-Wiener $\left(\mathrm{H}^{\prime}\right)$ y equitatividad de Pielou en 15 mallines de estepa y bosque, ubicados en el SO de la Provincia de Río Negro en dos momentos de muestreo (septiembre y diciembre de 2012). Uso del suelo R: referencia; A: agrícola; U: urbano.

\begin{tabular}{|c|c|c|c|c|c|c|c|c|}
\hline & & $\begin{array}{l}\circ \\
\text { 웅 } \\
\frac{8}{0}\end{array}$ & 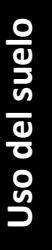 & 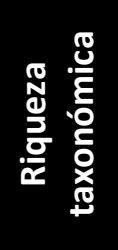 & 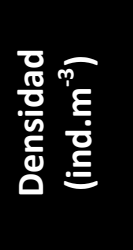 & 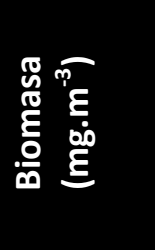 & 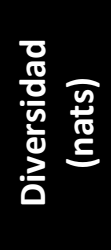 & 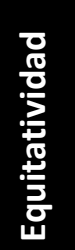 \\
\hline \multirow{6}{*}{ 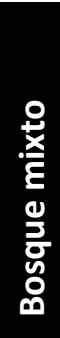 } & Vereertbrugghen & B1 & $\mathrm{R}$ & 48 & 1925 & 481,36 & 2,45 & 0,63 \\
\hline & Muelle viejo & B2 & $\mathrm{R}$ & 44 & 1516 & 689,31 & 2,29 & 0,61 \\
\hline & La Turbina & B3 & $\mathrm{R}$ & 56 & 896 & 482,15 & 2,91 & 0,72 \\
\hline & Playa Negra & B4 & A & 47 & 1603 & 417,86 & 2,64 & 0,69 \\
\hline & Cretón & B5 & $A$ & 37 & 559 & 662,62 & 2,79 & 0,77 \\
\hline & Lag. Pampa Linda & B6 & A & 38 & 299 & 254,29 & 2,49 & 0,68 \\
\hline \multirow{9}{*}{ 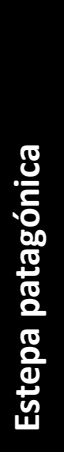 } & $\mathrm{Km} 5$ & B7 & $U$ & 30 & 364 & 197,6 & 2,45 & 0,72 \\
\hline & Km 12 & B8 & $U$ & 36 & 484 & 67,13 & 2,52 & 0,70 \\
\hline & Lag. Fantasma & B9 & $U$ & 32 & 2345 & 2646,65 & 1,44 & 0,42 \\
\hline & Ea. San Ramón & E1 & $\mathrm{R}$ & 44 & 1442 & 572,15 & 2,39 & 0,63 \\
\hline & Ea. El Cóndor & E2 & $\mathrm{R}$ & 26 & 323 & 55,43 & 2,36 & 0,72 \\
\hline & Ea. Pto. Moreno & E3 & $\mathrm{R}$ & 26 & 268 & 46,29 & 1,76 & 0,54 \\
\hline & Ea. Domínguez & E4 & $A$ & 33 & 656 & 159,92 & 2,1 & 0,60 \\
\hline & Ea. Pilcañeu & E5 & $A$ & 17 & 810 & 238,56 & 1,8 & 0,64 \\
\hline & Ea. Rayhuao & E6 & A & 20 & 1528 & 96,96 & 1,51 & 0,50 \\
\hline
\end{tabular}


La densidad media de los ensambles de invertebrados acuáticos, hallados en muestras procedentes de la columna de agua, osciló entre 268 ind. $\mathrm{m}^{-3}$ (Ea. Perito Moreno) y 2345 ind. $\mathrm{m}^{-3}$ (Laguna Fantasma) (Tabla 5.10). En tanto, en relación a la biomasa media, los valores extremos coincidieron con los sitios anteriores, así la menor biomasa, con 46,29 mg.m ${ }^{-3}$, correspondió la Ea. Perito Moreno y la más alta, con $2646,65 \mathrm{mg} \cdot \mathrm{m}^{-3}$, a la Laguna Fantasma. Sin embargo en el resto de los mallines ( $n=14$ ) el peso seco fue menor a $700 \mathrm{mg} \cdot \mathrm{m}^{-3}$. La elevada densidad y biomasa en la Laguna Fantasma se debió principalmente a la notable abundancia de Parabroteas sarsi y en menor medida, a tricópteros del género Verger, principalmente durante el muestreo de comienzos de la primavera (Tabla 5.10).

Por último, la diversidad acumulada, medida mediante el índice de ShannonWiener, estuvo comprendida entre 1,44 nats en Laguna Fantasma y 2,91 nats en La Turbina y la equitatividad, de acuerdo al índice de Pielou (J), varió entre 0,41 , en Laguna Fantasma y, 0,77 en el mallín Cretón.

\subsubsection{Atributos estructurales por biozona}

Al agrupar a los mallines según biozona, el bosque mixto mostró mayor riqueza taxonómica (134), con 44\% (64) de taxa exclusivos de la región. En cambio, en la estepa patagónica la comunidad estuvo representada por 79 taxa, con sólo 8\% de exclusivos (11). Finalmente, cerca del $48 \%$ (70) de los taxa fueron compartidos entre ambas biozonas (Figura 5.23). 


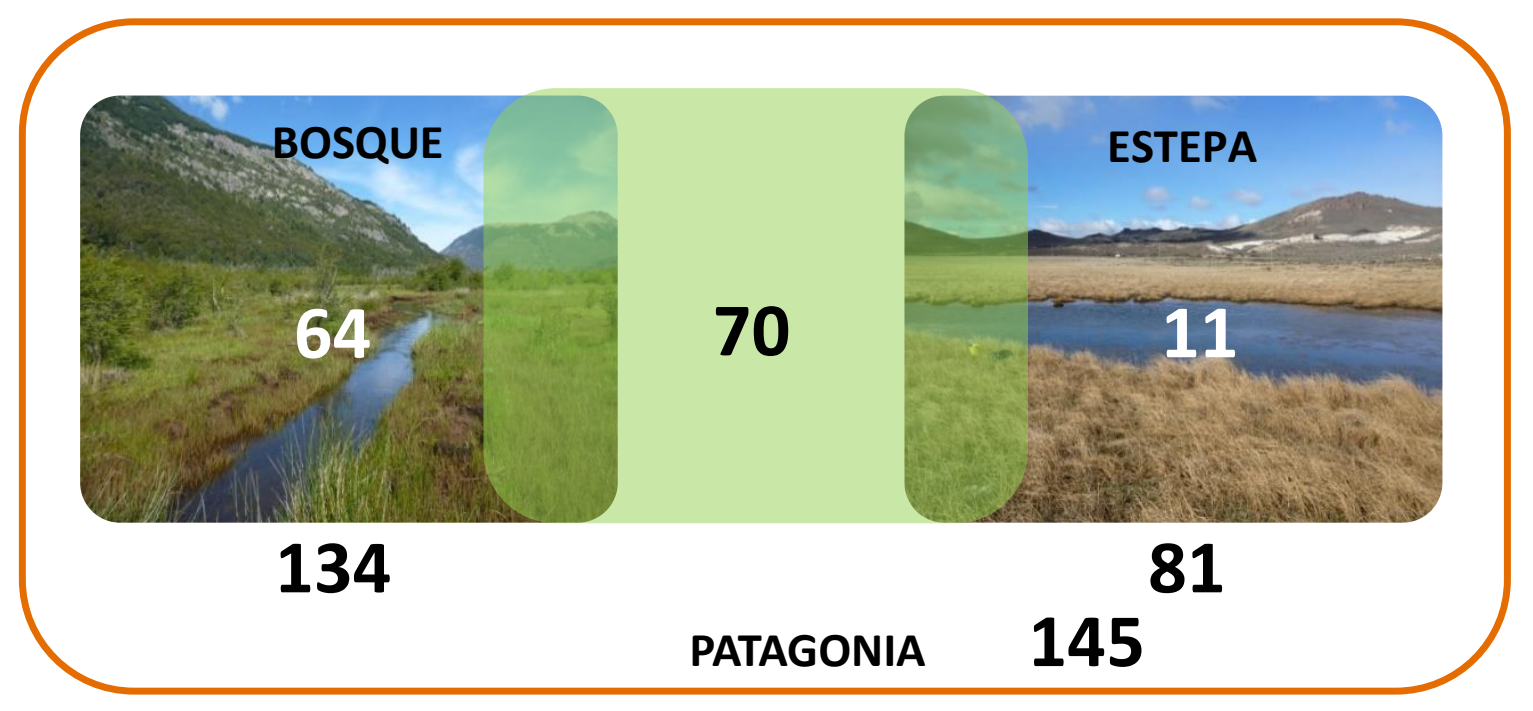

Figura 5.23: Riqueza taxonómica de invertebrados acuáticos (de la columna de agua) por biozona (números blancos indican taxa exclusivos, números en negro riqueza total), los taxa compartidos entre los mismos (cuadrado verde). Muestras tomadas en 15 mallines $(n=190)$ en el so de la Provincia de Río Negro (septiembre y diciembre de 2012).

Los mallines de bosque presentaron una riqueza taxonómica más alta (43) y significativamente superior que los de estepa (25) (Mann-Whitney $p=0,018$ ) (Figura 5.24). En los primeros la riqueza acumulada estuvo comprendida entre 30 ( $\mathrm{Km} \mathrm{5}$ ) y 56 taxa (La Turbina), en cambio en los segundos, los valores oscilaron entre 17 (Ea. Pilcañeu) y 44 taxa (Ea. El Cóndor). No se observaron diferencias significativas entre los valores de densidad (Mann-Whitney $p=0,407$ ), sin embargo la biomasa fue 3,7 veces superior, en los mallines de bosque respecto de la estepa (Mann-Whitney $\mathrm{p}=0,001$ ) (Figura 5.24). Por último, los mallines de bosque presentaron una diversidad acumulada más alta (3,59 nats) respecto a los de estepa (2,62 nats) (Figura 5.24).

Crustacea y Diptera fueron los dos taxa que explicaron $80 \%$ de la abundancia relativa en ambas biozonas (Figura 5.25). 

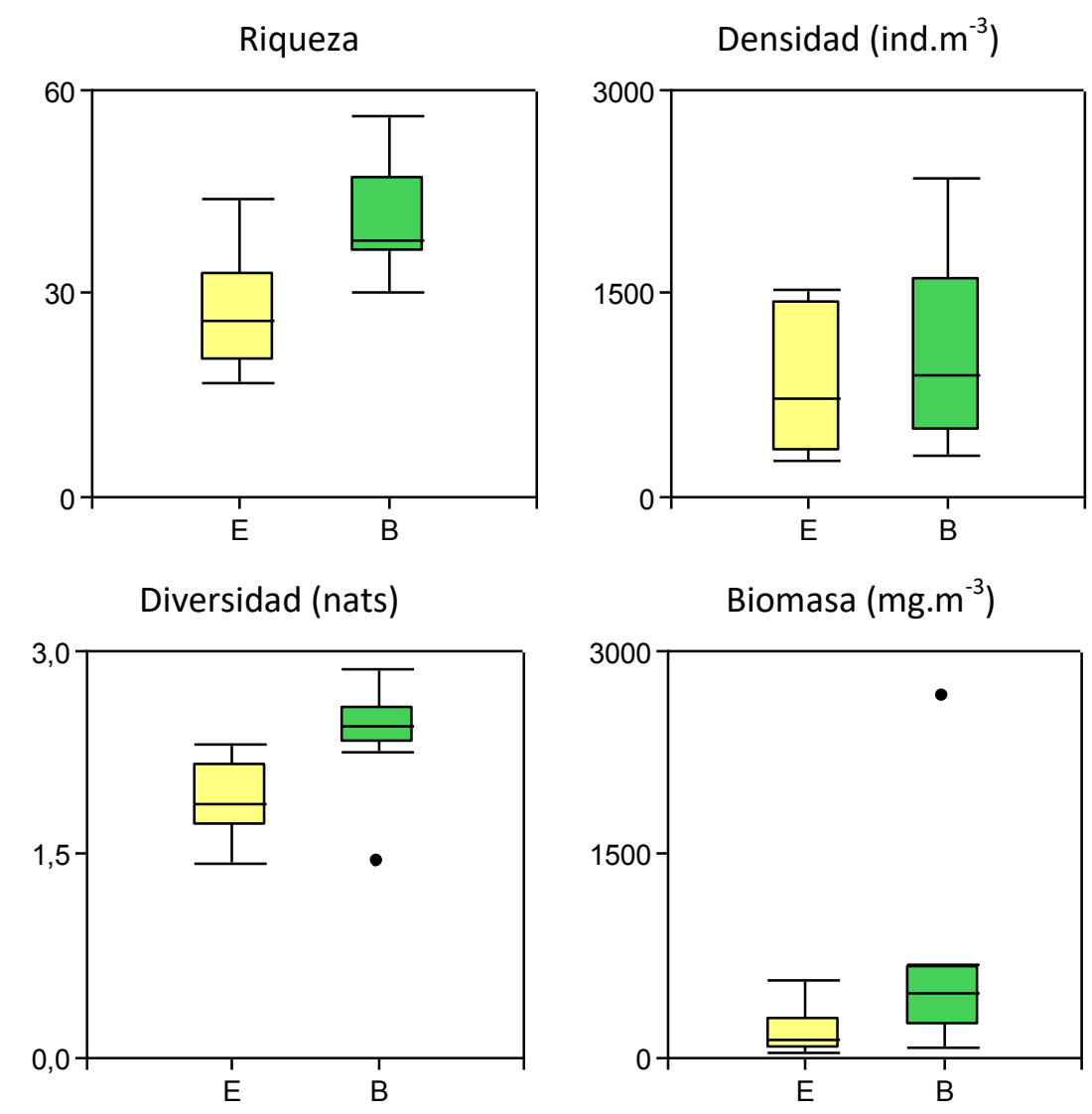

Figura 5.24: Distribución de los principales atributos comunitarios de invertebrados acuáticos según biozona, seis mallines de estepa, cajas amarillas $(n=12)$ y nueve mallines de bosque, cajas verdes ( $n=18$ ) en el SO de la Provincia de Río Negro (septiembre y diciembre de 2012). Cajas intercuartiles (25-75\%), línea: mediana, barras: máximos y mínimos, puntos negros valores extremos.

En mallines de bosque mixto, los dípteros, particularmente de la familia Chironomidae, fueron los de mayor representación (47\%), luego estuvieron los crustáceos (33 \%) por la presencia de Hyalella curvispina, H. patagonica y Parabroteas sarsi y finalmente, entre los más destacados pero con baja abundancia relativa, siguieron los anélidos y los tricópteros (ambos $6 \%$ ). En cambio en la estepa patagónica, los crustáceos fueron dominantes (60 \%) debido a la alta contribución de ostrácodos y copépodos. Luego los dípteros (22\%), donde también se destacaron diversos taxa de quironómidos y finalmente, aunque con baja contribución, estuvieron los heterópteros y los anélidos (ambos 6 \%). 
Abundancia

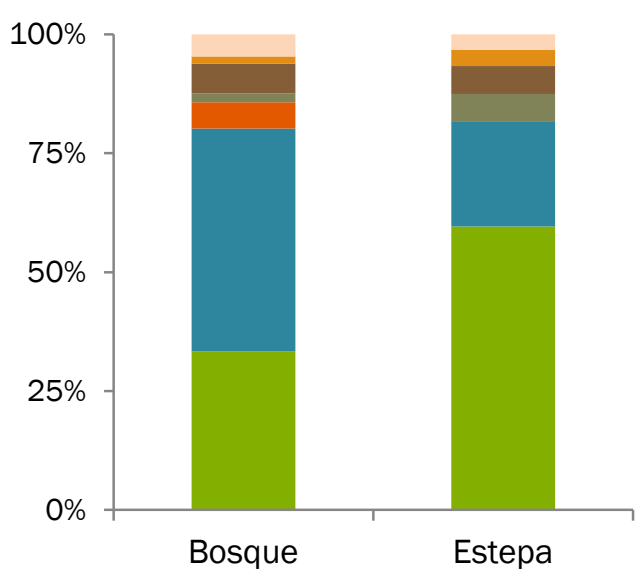

Biomasa

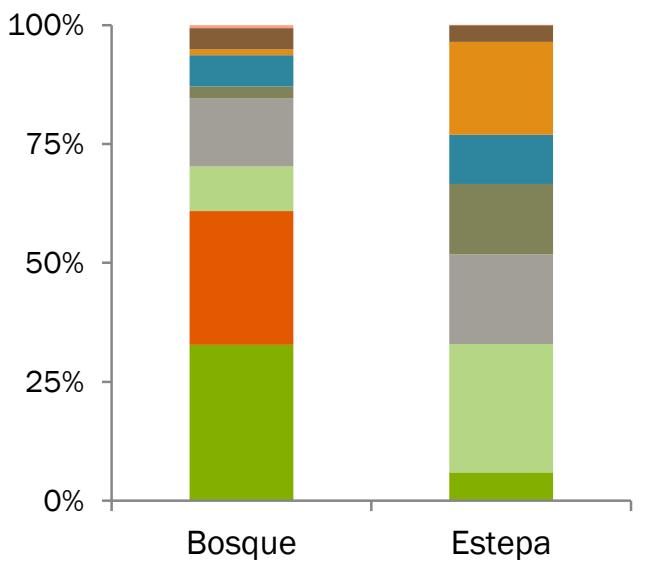

$\begin{array}{lll}\square \text { Crustacea } & \square \text { Trichoptera } & \square \text { Odonata } \\ \square \text { Mollusca } & \square \text { Heteroptera } & \square \text { Diptera } \\ \square \text { Coleoptera } & \square \text { Annelida } & \square \text { Otros }\end{array}$

Figura 5.25. Contribución relativa en función de la densidad y la biomasa de los principales taxa de invertebrados acuáticos en 15 mallines según biozona (bosque $n=18$; estepa $n=12$ ) en el SO de la Provincia de Río Negro durante dos momentos de muestreo (septiembre y diciembre de 2012).

En cuanto a la biomasa seca, en el bosque codominaron los crustáceos (32\%) y los tricópteros (28\%), casi exclusivamente del género Verger, luego siguieron los moluscos (14\%), con importantes contribuciones de Chilina dombeiana y Physa sp. y, por último los odonatos (9 \%) por presentar larvas de tallas grandes. En los mallines de estepa la mayor contribución en términos de biomasa estuvo dada por taxa diferentes, así en orden decreciente se destacaron los odonatos (27\%), los coleópteros (20\%), como T. setiger y Lancetes spp., los moluscos (19 \%) con L. viatrix y B. peregrina y, los heterópteros (15\%) entre los más importantes (Figura $5.25)$.

\subsubsection{Atributos de los ensambles en relación al uso del suelo en cada biozona}

En relación al comportamiento de los descriptores comunitarios de macroinvertebrados por uso del suelo (Figura 5.26), se observó que la riqueza taxónomica fue mayor en aquellos mallines de referencia respecto de los de uso 
agrícola y urbano. No obstante esta diferencia fue significativa sólo en comparación con los mallines urbanos (Kruskal-Wallis, $p=0,005$ ).

Aunque la diversidad y la equitatividad no reflejaron diferencias significativas entre los usos del suelo (Kruskal-Wallis, $p>0,05$ ), los valores del índice de ShannonWiener evidenciaron un gradiente de disminución hacia los mallines urbanos. En estos ambientes más degradados y junto a los de uso agrícola, la densidad de invertebrados acuáticos fue menor respecto a los de referencia (Kruskal-Wallis, $p>0,05)$, aunque no fue estadisticamente significativa. Si bien la biomasa en mallines urbanos fue casi el doble respecto de los otros usos, ésta diferencia no resultó significativa (Kruskal-Wallis, $\mathrm{p}>0,05$ ).

Riqueza Taxonómica

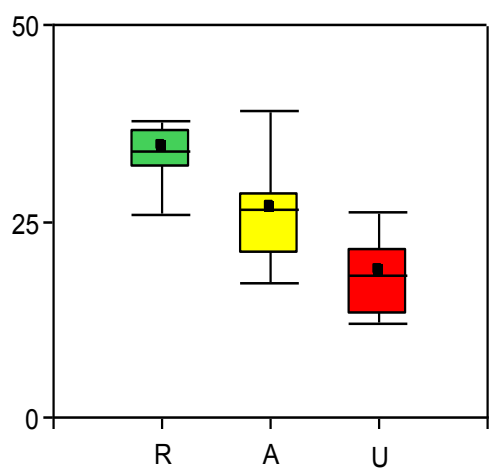

Diversidad (nats)

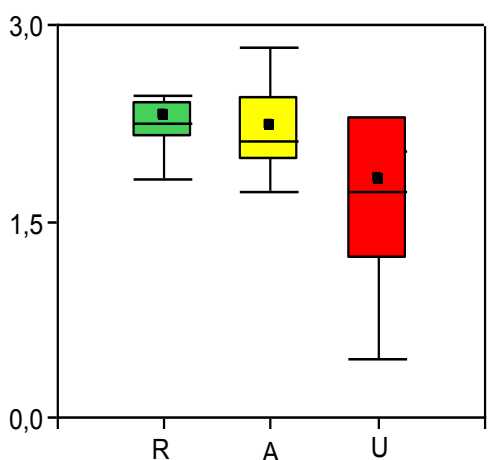

Equitatividad

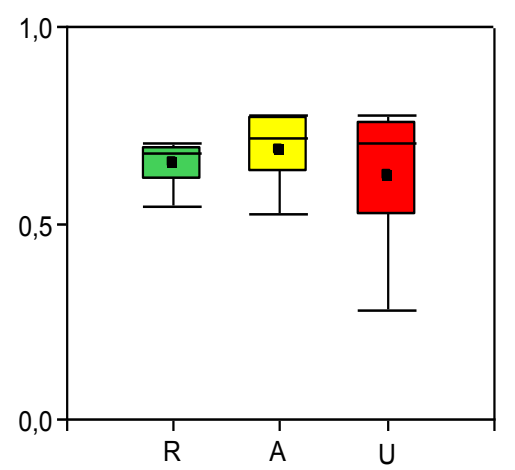

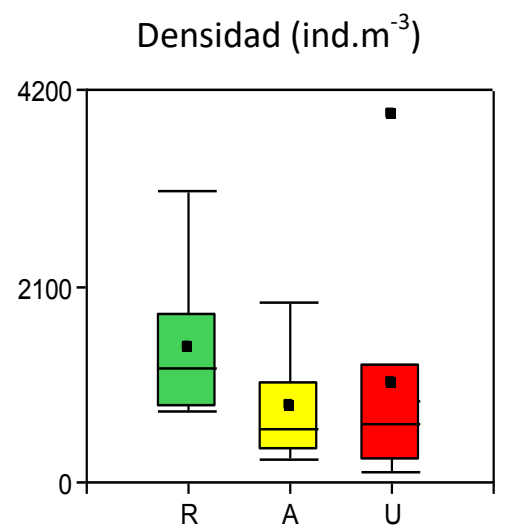

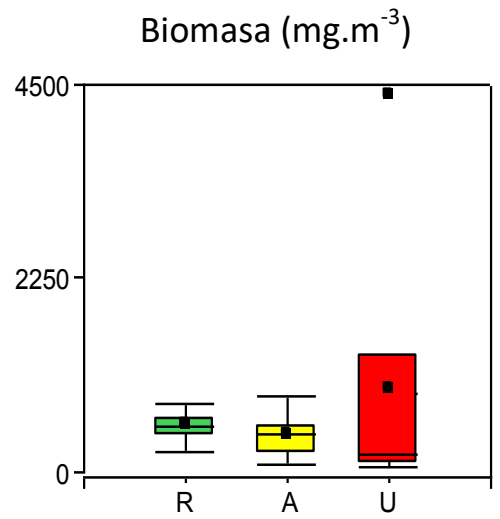

Figura 5.26: Comparación de los principales atributos comunitarios de invertebrados acuáticos en 9 mallines de bosque según usos de suelo (cada uso $n=3$ ) en el SO de la Provincia de Río Negro en dos períodos de muestreo (septiembre y diciembre de 2012). R: referencia cajas verdes ( $n=18)$; A: agrícola cajas amarillas $(n=18)$; U: urbano, cajas rojas $(n=18)$. Cajas intercuartiles $(25-75 \%)$, cuadrado negro en cajas: media, línea: mediana, barras: máximos y mínimos, puntos negros valores extremos. 
En la estepa, no se observaron diferencias entre las métricas comunitarias de los ensambles de invertebrados acuáticos entre mallines con diferente uso de suelo (Mann-Whitney $p>0,05$ ) (Figura 5.27). Sin embargo en aquellos con menor intensidad de uso ganadero, la riqueza taxonómica, la diversidad de Shannon y la densidad presentaron valores medios más altos.

Riqueza Taxonómica

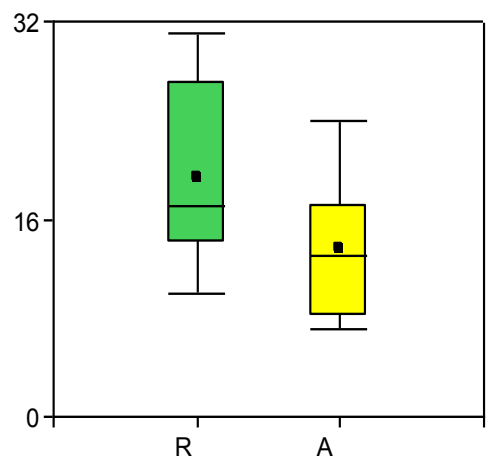

Diversidad (nats)

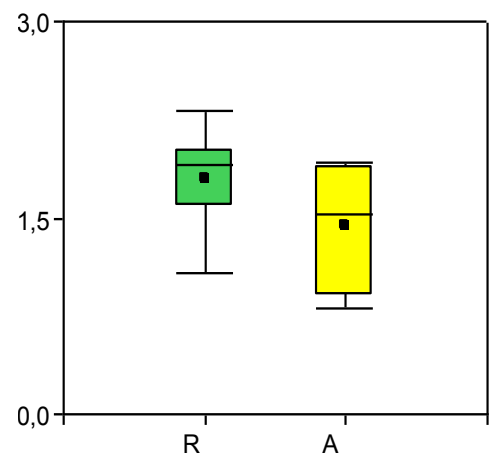

Equitatividad

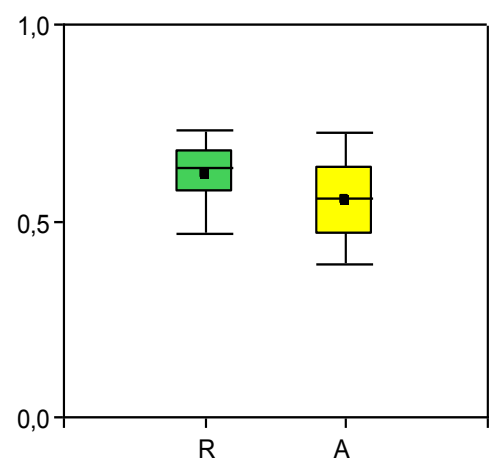

Densidad (ind. $\mathrm{m}^{-3}$ )

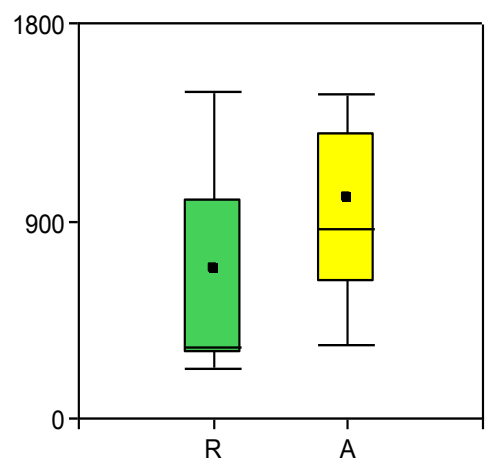

Biomasa $\left(\mathrm{mg} \cdot \mathrm{m}^{-3}\right)$

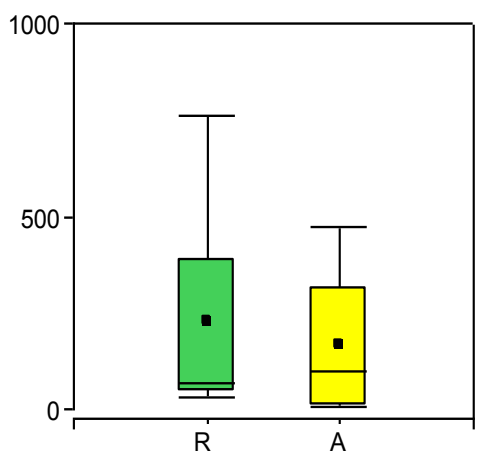

Figura 5.27: Comparación de los principales atributos comunitarios de invertebrados acuáticos en 6 mallines de estepa según usos de suelo (cada uso n=3) en el SO de la Provincia de Río Negro en dos períodos de muestreo (septiembre y diciembre de 2012). R: referencia cajas verdes ( $n=12) ; A$ : agrícola cajas amarillas $(n=12)$. Cajas intercuartiles $(25-75 \%)$, cuadrado negro en cajas: media, línea: mediana, barras: máximos y mínimos.

\subsubsection{Estructura trófica de los ensambles}

La estructura trófica a partir de la asignación de grupos funcionales a los 145 taxa de invertebrados acuáticos, mostró a los predadores (53 taxa) y colectores 
recolectores (48 taxa) como los mejores representados, luego siguieron los colectores filtradores (16 taxa), los raspadores (14 taxa), los desmenuzadores (9 taxa) y los succionadores herbívoros (4 taxa). Estas proporciones en la riqueza taxa de grupos funcionales, se mantuvieron tanto los ensambles de mallines de bosque mixto como de estepa patagónica.

En términos de abundancia relativa según la biozona, los grupos funcionales dominantes en bosque fueron en primer lugar los colectores recolectores (39\%) seguidos de los predadores (28 \%) y colectores filtradores (20\%), los que contribuyeron con $87 \%$ de la abundancia total. En cambio en la estepa los colectores filtradores dominaron ampliamente (59\%), seguidos de los colectores recolectores ( $25 \%$ ), los que en conjunto contribuyeron con $84 \%$ de la abundancia (Figura 5.28).

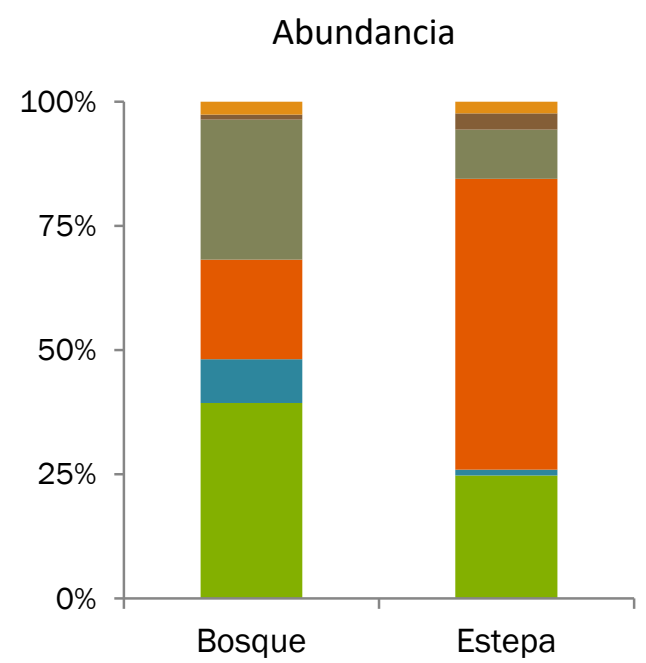

Colectores recolectores

- Predadores

- Succionadores herbívoros
Biomasa relativa

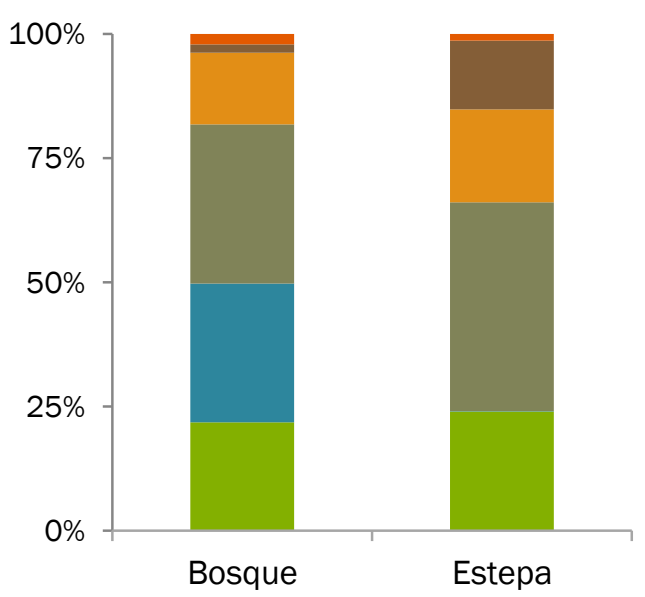

Desmenuzadores

Raspadores

- Colectores filtradores

Figura 5.28: Contribución relativa en función de la densidad y la biomasa seca de los grupos funcionales en 15 mallines según biozona (bosque $n=54$; estepa $n=36$ ), en el so de la Provincia de Río Negro durante dos momentos de muestreo (septiembre y diciembre de 2012). CR: colectores recolectores, De: desmenuzadores, Ra: raspadores, S-H: succionadores herbívoros, P: predadores, F: filtradores. 
La elevada abundancia de los colectores recolectores en mallines de bosque se atribuyó fundamentalmente a la presencia de los anfípodos Hyalella curvispina y H. patagonica junto a los quironómidos Paratrichoclaudius sp.1 y Parapsectrocladius sp. Estos cuatro taxa representaron más del $61 \%$ de la abundancia total de este grupo funcional. En cambio en la estepa los colectores recolectores estuvieron constituidos principalmente por $H$. curvispina y los quironómidos Paratrichoclaudius sp.2, Corynoneura sp.1, Parachironomus sp. y Orthocladinii sp., los que en conjunto sumaron más del 68 \% de la abundancia total del grupo.

Los colectores filtradores, que fueron dominantes en la estepa, estuvieron casi exclusivamente representados ( $>98 \%$ ) en esta biozona por crustáceos (Ostracoda, Copepoda y Cladocera). En cambio en el bosque, este grupo funcional estuvo mayormente representado por la gran contribución de los simúlidos Gigantodax marginalis y G. antarcticus.

Los predadores fueron el segundo grupo funcional en abundancia relativa en mallines de bosque, aunque este valor se debió principalmente a la elevada densidad del copépodo gigante Parabroteas sarsi en la Laguna Fantasma durante el muestreo de primavera, que aportó el 75 \% de la abundancia total del grupo. Otros depredadores que sobresalieron fueron los odonatos Cyanallagma interruptum, Erythrodiplax connata y Rhionaeschna variegata, los ceratopogónidos Bezzia sp. y Dasyhelea sp. y el quironómido Ablabesmyia sp., sin embargo sus contribuciones individuales no superaron el $8 \%$ de la abundancia total del grupo funcional. En la estepa los predadores representaron sólo $10 \%$ de la abundancia relativa y las especies más importantes fueron el oligoqueto Chaetogaster diaphanus, los heterópteros (Notonectidae) Notonecta virescens y $N$. vereertbruggheni y los coleópteros del género Lancetes.

Los succionadores herbívoros fueron en general escasos y particularmente su presencia, estuvo asociada a mallines de la estepa patagónica, representaron algo más del $3 \%$ de la abundancia relativa de los grupos funcionales, destacándose dos 
especies de heterópteros (Corixidae) Ectemnostega (Ectemnostega) quadrata y Sigara (Tropocorixa) santiagiensis.

Los desmenuzadores y raspadores contribuyeron escasamente en términos de abundancia de los grupos funcionales en ambas biozonas. Sus densidades fueron bajas, sin embargo, su mayor aporte fue en biomasa seca, dadas sus grandes tallas.

La importancia relativa de los grupos funcionales en términos de biomasa fue comparativamente mayor respecto a la observada en relación a la densidad en los grupos: colectores recolectores, predadores y raspadores en ambas biozonas. Adicionalmente los succionadores herbívoros fueron registrados en la estepa y los desmenuzadores en el bosque (Figura 5.28).

Los predadores representaron la mayor biomasa tanto en mallines de bosque (32\%) como en mallines de estepa (42\%). No obstante en los primeros se observó nuevamente la alta influencia de $P$. sarsi en su contribución a la abundancia total del grupo (>63 \%). Otros taxa con aportes moderados fueron los odonatos del género Rhionaeschna debido a sus grandes tallas. En la estepa sobresalieron como predadores con mayor contribución en biomasa el odonato $C$. interruptum y los coleópteros del género Lancetes.

Los colectores recolectores aportaron porcentajes similares de biomasa seca tanto en mallines de estepa ( $24 \%$ ) como de bosque (22 \%). Las especies con mayor contribución fueron similares en ambas biozonas: Lumbriculus variegatus (Oligochaeta) y Hyalella curvispina.

Los raspadores constituyeron un grupo funcional con un interesante aporte a la biomasa. En la estepa contribuyeron con algo más de $19 \%$, donde los gasterópodos Lymnaea viatrix y Biomphalaria peregrina superaron $95 \%$ de la biomasa total del grupo. En cambio en el bosque, donde representaron $14 \%$ de la biomasa, se destacaron además de esas dos especies, Chilina dombeiana y Heleobia hatcheri. 
Los desmenuzadores fueron el segundo grupo funcional más importante en los mallines de bosque ( $28 \%$ ) pero estuvieron casi ausentes en los de estepa. Las especies que mostraron picos máximos de biomasa fueron casi exclusivamente los tricópteros del género Verger debido a su gran tamaño y abundancia.

En los mallines de estepa se destacaron los succionadores herbívoros por su contribución a la biomasa (14\%) por la presencia de las mencionadas especies de corixidos, E. quadrata y S. santiagiensis (Figura 5.28). Finalmente, el aporte de los colectores filtradores, fue bajo con valores menores al $2 \%$ en ambas biozonas.

En relación a la distribución de los grupos funcionales tróficos según el uso del suelo (Figura 5.29), en el bosque mixto la contribución de los colectores recolectores fue dominante en los mallines de referencia (47\%) y agrícolas (53\%), a diferencia de los urbanos donde dominaron los predadores (59\%). Este patrón fue explicado por la disminución en términos de densidad de Hyalella curvispina y $\mathrm{H}$. patagonica, junto a diversos taxa de quironómidos colectores recolectores (Parapsectrocladius sp. Paratrichoclaudius sp.1 y Botryocladius sp.1) y al aumento relativo de los predadores como Parabroteas sarsi, Mesostoma ehrenbergii (Platyhelminthes) y Dasyhelea sp. (Ceratopogonidae).

Los colectores filtradores presentaron una mayor contribución en los sitios de referencia (35\%), debido a la alta densidad de simúlidos, disminuyendo su importancia relativa hacia los mallines más disturbados (agrícola y urbano). En tanto los desmenuzadores (principalmente Verger limnophilus y Verger sp.) presentaron un mayor aporte relativo en los mallines agricolas y urbanos (Figura 5.29).

En términos de biomasa relativa la contribución de colectores recolectores fue alta en los mallines de referencia (47\%), disminuyendo en un gradiente de disturbio, con aportes mínimos en los mallines de uso urbano (8\%). Situación inversa se observó en los predadores y desmenuzadores, los que presentaron una mayor biomasa relativa en los humedales agrícolas y urbanos (Figura 5.29). Los raspadores, debido a las grandes tallas de los gasterópodos, representaron importantes aportes a la biomasa en mallines de referencia (26\%) 


\section{BOSQUE MIXTO}
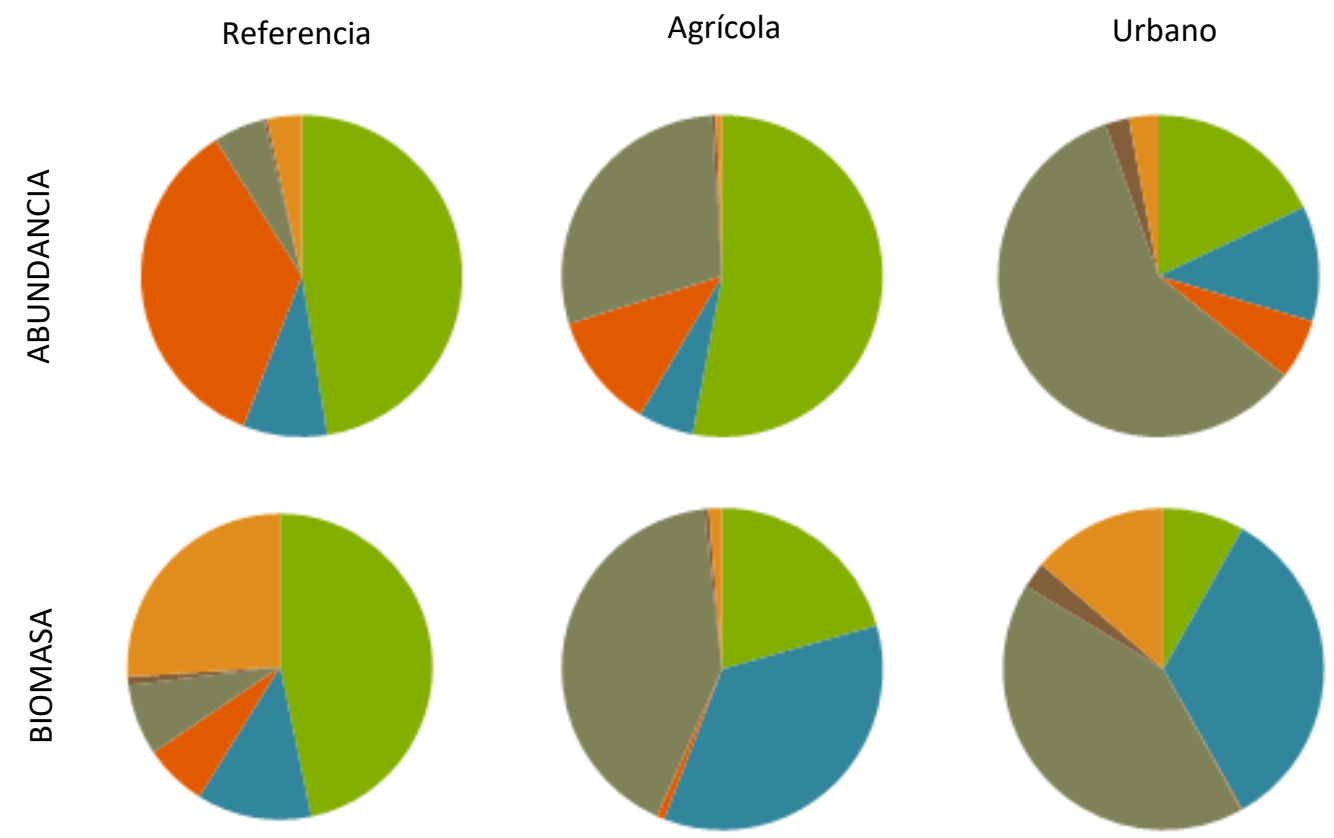

\section{ESTEPA PATAGÓNICA}

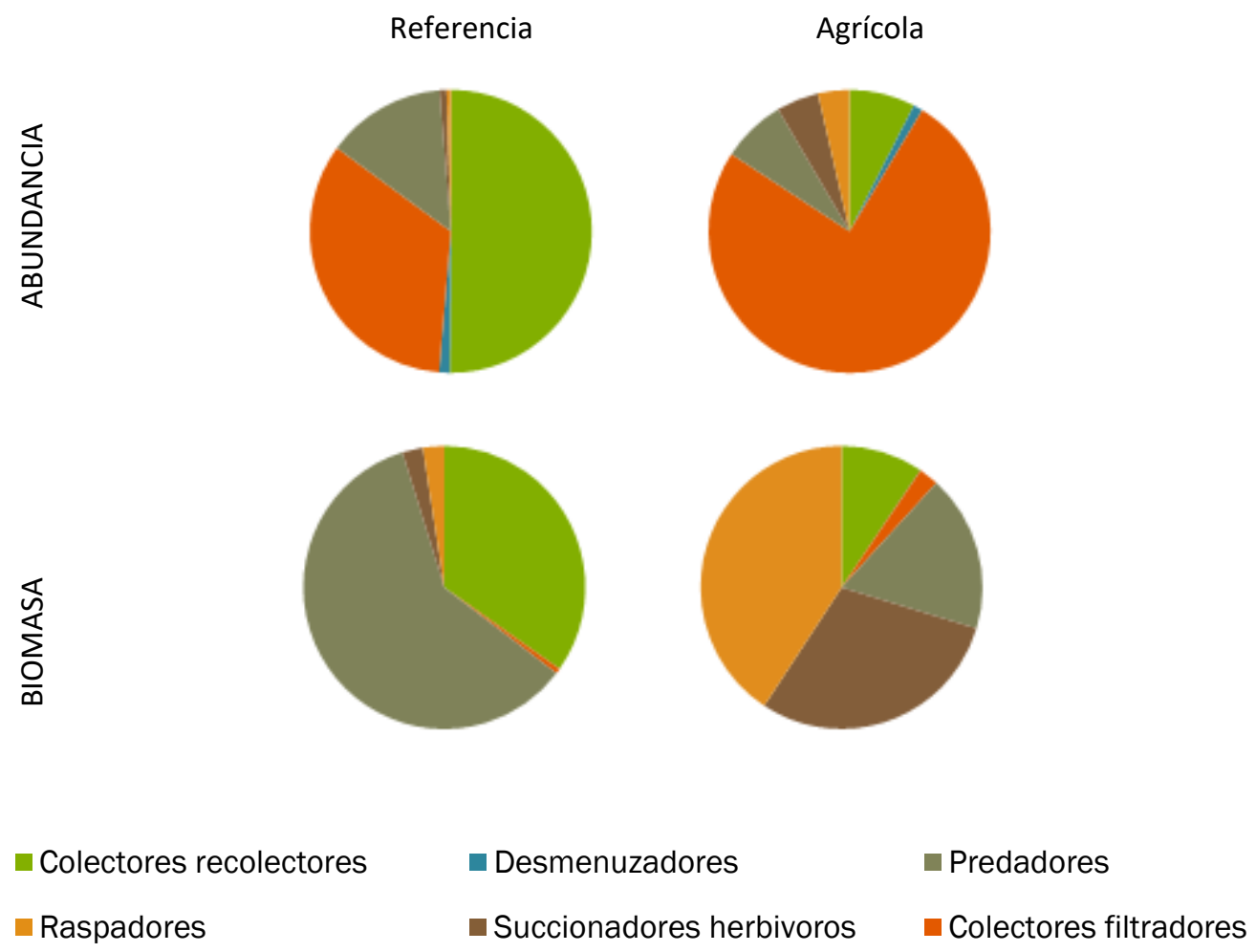

Figura 5.29: Contribución relativa de la densidad y la biomasa seca de los grupos funcionales de invertebrados acuáticos en 15 mallines según biozonas y uso de suelo en el SO de la Provincia de Río Negro durante dos momentos de muestreo (septiembre y diciembre de 2012). Cada uso de suelo representa $\mathrm{n}=18$. 
En la estepa patagónica los colectores recolectores, representados principalmente por diversos taxa de quironómidos (Paratrichoclaudius sp.2 y Orthocladinii sp. principalmente), fueron amplios dominantes en los mallines de referencia (50 \%) a diferencia de los aquellos agrícolas con mayor presión ganadera donde los colectores filtradores fueron los que más aportaron en abundancia relativa (76\%), con los crustáceos como taxa destacados (Cladocera, Copepoda y Ostracoda) (Figura 5.29).

Sin embargo, en términos de biomasa el aporte de los colectores filtradores fue escaso debido sus pequeñas tallas, destacándose los colectores recolectores (35 $\%)$ y los predadores (60 \%) en los sitios de referencia (Figura 5.29). Entre esos últimos los que más contribuyeron al peso seco fueron Cyanallagma interruptum, Notonecta virescens y los distícidos del género Lancetes.

En los mallines de uso agrícola, los raspadores presentaron una elevada biomasa relativa (41\%) por la presencia de los gasterópodos Lymnaea viatrix y Biomphalaria peregrina. También en estos mallines, los succionadores herbívoros tuvieron destacados aportes a la biomasa (30\%), sobresaliendo por sus tamaños los heterópteros Ectemnostega (Ectemnostega) quadrata y Sigara (Tropocorixa) santiagiensis y el coleóptero Haliplus subseriatus.

La síntesis de la comparación y significancia estadística de los atributos de los grupos funcionales con relación a los usos de suelo en la biozona de bosque se presenta en la figuras $5.30-5.31$. En los mallines de la biozona de bosque (Figura 5.30), se visualizó una reducción de la densidad de los colectores recolectores, colectores filtradores y raspadores, estos dos últimos significativas (Kruskal-Wallis, $\mathrm{p}<0,05$ ), hacia los mallines con mayor degradación (uso agrícola y urbano). Por otro lado, para la biomasa se evidenció un patrón similar, mayores valores de colectores recolectores y filtradores en humedales de referencia respecto de otro usos, aunque las diferencias solo fueron significativas para los últimos (Kruskal-Wallis, $p=0,005)$. 

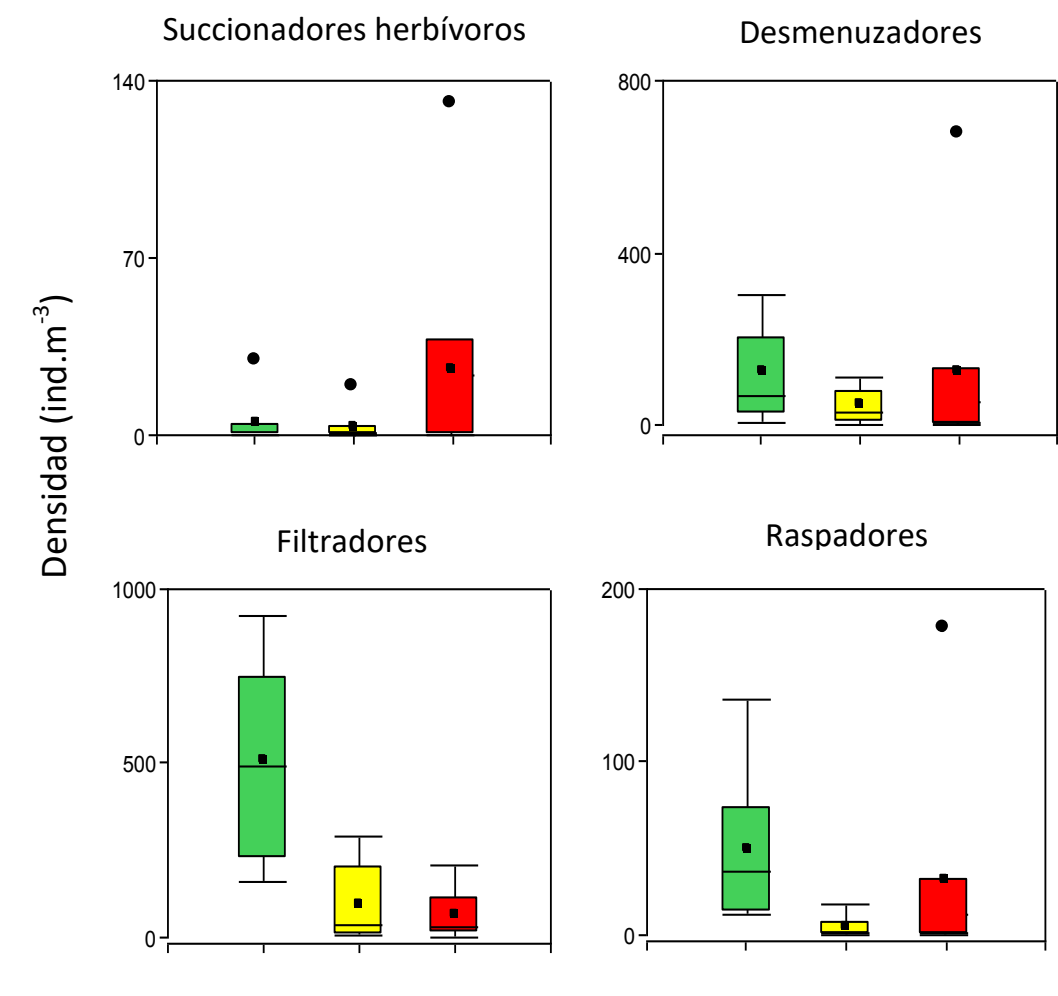

Colectores recolectores
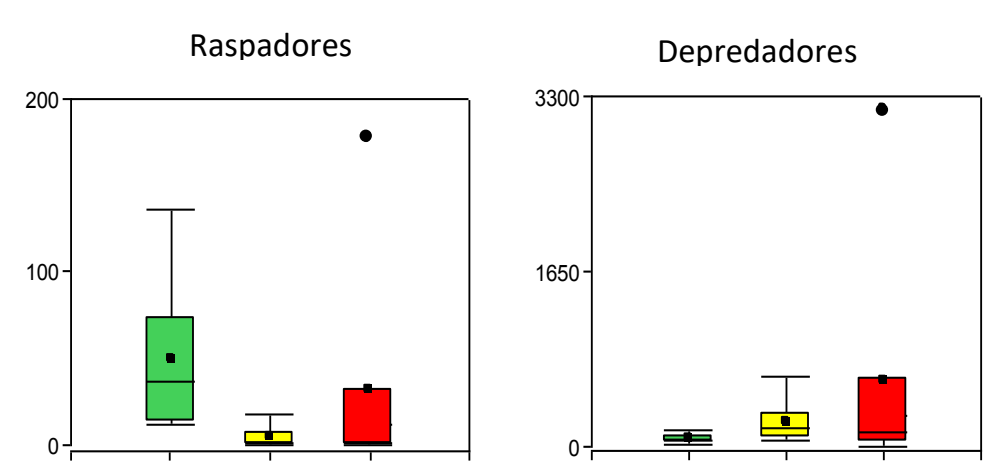

Succionadores herbívoros
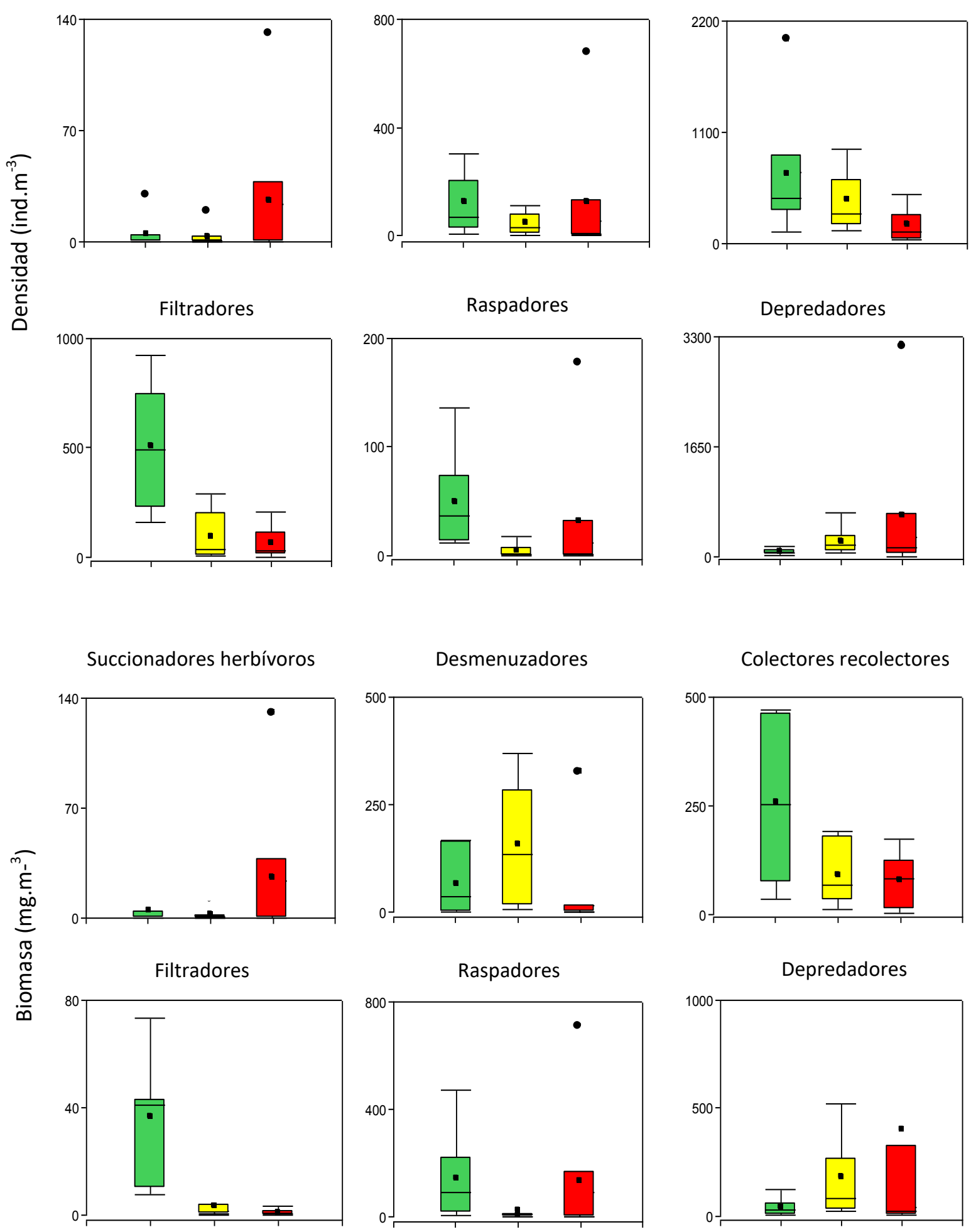

Figura 5.30: Variación de la densidad y biomasa seca de los grupos funcionales de las comunidades de invertebrados acuáticos en mallines de bosque según uso de suelo (cada uso $n=3$ en el so de la Provincia de Río Negro en dos períodos de muestreo (septiembre y diciembre de 2012). Referencia cajas verdes ( $n=18)$; Agrícola cajas amarillas $(n=18)$; Urbano, cajas rojas $(n=18)$. Cajas intercuartiles (2575\%), cuadrado negro en cajas: media, línea: mediana, barras: máximos y mínimos, circulos negros valores extremos. 


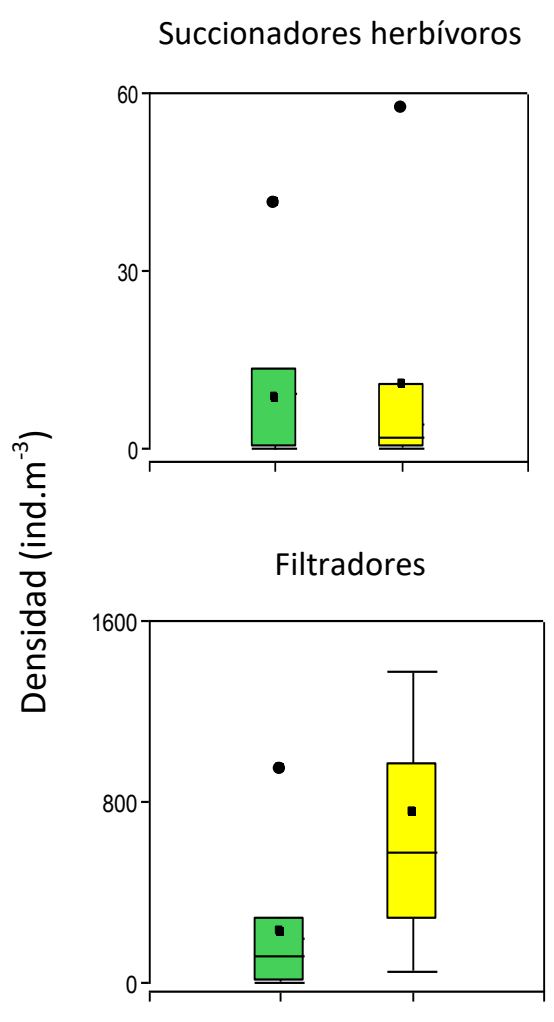

Succionadores herbívoros

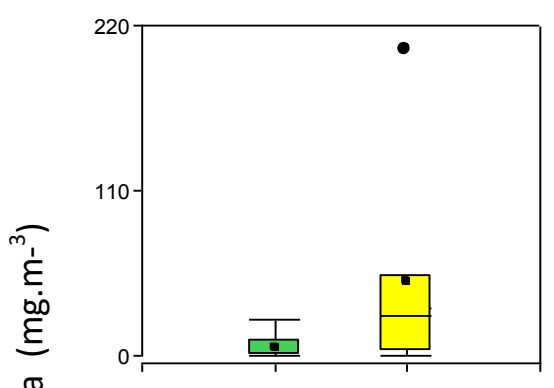

Filtradores

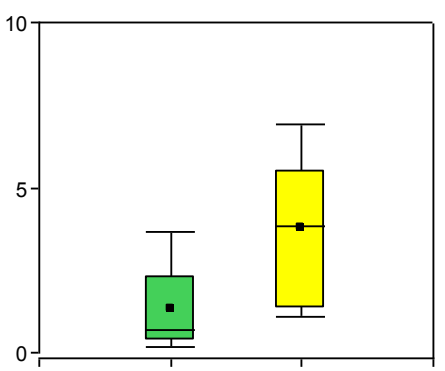

Desmenuzadores

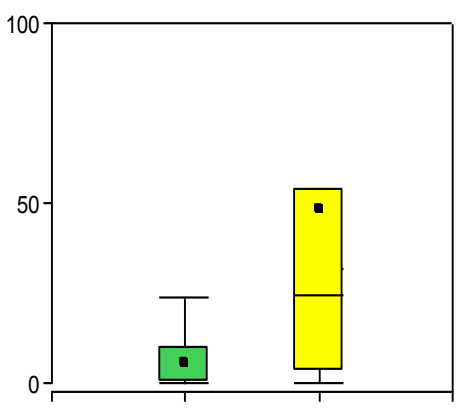

Raspadores

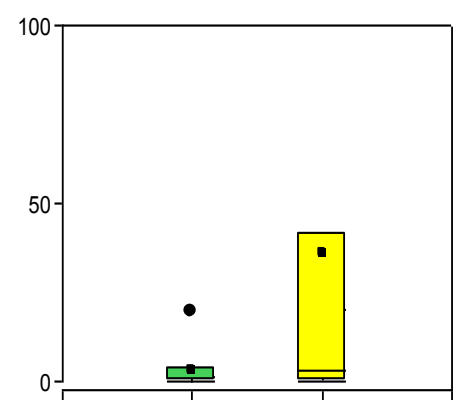

Desmenuzadores

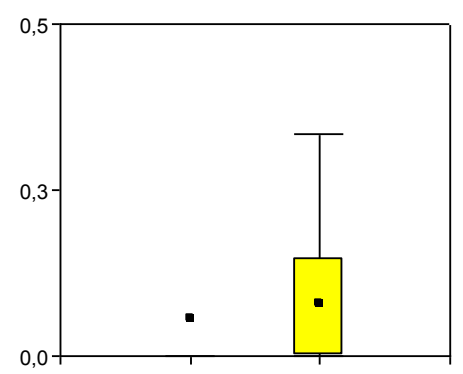

Raspadores

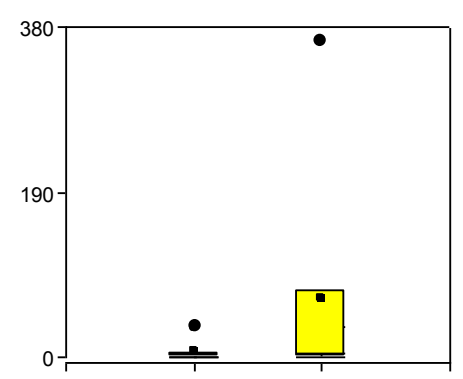

Colectores recolectores

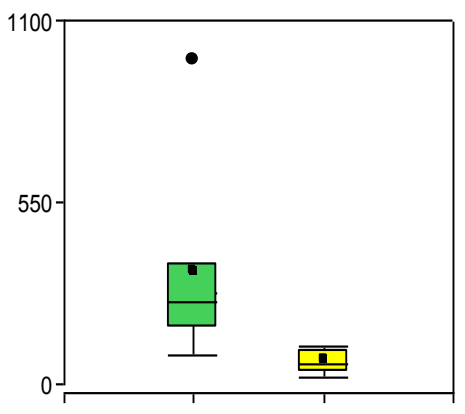

Depredadores

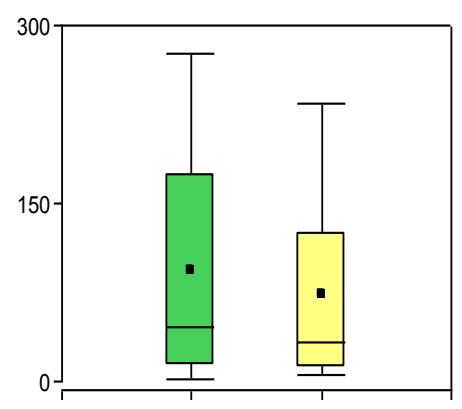

Colectores recolectores

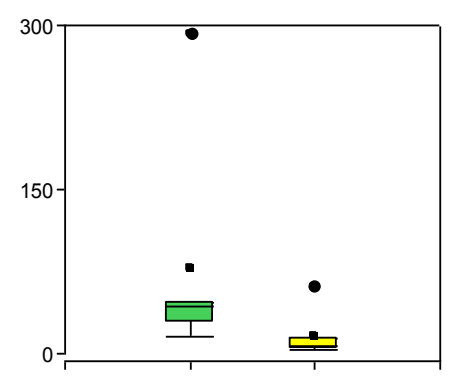

Depredadores

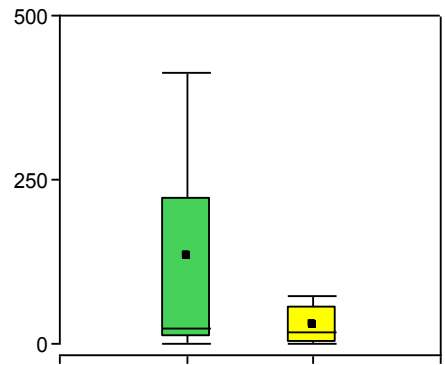

Figura 5.31: Variación de la densidad y biomasa seca de los grupos de las comunidades de invertebrados acuáticos en mallines de estepa según uso de suelo (cada uso $n=3$ en el SO de la Provincia de Río Negro en dos períodos de muestreo (septiembre y diciembre de 2012). Referencia cajas verdes $(n=12)$; Agrícola cajas amarillas ( $n=12$. Cajas intercuartiles (25-75\%), cuadrado negro en cajas: media, línea: mediana, barras: máximos y mínimos, circulos negros valores extremos. 
Respecto a los mallines de estepa (Figura 5.31), la densidad y biomasa seca de colectores recolectores fue significativamente más alta en los sitios de referencia (Mann-Whitney $p>0,05$ ), a diferencia de los colectores filtradores, los que fueron significativamente más abundantes y con mayor peso en los humedales más pastoreados (Mann-Whitney $p>0,05$ ). Los picadores herbívoros presentaron una densidad y biomasa seca superior en los mallines más degradados, aunque sólo esta última fue significativa ((Mann-Whitney $p>0,05)$.

\subsubsection{Macroinvertebrados bentónicos}

\subsubsection{Composición y estructura de los ensambles}

La comunidad de macroinvertebrados bentónicos estuvo representada por 29 taxa, los cuales estuvieron todos presentes en los ensambles de macroinvertebrados de la columna de agua (Tabla 5.9). Los taxa con mayor riqueza fueron Annelida (11), Diptera (10) y Mollusca (4) (Tabla 5.9). Sin embargo en términos de frecuencia, densidad y biomasa, Annelida, principalmente Oligochaeta, fue claramente dominante.

Las especies de macroinvertebrados más frecuentes en los mallines de estudio ( $n=15$ ) fueron los oligoquetos Lumbriculus variegatus $(n=12)$ y Limnodrilus hoffmeisteri $(n=10)$, luego siguieron Hyallela curvispina $(n=5)$ y Tubifex tubifex, Dasyhelea sp. y Alotanypus sp. $(\mathrm{n}=4)$.

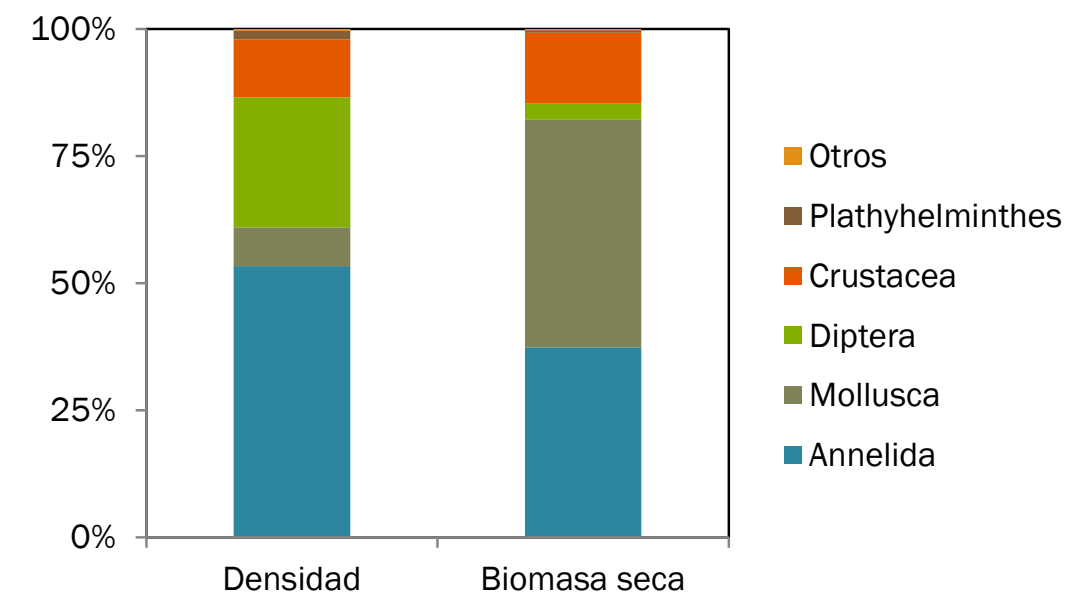

Figura 5.32. Contribución relativa en función de la densidad y la biomasa seca de los principales taxa de invertebrados acuáticos bentónicos en 15 mallines $(n=90)$ en el SO de la Provincia de Río Negro durante dos momentos de muestreo (septiembre y diciembre de 2012). 
En términos de densidad relativa (Figura 5.32), agrupando a todos los mallines, Annelida fue dominante con un aporte superior a $50 \%$, con L. variegatus, L. hoffmeisteri, Aulodrilus limnobius y Nais sp.1 (todos Oligochaeta) como taxa más abundantes. Luego siguió Diptera (26\%), donde sobresalieron Dasyhelea sp. (Ceratopogonidae), Parachironomus sp. y Riethia sp. (Chironomidae) y Crustacea (11 $\%)$, con destacadas contribuciones de Ostracoda spp., particularmente en mallines de estepa, y $H$. curvispina.

Respecto a la biomasa (Figura 5.32), Mollusca (45 \%) y Annelida (37 \%) codominaron como los taxa con mayor contribución. En el primero predominaron Chilina dombeiana y Muscullium sp. y el en segundo L. variegatus. Finalmente Crustacea (14\%), principalmente debido al aporte de $H$. curvispina, constituyo otro de los taxa más representativos del peso seco relativo.

Los resultados de las métricas comunitarias de macroinvertebrados bentónicos se muestran en la Tabla 5.11. A diferencia de los ensambles de columna de agua, en los sedimentos, la composición y estructura fue marcadamente más pobre, llegando incluso a estar ausentes en algunas de las réplicas extraídas en el muestreo.

La riqueza específica acumulada en los mallines osciló entre un valor mínimo de sólo 3 taxa (Km 12) y un valor máximo de 9 taxa (Ea. Dominguez). La densidad media presentó un valor extremo de 2589 ind. $\mathrm{m}^{-3}$ en Muelle Viejo a diferencia del resto de los mallines $(n=14)$, cuyos valores fueron menores a 1200 ind. $\mathrm{m}^{-3}$ (Tabla 5.11). En tanto la biomasa mostró valores muy heterogéneos con un pico de 2712,1 $\mathrm{mg} \cdot \mathrm{m}^{-3}$, también en Muelle Viejo y, un mínimo de $22,61 \mathrm{mg} \cdot \mathrm{m}^{-3}$ en Pampa Linda (tabla 5.11). Estas diferencias estuvieron muy relacionadas a la presencia de diversas especies de Gastropoda, que debido a sus grandes tallas, tuvieron una destacada contribución al peso seco en aquellos mallines donde estuvieron presentes. Finalmente la diversidad acumulada (Shannon-Wiener) presentó valores bajos y estuvo comprendida entre 0,87 nats, en Km 5 y 1,90 nats, en Ea. Domínguez. En tanto el rango de la equitatividad osciló entre 0,73 y 0,96, valores altos pero que 
tienen que ver con la baja riqueza taxonómica y con la escasa abundancia entre los taxa presentes en los ensambles.

Tabla 5.11: Valores de atributos comunitarios de macroinvertebrados acuáticos de sedimentos $(n=6)$ : Riqueza taxonómica acumulada, densidad, biomasa seca, diversidad de Shannon-Wiener $\left(H^{\prime}\right)$ y equitatividad de Pielou en 15 mallines de estepa y bosque, ubicados en el SO de la Provincia de Río Negro en dos momentos de muestreo (septiembre y diciembre de 2012). Uso del suelo R: referencia; A: Agricola; U: urbano.

\begin{tabular}{|c|c|c|c|c|c|c|c|}
\hline & 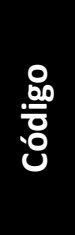 & 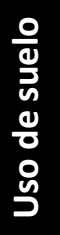 & 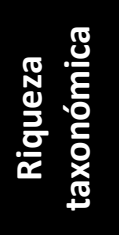 & 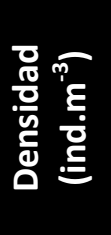 & 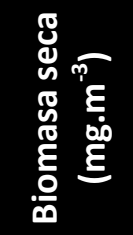 & 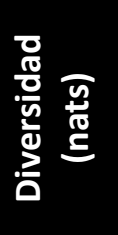 & 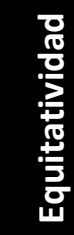 \\
\hline Vereertbrugghen & B1 & $\mathrm{R}$ & 3 & 551 & 243,6 & 0,94 & 0,86 \\
\hline Muelle viejo & B2 & $\mathrm{R}$ & 5 & 2589 & 2712,1 & 1,54 & 0,96 \\
\hline La Turbina & B3 & $\mathrm{R}$ & 5 & 891 & 233,0 & 1,26 & 0,78 \\
\hline Playa Negra & B4 & $A$ & 5 & 572 & 208,2 & 1,34 & 0,83 \\
\hline Cretón & B5 & A & 5 & 572 & 245,2 & 1,18 & 0,73 \\
\hline Lag. Pampa Linda & B6 & A & 4 & 190 & 22,6 & 1,27 & 0,92 \\
\hline Km 5 & B7 & $U$ & 3 & 742 & 394,1 & 0,87 & 0,79 \\
\hline Km 12 & B8 & $U$ & 2 & 297 & 98,9 & 0,67 & 0,97 \\
\hline Lag. Fantasma & B9 & U & 6 & 679 & 135,0 & 1,64 & 0,92 \\
\hline Ea. San Ramón & E1 & $\mathrm{R}$ & 6 & 891 & 197,7 & 1,50 & 0,84 \\
\hline Ea. El Cóndor & E2 & $\mathrm{R}$ & 4 & 530 & 27,6 & 1,05 & 0,76 \\
\hline Ea. Pto. Moreno & E3 & $\mathrm{R}$ & 7 & 1018 & 200,2 & 1,66 & 0,85 \\
\hline Ea. Domínguez & E4 & A & 9 & 1124 & 379,0 & 1,90 & 0,86 \\
\hline Ea. Pilcañeu & E5 & $A$ & 6 & 1082 & 311,8 & 1,47 & 0,82 \\
\hline Ea. Rayhuao & E6 & $A$ & 6 & 551 & 89,6 & 1,67 & 0,93 \\
\hline
\end{tabular}

Al agrupar y comparar los valores de los atributos comunitarios en función de la biozona y uso de suelo (Tabla 5.11) no se observaron diferencias estadísticamente significativas (Kruskal Wallis $p>0,05$ ), reflejando ensambles bentónicos similares bajo estos agrupamientos. Estas pobres características estructurales, sumadas a su escasa densidad, con elevados ceros en la matriz de abundancias, motivaron a no utilizar a los macroinvertebrados bentónicos para el siguiente análisis. 


\subsection{RELACIONES ENTRE LAS CONDICIONES AMBIENTALES $Y$ LOS ENSAMBLES DE MACROINVERTEBRADOS ACUÁTICOS}

El Análisis de Correspondencias Canónicas (ACC), realizado a partir de los datos de abundancias de invertebrados acuáticos y variables ambientales en mallines de bosque durante dos momentos de muestreo (principios de septiembre de 2012 y fines de diciembre de 2013), se presenta en la figura 5.33. La suma de los dos primeros ejes explicó el $42,6 \%$ de la varianza de la relación entre los diferentes taxa y los parámetros ambientales. Los valores de correlación especie-ambiente fueron de 0,98 para el primer eje y 0,97 para el segundo. De acuerdo al test de Montecarlo el ordenamiento obtenido, tanto para el primer eje como para los cuatro ejes en su conjunto, fue significativo (Tabla 5.12).

Tabla 5.12. Resultados del análisis de correspondencias canónicas estacional entre variables ambientales y la densidad de invertebrados acuáticos de nueve mallines de bosque en el SO de la Provincia de Río Negro en dos períodos de muestreo (septiembre y diciembre de 2012). Los valores de las correlaciones especie ambiente muestran la importancia de las relaciones entre especies y ambiente en los diferentes ejes. En las últimas filas de la tabla se detallan los resultados del test de Monte Carlo.

\begin{tabular}{|c|c|c|}
\hline Variable & ACC1 & ACC2 \\
\hline Temperatura del agua & 0,03 & 0,42 \\
\hline Profundidad máxima & $-0,38$ & $-0,15$ \\
\hline Oxígeno disuelto & 0,50 & $-0,005$ \\
\hline Alcalinidad & 0,37 & $-0,34$ \\
\hline Nitrógeno total & $-0,78$ & 0,30 \\
\hline Clorofila a & $-0,18$ & 0,78 \\
\hline$\%$ Aguas someras & 0,58 & 0,17 \\
\hline Autovalores & 0,515 & 0,373 \\
\hline Correlaciones taxa ambiente & 0,989 & 0,978 \\
\hline \multicolumn{3}{|l|}{ Porcentaje acumulado de varianza } \\
\hline de taxa & 14,1 & 24,3 \\
\hline de relación especie-ambiente & 24,7 & 42,6 \\
\hline Test de significancia del primer eje canónico & \multicolumn{2}{|c|}{$\mathrm{F}=1,638 \quad p<0,0002$} \\
\hline Test de significancia de todos los ejes canónicos & \multicolumn{2}{|c|}{$\mathrm{F}=1,891 \quad p<0,0001$} \\
\hline
\end{tabular}


El eje 1 (ACC 1) permitió discriminar un gradiente ambiental de degradación vinculados a los usos de suelo. El mismo estuvo definido por las concentraciones de nitrógeno total (NT) y oxígeno disuelto (OD), el porcentaje de cobertura del biotopo de aguas someras sin vegetación (\% AS) y en menor medida por la profundidad máxima y la alcalinidad. De este modo los sitios más disturbados, como los mallines de usos agrícolas y urbanos, caracterizados por altas concentraciones de NT, bajos niveles de OD, moderada alcalinidad, menor \% AS y mayor profundidad máxima se asociaron hacia el lado negativo del eje 1. En oposición, aquellos sitios con menor degradación, seleccionados como de referencia, se ubicaron hacia el lado positivo del eje 1.

El eje 2 (ACC 2), definió un gradiente estacional determinado por la variación de la temperatura del agua y la biomasa algal (clorofila a). Así al comparar cada humedal, la concentración de clorofila $a$ y la temperatura del agua fueron más altas durante el verano en el muestreo de aguas bajas (hacia el lado positivo del eje 2). Es interesante destacar el valor extremo de clorofila a que registró B8 durante el estiaje (Km 12 de uso urbano), que una concentración de 26,615 $\mu \mathrm{g} / \mathrm{L}$, mostró una manifiesta segregación en el ordenamiento, respecto del resto de los sitios.

En la figura 5.33 se representan los 134 taxa en el hiperespacio definido por las variables ambientales, el diagrama presenta las asociaciones de macroinvertebrados que caracterizaron los distintos tipos de usos y su variación estacional.

En el cuadrante superior izquierdo se localizaron los taxa que dominaron por su frecuencia los sitios con mayor grado de degradación en el estiaje (agrícola o urbano) relacionados a mayores concentraciones de NT, menores niveles de OD y baja representatividad del biotopo \% AS. Estos ensambles estuvieron caracterizados por: Hydra sp. (Cnidaria), Mesostoma ehrenbergii (Plathyhelminthes), Stephensoniana sp. (Oligochaeta), Copepoda spp. (Crustacea), Notonecta vereertbruggheni, Sigara santiagiensis (Hemiptera), Pseudosmittia sp. (Chironomidae) y Dolichopodidae sp. (Diptera). 

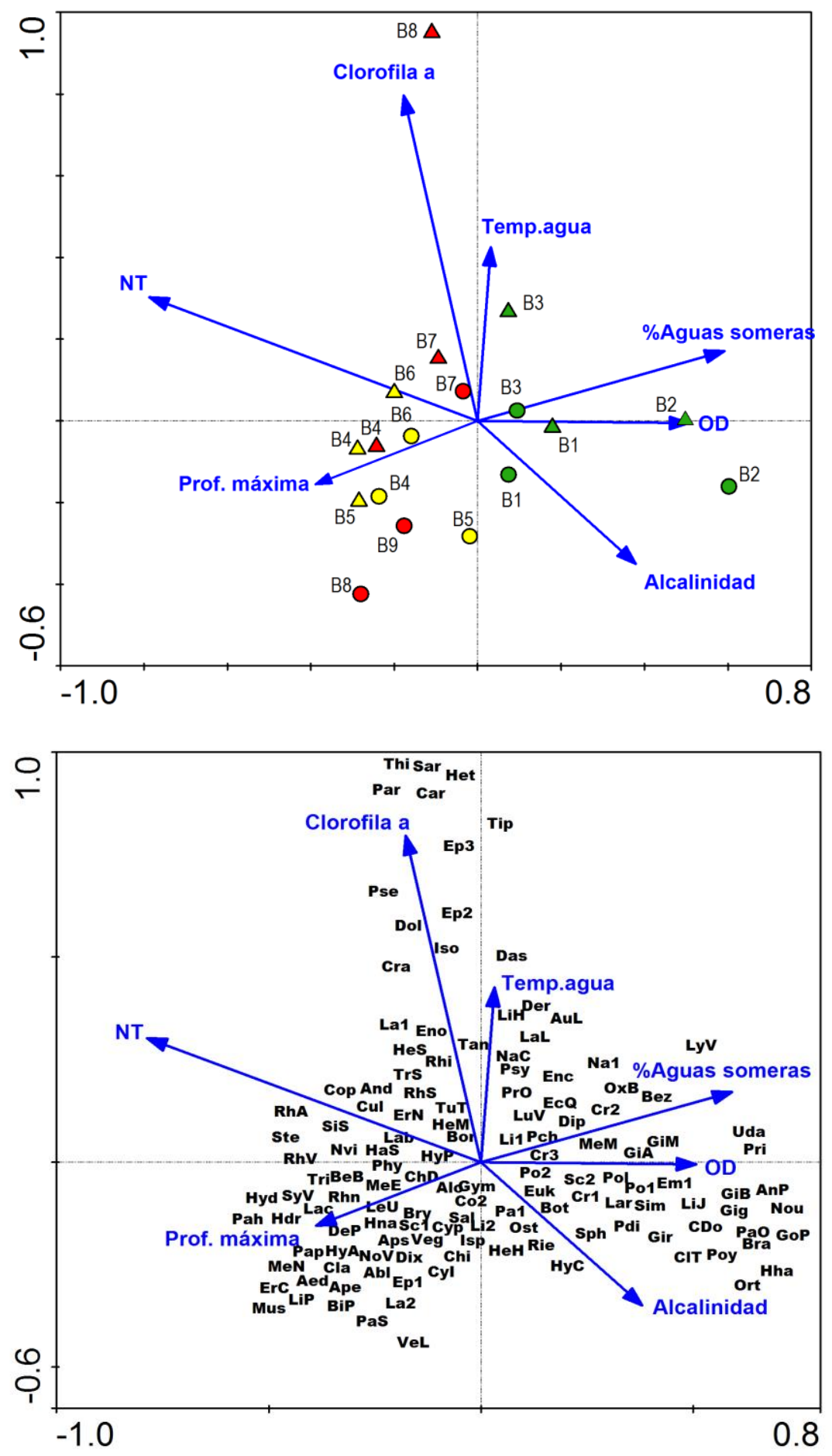

Figura 5.33: Representación del análisis de correspondencias canónica estacional (ACC) para nueve mallines de bosque en el SO de la Provincia de Río Negro en dos períodos de muestreo (aguas altas: círculos y aguas bajas: triángulos), reflejando las relaciones ambientales y asociaciones de invertebrados. Arriba: Biplot relaciones sitio-ambiente (Referencia: verde; Agrícola: amarillo; Urbano: rojo). Abajo: Biplot relaciones especie-ambiente. Los acrónimos de los taxa se detallan en la tabla 5.9. 
En cambio en el cuadrante inferior izquierdo, los taxa que dominaron esos sitios con mayor degradación, pero en el período de aguas altas fueron: Cladocera spp., Parabroteas sarsi (Copepoda), Parapsectrocladius sp. y Ablabesmyia sp. (Chironomidae). Finalmente en los mallines de referencia, los ensambles de macroinvertebrados asociados a ambientes con moderados $\%$ AS, con concentraciones más bajas de NT y clorofila $a$, pero con altos tenores de OD, estuvieron constituidos por principalmente por: Lymnaea viatrix (Gastropoda), Muscullium sp. (Bivalvia), Limnoperla jaffuelli, Claudioperla tigrina (Plecoptera), Saldula sp. (Hemiptera), Oxyethira bidentata (Trichoptera) y varios taxa de Diptera como Bezzia sp., Podonomus sp.1, Cricotopus sp.1, Cricotopus sp.2, Gigantodax antarcticus y G. marginalis. En cuanto a las variaciones estacionales, los cambios en la composición de los ensambles no fueron muy destacados, salvo algunos en taxa, entre los que se puede mencionar la disminución de Parabroteas sarsi, Ostracoda spp. (Crustacea) y Claudioperla tigrina (Plecoptera), con el aumento de Lumbriculus variegatus, Limnodrilus hoffmeisteri, Dero sp. (Oligochaeta), y Hyalella curvispina (Crustacea) durante el período de aguas bajas.

Respecto a los mallines de estepa patagónica, el ACC realizado con los datos de abundancias de invertebrados acuáticos y variables ambientales, para los dos momentos de muestreo, se muestra en la figura 5.34. Ambos ejes del ordenamiento explicaron el $42,4 \%$ de la varianza de la relación entre los diferentes taxa y los parámetros ambientales, con una alta correlación entre las especies y las variables $(>0,97)$ (Tabla 5.13). Asimismo, el modelo quedó validado por el test de Montecarlo indicando que los ejes extraídos fueron todos significativos (Tabla 5.13).

A diferencia del ACC para la biozona de bosque, en la estepa patagónica las diferencias estacionales en los mallines fueron reflejadas en el eje 1 (ACC1) del ordenamiento y, las diferencias entre los usos de suelo (referencia-agrícola) fueron principalmente capturadas por el eje 2 (ACC2) (Figura 5.34).

El gradiente estacional quedó definido por la temperatura del agua y la profundidad máxima, variables asociadas al ACC1. Así los sitios muestreados durante el periodo de aguas altas, con mayores profundidades máximas y menores 
temperaturas del agua, se localizaron sobre los valores positivos del eje 1 . En cambio los mismos sitios, pero muestreados en durante el estiaje, quedaron ubicados sobre el lado negativo del mencionado eje (Figura 5.34).

Tabla 5.12. Resultados del análisis de correspondencias canónicas estacional entre variables ambientales y la densidad de invertebrados acuáticos de seis mallines de estepa en el SO de la Provincia de Río Negro en dos períodos de muestreo (septiembre y diciembre de 2012. Los valores de las correlaciones especie ambiente muestran la importancia de las relaciones entre especies y ambiente en los diferentes ejes. En las últimas filas de la tabla se detallan los resultados del test de Monte Carlo.

\begin{tabular}{lcr} 
Variable & ACC1 & ACC2 \\
\hline Temperatura del agua & $-0,80$ & 0,30 \\
Profundidad máxima & 0,47 & $-0,42$ \\
Nitratos-Nitritos & $-0,20$ & 0,35 \\
Fósforo reactivo soluble & 0,60 & 0,68 \\
Clorofila a & $-0,06$ & 0,34 \\
\% Vegetación simple & $-0,17$ & $-0,30$ \\
\hline Autovalores & 0,453 & 0,402 \\
Correlaciones taxa ambiente & 0,994 & 0,978 \\
Porcentaje acumulado de varianza & & \\
\multicolumn{1}{c}{ de taxa } & 14,9 & 28,4 \\
\multicolumn{1}{c}{ de relación especie-ambiente } & 22,5 & 42,4 \\
\hline Test de significancia del primer eje canónico & $\mathrm{F}=0,875 \quad p<0,03$ \\
Test de significancia de todos los ejes canónicos & $\mathrm{F}=1,637 \quad p<0,0001$
\end{tabular}

En cuanto al ACC2, los mallines quedaron en su mayoría $(n=5)$ ordenados según un gradiente ambiental de uso de suelo, independientemente de la estacionalidad. Dicho gradiente estuvo definido por las concentraciones de nutrientes disueltos (nitratos-nitritos y fosforo reactivo soluble), clorofila $a$ y la cobertura relativa del biotopo vegetación simple (\% VS) (Figura 5.34). 

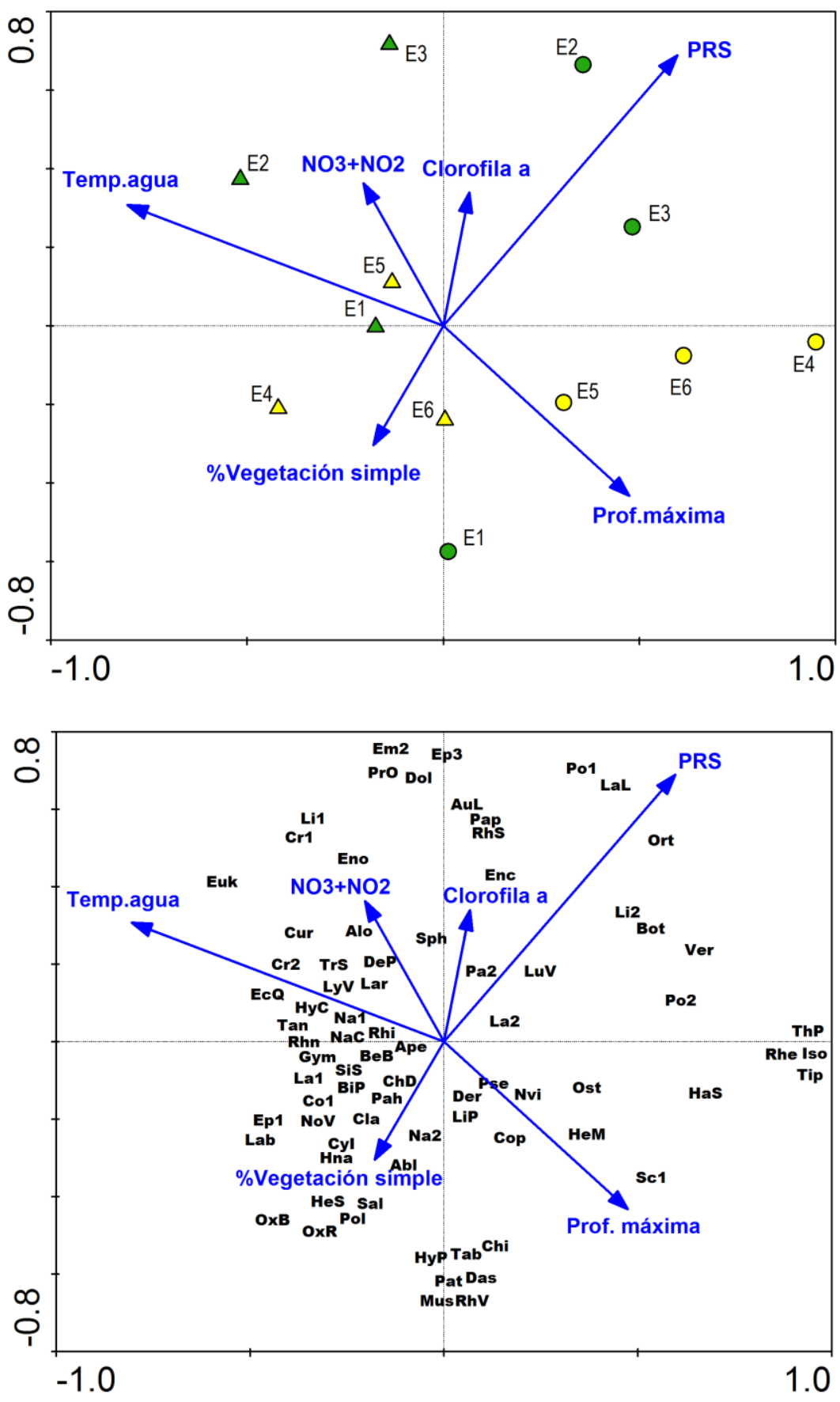

Figura 5.34: Representación del análisis de correspondencias canónica estacional (ACC) para 6 mallines de estepa en el SO de la Provincia de Río Negro en dos períodos de muestreo (aguas altas: círculos y aguas bajas: triángulos), reflejando las relaciones ambientales y asociaciones de invertebrados. Arriba: Biplot relaciones sitio-ambiente (Referencia: verde; Agrícola: amarillo). Abajo: Biplot relaciones especie-ambiente. Los acrónimos de los taxa se detallan en la tabla 5.9. 
Así sobre los valores positivos del ACC2 se localizaron los mallines sometidos a menores presiones ganaderas, con escasas intervenciones hidráulicas, los que presentaron mayores concentraciones de $\mathrm{NO}_{3}+\mathrm{NO}_{2}$, PRS y clorofila a y, menores coberturas \% VS. A este grupo se asoció el mallín de la Ea. Pilcañeu (E5, agrícola) durante el estiaje debido a que presentó una alta concentración de PRS (18,30 $\mu \mathrm{g} / \mathrm{L})$. Sobre los valores negativos del eje 2 se ubicaron los mallines con mayor uso ganadero y obras de drenaje, tanto para el muestreo de aguas altas como bajas, en los que se registraron menores concentraciones de nutrientes pero mayor cobertura del biotopo de vegetación simple. Se destaca en el extremo negativo de este eje, el mallín de la Ea. San Ramón (E1, referencia) que presentó, durante el periodo de aguas altas, bajas concentraciones de nutrientes y una alta cobertura de vegetación simple.

La representación de los 79 taxa según su presencia y abundancia, distribuidos en el espacio definido por las variables ambientales en mallines según el uso del suelo y estacionalidad se representa en la figura 5.34. Los taxa dominantes en los mallines más disturbados, con mayor \% del biotopo vegetación simple y aguas con menores contenidos de nutrientes fueron Chaetogaster diaphanus (Oligochaeta), Biomphalaria peregrina (Gastropoda), Copepoda spp., Ostracoda spp., Hyalella curvispina (Crustacea), Sigara santiagiensis (Heteroptero), Haliplus subseriatus (Coleoptera) y Ablabesmyia sp. (Chironomidae-Diptera) (Figura 5.34). Por otro lado, los ensambles que caracterizaron a los mallines de referencia, cuyas aguas mostraron mayores concentraciones de nutrientes disueltos y clorofila a, estuvieron constituidos por Lumbriculus variegatus, Enchytraeidae sp. (Oligochaeta), Tropisternus setiger, Rhantus signatus, Enochrus sp. (Coleopera) y Paratrichoclaudius sp.2, Limnophyes sp.1 y Orthocladinii sp. (ChironomidaeDiptera).

Finalmente, los taxa asociados a los cambios estacionales en mallines de estepa, que se destacaron por su dominancia y frecuencia en aguas altas fueron: Ostracoda spp. (Crustacea), Haliplus subseriatus (Coleoptera) y Podonomus sp.2 (Chironomidae). En cambio en aguas bajas, periodo de estiaje, sobresalieron una 
Macchi, Pablo. 2017. Macroinvertebrados acuáticos como indicadores ecológicos de cambios en el uso del suelo en mallines del sudoeste de la Provincia de Río Negro (Dra. María Laura Miserendino - Dra. Nora Gómez)

mayor cantidad de taxa como Chaetogaster diaphanus (Oligochaeta), Cladocera spp., Hyalella curvispina (Crustacea), Lymnaea viatrix, Biomphalaria peregrina (Gastropoda), Cyanallagma interruptum (Odonata), Ectemnostega quadrata, Notonecta virescens y Sigara santiagiensis (Hemiptera), Lancetes sp.1 (Coleoptera) y Cricotopus sp. 2 y Tanytarsus sp. (Chironomidae).

\subsection{ANÁLISIS DE MÉTRICAS: INVERTEBRADOS Y RESPUESTA AL USO DEL SUELO}

\subsubsection{Selección de métricas}

Se evaluaron 152 métricas simples que midieron atributos de riqueza, diversidad, composición, abundancia, tolerancia/intolerancia y estructura trófica de macroinvertebrados (ver metodología Tabla 4.2). En una primera preselección, y para cada biozona, se quitaron aquellas métricas con un reducido rango de valores (medidas de riqueza con rangos menores a 5 y medidas porcentuales con un rangos menores a $10 \%$ ) o con muchos valores similares (con más de $80 \%$ de valores iguales a cero), debido a que son incapaces de diferenciar sitios disturbados de aquellos no perturbados. De esta forma el total de métricas fue reducido a 91 medidas.

Posteriormente, en una siguiente instancia se descartaron aquellas métricas con un bajo poder de discriminación dado por la falta de diferenciación entre los rangos intercuartiles y las medianas en pares de comparaciones. Finalmente, fueron seleccionadas 12 métricas tanto para mallines de bosque como de estepa, por presentar las mejores respuestas frente al disturbio, debido al diferente uso del suelo y representado por el grado de apartamiento respecto de los sitios de referencia (Tabla 5.14). Es interesante destacar que nueve métricas que fueron comunes en ambas zonas biogeográficas y ocho de ellas, fueron capaces de evaluar de la misma manera la respuesta de las comunidades de macroinvertebrados en relación a la perturbación independientemente de la localización geográfica de los mallines. 
Tabla 5-14. Métricas seleccionadas en función de su respuesta a los disturbios debidos a los usos de suelo en mallines de bosque y estepa del SO de la Provincia de Río Negro. Se consigna el poder de discriminación según el grado de segregación entre pares de grupos: 3) fuerte, sin solapamiento y

2) fuerte con solapamiento. Casilleros en blanco, bajo poder de discriminación.

\begin{tabular}{|c|c|c|c|}
\hline \multirow[t]{2}{*}{ Medida } & \multirow[t]{2}{*}{ Métrica } & \multicolumn{2}{|c|}{$\begin{array}{c}\text { Poder de } \\
\text { discriminación }\end{array}$} \\
\hline & & Bosque & Estepa \\
\hline \multirow{7}{*}{$\begin{array}{l}\text { Riqueza y } \\
\text { diversidad }\end{array}$} & Riqueza taxonómica (RS) & 3 & 2 \\
\hline & № de familias de insectos (FI) & 3 & \\
\hline & № de taxa de insectos (TI) & 3 & 3 \\
\hline & $\mathrm{N}^{\circ}$ de taxa de dípteros (TD) & 3 & \\
\hline & № de taxa de quironómidos (TQ) & 3 & 3 \\
\hline & $\mathrm{N}^{\circ}$ de taxa OCD & 3 & 3 \\
\hline & $\mathrm{N}^{\circ}$ de taxa EOT & 2 & \\
\hline \multirow{4}{*}{$\begin{array}{l}\text { Composición y } \\
\text { abundancia }\end{array}$} & $\%$ crustáceos (\%Cr) & 2 & 3 \\
\hline & \% dípteros (\%D) & 3 & 3 \\
\hline & \% quironómidos (\%Q) & 2 & 3 \\
\hline & $\%$ OCD & 2 & 3 \\
\hline \multirow{4}{*}{$\begin{array}{l}\text { Características } \\
\text { tróficas }\end{array}$} & $\%$ biomasa depredadores (\%BD) & & 3 \\
\hline & $\%$ colectores recolectores (\%CR) & & 3 \\
\hline & $\%$ biomasa colectores recolectores (\%BCR) & & 3 \\
\hline & $\%$ filtradores (\%F) & 2 & 3 \\
\hline
\end{tabular}

Entre las métricas de riqueza y diversidad fueron seleccionadas: la riqueza taxonómica de macroinvertebrados, el número de familias de insectos y los números de taxa de insectos, dípteros, quironómidos, OCD (odonatos, coleópteros y dípteros) y EOT (efemerópteros, odonatos y tricópteros). En todas ellas puede observarse un patrón similar, la disminución a lo largo de un gradiente de disturbios (Figura 5.35). El número de taxa de insectos y OCD fueron las métricas más robustas, sin solapamiento entre los rangos intercuartiles y con una alta sensibilidad (tipo 3) tanto para bosque como para estepa, permitiendo discriminar las tipificaciones de los mallines asociados a cada uno de los usos de suelo (Figura 5.35). Aunque el número de taxa de quironómidos, presentó un bajo nivel de diferenciación entre los sitios de referencia y agrícolas en la biozona de bosque 
(medianas ocho y siete respectivamente), en el uso urbano mostró una reducción a la mitad (mediana cuatro) y en la estepa sus valores se redujeron ampliamente en los sitios más disturbados respecto de los referencia (medianas seis a dos). Finalmente el número de taxa de EOT, presentó una buena separación entre los mallines de uso urbano y el resto, pero sólo fue seleccionada para la biozona de bosque.

En las métricas de composición, las cuatro seleccionadas comparten la misma tendencia para ambas biozonas, pero con diferente grado de sensibilidad. El patrón general mostró una disminución de la abundancia relativa porcentual de dípteros, quironómidos y OCD con el consecuente aumento de la abundancia de crustáceos en la dirección del disturbio (Figura 5.35). Así, en el bosque la mediana del “\% de dípteros" disminuyó de $65 \%$ a $15 \%$ y en la estepa de $57 \%$ a sólo $4 \%$, en cambio la mediana del "\% de crustáceos" en el bosque aumentó de $15 \%$ a 35 \% y en la estepa de $22 \%$ a $80 \%$.

Por último entre las métricas tróficas, solo la abundancia relativa porcentual de filtradores fue seleccionada en ambas biozonas, pero su comportamiento fue inverso. Así para el bosque se observaron altos valores en los sitios de referencia (mediana $32 \%$ ) con una disminución en los agrícolas (7 \%) y urbanos (3\%), en cambio en los mallines de estepa aumentó hacia los sitios más degradados (medianas de $20 \%$ a $80 \%$ ) (Figura 5.36). En el bosque los filtradores estuvieron mayormente representados diferentes especies de simúlidos, a diferencia de la estepa donde abundaron los crustáceos como copépodos, ostrácodos y cladóceros. Por otro lado y únicamente para estepa, se destacaron por su alta sensibilidad (tipo 3) al disturbio, el "\% de colectores recolectores" y el "\% de biomasa de colectores recolectores", ambos presentaron altos valores en los sitios de referencia (medianas $>50 \%$ ), pero bajos en los mallines más degradados (medianas $<25 \%$ ). La restante métrica fue el "\% de biomasa de depredadores", aunque con cierto grado de dispersión, se observó una notable disminución hacia los mallines más disturbados en la estepa (Figura 5.36). 

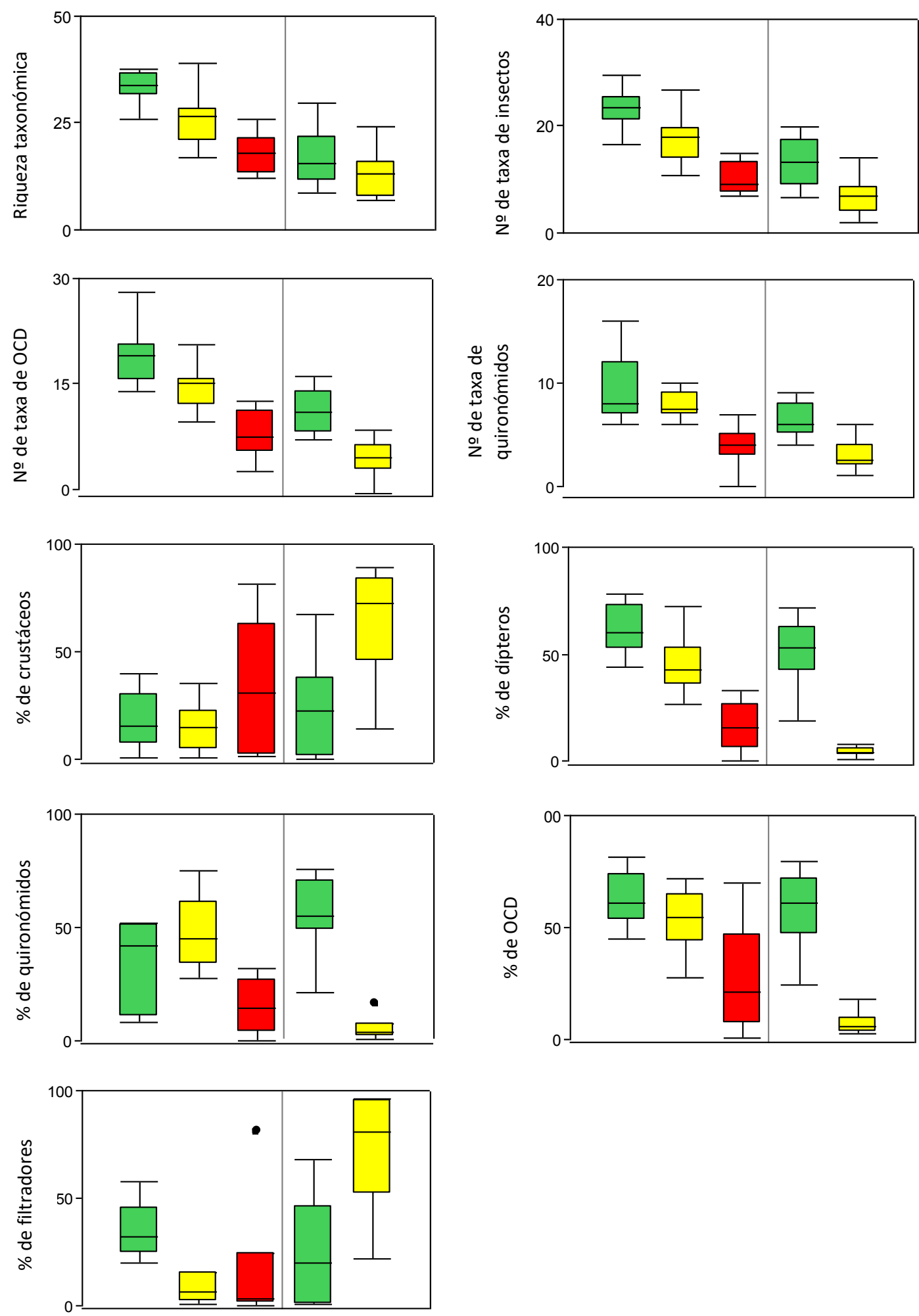

Figura 5.35. Métricas comunes de invertebrados a ambas biozonas según uso de suelo (verde: referencia; amarillo: agrícola; rojo: urbano) en 15 mallines en el So de la Pcia. de Río Negro (septiembre-diciembre de 2012). Rango de barras muestra el rango de los valores, cajas son rangos intercuartiles (percentiles: $25 \%$ al $75 \%$ ); las líneas son medianas y circulos negros son valores extremos. En cada gráfico, izquierda: métricos de mallines de bosque y derecha: métricos de mallines de estepa. 

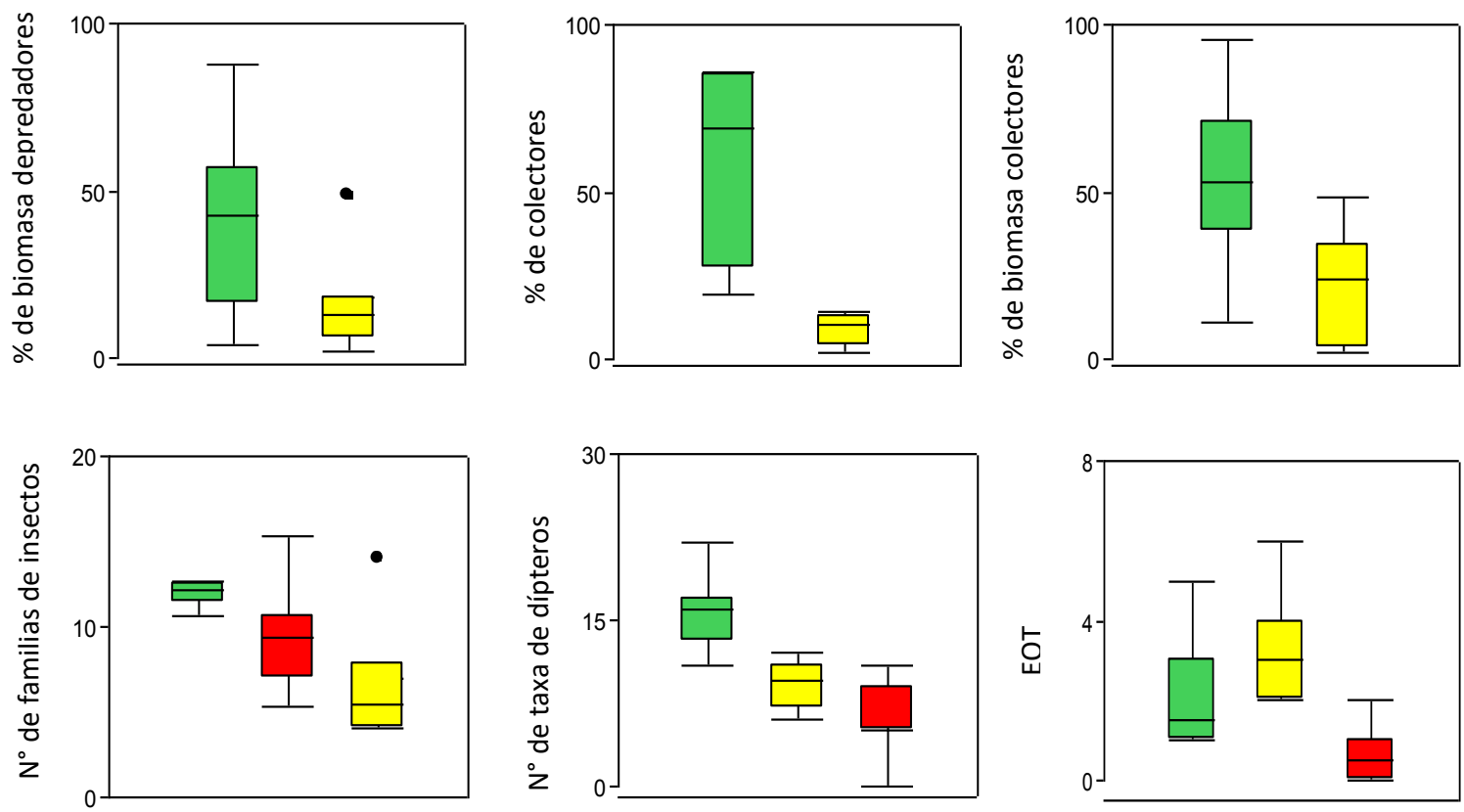

Figura 5.36. Métricas de invertebrados según biozona y uso de suelo (verde: referencia; amarillo: agrícola; rojo: urbano) en 15 mallines en el SO de la Provincia de Río Negro (septiembre-diciembre de 2012). Rango de barras muestra el rango de los valores, cajas son rangos intercuartiles (percentiles: $25 \%$ al $75 \%)$; líneas son medianas y puntos negros son valores extremos Arriba: Métricos de mallines de estepa. Abajo: Métricos de mallines de bosque.

\subsubsection{Relación estacional entre las métricas comunitarias y las variaciones ambientales}

Las relaciones entre las métricas comunitarias seleccionadas para cada una de las biozonas y los parámetros ambientales, evaluados mediante la correlación de Spearman, se muestran en las tablas $5.15-5.16$.

En los mallines de bosque, las métricas de riqueza y diversidad fueron las que se correlacionaron con mayor cantidad de parámetros. Particularmente en los fisicoquímicos, la riqueza taxonómica, en " $\mathrm{N}^{\circ}$ de taxa de insectos" y OCD disminuyeron significativamente con el aumento de la conductividad eléctrica y la alcalinidad, de igual forma lo hizo el " $\mathrm{N}^{\circ}$ de familias de insectos" pero solo para para la alcalinidad, y el " $\mathrm{N}^{\circ}$ quironómidos" y EOT para la conductividad eléctrica. Asimismo las métricas de riqueza mostraron una disminución significativa con el 
incremento de nutrientes. EOT disminuyó al aumentar las concentraciones de fósforo total y nitrógeno total, así como con los nutrientes solubles (NID, PRS y $\mathrm{NH}_{4}{ }^{+}$). El "No de quironómidos" mostró un patrón similar, pero su relación no fue significativa con el fósforo reactivo soluble y, la riqueza junto al los números de taxa de insectos y dípteros, se redujeron sólo significativamente al aumentar el fósforo total y el nitrógeno total.

Respecto a los parámetros biológicos de la columna de agua, se observó una reducción significativa en todas las métricas de riqueza, con excepción del “ $\mathrm{N}^{\circ}$ de familias de insectos", con el aumento de la clorofila $a$, de los feopigmentos, con el cociente $\mathrm{N}: \mathrm{P}$ y el índice $\mathrm{TSI}(\mathrm{CL})$.

En cuanto a la composición de biotopos presentes en los mallines, las métricas de riqueza mostraron un crecimiento altamente significativo a mayor porcentaje de vegetación compleja. En contraposición, sólo la riqueza taxonómica y el “ $\mathrm{N}^{\circ}$ de taxa de dípteros" evidenciaron una reducción significativa con el aumento del \% de vegetación simple.

La mayoría de las métricas de riqueza de macroinvertebrados mostraron una correspondencia significativa con la estructura de la vegetación acuática. El “ $\mathrm{N}^{\circ}$ de taxa de dípteros" y el " $\mathrm{N}^{\circ}$ de taxa de quironómidos" fueron significativamente más altos en mallines con mayor riqueza taxonómica (nativa y endémica). Similares respuestas se observaron con la riqueza taxonómica de invertebrados y " $N^{\circ}$ de taxa de insectos". En cambio, la métrica EOT solo se correlacionó significativamente con el aumento de la riqueza de endémicas.

En relación a la cobertura de los tipos de usos de suelo, las métricas de riqueza presentaron valores significativamente más altos en mallines con mayor \% de uso natural tanto en perímetros de 100 como de 500 metros. En oposición evidenciaron una reducción significativa al aumentar el \% de uso urbano y el \% de suelo degradado, este patrón presentó una mayor correlación significativa en áreas perimetrales de 100 metros. 
Las métricas de composición y abundancia relativa mostraron pocas correlaciones significativas con los parámetros ambientales con excepción del porcentaje de dípteros. Éste último disminuyó significativamente con el aumento de la conductividad eléctrica, el enriquecimiento de nutrientes (PT, NT, DIN, ${ }^{+} \mathrm{NH}_{4}$ ) y con una mayor concentración de clorofila a y feopigmentos. Los mallines con mayor degradación de su estado trófico, evaluados por la relación N:P y por el índice $\mathrm{TSI}_{(\mathrm{CL}) \text {, }}$ también evidenciaron una reducción en el \% de dípteros así como también en el “\% de OCD". En cambio tanto "\% de crustáceos" como el "\% de quironómidos" no mostraron correlaciones significativas con los parámetros fisicoquímicos y biológicos.

Respecto a los biotopos, el "\% de dípteros" aumentó significativamente en mallines con mayor porcentaje de vegetación compleja (\% VC). Lo mismo ocurrió con el "\% de crustáceos" pero a mayor porcentaje de aguas someras sin vegetación (\% AS), contrario al "\% de quironómidos" cuyos valores se redujeron significativamente. En tanto a la cobertura del uso del suelo, en áreas perimetrales a 100 metros, tanto el "\% de quironómidos" como el "\% de dípteros" disminuyeron significativamente con el aumento de la proporción de uso urbano.

Finalmente, el "\% de filtradores" mostró una disminución significativa con el aumento de la concentración de nitrógeno total pero un aumento significativo a mayor cobertura del biotopo vegetación compleja, y por ende, con una mayor riqueza específica de macrófitas.

Por otro lado, la correlación entre las métricas seleccionadas en los mallines de estepa y los parámetros ambientales mostró menor cantidad de relaciones significativas al compararlas con el análisis realizado para el bosque. Entre las métricas de riqueza y los parámetros fisicoquímicos, solo se observó un aumento significativo de OCD y " $\mathrm{N}^{\circ}$ de taxa de insectos" a menores tenores de oxígeno disuelto. La riqueza de insectos fue significativamente más alta en mallines con mayores concentraciones de clorofila detrítica, así como la riqueza taxonómica fue significativamente superior a mayores relaciones de N:P. 
Tabla 5.15. Correlaciones de Spearman entre las métricas seleccionadas en la biozona de bosque y los parámetros ambientales (con relaciones significativas) fisicoquímicos y biológicos, biotopos, macrófitas y cobertura de la tierra en 9 mallines del So de la Provincia de Río Negro (septiembrediciembre de 2012). Se consignan en la tabla las variables ambientales con al menos una correlación significativa (* $p<0,5$ y ** $p<0,005)$. ns: no significativo ( $p>0,05)$. Los nombres de las métricas se consignas en la tabla 5.14 .

\begin{tabular}{|c|c|c|c|c|c|c|c|c|c|c|c|c|c|}
\hline & & RS & $\mathbf{N}^{0} \mathbf{F I}$ & $\mathbf{N}^{0} \mathrm{TI}$ & $\mathbf{N}^{\circ} \mathrm{TD}$ & $\mathbf{N}^{\circ} \mathrm{TQ}$ & OCD & EOT & $\% \mathrm{Cr}$ & $\%$ D & $\% \mathbf{Q}$ & $\%$ OCD & $\% F$ \\
\hline \multirow{12}{*}{$\begin{array}{l}\text { Fisicoquímicos y } \\
\text { biológicos }\end{array}$} & CE & $-0,55^{\star}$ & ns & $-0,49^{*}$ & ns & $-0,47^{*}$ & $-0,54^{*}$ & $-0,5^{*}$ & ns & $-0,48^{*}$ & ns & ns & ns \\
\hline & Alcalinidad & $-0,58^{*}$ & $-0,59^{*}$ & $-0,56^{*}$ & ns & ns & $-0,64^{* *}$ & ns & ns & ns & ns & ns & ns \\
\hline & PT & $-0,54^{*}$ & ns & $-0,59^{* *}$ & $-0,57^{*}$ & $-0,71^{* *}$ & $-0,51^{*}$ & $-0,67^{* *}$ & ns & $-0,55^{*}$ & ns & $-0,51^{*}$ & ns \\
\hline & PRS & ns & ns & ns & ns & ns & ns & $-0,47^{*}$ & ns & ns & ns & ns & ns \\
\hline & NT & $-0,54^{*}$ & ns & $-0,56^{*}$ & $-0,71^{\star *}$ & $-0,69^{* *}$ & ns & $-0,52^{*}$ & ns & $-0,6^{* *}$ & ns & ns & $-0,58^{*}$ \\
\hline & $\mathrm{NH}_{4}$ & ns & ns & ns & ns & $-0,68^{* *}$ & ns & $-0,7^{\star *}$ & ns & $-0,61^{* *}$ & ns & $-0,53^{*}$ & ns \\
\hline & DIN & ns & ns & ns & ns & $-0,59^{*}$ & ns & $-0,63^{* *}$ & ns & $-0,56^{*}$ & ns & ns & ns \\
\hline & $N: P$ & ns & ns & $-0,47^{*}$ & $-0,71^{* *}$ & $-0,51^{*}$ & ns & ns & ns & $-0,54^{*}$ & ns & ns & ns \\
\hline & SST & ns & ns & ns & ns & $-0,52^{*}$ & ns & ns & ns & ns & ns & ns & ns \\
\hline & Chl- a & $-0,61^{* *}$ & ns & $-0,63^{\star *}$ & $-0,63^{\star *}$ & $-0,64^{* *}$ & $-0,54^{*}$ & $-0,54^{*}$ & ns & $-0,58^{*}$ & ns & $-0,49^{*}$ & ns \\
\hline & Feopigmentos & $-0,49^{*}$ & ns & $-0,6^{* *}$ & $-0,55^{\star}$ & $-0,66^{* *}$ & $-0,49^{*}$ & $-0,79^{* *}$ & ns & $-0,66^{* *}$ & ns & $-0,63^{* *}$ & ns \\
\hline & TSI (CI) & $-0,61^{* *}$ & ns & $-0,63^{\star *}$ & $-0,63^{* *}$ & $-0,64^{* *}$ & $-0,54^{*}$ & $-0,54^{*}$ & ns & $-0,58^{*}$ & ns & $-0,49^{*}$ & ns \\
\hline \multirow[t]{3}{*}{ Biotopos } & $\%$ VC & $0,84^{* *}$ & $0,68^{* *}$ & $0,77^{\star *}$ & $0,68^{\star *}$ & $0,57^{*}$ & $0,73^{* *}$ & ns & ns & $0,56^{*}$ & ns & ns & $0,57^{*}$ \\
\hline & $\%$ VS & $-0,49^{*}$ & ns & ns & $-0,51^{*}$ & ns & ns & ns & ns & ns & ns & ns & ns \\
\hline & $\%$ AS & ns & ns & ns & ns & ns & ns & ns & $0,69^{*}$ & ns & $-0,65^{\star *}$ & ns & ns \\
\hline \multirow[t]{3}{*}{ Macrófitas } & R. nativas & $0,89^{* *}$ & $0,73^{*}$ & $0,9^{* *}$ & $0,9^{* *}$ & $0,83^{* *}$ & $0,82^{* *}$ & ns & ns & $0,94^{* *}$ & ns & $0,69^{*}$ & $0,77^{*}$ \\
\hline & R. endémicas & $0,82^{* *}$ & ns & 0,8 & $0,81^{* *}$ & $0,73^{*}$ & $0,68^{*}$ & $0,71^{*}$ & ns & $0,71^{*}$ & $0,72^{*}$ & ns & ns \\
\hline & Riqueza esp. & $0,85^{* *}$ & $0,69^{*}$ & $0,88^{* *}$ & $0,82^{* *}$ & $0,8^{*}$ & $0,78^{*}$ & ns & ns & $0,88^{* *}$ & $0,69^{*}$ & ns & $0,68^{*}$ \\
\hline \multirow{6}{*}{$\begin{array}{l}\text { Cobertura de } \\
\text { uso suelo }\end{array}$} & $\%$ N 100 & $0,9^{* *}$ & $0,81^{* *}$ & $0,88^{\star *}$ & $0,77^{*}$ & ns & $0,82^{* *}$ & $0,78^{*}$ & ns & $0,74^{*}$ & ns & ns & ns \\
\hline & $\%$ U 100 & $-0,8^{\star *}$ & $-0,73^{*}$ & $-0,79^{*}$ & ns & ns & $-0,72^{*}$ & $-0,87^{\star *}$ & ns & $-0,67^{*}$ & $-0,75^{\star}$ & ns & ns \\
\hline & $\%$ SD 100 & ns & ns & $-0,7^{*}$ & $-0,75^{*}$ & $-0,76^{*}$ & ns & ns & ns & ns & ns & ns & ns \\
\hline & $\%$ N 500 & $0,85^{\star *}$ & $0,69^{*}$ & $0,83^{\star *}$ & $0,82^{* *}$ & $0,8^{*}$ & $0,77^{*}$ & ns & ns & ns & ns & ns & ns \\
\hline & \% U 500 & $-0,73^{*}$ & ns & $-0,71^{*}$ & ns & ns & ns & $-0,75^{*}$ & ns & ns & $-0,81^{* *}$ & ns & ns \\
\hline & $\%$ SD 500 & $-0,71^{*}$ & $-0,68^{*}$ & ns & ns & ns & $-0,69^{*}$ & ns & ns & ns & ns & ns & ns \\
\hline
\end{tabular}


Tabla 5.16. Correlaciones de Spearman entre las métricas seleccionadas en la biozona de estepa y los parámetros ambientales (con relaciones significativas) Fisicoquímicos y biológicos, biotopos, macrófitas y cobertura de la tierra en 6 mallines del SO de la Provincia de Río Negro (septiembre- diciembre de 2012). Se consignan en la tabla las variables ambientales con al menos una correlación significativa (* $p<0,5$ y ** $p<0,005)$. ns: no significativo ( $p>0,05)$. Los nombres de las métricas se consignan en la tabla 5.14.

\begin{tabular}{|c|c|c|c|c|c|c|c|c|c|c|c|c|c|}
\hline & & RS & $\mathbf{N}^{\circ} \mathrm{TI}$ & $N^{\circ} T Q$ & OCD & $\% \mathrm{Cr}$ & $\%$ D & $\% \mathbf{Q}$ & $\%$ OCD & $\%$ BD & $\%$ CR & $\%$ BCR & $\% F$ \\
\hline \multirow{6}{*}{$\begin{array}{l}\text { Fisicoquímicos } \\
\text { y biológicos }\end{array}$} & OD & ns & $-0,64^{*}$ & ns & $-0,67^{*}$ & ns & ns & ns & ns & ns & $-0,62^{*}$ & ns & ns \\
\hline & PRS & ns & ns & ns & ns & ns & ns & ns & ns & ns & ns & $0,58^{*}$ & ns \\
\hline & NT & ns & ns & ns & ns & ns & ns & ns & ns & $0,72^{*}$ & ns & ns & ns \\
\hline & SST & ns & ns & ns & ns & ns & ns & ns & ns & $0,61^{*}$ & ns & ns & ns \\
\hline & Feopigmentos & ns & $0,58^{*}$ & ns & ns & ns & ns & ns & ns & $0,72^{*}$ & ns & ns & ns \\
\hline & $N: P$ & $0,64^{*}$ & ns & ns & ns & ns & ns & ns & ns & ns & ns & $-0,59^{*}$ & ns \\
\hline \multirow[t]{2}{*}{ Biotopos } & $\%$ VC & $0,75^{\star *}$ & $0,75^{\star *}$ & ns & $0,77^{\star *}$ & ns & ns & $\mathrm{ns}$ & ns & ns & ns & ns & ns \\
\hline & $\%$ AP & ns & $-0,7^{*}$ & $-0,71^{* *}$ & $-0,8^{* *}$ & $0,59^{*}$ & $-0,68^{* *}$ & $-0,68^{* *}$ & $-0,79^{\star *}$ & ns & ns & $-0,84^{* *}$ & $0,64^{*}$ \\
\hline \multirow[t]{5}{*}{ Macrófitas } & R. exóticas & ns & ns & ns & ns & $-n s$ & ns & ns & ns & ns & ns & ns & $-0,85^{*}$ \\
\hline & R. nativas & ns & $0,81^{*}$ & $0,86^{*}$ & $0,88^{*}$ & $-0,83^{*}$ & $0,86^{*}$ & $0,87^{*}$ & ns & ns & ns & ns & ns \\
\hline & R. endémicas & $0,81^{*}$ & ns & ns & ns & ns & ns & ns & ns & ns & ns & ns & ns \\
\hline & Riqueza esp. & ns & $0,82^{*}$ & $0,94^{* *}$ & $0,87^{*}$ & ns & ns & ns & $0,81^{*}$ & ns & ns & ns & ns \\
\hline & $\%$ SD 100 & ns & ns & $-0,87^{*}$ & ns & ns & ns & ns & ns & ns & ns & ns & $0,87^{*}$ \\
\hline \multirow{3}{*}{$\begin{array}{l}\text { Cobertura de } \\
\text { uso suelo }\end{array}$} & $\%$ N 500 & ns & ns & ns & ns & $0,85^{*}$ & ns & ns & ns & ns & ns & ns & ns \\
\hline & $\%$ CA 500 & ns & ns & $-0,85^{*}$ & ns & ns & ns & ns & ns & ns & ns & ns & ns \\
\hline & $\%$ SD 500 & ns & ns & $-0,84^{*}$ & ns & ns & $-0,83^{*}$ & $-0,83$ & $-0,83^{*}$ & ns & $-0,81^{*}$ & ns & $0,81^{*}$ \\
\hline
\end{tabular}


Al igual que en la biozona de bosque, la riqueza taxonómica, el número de taxa de insectos y OCD fueron significativamente más altos en ambientes con mayor porcentaje de vegetación compleja, pero menores en aquellos con mayor porcentaje de aguas profundas sin vegetación (\% AP), biotopo al que respondió de la misma manera también el " $\mathrm{N}^{\circ}$ de taxa de quironómidos".

Las métricas de riqueza de invertebrados mostraron fuertes relaciones con la composición y diversidad de macrófitas. De esta forma los mallines con mayor riqueza de plantas acuáticas, y particularmente con mayor riqueza de nativas, presentaron valores significativamente más altos de los números de taxa de insectos, quironómidos y OCD. En tanto que la riqueza taxonómica de macroinvertebrados solo correlacionó de manera positiva y significativa con la riqueza de plantas endémicas.

La cobertura de usos de suelo mostró únicamente sus efectos significativos en el " $\mathrm{N}^{\circ}$ de taxa de quironómidos", que disminuyó en mallines con mayor cobertura perimetral de suelos degradados (100 y 500 metros) y con mayor cobertura de cuerpos de agua adyacentes (500 metros).

Con respecto a las métricas de composición y abundancia, ninguna de ellas correlacionó significativamente con los parámetros fisicoquímicos y biológicos, pero sí lo hicieron con la composición de los biotopos. Así, el “\% de crustáceos" fue significativamente más alto en mallines con mayor porcentaje de aguas profundas sin vegetación, a diferencia de las abundancias relativas porcentuales de dípteros, quironómidos y $\mathrm{OCD}$, cuyos valores se redujeron significativamente.

En mallines con mayor riqueza de macrófitas nativas, se observó significativamente menor "\% de crustáceos", pero mayor "\% de dípteros" y "\% de quironómidos". En tanto que el "\% de OCD" aumentó con el incremento de la riqueza específica de plantas acuáticas. En relación a la cobertura del uso de suelo, las métricas de abundancia mostraron correlaciones significativas sólo en la dimensión de radio de 500 metros. El “\% de crustáceos" aumentó significativamente con mayores proporciones de cobertura natural y el "\% de 
Macchi, Pablo. 2017. Macroinvertebrados acuáticos como indicadores ecológicos de cambios en el uso del suelo en mallines del sudoeste de la Provincia de Río Negro (Dra. María Laura Miserendino - Dra. Nora Gómez)

dípteros" y el "\% de quironómidos" se redujo significativamente a mayor porcentaje de cobertura de suelo degradado.

Las medidas de estructura trófica reflejaron relaciones dispares con los parámetros fisicoquímicos y biológicos en los mallines de estepa. El “\% de biomasa de predadores" fue significativamente mayor en humedales con más altas concentraciones de NT, SST y feopigmentos. La biomasa relativa de colectores recolectores respondió de la misma manera pero con el aumento del PRS y en cambio, disminuyó significativamente al subir la relación de N:P.

Por último, el "\% de filtradores" aumentó significativamente con el incremento del porcentaje de aguas profundas sin vegetación, pero decreció con incremento de la riqueza de macrófitas exóticas. En cambio el “\% de colectores recolectores disminuyó con el aumento de la concentración de oxígeno disuelto y del porcentaje de suelo degradado en áreas de 500 metros (Tabla 5.16).

\subsection{INTEGRACIÓN DE MÉTRICAS Y CARACTERÍSTICAS AMBIENTALES: RESPUESTA AL USO DEL SUELO EN MALLINES}

A partir de las métricas comunitarias, comunes para ambas biozonas y que respondieron de la misma forma al disturbio (excepto "\% filtradores") (Tabla 5.14), y las variables ambientales, se realizó un análisis de redundancia (RDA), para integrar la respuesta de las métricas debidas al uso del suelo en los mallines (Figura 5.37). Los dos primeros ejes del ordenamiento explicaron el $93,2 \%$ de la varianza, con altas correlaciones significativas (Tabla 5.17). El modelo fue validado por el test de Monte-carlo mostrando que los ejes extraídos fueron todos significativos (Tabla 5.17). 
Tabla 5-17. Resultados del análisis de redundancia entre variables ambientales y las métricas comunitarias comunes para las biozonas de bosque mixto y estepa patagónica del SO de la Provincia de Río Negro (septiembre y diciembre de 2012). En las últimas filas de la tabla se detallan los resultados del test de Monte-Carlo.

\begin{tabular}{lcc} 
Variable & RDA1 & RDA2 \\
\hline Conductividad eléctrica & 0,56 & $-0,10$ \\
Oxígeno disuelto & 0,32 & 0,09 \\
pH & 0,34 & 0,19 \\
Fósforo reactivo soluble & 0,35 & 0,43 \\
\% Vegetación compleja & $-0,54$ & $-0,20$ \\
\% Suelo degradado (100m) & 0,70 & $-0,03$ \\
Riqueza de macrófitas & $-0,71$ & $-0,03$ \\
\% Cobertura de macrófitas nativas & $-0,26$ & 0,13 \\
\hline Autovalores & 0,561 & 0,067 \\
Correlaciones taxa ambiente & 0,862 & 0,692 \\
Porcentaje acumulado de varianza & & \\
\multicolumn{1}{c}{ de taxa } & 56,1 & 62,7 \\
\multicolumn{1}{c}{ de relación especie-ambiente } & 84,5 & 94,5 \\
\hline Test de significancia del primer eje canónico & $\mathrm{F}=26,791 \quad p<0,001$ \\
Test de significancia de todos los ejes canónicos & $\mathrm{F}=5,182$ & $p<0,001$ \\
\hline
\end{tabular}

El eje 1 (RDA1), que capturó la mayoría de la varianza explicada por el modelo (83,3\%), evidenció un gradiente ambiental que representa el sentido de degradación de los mallines en relación al uso del suelo. Este gradiente estuvo determinado por la estructura de la comunidad de macrófitas de los mallines, el porcentaje de suelo degradado en áreas perimetrales de $100 \mathrm{~m}$ (\% SD), la conductividad eléctrica (CE), el pH y la concentración de oxígeno disuelto (OD). En cambio sobre el eje 2 (RDA2), que acumuló el 10\% de la varianza, fue importante el fósforo reactivo soluble (PRS). 


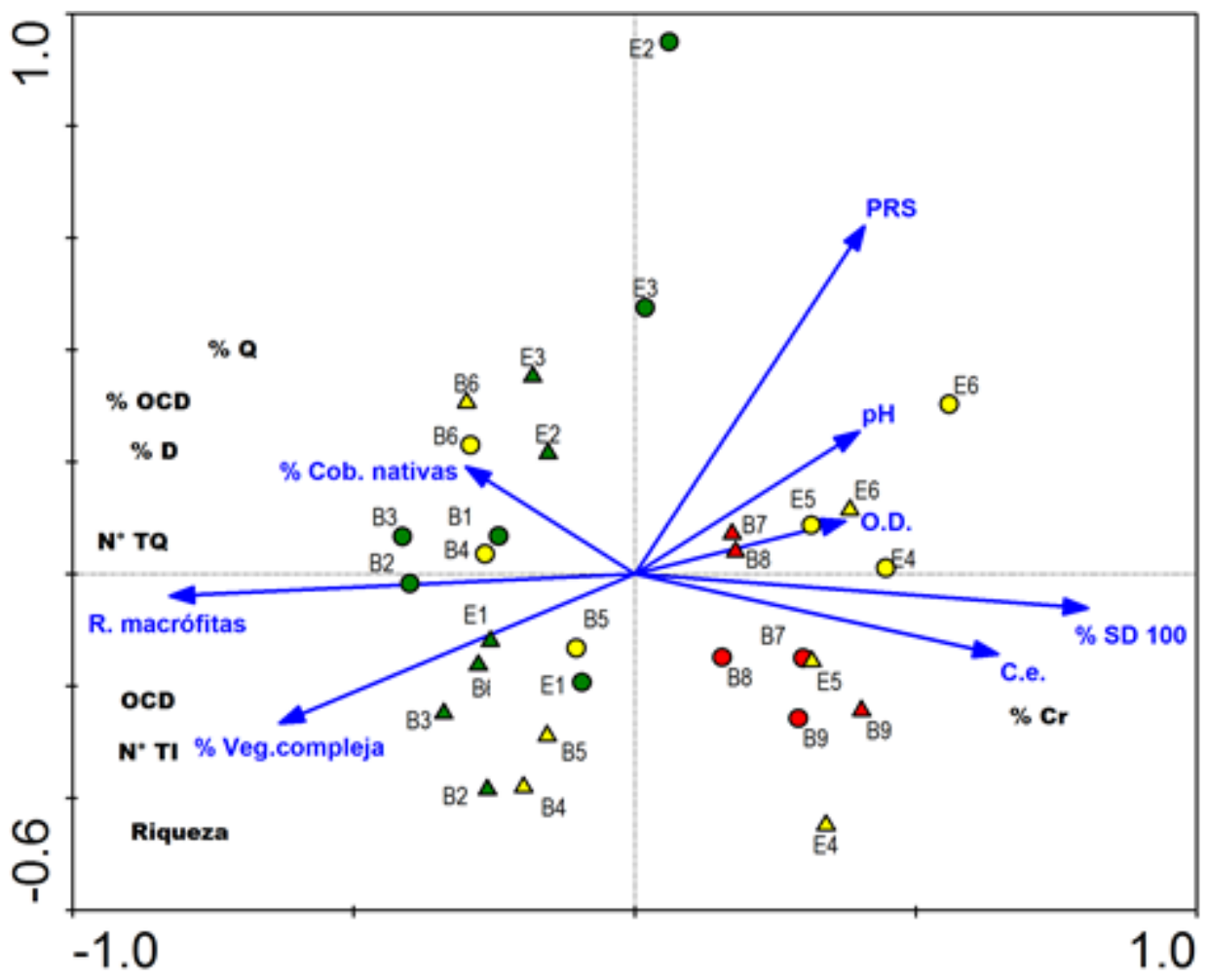

Figura 5.37: Representación del análisis de redundancia (RDA) para 12 mallines del SO de la Provincia de Río Negro, reflejando las relaciones ambientales y asociaciones con las métricas comunitarias de invertebrados de columna de agua. Sitios Letras= B: bosque; E: estepa. Fecha de muestreo= circulos: septiembre de 2012; triangulos: diciembre de 2012. Colores= referencia: verde; agrícola: amarillo; urbano: rojo. Los nombres completos de las métricas figuran en la tabla 5.14.

El ordenamiento representado por el triplot (Figura 5.37) mostró hacia la izquierda sobre el eje 1, la asociación de los sitios de referencia de ambas biozonas y los sitios agricolas de bosque, los que evidenciaron mejores condiciones ambientales, caracterizados por ensambles de macrófitas con mayor riqueza y cobertura relativa de nativas, con altos porcentajes del biotopo de vegetación compleja, asi como por bajos porcentajes de suelo degradado en las áreas adyacentes a los mallines (100 metros). La calidad del agua, de estos sitios indicó menor conductividad eléctrica, $\mathrm{pH}$ y tenor de oxígeno disuelto respecto de aquellos con mayores evidencias de degradación, como los de uso urbano en bosque y los agricolas de la biozona de estepa patagónica, que se localizaron a la derecha del ordenamiento (Figura 5.37). Estos mallines se asociaron asimismo, con altos 
porcentajes de suelo degradado y con pobres ensambles de macrófitas. Sobre el eje 2, hacia arriba se separan dos sitios de referencia de estepa (E2 - E3) por presentar altos valores de fósforo reactivo soluble, principalmente durante el periodo de aguas altas.

Respecto a los métricos, aquellos que presentaron una respuesta negativa frente al disturbio, como la riqueza taxonómica, el "\% dípteros", el "\% de quironómidos", el "\% de OCD" y los números de taxa de insectos, quironómidos y OCD (odonatos, coleópteros y dipteros), mostraron una estrecha relación con los mallines de referencia y agricolas de bosque, por sus características ecológicas y fisicoquímicas (Figura 5.37). Por el contrario, el “\% de crustáceos" presentó una mayor relación con aquellos mallines más perturbados, como los agrícolas de estepa y los urbanos de bosque. 


\section{DISCUSIÓN}

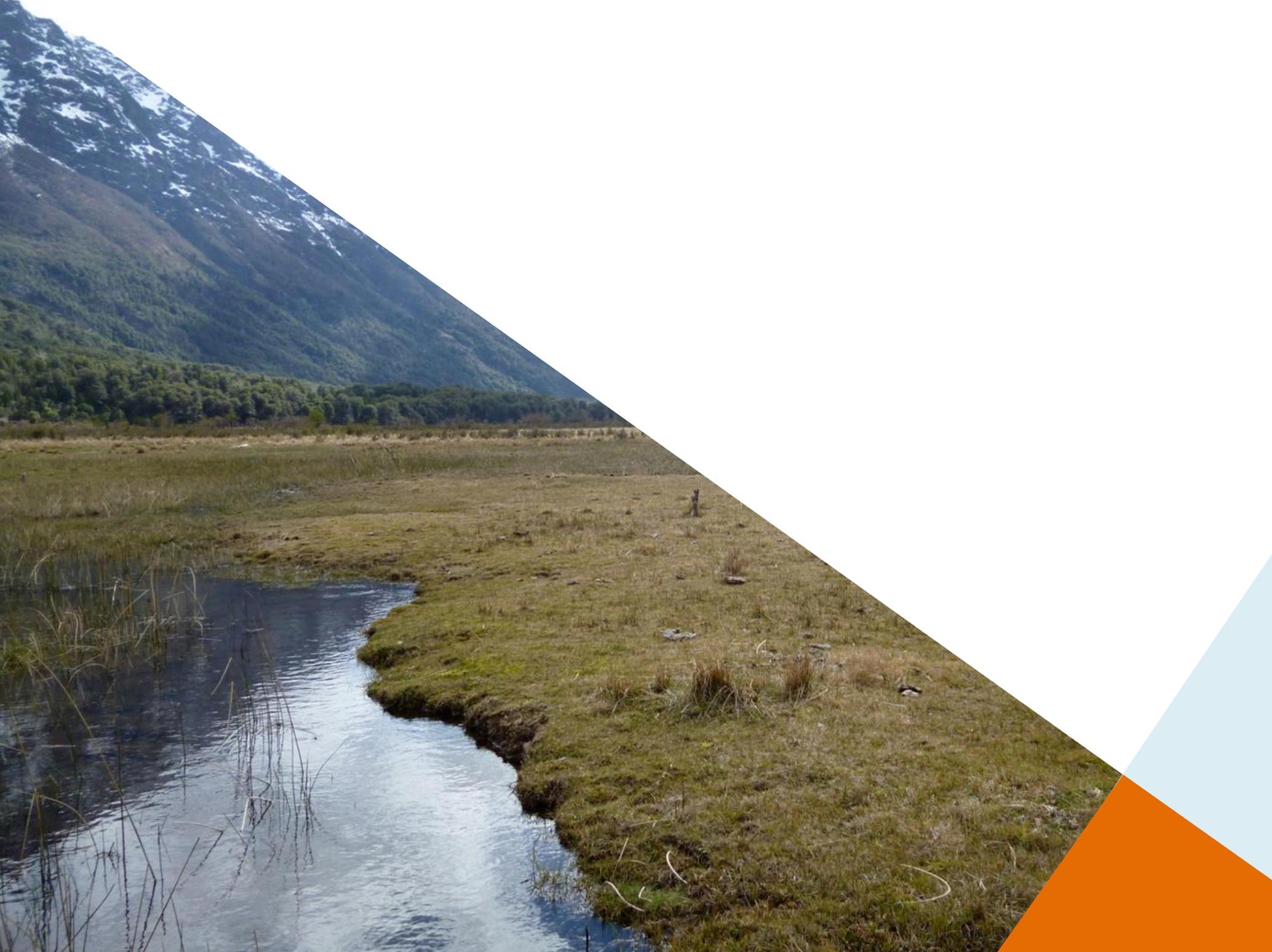




\subsection{BIODIVERSIDAD REGIONAL EN MALLINES DE RÍO NEGRO}

\subsubsection{Ensambles de macroinverterbados acuáticos}

Los resultados obtenidos en este estudio demostraron que los mallines de la Provincia de Río Negro albergan una abundante y diversa fauna de macroinvertebrados acuáticos. Se registró una alta riqueza taxonómica con 145 taxa identificados, distribuidos en 5 Phyla y 65 familias. Estos valores son comparables a los reportados por Epele (2014) quien documentó 130 taxa y 61 familias en mallines aislados y conectados de la Provincia de Chubut y superiores a los 80 taxa registrados en humedales boscosos de la Región de la Araucanía (Chile) (CorreaAraneda et al. 2014). Otros estudios realizados en diversas regiones templadas del mundo, también reportaron una alta riqueza taxonómica: en charcas y estanques de Inglaterra y Gales (242 especies) (Nicolet et al. 2004), en humedales templados de la zona de transición del bosque Boreal en Alberta, Canadá (101 especies) (Silver et al. 2012), en lagunas temporarias de Hampshire, al sur de Inglaterra (165 especies) (Bilton et al. 2009) y en humedales de tierras bajas inundables distribuidos a lo largo de Nueva Zelanda (133 especies) (Suren y Sorrell 2010). También en una revisión de más de 27 publicaciones sobre humedales someros de la extensa región de Prairie Pothole, Canadá y Estados Unidos, se reportaron 401 especies de invertebrados acuáticos (Wrubleski y Ross 2011).

Si bien existen escasos estudios sobre la diversidad de macroinvertebrados de mallines en Patagonia, su riqueza ha sido bien documentada para ecosistemas lóticos. En un estudio a escala de paisaje en 36 ríos y arroyos de Patagonia, Miserendino (2001) describió 104 taxa, en ríos de montaña y piedemonte en el noroeste de Chubut se reportaron 127 taxa (Brand y Miserendino 2015) y en un estudio estacional en 18 ríos cordilleranos se identificaron 158 taxa (Miserendino et al. 2011). Estos valores sugieren que la riqueza de macroinvertebrados en los mallines de Patagonia, a escala regional, podría ser similar o incluso mayor, que aquella de los ambientes lóticos. Estos resultados son consistentes a los documentados por Biggs y otros (2000) donde ensambles de macroinvertebrados en lagunas someras y estanques de Inglaterra, en una escala regional, fueron más 
ricos y albergaron más especies raras que los ríos y arroyos de la región. Similares resultados fueron reportados por Usseglio-Polatera (1994), Williams et al. (2004) y Davis et al. (2008). Dos factores podrían explicar la mayor diversidad de macroinvertebrados acuáticos en humedales de diversas partes del mundo y particularmente en los mallines patagónicos. Por un lado la heterogeneidad del paisaje que favorece la existencia de una variedad de hábitats con características fisicoquímicas del agua disímiles y, por el otro la conectividad diferencial, donde humedales conectados temporalmente con otros cuerpos de agua (Ilanuras de inundación en ríos o lagos) son principalmente colonizados por especies de baja dispersión aérea, y humedales relativamente aislados, son dominados por especies de amplia dispersión (Jeffries 1988, Williams et al. 2004).

Los ensambles de macroinvertebrados en los mallines patagónicos relevados, mostraron a Chironomidae (Diptera) y Dytiscidae (Coleoptera), en ese orden, como los taxa más ricos y frecuentes. Chironomidae, es una de las familias que presentan mayor riqueza taxonómica y abundancia en los humedales (Reckendorfer et al. 1996, Brooks 2000, Wrubleski y Ross 2011, Maltchik et al. 2012). Un estudio que abarcó la recopilación de la riqueza de macroinvertebrados en 447 humedales de distintas partes del mundo, reveló que Chironomidae y Dytiscidae presentaron una ocurrencia de $97,3 \%$ y $87,5 \%$ respectivamente (Batzer y Ruhí 2013), constituyéndose en familias ubiquistas, cuyas especies son capaces de tolerar un amplio rango de gradientes ambientales (Epler 2001, King y Richardson 2002, Epele y Archangelsky 2012).

La presente tesis constituye el primer estudio comparativo entre ensambles de macroinvertebrados acuáticos presentes en la columna de agua respecto de aquellos encontrados en los sedimentos de mallines patagónicos, siendo el principal hallazgo que la comunidad bentónica fue notablemente más pobre. La riqueza de macroinvertebrados bentónicos de los mallines fue de 29 taxa, alcanzando sólo un $20 \%$ de la riqueza registrada en los ensambles de la columna de agua. En términos de densidad y biomasa se destacó Oligochaeta, principalmente por la presencia de Lumbriculus variegatus y Limnodrilus hoffmeisteri. 
Macchi, Pablo. 2017. Macroinvertebrados acuáticos como indicadores ecológicos de cambios en el uso del suelo en mallines del sudoeste de la Provincia de Río Negro (Dra. María Laura Miserendino - Dra. Nora Gómez)

En otras regiones de la Argentina como por ejemplo en el bañado Carilauquen, (SO de la Provincia de Mendoza), Scheibler y Ciocco (2011) documentaron valores similares a los aquí reportados para macroinvertebrados de sedimentos (36 taxa). En cambio para humedales de la llanura de inundación del río Paraná la riqueza de macroinvertebrados bentónicos fue casi tres veces superior (Zilli et al. 2008, Zilli y Marchese 2011, entre otros).

Al igual que lo registrado en los mallines rionegrinos, la baja abundancia y diversidad de macroinvertebrados de sedimentos encontrada en humedales templados y someros al norte del Lago Hurón (Michigan), hizo impracticable su aplicación para potenciales métricas (Kashian y Burton 2000).

\subsubsection{Ensambles de macrófitas}

Los ensambles de macrófitas en los mallines del presente estudio mostraron ser ricos y diversificados, con 76 taxa, de los cuales 71 fueron identificados hasta el nivel de especie. Esta riqueza fue similar a la registrada en lagunas costeras y altoandinas de la Araucanía (77 especies) (Urrutia et al. 2014) y en lagunas costeras de la Patagonia Chilena (82 especies) (Hauenstein et al. 2008), pero superior a la documentada en mallines del oeste de la Provincia de Chubut (52 especies) (Kutschker et al. 2014). Comparada con cuerpos de agua someros de regiones subtropicales, fue menor a la registrada en los Esteros del Iberá (161 especies) (Neiff et al. 2011) y en humedales de Rio Grande do Sul (250 especies) (Rolon et al. 2010). Las familias con mayor riqueza específica en los mallines relevados, y coincidiendo con los trabajos precedentes, fueron Ciperaceae y Poaceae, que son consideradas como las familias de plantas acuáticas de mayor diversidad en los humedales de todo el mundo, excepto Antártida (Chambers et al. 2008).

De acuerdo a su origen geográfico, la proporción de especies exóticas (39\%) fue similar a la registrada en lagunas temporarias de la región montañosa de Tromen (San Martín y Álvarez 2009), y en cuerpos de agua de Valdivia en la Región de Los Ríos (ambos en Chile) (Ramírez et al. 1996). Las formas de vida dominantes fueron las emergentes y las subemergentes, patrón muy frecuentemente observado 
Macchi, Pablo. 2017. Macroinvertebrados acuáticos como indicadores ecológicos de cambios en el uso del suelo en mallines del sudoeste de la Provincia de Río Negro (Dra. María Laura Miserendino - Dra. Nora Gómez)

en otros humedales someros de áreas templadas (Nicolet et al. 2004, Gioria et al. 2010).

\subsubsection{Variaciones de la biodiversidad a escala regional}

A escala de paisaje los mallines del presente estudio se localizaron en dos grandes biozonas: bosque mixto y estepa patagónica (Paruelo et al. 1998a). Los nueve mallines de bosque mixto, estuvieron comprendidos dentro de un rango de precipitaciones medias anuales (oeste-este) entre $2000-1200 \mathrm{~mm}$ y los seis de estepa patagónica entre los 694-264 mm. Estas marcadas diferencias de precipitaciones, sumadas al entorno geomorfológico, se tradujeron en las características fisicoquímicas del agua y en las comunidades de macroinvertebrados y macrófitas presentes, estableciendo una clara diferenciación entre los mallines de ambas biozonas.

Particularmente, la comparación entre los ensambles de macrófitas en las biozonas de estudio, mostró mayor riqueza específica en los mallines de bosque mixto. Sin embargo, analizando el nivel de complejidad estructural, ambas regiones presentaron mallines con especies de hojas flotantes Potamogeton linguatus o subemergentes como Callitriche lechleri y Myriophyllum quitense, junto a emergentes Juncáceas, Ciperáceas y Poáceas. En mallines de bosque Juncus balticus, Eleocharis pachycarpa, E. melanostachis y Carex spp. fueron las especies más abundantes y con altos valores de cobertura; similares resultados fueron registrados por Chimner et al. (2011) en mallines de bosque de Nothofagus en la Provincia de Río Negro. En tanto en la estepa patagónica, la cobertura de macrófitas estuvo dominada en líneas generales por Juncus balticus, Carex gayana y Eleocharis pseudoalbibracteata, acompañadas por las exóticas Poa pratensis, Taraxacum officinale y Trifolium repens. Estas últimas son las más importantes para la ganaderia, debido a su alta productividad y calidad de forraje (Gaitan 2011).

En consonancia con lo documentado para la vegetación acuática, los ensambles de macroinvertebrados evidenciaron, también una mayor diversidad en los humedales de bosque mixto, los que congregaron casi el $93 \%$ de los taxa descriptos. Asimismo, aunque la densidad entre ambas biozonas fue similar y, en 
términos relativos los taxa dominantes fueron Diptera y Crustacea (>75\%), el primero fue superior en los mallines de bosque y el segundo en aquellos de estepa. Este patrón fue también registrado en anteriores trabajos, con Diptera y particularmente Chironomidae, dominante en humedales de bosque (CorreaAraneda et al. 2014) y Crustacea en aquellos de estepa, asociados a ambientes con diferentes grados de disturbio (Epele 2014).

Otro de los atributos comparados fue la biomasa de macroinvertebrados, que resultó ser tres veces superior en los mallines de bosque $\left(655 \mathrm{mg} \cdot \mathrm{m}^{-3}\right)$ respecto de los de estepa (195 mg.m $\mathrm{m}^{-3}$. La mayoría de los estudios ecológicos de macroinvertebrados acuáticos en mallines de Patagonia carecen de información sobre su biomasa (Perotti et al. 2004, Villagrán-Mella et al. 2006, Jara et al. 2013, Correa-Araneda et al., 2014), una excepción es el realizado por Epele (2014), quien reportó en mallines de estepa de la Provincia de Chubut, una biomasa media de invertebrados acuáticos de $413 \mathrm{mg} \cdot \mathrm{m}^{-3}$.

La mayor biomasa registrada en los mallines de bosque se debió principalmente a la presencia de tricópteros de gran talla, limnefílidos del género Verger, así como a la elevada abundancia de los crustáceos Hyalella curvispina, $H$. patagonica y Parabroteas sarsi, lo cual explica en gran parte, las diferencias de biomasa observadas entre ambas biozonas. Particularmente Limnephilidae, es una familia extremadamente abundante, con un alto aporte a la biomasa de invertebrados (>50 \%) en humedales subalpinos (Klemmer et al. 2012, Wissinger et al. 2016).

\subsubsection{Efectos locales que afectan a la biodiversidad regional}

Los resultados de este estudio evidenciaron que los ensambles de macroinvertebrados acuáticos entre ambas biozonas difieren en composición y estructura. Las comunidades acuáticas pueden estar influenciadas tanto por factores regionales como locales (Urban 2004, Holyoak et al. 2005). Los factores regionales (clima, barreras geográficas, etc.) se refieren a las características que influyen directamente en la probabilidad de que los individuos o especies alcancen un determinado hábitat, dando lugar a diferentes tasas de dispersión (Leibold et al. 
2004). En tanto los factores locales están constituidos por el ambiente abiótico y las interacciones bióticas (Meester et al. 2005).

Diversos estudios muestran que el principal factor local que ejerce mayor influencia sobre la estructura de las comunidades de macroinvertebrados es el hidroperíodo (Schneider y Frost 1996, Williams 1996, Brooks 2000). Sin embargo, en este estudio estas diferencias no fueron comprobables debido a que todos los mallines, con excepción de la Laguna del Fantasma, fueron permanentes o semipermanentes.

Otros factores locales, que regulan la estructura de las comunidades de macroinvertebrados en los humedales, son las características fisicoquímicas del agua (Nicolet et al. 2004, Biggs et al. 2005) y la heterogeneidad espacial asociada a la vegetación acuática (Wissinger 1999, Cottenie and De Meester (2004). En tal sentido este trabajo mostró diferencias en el $\mathrm{pH}$, en la conductividad eléctrica, turbidez y en los nutrientes en los mallines de estudio según las biozonas. En el bosque predominaron aguas cercanas a la neutralidad o levemente alcalinas, en cambio en la estepa los valores indicaron aguas alcalinas a fuertemente alcalinas $(\mathrm{pH}>9)$. Asociada a la variación del $\mathrm{pH}$, la conductividad eléctrica del agua mostró también un incremento significativo hacia el este (estepa patagónica), duplicando los valores respecto a los mallines de bosque. Patrón similar de variación fue observado en el aumento de la concentración de sólidos suspendidos totales en los mallines de estepa. Estos resultados son coincidentes a los documentados en estudios anteriores tanto para humedales de bosque patagónico, con aguas ácidas hasta levemente alcalinas y baja conductividad eléctrica, generalmente menor a $150 \mu \mathrm{S} / \mathrm{cm}$ (Perotti et al. 2005, Clausen et al. 2006, Jara et al. 2012), como para humedales de estepa, con valores de $\mathrm{pH}$ mayormente alcalinos y conductividad eléctrica superior a $200 \mu \mathrm{S} / \mathrm{cm}$ (Perotti et al. 2005, Gaitán et al. 2011, Epele 2014).

Respecto al aumento de la turbidez, evidenciada por la concentración de sólidos suspendidos totales, un aspecto a considerar es la mezcla inducida por el viento y la resuspensión del sedimento en la columna de agua, y su posterior reasentamiento, fenómeno observado en cuerpos de agua someros (Søndergaard 
et al. 1992). En Patagonia los vientos dominates provienen del oeste ( $65 \%$ a $75 \%$ de las observaciones diarias) y se caracterizan por una alta persistencia e intensidad (valores promedio anual: $15-22 \mathrm{~km} . \mathrm{h}^{-1}$ ) (Paruelo et al. 1998). Paticularmente los mallines de estepa se encuentran más expuestos a los fuertes vientos debido a la falta de vegetación natural que funcione como cortina forestal.

En relación a las concentraciones de nutrientes, sólo el fósforo total y su fracción biodisponible fueron significativamente mayores en los mallines de estepa respecto de aquellos de bosque. Correa-Araneda y otros 2014 registraron en humedales permanentes del bosque de Chile valores medios de fósforo total y fósforo reactivo soluble coincidentes con los aquí registrados. Respecto al nitrógeno y sus especies químicas disueltas, las concentraciones determinadas reflejaron valores heterogéneos, en algunos casos similares entre ambas biozonas. Esta variabilidad observada estaría más asociada a los aportes de nitrógeno antropogénico asociados a mallines urbanos (Pellerin et al. 2004).

Chimner et al. (2011) concluyeron, luego de su relevamiento en mallines en la Provincia de Río Negro, que la hidrología, química del agua y la vegetación varían a lo largo del gradiente de precipitaciones (3000 a $150 \mathrm{~mm}$ ). Este gradiente genera mallines con cuerpos de agua de menor profundidad y con gran acumulación de sales por los aportes del lavado de rocas sedimentarias de la cuenca (López et al. 2005) y que debido a la escasez de agua para su drenaje, permanecen a lo largo del perfil del suelo (Dufilho et al. 1999). Estas características son reflejadas en la fisicoquímica del agua $(\mathrm{pH}$, conductividad y cationes, sodio y calcio), la que resulta en cambios significativos en la estructura de las comunidades vegetales (Gaitan 2011, Chimner et al. 2011). Otros estudios realizados en Gran Bretaña, en más de 70 humedales templados, documentaron que el $\mathrm{pH}$ y los factores asociados (alcalinidad, conductividad eléctrica), fueron las principales variables que estructuraron las comunidades de macroinvertebrados y macrófitas de los humedales (Nicolet et al. 2004, Biggs et al. 2005). De la misma manera en los mallines relevados, el $\mathrm{pH}$ y sus variables asociadas, evidenciaron ser uno de los 
principales factores que regulan la composición y estructura de los ensambles de macroinvertebrados a escala regional.

A diferencia de los mallines de bosque, en la estepa se registraron variaciones estacionales en la composición de los ensambles de macroinvertebrados tal como fue evidenciado en el ACC. Durante el verano el fuerte déficit hídrico que caracteriza a la biozona (del Valle 2003), disminuye la profundidad del agua y favorece el aumento de la temperatura. Los ensambles en el período de estiaje mostraron un incremento de depredadores, debido a la colonización de larvas y adultos de Coleoptera, así como por la presencia de larvas de Odonata (Williams 2006, Bazzanti et al. 2009, Epele 2014). Según Jara et al. 2012, la reducción del volumen de agua durante el verano, cuando la oferta de presas es elevada, reduce la competencia interespecífica, permitiendo la coexistencia de especies con requerimientos tróficos muy similares (Nilsson 1986).

\subsubsection{Estado trófico y su relación con la biodiversidad}

Los dos factores más importantes que determinan la productividad primaria del fitoplancton en los ecosistemas acuáticos son la disponibilidad de luz y de nutrientes (principalmente fósforo P y nitrógeno N) (Osborne, 2012).

El análisis de las proporciones entre los nutrientes (NT:PT y NID:PT) permitió explorar los posibles efectos limitantes en la productividad del fitoplancton en los mallines patagónicos. Para la relación NT:PT los resultados mostraron, según el criterio de Sakamoto (1966), que el $\mathrm{N}$ sería limitante $(<10 ; n=22)$ o coliminante junto al $P(n=8 ; N T: P T=10-17)$. De acuerdo a Bergström (2010), el N también actuaría como limitante de la productividad del fitoplancton debido a la relación NID:PT observada $(<2,2 ; n=27)$ en los mallines patagónicos.

Aunque estudios recientes demuestran cierta controversia sobre el papel del $\mathrm{N}$ y $\mathrm{P}$ como limitantes de la productividad de los ecosistemas acuáticos (Lewis y Wurtsbaugh 2008, Schindler et al. 2008), existe una acumulada evidencia del rol del $\mathrm{N}$ como limitante (Elser et al. 1990, Bunting et al. 2005) o de una colimitancia de NP (Morris y Lewis 1988, Dodds et al. 1989) en una amplia variedad de ecosistemas 
acuáticos. Particularmente para humedales de agua dulce existen varios trabajos que muestran al $\mathrm{N}$ como limitante (Bedford et al. 1999, Sahuquillo et al. 2012; Mischler et al. 2014). Epele (2014) en un estudio anual de un mallín temporario en Patagonia, sugirió que el nitrógeno actuaría como limitante de la productividad primaria.

Es bien conocida la capacidad de los humedales para la retención y remoción de nutrientes (Brix 1994, Sundaravadivel y Vigneswaran 2001, Bassi et al. 2014). Sin embargo, cuando la tasa de carga de nutrientes supera cierto nivel crítico, la composición de especies y funcionamiento de los ecosistemas cambia dramáticamente en cortos períodos de tiempo y los sistemas a menudo se mueven a un estado trófico diferente (Verhoeven et al. 2006). De esta forma, el enriquecimiento de nutrientes en los cuerpos de agua se puede traducir en un crecimiento excesivo de fitoplancton (Vollenweider 1968, Stevenson et al. 1996, Smith et al. 2006).

La biomasa del fitoplancton en los mallines, evaluada a partir de la concentración de la clorofila $a($ chl-a), mostró en la mayoría de los casos valores menores a de $6 \mu \mathrm{g} \cdot \mathrm{L}^{-1}(\mathrm{n}=23)$, pero con un máximo de 32,5 $\mu \mathrm{g} \cdot \mathrm{L}^{-1}$ en Ea. El Cóndor durante el periodo de aguas altas. En líneas generales, la concentración de clorofila en los humedales someros de agua dulce son altamente variables y normalmente pueden exceder los $50 \mu \mathrm{g} . \mathrm{L}^{-1}$ (Sigee 2005). En Patagonia, en mallines de bosque en la Provincia de Río Negro, estudios anteriores reflejaron valores muy heterogéneos, Cuassolo et al. (2011) registraron en un mallín de altura (Los Patos, Chalhuaco) concentraciones entre 2-3 $\mu \mathrm{g} \cdot \mathrm{L}^{-1}$ de clorofila $a$, Trochine et al. (2008) $1,96 \mu \mathrm{g} \cdot \mathrm{L}^{-1}$ en el mallín Ñireco y $13,04 \mu \mathrm{g} \cdot \mathrm{L}^{-1}$ en La Laguna Fantasma, valor casi tres veces superior al máximo registrado para ese mallín durante el presente estudio $\left(4,93 \mu \mathrm{g} . \mathrm{L}^{-1}\right)$. Un extenso estudio sobre lagos y reservorios de Patagonia documentó, particularmente en lagunas someras, concentraciones medias de clorofila $a$ que oscilaron entre 0,1 10,8 $\mu \mathrm{g} \cdot \mathrm{L}^{-1}$ (Díaz et al. 2007).

La eutrofización en los ecosistemas acuáticos es definida como una respuesta al incremento de nutrientes (Balali et al. 2013). Particularmente en los humedales la 
carga de nutrientes suele estar vinculada, entre otras, a alteraciones hidrológicas que abarcan cambios en la distribución espacio-temporal de la vegetación y en el ciclo de nutrientes. El proceso de eutrofización en los humedales acelera la productividad primaria y aumenta la acumulación neta de materia orgánica y nutrientes. Asimismo favorece el aumento de la actividad microbiana y la consecuente descomposición y mineralización de la materia orgánica en nutrientes (Sánchez-Carrillo et al. 2010).

La evaluación del estado trófico de los mallines según el índice de Carlson modificado por Aizaki (1981) para clorofila a (TSI $I_{\mathrm{Cl}}$ ) y para fósforo total (TSI $\mathrm{PT}_{\mathrm{PT}}$,

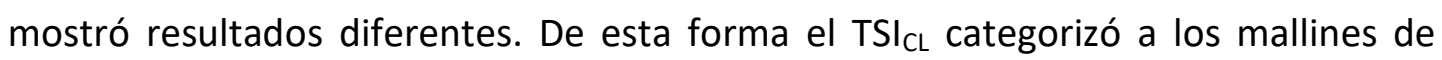
bosque entre oligotróficos y mesotróficos $y$, a los de estepa como mayormente mesotróficos. Mientras que el TSI ${ }_{\mathrm{PT}}$ indicó estados principalmente mesotróficos en bosque, salvo aquellos urbanos, y eutróficos en mallines de estepa. Similares discrepancias entre ambos índices TSI, se registraron en la evaluación del estado trófico en humedales mediterráneos de Guadalquivir (Gilbert et al. 2015).

En la mayoría de los mallines estudiados, el estado trófico estimado por el TSI $_{\mathrm{PT}}$ es mucho más alto que el calculado a partir de $\mathrm{TSI}_{\mathrm{Cl}}$, en coincidencia a lo documentado en otros estudios (Elmaci et al. 2009, Jarosiewicz et al. 2011, Vidović et al. 2015). Esto ocurre porque la concentración de clorofila a es notablemente más baja a la esperada de acuerdo a la concentración de fósforo total (Gilbert et al. 2015). Una de las probables causas de este fenómeno es que el nitrógeno puede actuar como nutriente limitante del fitoplancton y el fósforo encontrarse en exceso, de acuerdo a la relación N:P (Reddy y De Laune 2008, Sánchez-Carrillo et al. 2010); otra causa importante es debida de la presencia de las macrófitas (Gilbert et al. 2015). Gran parte de los mallines estudiados presentaron cuerpos de agua con lechos de macrófitas, con coberturas superiores a $50 \%$, como fue evidenciado en la caracterización de los biotopos, con altos porcentajes de vegetación compleja (subemergente y emergente) y/o vegetación simple (sólo emergentes). Es bien conocido que las macrófitas, bajo ciertas condiciones, pueden ejercer efectos negativos sobre la biomasa de fitoplancton, ya sea porque compiten por los 
nutrientes inorgánicos o porque que actúan como refugio del zooplancton, incrementando la presión de pastoreo o porque pueden liberar sustancias alelopáticas (Gulati y Van Donk 2002).

De esta forma la aplicación de los índices basados únicamente en parámetros de la columna de agua, tales como los TSI $\mathrm{CL}_{\mathrm{Y}} \mathrm{TSI}_{\mathrm{PT}}$ (Carlson 1977), pueden presentar discrepancias al evaluar el estado trófico de humedales someros dominados por macrófitas (Gilbert et al. 2015). Recientemente, de Vicente et al. (2010) señalaron que el uso del número de bioproducción (BPN, Håkanson, 1984) puede representar un indicador más apropiado para humedales, lagos poco profundos y los sistemas acuáticos caracterizados por una extrema variabilidad temporal, debido a que es calculado a partir de la composición de los sedimentos (nitrógeno total y materia orgánica).

\subsection{EFECTOS DEL USO DEL SUELO SOBRE LA BIOTA DE MALLINES}

\subsubsection{Uso urbano y agrícola en mallines de bosque mixto}

En coindicencia con la predicción $A$, los efectos del uso del suelo sobre la calidad fisicoquímica del agua fueron claramente visualizados en los mallines urbanos del bosque mixto, con mayor enriquecimiento de nutrientes y aumento de la conductividad electrica, alcalinidad y turbidez. Las concentraciones de nitrógeno total y amonio fueron casi 10 veces superiores (> 423,90 $\mu \mathrm{gNT} . \mathrm{L}^{-1} ;>14 \mu \mathrm{g}^{+} \mathrm{NH}_{4} \cdot \mathrm{L}^{-1}$ ), los sólidos suspendidos totales más de cinco $\left(>5,7 \mu \mathrm{g} \cdot \mathrm{L}^{-1}\right)$ y, el fósforo total y la conductividad eléctrica se triplicaron $\left(>50 \mu \mathrm{g} . \mathrm{L}^{-1} ;>130 \mu \mathrm{S} . \mathrm{cm}^{-1}\right)$ en los mallines urbanos respecto a los de referencia. El incremento de nutrientes y el aumento de sales disueltas es uno de los principales impactos directos que reciben los humedales urbanos debido a descarga de desagües de aguas residuales y pluviales (Boyer y Polasky 2004, Rybczyk et al. 2002, Lee et al. 2006). Azous y Horner (2000) observaron en humedales someros de áreas urbanas de la cuenca del Estrecho de Puget, Washington, valores medios similares a los registrados en este estudio, con incrementos sustanciales de amonio, nitratos-nitritos, fotóforo total y conductividad eléctrica respecto de sitios no urbanizados. 
En tanto a los mallines de uso agrícola, la composición fisicoquímica del agua mostró similitudes con aquellos utilizados de referencia y solo existieron diferencias significativas en las concentraciones de nitrógeno total. En los mallines Playa Negra y Cretón las concentraciones de NT fueron cercanas a $400 \mu \mathrm{g} / \mathrm{L}$, coincidentes a la documentada por Alonso et al. (2010) en un estudio anterior realizado en ese último mallín. Los aportes de nitrógeno en humedales agrícolas pueden ocurrir debido a ciertas prácticas de fertilización de suelo, o por aportes de fecas y orina del ganado (Collins et al. 1998, Mitsch y Gosselink 2007).

Estas similitudes, entre las características fisicoquímicas de los mallines de uso agrícola y de referencia, pueden atribuirse a que en general los mallines de bosque se encuentran frecuentemente menos disturbados por el ganado que aquellos de estepa, aunque presentan condiciones ambientales más rigurosas (permanecen más meses cubiertos por nieve y la estación de crecimiento de las plantas es más corta) (Raffaele 1999).

La percepción tradicional de que los humedales funcionan como sumideros los ha llevado a ser utilizados como zonas de vertido de aguas residuales causando severos cambios ecológicos, como la ineficiencia en la remoción de nutrientes (Jingfeng et al. 2011, Mukherjee 2011), la eutrofización (Davis et al. 2010, SánchezCarrillo et al. 2010), la acumulación de metales pesados y su biomagnificación en cadenas tróficas, ciertos problemas sanitarios para la salud humana y la degradación de áreas recreativas, entre otros (Azous y Horner 2000, Bassi et al. 2014). Los mallines de uso urbano en San Carlos de Bariloche, a diferencia del resto, mostraron un patrón típico de eutrofización con un incremento significativo de los nutrientes, la turbidez (SST) y la biomasa del fitoplancton (clorofila a) con la consecuente reducción de la biodiversidad de plantas acuáticas (Sayer et al. 2010). Esta valoración fue similar con la obtenida por los índices de estado trófico TSL $\mathrm{TL}_{\mathrm{CL}}$ TSI $_{\mathrm{PT}}$, categorizando a los mallines urbanos como mesotróficos y eutróficos respectivamente. Paralelamente la riqueza específica de macrófitas fue casi tres veces menor en los mallines urbanos respecto a la de los sitios de referencia, con ausencia del biotopo "vegetación compleja" por la falta de especies subemergentes 
Existe una amplia bibliografía documentado la reducción de la biodiversidad de macrófitas en humedales de áreas urbanas (Findlay y Houlahan 1997, Lee et al. 2006, Zelnik et al. 2012) y de áreas agrícolas (Faulkner 2004, Hauenstein et al. 2014, Kutschker et al. 2014). Diversos estudios han demostrado que el aumento de fósforo y nitrógeno afecta a la composición y diversidad de los ensambles de plantas acuáticas (Carbiener et al. 1990, Lacoul y Freedman 2006, Bornette y Puijalon 2011). Entre otros, Lougheed et al. (2001) encontraron en un relevamiento de 62 humedales someros en el área de Los Grandes Lagos, que la riqueza de macrófitas subemergentes declinó con el deterioro de la calidad del agua.

El enriquecimiento de nutrientes puede producir el reemplazo de plantas sumergidas por algas planctónicas (Sayer et al. 2010). Mientras que los niveles de fósforo total permanecen por debajo de un valor umbral (generalmente $<25 \mu . \mathrm{L}^{-1}$ ), las macrófitas sumergidas son comunes en áreas libres de vegetación emergente (van der Valk 2012). Sin embargo, cuando los niveles de fósforo exceden ese valor, un rápido crecimiento del fitoplancton (bloom) disminuye significativamente la disponibilidad de la luz reduciendo o eliminando a las plantas sumergidas (Declerck et al. 2005, van der Valk 2012). De esta forma a medida que se incrementa la eutrofización, con el consecuente aumento de la turbidez, los humedales pasan gradualmente de un estado dominado de macrófitas a otro dominado por fitoplancton (Sayer et al. 2010). Situación claramente evidenciada en los mallines de uso urbano del presente estudio.

Esos cambios en la estructura y funcionamiento de los mallines en relación al uso del suelo, mostraron su correlato con la biodiversidad de los ensambles de macroinvertebrados. De esta forma, tanto la riqueza taxonómica, y en menor medida, la diversidad de Shannon-Wienner y la densidad, disminuyeron acorde con el incremento de la degradación de los mallines. Particularmente en relación a la riqueza, los ensambles estuvieron muy simplificados en los mallines urbanos, con una reducción significativa ( $30 \%$ ) al compararla con los sitios de referencia. Estos resultados concuerdan con los encontrados por Johnson et al. (2013), en un extenso estudio de 219 humedales templados de la Región de Colorado. Los autores 
documentaron una disminución gradual de la biodiversidad de macroinvertebrados en el sentido del incremento del disturbio (natural-agrícola-urbano), donde en áreas urbanizadas la riqueza llegó reducirse 33\% respecto de los sitios naturales. En Patagonia, diferentes estudios documentaron la reducción de la riqueza taxonómica y de la diversidad Shannon-Wiener relacionadas a áreas agrícolas como urbanas para macroinvertebrados de ríos y arroyos en la biozona de bosque (Macchi y Dufilho 2008, Miserendino 2009, Miserendino et al. 2011).

Las relaciones de dominancia que mostraron los grupos funcionales asociados a los usos del suelo, reflejaron una amplia mayoría de colectores recolectores en los mallines de referencia y de uso agrícola, con una alta contribución de diversos taxa de Chironomidae y Oligochaeta (Spieles y Mitsch 2000, Zilli et al. 2008, Bazzanti et al. 2009, Epele 2014). Los humedales son ecosistemas típicamente autotróficos en donde la producción primaria excede a la respiración total de las comunidades y el rápido decaimiento de las plantas acuáticas, con la consecuente acumulación de necromasa, favorece el desarrollo de invertebrados colectores y raspadores (Wissinger 1999). Particularmente este último grupo se destacó por su alta biomasa en los mallines de referencia, y su disminución hacia los sitios más impactados guardó estrecha relación con la reducción de la riqueza y la cobertura de macrófitas (Della Bella et al. 2008).

Asimismo los resultados de este estudio mostraron una fuerte disminución de la densidad y biomasa de los colectores filtradores con el incremento del disturbio en los mallines de bosque. Diversos estudios describieron que la reducción de los filtradores en humedales afectados por actividades agrícolas o urbanas, respondieron a cambios en la composición química del agua (Kashian y Burton 2000, Bazzanti et al. 2009) o al aumento de la sedimentación (Mereta et al. 2013). En coincidencia con algunos de esos estudios, los taxa más afectados fueron Muscullium sp (Sphaeriidae) y diversas especies de Simuliidae. Estos últimos son fuertemente afectados y tienden a desaparecer en aguas con alto contenido de sedimentos en suspensión (Armitage y Blackburn 2001, Jones et al. 2012). El incremento de la sedimentación en los humedales suele asociarse a prácticas 
Macchi, Pablo. 2017. Macroinvertebrados acuáticos como indicadores ecológicos de cambios en el uso del suelo en mallines del sudoeste de la Provincia de Río Negro (Dra. María Laura Miserendino - Dra. Nora Gómez)

agrícolas de labranza, pisoteo de ganado, alteraciones hidrológicas así como a la escorrentía de aguas residuales en las ciudades (Steinman y Rosen 2000).

\subsubsection{Uso agrícola en estepa patagónica}

En general, los humedales sujetos a actividades agrícolas y mejoramiento de pasturas presentan mayores valores de nutrientes, turbidez, conductividad eléctrica y $\mathrm{pH}$, que los sitios no disturbados (Helgen y Gernes 2001, Gleason et al. 2003, Chipps et al. 2006). Sin embargo la densidad ganadera puede tener pocos efectos significativos sobre la concentración de los nutrientes (Steinman et al. 2003). Scrimgeour y Kendall (2002) afirman que la acción del ganado puede no resultar en un aumento neto de los nutrientes en un humedal, debido a que el pastoreo y los procesos de degradación pueden alterar sus formas y volverlos más disponibles. En este sentido los mallines de referencia en la biozona de estepa, también utilizados para el pastoreo pero con menor carga ganadera y con manejo diferencial, presentaron concentraciones de nutrientes que no difirieron significativamente respecto de aquellos sitios sometidos a mayor intensidad ganadera (uso agrícola). Epele y Miserendino (2016) registraron, en un estudio temporal en un mallín de estepa, que los valores de nitrógeno y de fósforo, tanto en sus fracciones solubles como totales, se mantuvieron relativamente sin cambios y fueron comparables a los valores encontrados en los meses previos a la incorporación del ganado. Sin embargo los efectos del pastoreo intensivo, junto a los cambios asociados a la dinámica hídrica por obras hidráulicas en mallines de uso agrícola fueron claramente reflejados por el aumento significativo del $\mathrm{pH}$ y de la conductividad eléctrica del agua respecto de los sitios de referencia. Éstos valores resultaron similares a los documentados en otros mallines patagónicos, con impactos ganaderos moderados y altos (CE: 237,8 $\mu \mathrm{S} . \mathrm{cm}^{-1}, \mathrm{pH}: 8,7$ ) (Epele y Miserendino 2015).

Los principales disturbios que afectan a los mallines de la estepa patagónica se relacionan a las alteraciones en su dinámica hídrica y en el pastoreo intensivo y continuo durante períodos prolongados (Raffaele 1999, Utrilla et al. 2013). Estos disturbios han provocado procesos de degradación por disminución de la cobertura 
vegetal, erosión hídrica por escurrimiento superficial resultante en surcos y cárcavas, salinización debido a la alta evaporación de agua y compactación del suelo por efecto del pisoteo animal (del Valle 1998, Ciari 2009, Peña y de Ferreras 2012). Particularmente, el sobrepastoreo constituye el mayor disturbio antrópico sobre los mallines de estepa debido a que altera la dinámica del agua en el perfil del suelo, ocasionando grandes cambios en los mallines (Raffaele 1999). La disminución de la cobertura vegetal por pastoreo continuo, induce una mayor tasa de evaporación sobre el suelo, acarreando por capilaridad sales disueltas que se acumulan en la superficie modificando así, las propiedades fisicoquímicas del suelo y del agua (Ciari 2009, Utrilla et al. 2013). Asimismo, el aumento de suelo desnudo crea condiciones para la erosión debido al escurrimiento superficial y a la remoción de los sedimentos (Raffaele 1999).

De esta forma, las altas cargas ganaderas favorecen la salinización y erosión por el agua, lo que determinan la desertificación severa de los mallines con cambios drásticos en la composición y cubierta vegetal, así como en su fisionomía (Aguiar y Paruelo 2003, Buono et al. 2010). Estos efectos fueron notoriamente observados en los mallines tipificados de uso agrícola, con una disminución significativa de la diversidad de los ensambles de macrófitas y la consecuente simplificación de biotopos, por la reducción de la cobertura de vegetación compleja (subemergenteemergente), así como por el aumento de la cobertura de suelo degradado, con valores superiores a $30 \%$, en áreas perimetrales tanto a 100 metros como a 500 metros.

Diferentes autores (Andersen y Calov 1996, Hornung y Rice 2003, Haynes et al. 2013) atribuyen que los humedales con una alta perturbación ganadera presentan ensambles de plantas acuáticas con menor riqueza, abundancia y diversidad de biotopos debido a los daños físicos directos que se producen como consecuencia del pastoreo (Declerck et al. 2005), pero también por el aumento de la turbidez que ocasiona el pisoteo al liberar sedimentos finos del suelo (Kutschker et al. 2014). 
Los efectos de estas alteraciones, en los mallines de estepa, también se reflejaron en los atributos comunitarios de los macroinvertebrados. Aunque no hubo diferencias significativas, la riqueza taxonómica y la diversidad fueron más bajas en los mallines de uso agrícola, con valores medios similares a los descriptos por Epele (2014) para estos humedales con altos impactos ganaderos. Es evidente que los efectos del pastoreo sobre la vegetación acuática tienen un efecto indirecto sobre los macroinvertebrados, generando ensambles más simplificados debido a la pérdida de la complejidad de hábitats (Silla 2005, Epele y Miserendino 2015). En particular los mallines degradados estuvieron dominados por Copepoda spp., Ostracoda spp., Sigara santiagiensis (Corixidae), Haliplus subseriatus (Coleoptera) y Ablabesmyia sp. (Chironomidae), coincidiendo en general con lo reportado por Steiman et al. (2003), Picazo et al. (2012), Silver et al. (2012) y Epele (2014). Estos ensambles de invertebrados se caracterizan por presentar especies con ciclos de vida más corto, o poseer mecanismos de reproducción a partir de huevos de resistencia o cistos, o por tener estadios alados que les permiten colonizar nuevos ambientes (Wissinger 1999).

Respecto a la estructura trófica, los colectores recolectores disminuyeron su abundancia hacia los sitios más disturbados, tal como fue registrado en los mallines de bosque. Este grupo funcional, que requiere de altas cantidades de materia orgánica particulada fina depositada sobre sustratos (MOPF) (Wright y Smock 2001, Kreutzweiser et al. 2005), estuvo mayormente representado por dípteros de la familia Chironomidae. La acción del ganado pastoreando dentro de los humedales, reduce la disponibilidad de hábitat de gran parte de los taxa de Chironomidae, debido a que mezcla y remueve la MOPF de la vegetación y de los sedimentos (Silver y Vamosi 2012).

Por el contrario, los mallines de uso agrícola presentaron un aumento significativo de los colectores filtradores, tanto en densidad como en biomasa, representados principalmente por Cladocera, Copepoda y Ostracoda. Esto es consistente con lo documentado por Smith (2012) y Epele (2014), observando una 
Macchi, Pablo. 2017. Macroinvertebrados acuáticos como indicadores ecológicos de cambios en el uso del suelo en mallines del sudoeste de la Provincia de Río Negro (Dra. María Laura Miserendino - Dra. Nora Gómez)

dominancia de colectores filtradores en humedales someros y mallines de estepa intensamente pastoreados.

\subsection{MÉTRICAS PARA EL MONITOREO DE LA CALIDAD DEL AGUA EN MALLINES}

Los indicadores del estado ecológico de los ecosistemas acuáticos son reconocidos cada vez más como herramientas fundamentales para la gestión y el manejo adecuado de estos ecosistemas (Niemi y McDonald 2004, Brazner et al. 2007). Particularmente, los macroinvertebrados acuáticos juegan un papel importante en el funcionamiento de los humedales, por lo tanto el análisis exhaustivo de estas comunidades puede proporcionar una visión general del estado de conservación del mismo (Balcombe et al. 2005). En este sentido un enfoque multimétrico permite evaluar el efecto de diversos factores de estrés en diferentes atributos de los ensambles de macroinvertebrados (Brand y Miserendino 2015), donde cada métrica evaluada es una característica de la biota que cambia de una manera predecible a medida que aumenta la intensidad del estrés ambiental (Barbour et al. 1996).

Diversos estudios realizados en humedales de agua dulce de zonas templadas han demostrado que los macroinvertebrados acuáticos constituyen buenos indicadores del estado ecológico de esos ecosistemas (Kashian y Burton 2000, Tangen et al. 2003, Lunde y Resh 2012, Batzer 2013, Epele y Miserendino 2015).

Los efectos antrópicos del uso del suelo sobre los ensambles de macroinvertebrados de mallines tanto de bosque como de estepa fueron reflejados en diversos atributos ambientales y métricas simples. El modelo conceptual propuesto en la presente tesis (Figura 6.1), evidencia un gradiente de disturbio asociado a los usos del suelo (referencia - agrícola - urbano), a partir de la degradación de la calidad de agua junto a la reducción de la riqueza, la cobertura y la complejidad estructural de los ensambles de macrófitas. Estos cambios, que simplifican la estructura de los ensambles de macroinvertebrados acuáticos, son evidenciados por una serie de métricos de riqueza y composición. 
La relevancia de diversas condiciones ambientales asociadas a la degradación de los humedales debido a los diferentes usos del suelo y sus efectos sobre las métricas de macroinvertebrados acuáticos, ha sido estudiada en trabajos anteriores: exceso de nutrientes y eutrofización (Robson y Clay 2005, Kadoya et al. 2011), aumento de pH y salinidad (Chipps et al. 2006, Gascón et al. 2009), reducción de la riqueza y cobertura de macrófitas (Steiman et al. 2003, Della Bella et al. 2008), y la disminución de la complejidad estructural del hábitat (Silver y Vamosi 2012, Bird 2013).

Aunque naturalmente existen variaciones fisicoquímicas entre los mallines de ambas biozonas debidas al clima y a la geomorfología, principalmente en salinidad y alcalinidad (como fuera explicado anteriormente), la comparación de los diferentes usos de suelo respecto a los sitios de referencia (tanto en bosque como en estepa), permitió poner de manifiesto que esas variables, que difieren regionalmente, cambian igualmente dentro de cada biozona, producto de los disturbios antrópicos. En este sentido, ocho de las métricas seleccionadas de macroinvertebrados evidenciaron esa degradación de la misma manera, independientemente de las características particulares de cada biozona.

Dentro de esas métricas, las de riqueza resultaron ser las más sensibles frente al disturbio, en coincidencia con otros estudios (Boix et al. 2007 y Gascón et al. 2009) y sus valores disminuyeron a medida que aumentó la degradación en los mallines (Figura 6.1). Las métricas de riqueza reflejan la diversidad de las comunidades acuáticas (Resh et al. 1995) y su aumento se correlaciona con el incremento de la salud de las comunidades y sugieren que el nicho, el hábitat y los recursos son adecuados para soportar la supervivencia y propagación de muchas especies (Barbour et al. 1996). 


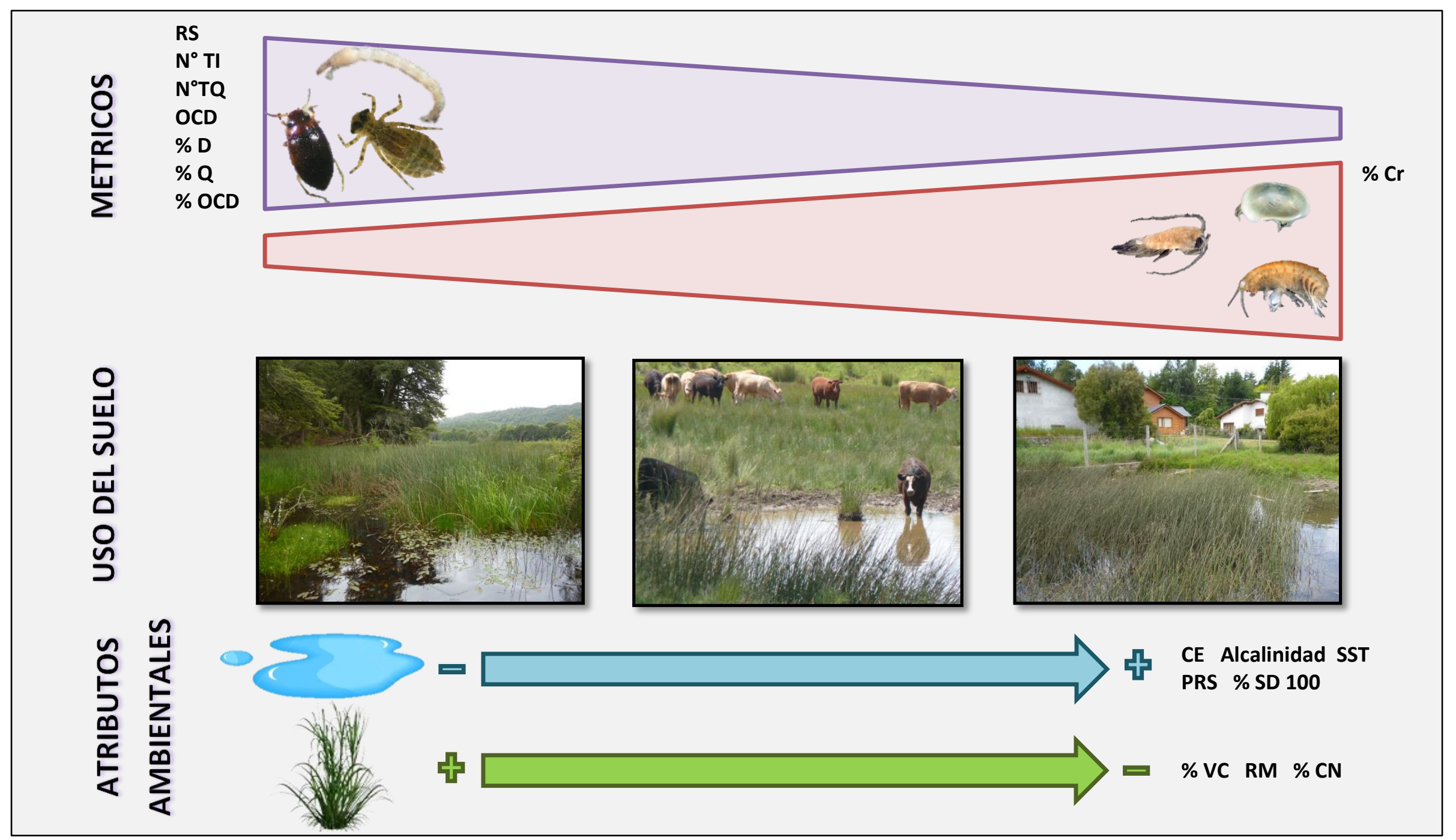

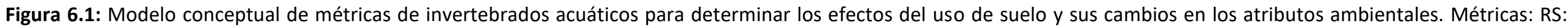

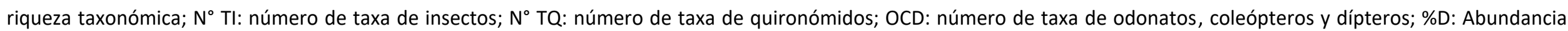

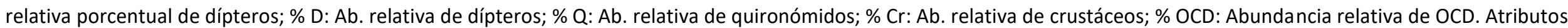

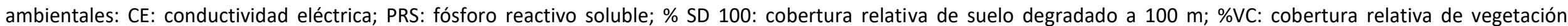
compleja; RM: riqueza de macrófitas; \% CN: cobertura relativa de macrófitas nativas. 
El " $n^{\circ}$ de taxa de insectos" y particularmente el " $n$ " de taxa OCD" y el " $n^{\circ}$ de taxa de quironómidos" fueron las métricas de riqueza que correlacionaron con mayor cantidad de parámetros ambientales en ambas biozonas. El incremento excesivo de nutrientes, principalmente PRS, junto a un aumento de la conductividad eléctrica, alcalinidad y SST fueron los parámetros fisicoquímicos que más influyeron sobre ellas. De forma similar pero con menor intensidad respondieron las métricas de composición el "\% de dípteros", el "\% de quironómidos" y el "\% OCD". Sin embargo todas esas métricas presentaron correlaciones significativas positivas con el aumento de la complejidad del hábitat (\% de vegetación compleja) y con los atributos comunitarios de macrófitas, pero negativas con el aumento de la cobertura de suelo con mayor grado de degradación (\% SD 100).

Los disturbios antrópicos son conocidos por tener un gran impacto en la diversidad de los invertebrados acuáticos en los humedales (Batzer 2013) y los resultados de este estudio apoyan esta conclusión en relación a la degradación de la zona más próxima a los mallines. La cobertura del uso del suelo con el incremento de áreas urbanas $(\% \quad \mathrm{U}) \mathrm{y}$ de suelo degradado (\% SD), principalmente en áreas perimetrales de 100 metros, guardó una estrecha relación con la disminución de la calidad del agua de los mallines, en coincidencia con lo documentado en otros trabajos (Brooks et al. 2002, Faulkner 2004, Bird y Day 2014). Estos disturbios antrópicos repercutieron sobre los ensambles de macroinvertebrados, a través de la reducción de los valores de las métricas anteriormente mencionadas según la predicción realizada.

En la mayoría de los humedales de agua dulce, el grupo Chironomidae es el más diverso y abundante de macroinvertebrados acuáticos (Stagliano et al.1998, Kratzer y Batzer 2007, Wrubleski y Ross 2011) y su ausencia indica que el hábitat tiene características particulares (Batzer y Ruhí 2013). Aunque ciertos taxa de Chironomidae pueden dominar ensambles en ambientes disturbados (Coffman y Ferrington 1996, Moya et al. 2007), muchos otros son sensibles a los cambios en la calidad del agua y a la degradación del hábitat (Campbell et al. 2009). La complejidad estructural del hábitat favorece el desarrollo diversas asociaciones de Chironomidae (Brodersen et al. 2001) y su simplificación, por acción del pastoreo y pisoteo del ganado en áreas 
agrícolas (Campbell et al. 2009, Silver y Vamosi 2012), o por la contaminación en áreas urbanas (Carew et al. 2007), afectan drásticamente a la composición y diversidad de los ensambles de esta familia.

Existen pruebas concluyentes sobre la utilidad de Chironomidae, a nivel de género, como biomonitores en humedales someros (King y Richardson 2002, Campbell et al. 2009). Incluso la reducción de la abundancia de Chironomidae a nivel de familia puede brindar valiosa información sobre el nivel de disturbio (Steiman et al. 2003, Chipps et al. 2006).

Otros taxa potencialmente indicadores de la degradación de los humedales y que formaron parte las métricas compuestas, el " $n$ de taxa OCD" y el "\% de OCD" fueron Coleoptera y Odonata. Dytiscidae e Hydrophilidae son las familias de Coleoptera más frecuentes en los humedales (Batzer y Ruhí 2013) y junto a las larvas de Odonata constituyen los depredadores más destacados (Hydrophilidae solo sus larvas).

Un creciente número de estudios han demostrado la fuerte influencia de la heterogeneidad de las comunidades de macrófitas en la estructuración del hábitat para los ensambles de Coleoptera (Fairchild et al. 2000, Menetrey et al. 2005, Epele y Archangelsky 2012), de Odonata (Sahlen y Ekestubbe 2001, Lee Foote et al. 2005, Oertli 2008) y de Diptera, particularmente Chironomidae (Batzer y Resh 1991, Aditya y Saha 2006, Frelik 2014). Es por ello que la degradación ambiental de los mallines, a partir de la reducción de la complejidad estructural de macrófitas, afectaría de manera similar a estos tres taxa que conforman esas métricas combinadas (OCD), sugiriendo que ambas, podrían funcionar adecuadamente para la valoración de las consecuencias del uso del suelo en los mallines patagónicos, dado que respondieron como se esperaba al disturbio.

Finalmente, y según lo esperado, la única métrica que tuvo una respuesta positiva al disturbio fue el "\% de crustáceos", principalmente debido al aumento de la abundancia de Cladocera, Copepoda y Ostracoda y en menor medida Hyalella curvispina. Estos mallines más impactados por el uso del suelo presentaron en general un ambiente más simplificado, una menor riqueza de macrófitas y un mayor grado de eutrofización, junto a una mayor conductividad eléctrica y alcalinidad del agua. Epele 
(2014) documentó un aumento de la abundancia de diversos taxa de Cladocera y Copepoda asociados a mallines degradados con menor riqueza de plantas acuáticas, elevados valores de nutrientes, $\mathrm{pH}$ y conductividad eléctrica. Estos resultados son coincidentes a los encontrados en ambientes eutróficos (Pinto-Coelho et al. 2005, Kagalou et al., 2010, van Egeren et al. 2011). El aumento de la densidad del fitoplancton (Clorofila a), la simplificación del hábitat, junto a una baja competencia interespecífica, probablemente contribuyen a un incremento en la abundancia de estos crustáceos (Smith 2012, Tibúrcio et al. 2015).

Las principales causas de la pérdida y degradación de los humedales, y tal lo demostrado en el presente estudio para los mallines patagónicos, son debidas al pastoreo intensivo, al drenaje para la agricultura, a la urbanización, a los vertidos de aguas residuales, etc.) (Assessment M. E. 2005). Por lo tanto, la evaluación integral del estado ecológico de los mallines, combinando los parámetros fisicoquímicos y las métricas basadas en macroinvertebrados, podría proporcionar una herramienta valiosa para su evaluación y monitoreo, facilitando el desarrollo de acciones tendientes a la conservación y a la gestión sustentable de estos ecosistemas acuáticos patagónicos. 


\section{CONCLUSIONES}

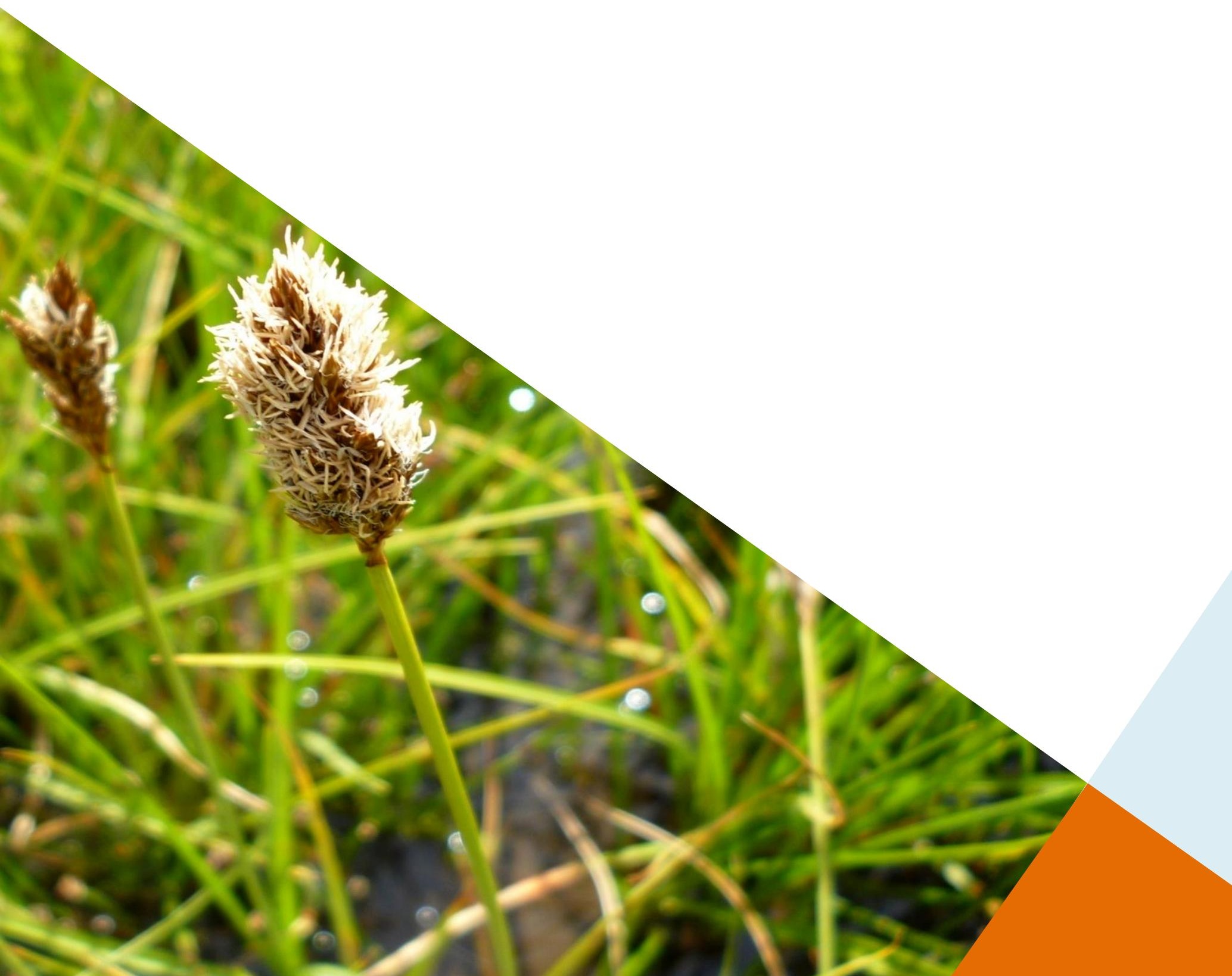




\subsection{CONCLUSIONES}

Las comunidades acuáticas de los mallines del presente estudio evidenciaron su importancia como reservorios de biodiversidad regional, comparable a la registrada para ríos y arroyos patagónicos. Con la identificación de 145 taxa de macroinvertebrados y 76 taxa de plantas acuáticas, donde la riqueza de ambas comunidades se constituyó en la más alta registrada respecto a la de trabajos precedentes.

Los taxa de macroinvertebrados dominantes en los mallines fueron Diptera y Crustacea. Sin embargo, al igual que en otros humedales someros del mundo, se destacó particularmente la diversidad de la familia Chironomidae con la presencia de 33 taxa, lo que constituyó el $23 \%$ del total de los descriptos.

La comparación entre los ensambles de macroinvertebrados de la columna de agua y de sedimentos mostró a estos últimos notablemente más pobres, con baja riqueza y abundancia, sin el aporte de taxa exclusivos para este hábitat. Este estudio, que constituyó el primer aporte al conocimiento de macroinvertebrados de sedimentos en mallines, sugiere que no serían muy apropiados para su uso como bioindicadores para la vigilancia ambiental de estos humedales.

A escala biogeográfica, la composición y estructura de las comunidades biológicas mostró su correlato con el gradiente de precipitaciones oeste-este. De esta forma ensambles con mayor riqueza y biodiversidad se localizaron en la biozona de bosque mixto, presentado una reducción significativa en los mallines localizados en la estepa patagónica. Asimismo, aunque la densidad de macroinvertebrados fue similar en ambas zonas ecológicas, la biomasa fue tres veces superior en los mallines de bosque debido principalmente a la presencia de tricópteros del género Verger (Limnephilidae), ausentes en mallines de estepa, así como por la abundancia de los anfípodos Hyalella curvispina, H. patagonica y a la alta abundancia estacional de Parabroteas sarsi (Copepoda).

El aumento de $\mathrm{pH}$ y conductividad eléctrica fueron los parámetros fisicoquímicos del agua que mejor explicaron las variaciones en las comunidades acuáticas. Conforme 
disminuyen las precipitaciones hacia el este, el lavado de rocas sedimentarias de la cuenca hidrológica produce un flujo natural de sales hacia los bajos ocupados por los mallines, donde se acumulan debido a la escasez de agua para su drenaje. Este fenómeno se traduce en un aumento de la alcalinidad y de la salinidad, variables que mostraron estructurar $\mathrm{y}$ diferenciar a las comunidades de macroinvertebrados $\mathrm{y}$ macrófitas de estos humedales.

El análisis de los mallines teniendo en cuenta el uso del suelo permitió evidenciar claramente los efectos antrópicos sobre las condiciones ambientales. Esto fue validado por los análisis de componentes principales, dónde los sitios más disturbados, agrícolas y urbanos en ese orden, fueron caracterizados por poseer mayor conductividad eléctrica y concentración de nutrientes, en coincidencia con lo afirmado en la predicción A.

La urbanización causó los impactos más severos en los mallines de bosque. Al compararlos con los sitios de referencia y agrícolas, la degradación de la calidad del agua se tradujo en un aumento de la conductividad eléctrica y de la concentración de nutrientes con la consecuente eutrofización de sus aguas. El incremento de nutrientes favoreció el aumento de la biomasa del fitoplancton (clorofila $a$ ) y podría constituir la principal causa de la ausencia de las macrófitas subemergentes registrada en los mallines urbanos, debido al aumento de la turbidez (aumento de sólidos suspendidos totales).

Los efectos del uso agrícola, debidos exclusivamente al pastoreo, sobre los parámetros fisicoquímicos de los mallines fueron mayormente diferenciados en aquellos de estepa. Historicamente en esta biozona los mallines son utilizados intensamente para la ganadería con diferentes prácticas de manejo, las que en algunos casos incluyen modificaciones hidráulicas de canalización y almacenamiento de agua. Aquellos mallines con mayor carga ganadera y alteraciones en la dinámica hídrica evidenciaron mayor erosión de suelo, tanto en áreas perimetrales a 100 como a 500 metros, producto de la compactación del suelo (por pisoteo) y de la pérdida de vegetación por sobrepastoreo. Estos disturbios provocan un aumento de la erosión 
hídrica y de la salinización, que se reflejó en una mayor conductividad eléctrica, alcalinidad y sólidos suspendidos totales en los mallines de uso agrícola.

La pérdida de la complejidad estructural del hábitat (vegetación compleja: subemergentes y emergentes) hacia ambientes más simplificados (vegetación simple: únicamente emergentes) estuvo fuertemente influenciada por el uso del suelo, apoyando la predicción C. De esta forma, la riqueza de macrófitas, tanto nativas como endémicas, así como la presencia de macrófitas con hojas flotantes como Potamogeton linguatus o subemergentes como Callitriche lechleri y Myriophyllum quitense, se redujeron ampliamente con el aumento del disturbio.

Los cambios ambientales debidos al uso del suelo en los mallines repercutieron en los atributos estructurales de los ensambles de macroinvertebrados. De esta forma, independientemente de la biozona de estudio, tanto la riqueza taxonómica como la diversidad disminuyeron acorde con el gradiente de disturbio, en consonancia con lo planteado en la predicción B.

En líneas generales la estructura funcional de la comunidad de macroinvertebrados, también fue afectada por el uso del suelo. Tanto la densidad como la biomasa de los colectores recolectores mostraron una reducción destacada en mallines agrícolas y urbanos respecto de aquellos de referencia en ambas biozonas. En cambio, la respuesta de los colectores filtradores mostró un patrón diferente, su contribución fue menor hacia los sitios disturbados en la biozona de bosque, pero mayor en los mallines más degradados en la estepa. Estos cambios pueden explicarse debido a la diferente composición de los ensambles, mientras que en el bosque dominaron como colectores filtradores diversos taxa de Simuliidae, en la estepa lo hicieron mayormente los microcrustáceos.

Los modelos obtenidos de las relaciones especie ambiente, según los análisis de correspondencias canónicas basados en los datos ambientales y biológicos de mallines, permitieron identificar grupos de taxa tolerantes al disturbio antrópico que se repitieron en ambas biozonas. Éstos estuvieron mayormente representados por, Copepoda spp., Cladocera spp., Ostracoda spp., Hyalella curvispina, Sigara santiagiensis (Hemiptera) y Ablabesmyia sp. (Chironomidae). Además, particularmente 
en bosque se destacaron Mesostoma ehrenbergii (Plathyhelminthes), Stephensoniana sp. (Oligochaeta) y Notonecta vereertbruggheni (Hemiptera) y en estepa Chaetogaster diaphanus (Oligochaeta) y Haliplus subseriatus (Coleoptera). Estas especies presentan diversas estrategias que les permiten colonizar una gran variedad de hábitat como ciclo de vida corto, huevos de resistencia o cistos, o mecanismos de dispersión con estadios alados.

La alteración del estado ecológico de los mallines fue evidenciada por la selección de ocho métricas comunitarias que respondieron de igual manera en cada biozona. Las métricas de riqueza y diversidad ("riqueza taxonómica", "N de taxa de insectos", "N de taxa de dípteros", " $\mathrm{N}^{\circ}$ de taxa de quironómidos" y " $\mathrm{N}^{\circ}$ de OCD") declinaron fuertemente con la reducción de la heterogeneidad espacial, dada fundamentalmente por la riqueza y diversidad de plantas acuáticas, junto con la degradación de la calidad del agua (aumento de alcalinidad, conductividad eléctrica, sólidos suspendidos totales y fósforo reactivo soluble) y con una mayor cobertura de suelo degradado en áreas perimetrales a los mallines. De igual manera respondieron las métricas de composición y abundancia ("\% de dípteros", "\% de quironómidos" y el “\% de $O C D)$, salvo el "\% de crustáceos" que creció conforme aumentó el grado de disturbio.

La degradación de los mallines debido a los diferentes usos del suelo, evidenciaron a partir de este estudio, una diferente respuesta entre dípteros, particularmente quironómidos, y crustáceos. Los dipteros mostraron ser más sensibles frente al disturbio, en cambio los crustaceos por poseer mayor plasticidad ambiental (tolerantes). Estos resultados sugieren que estos grupos podrían resultar apropiados como herramientas metodológicas que permitan la evaluación y vigilancia ambiental de la calidad ecológica de los mallines patagónicos.

Las diversas presiones antrópicas debidas a los diferentes usos del suelo han puesto en evidencia la manera que afectan a la integridad de la biota, y a sus funciones ecológicas, en los mallines de Patagonia. El presente trabajo resalta la vulnerabilidad de estos ambientes frente al disturbio y la respuesta de los ensambles de macroinvertebrados acuáticos. Por ello es prioritario el desarrollo de programas de 
Macchi, Pablo. 2017. Macroinvertebrados acuáticos como indicadores ecológicos de cambios en el uso del suelo en mallines del sudoeste de la Provincia de Río Negro (Dra. María Laura Miserendino - Dra. Nora Gómez)

manejo y gestión integral de estos ambientes, con el objetivo de garantizar su sustentabilidad, conservando los importantes servicios ecosistémicos que brindan a la sociedad. 


\section{BIBLIOGRAFÍA}

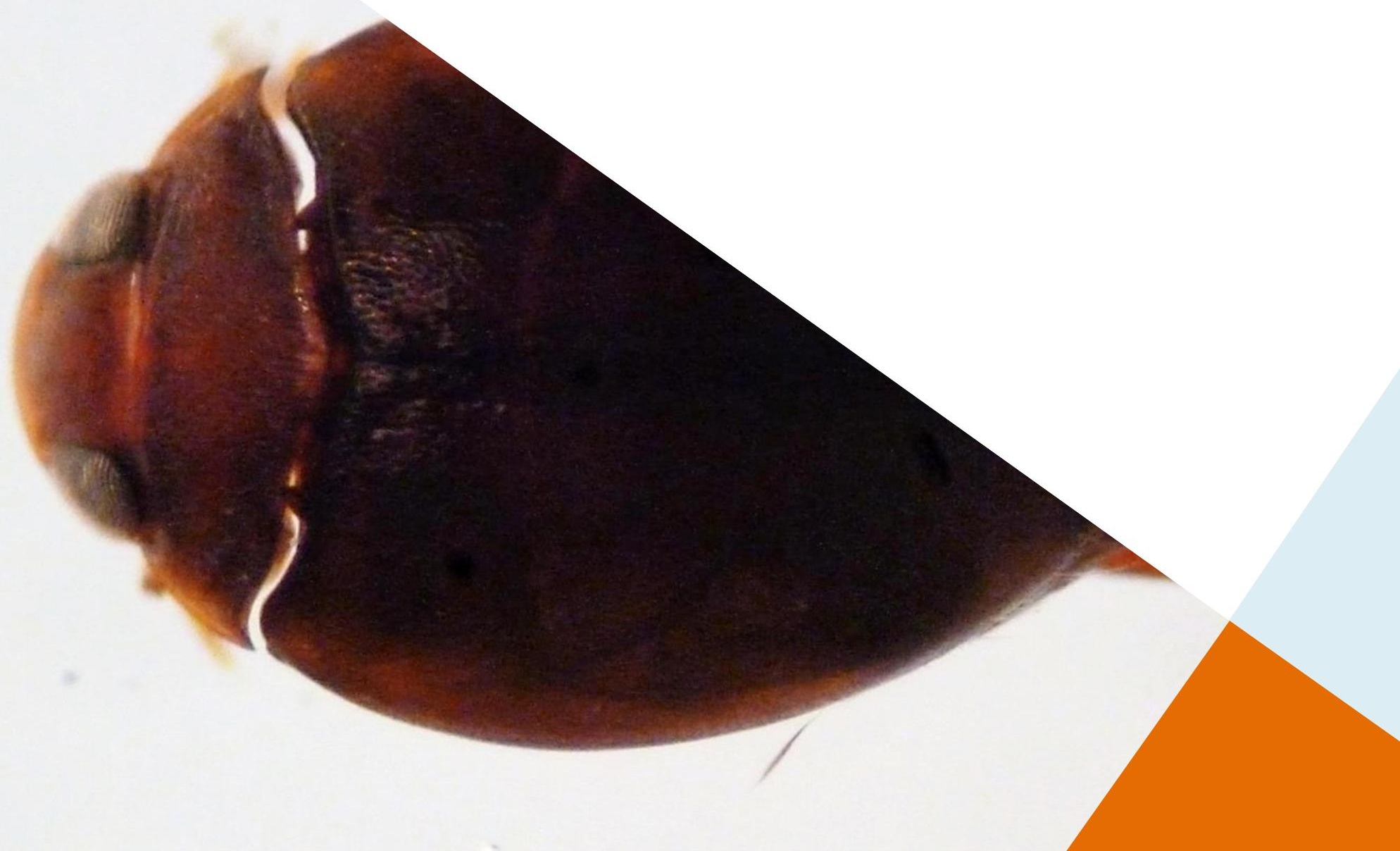


Macchi, Pablo. 2017. Macroinvertebrados acuáticos como indicadores ecológicos de cambios en el uso del suelo en mallines del sudoeste de la Provincia de Río Negro (Dra. María Laura Miserendino - Dra. Nora Gómez)

\subsection{BIBLIOGRAFÍA}

Adamus, P. y Brandt, K. (1990). Impacts on quality of inland wetlands of the United States: A survey of indicators, techniques, and applications of community-level biomonitoring data (No. PB-91-113837/XAB; EPA--600/3-90/073). Environmental Protection Agency, Corvallis, OR (USA). Environmental Research Lab.

Aditya, G. y Saha, G. K. (2006). Predation of the beetle Rhantus sikkimensis (Coleoptera: Dytiscidae) on the larvae of Chironomus Meigen (Diptera: Chironomidae) of the Darjeeling Himalayas of India.Limnologica-Ecology and Management of Inland Waters, 36(4), 251257.

Aguiar, M. R. y Paruelo, J. M. (2003). Impacto humano sobre los ecosistemas.: El caso de la desertificación. Ciencia hoy, 13(77), 48-59.

Aguirre, L. (1985). The Southern Andes. In: The ocean basins and margins. Springer US. (pp. 265-376).

Ahmadi, R., Mohebbi, F., Hagigi, P., Esmailly, L. y Salmanzadeh, R. (2011). Macroinvertebrates in the Wetlands of the Zarrineh estuary at the south of Urmia Lake (Iran). International Journal of Environmental Research, 5(4), 1047-1052.

Aizaki, M. (1981). Application of modified Carlson's trophic state index to Japanese lakes and its relationships to other parameters related to trophic state (in Japanese with English summary). Res Rep Natl Inst Environ Stud Jpn, 23, 13-31.

Alarie, Y., Michat, M. C., Nilsson, A. N., Archangelsky, M. y Hendrich, L. (2009). Larval morphology of Rhantus Dejean, 1833 (Coleoptera: Dytiscidae: Colymbetinae): descriptions of 22 species and phylogenetic considerations. Zootaxa,2317, 1-102.

Alonso, M., Planas, H., Raffaele, E., Añón Suarez, D., Reissig, M., Diéguez, M. C., Temporetti, P. y García, P. (2010). Estudio de Situación Ambiental del Humedal incluido en el Emprendimiento Lago Moreno - Cerro López. Informe Centro Regional Universitario Bariloche, Universidad Nacional del Comahue.

American Public Health Association (APHA). (2001). Standard Methods for the examination of water and wastewater. American Water Works Association, Hanover, Maryland USA.

Andersen, U. V. y Calov, B. (1996). Long-term effects of sheep grazing on giant hogweed (Heracleum mantegazzianum). Hydrobiologia, 340(1-3), 277-284. 
Anderson, A. M., Haukos, D. A. y Anderson, J. T. (1999). Diet composition of three anurans from the Playa Wetlands of Northwest Texas. Copeia, 515-520.

Archangelsky, M. (1997). Studies on the biology, ecology, and systematics of the immature stages of New World Hydrophiloidea (Coleoptera: Staphyliniformia). Ohio Biological Survey, College of Biological Sciences, the Ohio State University.

Armitage, P. D. y Blackburn, J. H. (2001). The macroinvertebrate fauna of the Holy Stream, a small tributary of the River Frome, Dorset. Proceedings of the Dorset Natural History and Archeological Society, 123, 95-100.

Assessment, M. E. (2005). Ecosystems and human well-being: wetlands and water. World Resources Institute, Washington, DC, 5.

Azous, A., y Horner, R. R. (Eds.). (2000). Wetlands and urbanization: Implications for the future. CRC Press.

Bachmann A.O. (1981). Insecta, Hemiptera, Corixidae. En: Ringuelet, A. (dir.), Fauna de Agua Dulce de la República Argentina, FECIC, Bs.As., 35(2): 1-270

Balali, S., Hoseini, S. A., Ghorbani, R., \& Kordi, H. (2013). Relationships between Nutrients and Chlorophyll a Concentration in the International Alma Gol Wetland. Iran. J Aquac Res Development, 4(173), 2.

Balcombe, C. K., Anderson, J. T., Fortney, R. H. y Kordek, W. S. (2005). Aquatic macroinvertebrate assemblages in mitigated and natural wetlands. Hydrobiologia, 541(1), 175-188.

Balla, S. A. y Davis, J. A. (1995). Seasonal variation in the macroinvertebrate fauna of wetlands of differing water regime and nutrient status on the Swan Coastal Plain, Western Australia. Hydrobiologia, 299(2), 147-161.

Barbour, M. T., Gerritsen, J., Griffith, E., Frydenborg, R., McCarron, E., White, J. S. y Bastian, M. L. (1996). A framework for biological criteria for Florida streams using benthic macroinvertebrates. Journal of the North American Benthological Society, 185-211.

Barbour, M. T., Gerritsen, J., Snyder, B. D. y Stribling, J. B. (1999). Rapid bioassessment protocols for use in streams and wadeable rivers. USEPA, Washington.

Barbour, M.T., Stribling, J.B. y Karr K.R. (2006). Multimetric approach for establishing biocriteria and measuring biological condition. In Biological assessment and criteria: tools 
Macchi, Pablo. 2017. Macroinvertebrados acuáticos como indicadores ecológicos de cambios en el uso del suelo en mallines del sudoeste de la Provincia de Río Negro (Dra. María Laura Miserendino - Dra. Nora Gómez)

for water resource planning and decision making, W.S. Davis and T.P. Simon, eds. CRC Press, Boca Ratan, FL. 63-77.

Barros, V., Scian, B. y Matto, H. (1979). Campos de precipitación en la Provincia de Chubut (período 1931-1960). Geoacta, 10(1), 175-192.

Bassi, N., Kumar, M. D., Sharma, A. y Pardha-Saradhi, P. (2014). Status of wetlands in India: A review of extent, ecosystem benefits, threats and management strategies. Journal of Hydrology: Regional Studies, 2, 1-19.

Batzer, D. P. y Resh, V. H. (1991). Trophic interactions among a beetle predator, a chironomid grazer, and periphyton in a seasonal wetland. Oikos, 251-257.

Batzer, D. P. y Wissinger, S. A. (1996). Ecology of insect communities in nontidal wetlands. Annual review of entomology, 41(1), 75-100.

Batzer, D. P. y Boix, D. (1999). Invertebrates in Freshwater Wetlands. John Wiley \& Sons, New York.

Batzer, D. P. (2013). The seemingly intractable ecological responses of invertebrates in North American wetlands: a review. Wetlands, 33(1), 1-15.

Batzer, D. P. y Ruhí, A. (2013). Is there a core set of organisms that structure macroinvertebrate assemblages in freshwater wetlands?. Freshwater biology, 58(8), 16471659.

Batzer, D. P. y Sharitz, R. R. (Eds.). (2014). Ecology of freshwater and estuarine wetlands. Univ of California Press.

Batzer, D. P. y Boix, D. (2016). An Introduction to Freshwater Wetlands and Their Invertebrates. InInvertebrates in Freshwater Wetlands (pp. 1-23). Springer International Publishing.

Bazzanti, M., Della Bella, V. y Grezzi, F. (2009). Functional characteristics of macroinvertebrate communities in Mediterranean ponds (Central Italy): influence of water permanence and mesohabitat type. In Annales de Limnologie- International Journal of Limnology (Vol. 45, No. 1, pp. 29-39). EDP Sciences.

Bedford, B. L., Walbridge, M. R. y Aldous, A. (1999). Patterns in nutrient availability and plant diversity of temperate North American wetlands.Ecology, 80(7), 2151-2169. 
Benke, A. C., Huryn, A. D., Smock, L. A. y Wallace, J. B. (1999). Length-mass relationships for freshwater macroinvertebrates in North America with particular reference to the southeastern United States. Journal of the North American Benthological Society, 308-343.

Bergström, A. K. (2010). The use of TN: TP and DIN: TP ratios as indicators for phytoplankton nutrient limitation in oligotrophic lakes affected by N deposition. Aquatic Sciences, 72(3), 277-281.

Biggs, J., Williams, P., Whitfield, M., Nicolet, P. y Weatherby, A. (2005). 15 years of pond assessment in Britain: results and lessons learned from the work of Pond Conservation. Aquatic Conservation: Marine and Freshwater Ecosystems, 15(6), 693-714.

Bilton, D. T., McAbendroth, L. C., Nicolet, P., Bedford, A., Rundle, S. D., Foggo, A. y Ramsay, P. M. (2009). Ecology and conservation status of temporary and fluctuating ponds in two areas of southern England. Aquatic Conservation: Marine and Freshwater Ecosystems, 19 (2), 134.

Bird, M. S. (2012). Effects of Habitat Transformation on Temporary Wetlands in the SouthWestern Cape, South Africa. Journal of Aquatic Science, 36, 299-308.

Bird, M. S., Mlambo, M. C. y Day, J. A. (2013). Macroinvertebrates as unreliable indicators of human disturbance in temporary depression wetlands of the south-western Cape, South Africa. Hydrobiologia,720(1), 19-37.

Bird, M. S. y Day, J. A. (2014). Wetlands in changed landscapes: the influence of habitat transformation on the physico-chemistry of temporary depression wetlands. PloS one, 9(2), e88935.

Bobbink, R., Beltman, B., Verhoeven, J. T. y Whigham, D. F. (Eds.). (2007). Wetlands: functioning, biodiversity conservation, and restoration (Vol. 191). Springer Science \& Business Media.

Boelcke, O. (1957). Comunidades herbáceas del Norte de la Patagonia y sus relaciones con la ganadería. Revista de Investigación Agrícola (Argentina) 11:5-98.

Boix, D., Sala, J., Gascon, S., Martinoy, M., Gifre, J., Brucet, S. y Quintana, X. D. (2007). Comparative biodiversity of crustaceans and aquatic insects from various water body types in coastal Mediterranean wetlands.Hydrobiologia, 584(1), 347-359. 
Boix, D., Kneitel, J., Robson, B. J., Duchet, C., Zúñiga, L., Day, J. y Blaustein, L. (2016). Invertebrates of Freshwater Temporary Ponds in Mediterranean Climates. In Invertebrates in Freshwater Wetlands (pp. 141-189). Springer International Publishing.

Bolduc, F. y Afton, A. D. (2003). Effects of structural marsh management and salinity on invertebrate prey of waterbirds in marsh ponds during winter on the Gulf Coast Chenier Plain. Wetlands,23(4), 897-910.

Bonada, N., Prat, N., Resh, V. H. y Statzner, B. (2006). Developments in aquatic insect biomonitoring: a comparative analysis of recent approaches. Annu. Rev. Entomol., 51, 495523.

Bonvissuto, G. L. y Somlo, R. (1998). Guías de condición para los campos naturales de Precordillera y Sierras y Mesetas de Patagonia. PRODESAR (INTA EEA Bariloche, Macrorregión Patagonia Norte-GTZ).

Boon, P. I. (2006). Biogeochemistry and bacterial ecology of hydrologically dynamic wetlands. Ecology of freshwater and estuarine wetlands. University of California Press, Berkeley, 568.

Bornette, G. y Puijalon, S. (2011). Response of aquatic plants to abiotic factors: a review. Aquatic Sciences, 73(1), 1-14.

Boyer, T. y Polasky, S. (2004). Valuing urban wetlands: a review of non-market valuation studies. Wetlands, 24(4), 744-755.

Brainard, A. S. y Fairchild, G. W. (2012). Sediment characteristics and accumulation rates in constructed ponds. Journal of Soil and Water Conservation, 67(5), 425-432.

Bran, D. E. (1992). Las regiones ecológicas de Patagonia y sus principales formaciones vegetales. Primer curso de planificación integral de campo. INTA. Estación Experimental Agropecuaria Bariloche. PRECODEPA (1): 1-11.

Bran, D.E., J.A. Ayesa y C.R. López. (2000). Regiones Ecológicas de Río Negro. Comunicación Técnica N59, Área de Investigación de Recursos Naturales, INTA EEA Bariloche.

Brand, C. y Miserendino, M. L. (2011). Characterizing Trichoptera trophic structure in rivers under contrasting land use in Patagonia, Argentina. Zoosymposia, 5(1), 29-40.

Brand, C. y Miserendino, M. L. (2015). Testing the Performance of Macroinvertebrate Metrics as Indicators of Changes in Biodiversity After Pasture Conversion in Patagonian Mountain Streams. Water, Air, \& Soil Pollution, 226(11), 1-18.

Braun-Blanquet, J. (1979). Fitosociología. Ed. Blume. Madrid. 
Brazner, J. C., Danz, N. P., Niemi, G. J., Regal, R. R., Trebitz, A. S., Howe, R. W. y Reavie, E. D. (2007). Evaluation of geographic, geomorphic and human influences on Great Lakes wetland indicators: a multi-assemblage approach. Ecological Indicators, 7(3), 610-635.

Brinson, M.M. (1993). A hydrogeomorphic classification for wetlands. U.S. Army Corps of Engeneers. Washington, DC, USA. Technical Report WRP-DE-4.

Brinson, M. M. y Malvárez, A. I. (2002). Temperate freshwater wetlands: types, status, and threats. Environmental conservation, 29(02), 115-133.

Brix, H. (1994). Functions of macrophytes in constructed wetlands. Water Science and Technology, 29(4), 71-78.

Brix, H. (1997). Do macrophytes play a role in constructed treatment wetlands?. Water science and technology, 35(5), 11-17.

Brodersen, K. P., Odgaard, B. V., Vestergaard, O. y Anderson, N. J. (2001). Chironomid stratigraphy in the shallow and eutrophic Lake Søbygaard, Denmark: chironomidmacrophyte co-occurrence. Freshwater Biology, 46(2), 253-267.

Brooks, R. T. (2000). Annual and seasonal variation and the effects of hydroperiod on benthic macroinvertebrates of seasonal forest ("vernal") ponds in central Massachusetts, USA. Wetlands,20(4), 707-715.

Bunting, L., Leavitt, P. R., Hall, V. A., Gibson, C. E. y McGee, E. J. (2005). Nitrogen degradation of water quality in a phosphorus-saturated catchment: The case of Lough Neagh, Northern Ireland. Internationale Vereinigung fur Theoretische und Angewandte Limnologie Verhandlungen, 29(2), 1005-1010.

Buono, G., Oesterheld, M., Nakamatsu, V. y Paruelo, J. M. (2010). Spatial and temporal variation of primary production of Patagonian wet meadows.Journal of Arid Environments, 74(10), 1257-1261.

Burks, R. L., Mulderij, G., Gross, E., Jones, I., Jacobsen, L., Jeppesen, E. y Van Donk, E. (2006). Center stage: the crucial role of macrophytes in regulating trophic interactions in shallow lake wetlands. In Wetlands: functioning, biodiversity conservation, and restoration (pp. 3759). Springer Berlin Heidelberg.

Burroni, N. E., Marinone, M. C., Freire, M. G., Schweigmann, N. y Loetti, M. V. (2011). Invertebrate communities from different wetland types of Tierra del Fuego. Insect Conservation and Diversity, 4(1), 39-45. 
Burton, T. M., Uzarski, D. G., Gathman, J. P., Genet, J. A., Keas, B. E. y Stricker, C. A. (1999). Development of a preliminary invertebrate index of biotic integrity for Lake Huron coastal wetlands.Wetlands, 19(4), 869-882.

Calabrerse, G., López, C., Perren, G. y Macchi, P. (2012). Caracterización y evaluación del estado de degradación de los humedales, como base para la gestión sustentable en la región semiárida del sudoeste de la Provincia de Río Negro. Informe Final (PI-UNRN 40-B050). Universidad Nacional de Río Negro.

Campbell, B. D., Haro, R. J. y Richardson, W. B. (2009). Effects of agricultural land use on chironomid communities: comparisons among natural wetlands and farm ponds. Wetlands, 29(3), 1070-1080.

Canevari P., Blanco D.E., Bucher E.H., Castro G. y I. Davidson. (1998). Los humedales de la Argentina clasificación, situación actual, conservación y legislación. Wetlands International: Buenos Aires, Argentina. 208 pp.

Carbiener, R., Trémolières, M., Mercier, J. L. y Ortscheit, A. (1990). Aquatic macrophyte communities as bioindicators of eutrophication in calcareous oligosaprobe stream waters (Upper Rhine plain, Alsace). Vegetatio, 86(1), 71-88.

Carew, M. E., Pettigrove, V., Cox, R. L. y Hoffmann, A. A. (2007). The response of Chironomidae to sediment pollution and other environmental characteristics in urban wetlands. Freshwater Biology, 52(12), 2444-2462.

Carlson, R. E. (1977). A trophic state index for lakes.Limnology and oceanography, 22(2), 361369.

Céréghino, R., Boix, D., Cauchie, H. M., Martens, K. y Oertli, B. (2014). The ecological role of ponds in a changing world. Hydrobiologia, 723(1), 1-6.

Chambers, P. A., Lacoul, P., Murphy, K. J. y Thomaz, S. M. (2008). Global diversity of aquatic macrophytes in freshwater. Hydrobiologia, 595(1), 9-26.

Chimner, R. A., Bonvissuto, G. L., Cremona, M. V., Gaitan, J. J. y López, C. R. (2011). Ecohydrological conditions of wetlands along a precipitation gradient in Patagonia, Argentina. Ecología austral, 21, 329-337.

Chipps, S. R., Hubbard, D. E., Werlin, K. B., Haugerud, N. J., Powell, K. A., Thompson, J. y Johnson, T. (2006). Association between wetland disturbance and biological attributes in floodplain wetlands. Wetlands, 26(2), 497-508. 
Ciari, G. (2009). Funcionamiento hidrológico de los mallines y sus cuencas asociadas. Carpeta Técnica.Medio Ambiente, (13).

Clausen, J. C., Ortega, I. M., Glaude, C. M., Relyea, R. A., Garay, G. y Guineo, O. (2006). Classification of wetlands in a Patagonian national park, Chile.Wetlands, 26 (1), 217-229.

Coffman, W. P. y Ferrington Jr, L. C. (1996). Chironomidae. In: K. W. Merrit \& R. W. Cummins (eds.), An introduction of aquatic insects of North America (pp: 635-754). 3. ed. Kendall Hunt Publishing Co., Dubuque.

Collantes, M. B. y Faggi, A. M. (1999). Los humedales del sur de Sudamérica. Tópicos sobre humedales subtropicales y templados de Sudamérica, 15-25.

Collins, A. L., Walling, D. E. y Leeks, G. J. L. (1998). Use of composite fingerprints to determine the provenance of the contemporary suspended sediment load transported by rivers. Earth surface processes and landforms, 23(1), 31-52.

Colmet Daage, F., Marcolin, A., López, C., Lanciotti, M., Ayesa, J., Bran, D. y Irisarri, J. (1988). Características de los suelos derivados de cenizas volcánicas de la cordillera y precordillera del norte de la Patagonia. INTA-ORSTOM. SC Bariloche, Argentina.

Cooper, M. J. y Uzarski, D. G. (2016). Invertebrates in Great Lakes Marshes. In Invertebrates in Freshwater Wetlands (pp. 287-320). Springer International Publishing.

Correa-Araneda, F., Díaz, M. E., Merino, K. O., Montoya, F. E., Urrutia, R. y Figueroa, R. (2014). Benthic macroinvertebrate community patterns of Mediterranean forested wetlands and their relation to changes in the hydroperiod. Limnetica, 33(2), 361-374.

Cottenie, K. y De Meester, L. (2004). Metacommunity structure: synergy of biotic interactions as selective agents and dispersal as fuel. Ecology, 85(1), 114-119.

Cranston, P. S. (2000). Electronic guide to the Chironomidae of Australia. h ttp://entomology. ucdavis. edu/chiropage/index. html.

Cronk, J. K. y Fennessy, M. S. (2016). Wetland plants: biology and ecology. CRC press.

Cuassolo, F., Navarro, M. B., Balseiro, E. y Modenutti, B. (2011). Leachates and elemental ratios of macrophytes and benthic algae of an Andean high altitude wetland. Journal of Limnology,70(2), 168-176.

Cuassolo, F., Balseiro, E. y Modenutti, B. (2012). Alien vs. native plants in a Patagonian wetland: elemental ratios and ecosystem stoichiometric impacts. Biological invasions, 14(1), 179-189. 
Cuassolo, F. (2013). El papel de las macrófitas en las relaciones elementales de humedales patagónicos (tesis de doctorado). Universidad Nacional del Comahue, Bariloche, Argentina.

Cushing, C. E. y Allan, J. D. (2001). Streams: their ecology and life. Gulf Professional Publishing.

Cussac, V., Ortubay, S., Iglesias, G., Milano, D., Lattuca, M. E., Barriga, J. P. y Gross, M. (2004). The distribution of South American galaxiid fishes: the role of biological traits and postglacial history. Journal of Biogeography, 31(1), 103-121.

Daniels, A. E. y Cumming, G. S. (2008). Conversion or conservation? Understanding wetland change in northwest Costa Rica. Ecological Applications, 18(1), 49-63.

Davies, B., Biggs, J., Williams, P., Whitfield, M., Nicolet, P., Sear, D. y Maund, S. (2008). Comparative biodiversity of aquatic habitats in the European agricultural landscape. Agriculture, Ecosystems \& Environment, 125(1), 1-8. De Klerk, A. R. y Wepener, V. (2011). The influence of biotope and sampling method on the assessment of the invertebrate community structure in endorheic reed pans in South Africa. African Journal of Aquatic Science, 36(1), 67-74.

Davis, J., Sim, L. y Chambers, J. (2010). Multiple stressors and regime shifts in shallow aquatic ecosystems in antipodean landscapes. Freshwater Biology,55(s1), 5-18.

De Meester, L., Declerck, S., Stoks, R., Louette, G., Van De Meutter, F., De Bie, T. y Brendonck, L. (2005). Ponds and pools as model systems in conservation biology, ecology and evolutionary biology. Aquatic conservation: Marine and freshwater ecosystems, 15(6), 715-725.

De Vicente I., Guerrero F. y Cruz-Pizarro L. (2010). Chemical composition of wetland sediments as an integrator of trophic state. Aquat. Ecosyst. Health Manag., 13, 99-103

Declerck, S., De Bie, T., Ercken, D., Hampel, H., Schrijvers, S., Van Wichelen, J. y Keijers, S. (2006). Ecological characteristics of small farmland ponds: associations with land use practices at multiple spatial scales. Biological conservation,131(4), 523-532.

del Valle, H. F., Elissalde, N. O., Gagliardini, D. A. y Milovich, J. (1998). Status of desertification in the Patagonian region: Assessment and mapping from satellite imagery. Arid Soil Research and Rehabilitation, 12, 1-27.

del Valle, H. F., Labraga, J. C. y Goergen, J. (2003). Biozonas en la Región Patagónica. En: Cooperación Técnica Argentino Alemana (Ed.) Evaluación del estado actual de la 
desertificación en áreas representativas de la Patagonia (pp.37-55). Buenos Aires, Talleres gráficos Colegio Argentino-Alemán.

Della Bella, V., Bazzanti, M. y Chiarotti, F. (2005). Macroinvertebrate diversity and conservation status of Mediterranean ponds in Italy: water permanence and mesohabitat influence. Aquatic Conservation: Marine and Freshwater Ecosystems, 15(6), 583-600.

Della Bella, V., Bazzanti, M., Dowgiallo, M. G. y Iberite, M. (2008). Macrophyte diversity and physico-chemical characteristics of Tyrrhenian coast ponds in central Italy: implications for conservation.Hydrobiologia, 597(1), 85-95.

Di Rienzo, J. A., Casanoves, F., Balzarini, M. G., Gonzalez, L., Tablada, M. y Robledo, Y. C. (2011). InfoStat versión 2014. Grupo InfoStat, FCA, Universidad Nacional de Córdoba, Argentina. URL http://www. infostat. com. Ar.

Diaz, M., Pedrozo, F., Reynolds, C. y Temporetti, P. (2007). Chemical composition and the nitrogen-regulated trophic state of Patagonian lakes.Limnologica-Ecology and Management of Inland Waters, 37(1), 17-27.

Dickens, C. W. y Graham, P. M. (2002). The South African Scoring System (SASS) version 5 rapid bioassessment method for rivers. African Journal of Aquatic Science, 27(1), 1-10.

Dodds, W. K., Johnson, K. R. y Priscu, J. C. (1989). Simultaneous nitrogen and phosphorus deficiency in natural phytoplankton assemblages: theory, empirical evidence, and implications for lake management. Lake and Reservoir Management, 5(1), 21-26.

Domínguez, E. y Fernández, H. R. (2009).Macroinvertebrados bentónicos sudamericanos: sistemática y biología. Tucumán: Fundación Miguel Lillo.

Donato, M., Massaferro, J. y Brooks, S. J. (2009). Estado del conocimiento taxonómico de la fauna de Chironomidae (Diptera: Nematocera) de la Patagonia. Revista de la Sociedad Entomológica Argentina, 68.

Dufilho,C., Horne ,F. y G. Polla. (1999). Dinámica del agua en mallines de Patagonia. Comportamiento espacial del escurrimiento subterráneo. Revista extraordinaria de resumenes. Chillán. Agrociencia III Congreso Chileno de Ingeniería Agrícola. I Congreso Americano de Educación en Ingenieria Agricola.

Ehrenfeld, J. G. (2000). Evaluating wetlands within an urban context. Ecological Engineering, 15(3), 253-265. 
Eisenbeis, G., Rich, C. y Longcore, T. (2006). Artificial night lighting and insects: attraction of insects to streetlamps in a rural setting in Germany. In: C. Rich and T. Longcore, editors. Ecological consequences of artificial night lighting. (pp. 191-198.) Island Press, Washington, D.C., USA.

Ellison, G. N. y Gotelli, N. J. (2004). A primer of ecological statistics. Sinauer, Sunderland, Massachusetts, USA.

Elmaci, A., Ozengin, N., Teksoy, A., Topac, F. O. y Baskaya, H. S. (2009). Evaluation of trophic state of lake Uluabat, Turkey. Journal of Environmental Biology 30(5) 757-760.

Elser, J. J., Marzolf, E. R. y Goldman, C. R. (1990). Phosphorus and nitrogen limitation of phytoplankton growth in the freshwaters of North America: a review and critique of experimental enrichments. Canadian Journal of fisheries and aquatic sciences, 47 (7), 1468-1477.

Engelhardt, K. A. y Ritchie, M. E. (2001). Effects of macrophyte species richness on wetland ecosystem functioning and services. Nature, 411(6838), 687-689.

Epele, L. B. y Archangelsky, M. (2012). Spatial variations in water beetle communities in arid and semi-arid Patagonian wetlands and their value as environmental indicators. Zoological Studies, 51(8), 1418-1431.

Epele, L. B. (2014). Comunidades de invertebrados acuáticos de mallines de Patagonia, bajo distintos niveles de antropización (tesis de doctorado). Universidad Nacional de La Plata, Buenos Aires, Argentina.

Epele, L. B. y Miserendino, M. L. (2015). Environmental quality and aquatic invertebrate metrics relationships at Patagonian wetlands subjected to livestock grazing pressures. PloS one, 10(10), e0137873.

Epele, L. B. y Miserendino, M. L. (2016). Temporal dynamics of invertebrate and aquatic plant communities at three intermittent ponds in livestock grazed Patagonian wetlands. Journal of Natural History, 50(11-12), 711-730.

Epler, J. H. (2001). Identification manual for the larval Chironomidae (Diptera) of North and South Carolina. A guide to the taxonomy of the midges of the southeastern United States, including Florida. Special Publication SJ2001-SP13. North Carolina Department of Environment and Natural Resources, Raleigh, NC, and St. Johns River Water Management District, Palatka, FL,526. 
Macchi, Pablo. 2017. Macroinvertebrados acuáticos como indicadores ecológicos de cambios en el uso del suelo en mallines del sudoeste de la Provincia de Río Negro (Dra. María Laura Miserendino - Dra. Nora Gómez)

Espósito, M. (2003). Diccionario mapuche castellano, castellano mapuche. Editorial Guadal.

Euliss, N. H., LaBaugh, J. W., Fredrickson, L. H., Mushet, D. M., Laubhan, M. K., Swanson, G. A. y Nelson, R. D. (2004). The wetland continuum: a conceptual framework for interpreting biological studies. Wetlands, 24(2), 448-458.

Fairchild, G. W., Faulds, A. M. y Matta, J. F. (2000). Beetle assemblages in ponds: effects of habitat and site age. Freshwater Biology, 44(3), 523-534.

Faulkner, S. (2004). Urbanization impacts on the structure and function of forested wetlands. Urban Ecosystems, 7(2), 89-106.

Fernández, H. y Domínguez, E. (2001). Guía para la determinación de los arthrópodos bentónicos Sudamericanos. Entomotropica, 16(3), 219.

Ferrer, J., Irisarri, A., Mendia, J. A. y Asseff, A. E. E. A. (2006). Suelos de la Provincia del Neuquén. Consejo Federal de Inversiones.

Findlay, C. S. y Houlahan, J. (1997). Anthropogenic correlates of species richness in southeastern Ontario wetlands. Conservation Biology, 11(4), 1000-1009.

Fiorio, D. (1997). Manejo del agua en mallines. Presencia 41,19-23.

Frelik, A. (2014). Predation of adult large diving beetles Dytiscus marginalis (Linnaeus, 1758), Dytiscus circumcinctus (Ahrens, 1811) and Cybister lateralimarginalis (De Geer, 1774)(Coleoptera: Dytiscidae) on fish fry. Oceanological and Hydrobiological Studies, 43(4), 360-365.

Gaitán, J., López, C., Bran, D., Siffredi, G., Ayesa, J. y Cremona, M. V. (2006). Investigación en mallines en Patagonia Norte [Argentina]. avances recientes y próximos pasos. Reunión del Grupo Regional Patagónico de Ecosistemas de Pastoreo. Coyhaique, Chile.

Gaitán, J. J. y López, C. R. (2007). Análisis del gradiente edáfico en la región andinopatagónica. Ciencia del suelo, 25(1), 53-63.

Gaitán, J. J., López, C. R. y Bran, D. E. (2011). Vegetation composition and its relationship with the environment in mallines of north Patagonia, Argentina. Wetlands ecology and management,19 (2), 121-130.

Gandullo, R. y Schmid, P. (2001). Análisis ecológico de mallines del Parque Provincial Copahue, Neuquén, Argentina. Agro sur, 29(2), 83-99. 
Macchi, Pablo. 2017. Macroinvertebrados acuáticos como indicadores ecológicos de cambios en el uso del suelo en mallines del sudoeste de la Provincia de Río Negro (Dra. María Laura Miserendino - Dra. Nora Gómez)

Gandullo, R. y Faggi, A. M. (2003). Análisis fitosociológico de los mallines del piso andino del Parque Provincial Copahue, Neuquén, Argentina. Kurtziana, 30(1-2), 45-55.

Gandullo, R. y Faggi, A. M. (2005). Interpretación sintaxonómica de los humedales del noroeste de la Provincia de Neuquén, Argentina. Darwiniana, 10-29.

Gascón, S., Boix, D. y Sala, J. (2009). Are different biodiversity metrics related to the same factors? A case study from Mediterranean wetlands. Biological conservation, 142(11), 2602-2612.

Giacosa, R. E. y Heredia, N. (2004). Estructura de los Andes Nordpatagónicos en los cordones Piltriquitrón y Serrucho y en el valle de El Bolsón (4130-4200 S), Río Negro. Revista de la Asociación Geológica Argentina, 59(1), 91-102.

Gibbs, J. P. (2000). Wetland loss and biodiversity conservation. Conservation biology, 14(1), 314-317.

Gibson, G. R., Barbour, M. T., Stribling, J. B., Gerritsen, J. y Karr, J. R. (1996). Biological Criteria: Technical guidance for streams and small rivers (No. PB--96-209770/XAB; EPA--822/B96/001). Environmental Protection Agency, Washington, DC (United States). Office of Water.

Gilbert, J. D., Guerrero, F., Jiménez-Melero, R. y De Vicente, I. (2015). Is the bioproduction number a good index of the trophic state in Mediterranean wetlands?. Knowledge and Management of Aquatic Ecosystems, (416), 05.

Gioria, M., Schaffers, A., Bacaro, G. y Feehan, J. (2010). The conservation value of farmland ponds: predicting water beetle assemblages using vascular plants as a surrogate group. Biological Conservation,143(5), 1125-1133.

Gleason, R. A., Euliss, N. H., Hubbard, D. E. y Duffy, W. G. (2003). Effects of sediment load on emergence of aquatic invertebrates and plants from wetland soil egg and seed banks. Wetlands, 23(1), 26-34.

Godagnone, R. E. y Bran, D. E. (2009). Inventario integrado de los recursos naturales de la Provincia de Río Negro: geología, hidrogeología, geomorfología, suelos, clima, vegetación y fauna. Ediciones INTA. Buenos Aires, Argentina.

Golterman H.L., Clymo R.S. y Ohnstad M.A., (1978). Methods for physical and chemical analysis of freshwater. Oxford: Blackwell Scientific, (JNP Handbook, 8). 
Gómez, N., Sierra, M. V., Cochero, J., Licursi, M. y Bauer, D. E. (2011). Epipelic biofilms as indicators of environmental changes in lowland fluvial systems. Biofilms: Formation, Development and Properties. Nova Science Publishers, Inc.[Links], 259-291.

González Díaz, E.F. y Malagnino, E.C. (1984). Geomorfología de la Provincia de Río Negro. En: IX Congreso Geológico Argentino. Bariloche, Río Negro.

Grace, J. B. (1999). The factors controlling species density in herbaceous plant communities: an assessment. Perspectives in plant ecology, evolution and systematics, 2(1), 1-28.

Grasshoff, K., Kremling, K. y Ehrhardt, M. (Eds.). (2009). Methods of seawater analysis. John Wiley \& Sons.

Gulati, R. D. y Van Donk, E. (2002). Lakes in the Netherlands, their origin, eutrophication and restoration: state-of-the-art review. In Ecological Restoration of Aquatic and Semi-Aquatic Ecosystems in the Netherlands (NW Europe) (pp. 73-106). Springer Netherlands.

Håkanson, L. (1984). On the relationship between lake trophic level and lake sediments. Water research, 18(3), 303-314.

Hassall, C. y Anderson, S. (2015). Stormwater ponds can contain comparable biodiversity to unmanaged wetlands in urban areas. Hydrobiologia, 745(1), 137-149.

Hauenstein, E., Peña-Cortés, F., Bertrán, C., Tapia, J. y Schlatter, R. (2008). Comparación florística y estado trófico basado en plantas indicadoras de lagunas costeras de la región de La Araucanía, Chile. Ecología austral, 18(1), 43-53.

Hauenstein, E., Peña-Cortés, F., Bertrán, C., Tapia, J., Vargas-Chacoff, L. y Urrutia, O. (2014). Composición florística y evaluación de la degradación del bosque pantanoso costero de temu-pitra en la Región de La Araucanía, Chile. Gayana. Botánica, 71(1), 43-57.

Haynes, M. A., Fang, Z. y Waller, D. M. (2013). Grazing impacts on the diversity and composition of alpine rangelands in Northwest Yunnan. Journal of Plant Ecology, 6(2), 122130.

Heckman, C. W. (2006). Encyclopedia of South American Aquatic Insects: Odonata-Anisoptera: Illustrated Keys to Known Families, Genera, and Species in South America. Springer Science \& Business Media.

Heckman, C. W. (2008). Encyclopedia of South American aquatic insects: Odonata-Zygoptera: Illustrated keys to known families, genera, and species in South America. Springer Science \& Business Media. 
Helgen, J. C. y Gernes, M. C. (2001). Monitoring the condition of wetlands: indexes of biological integrity using invertebrates and vegetation. IN: RB Rader, DP Batzer, and SA Wissinger (eds.), Bioassessment and Management of North American Freshwater Wetlands, John Wiley and Sons, New York, NY, 167-185.

Hering, D., Feld, C. K., Moog, O. y Ofenböck, T. (2006). Cook book for the development of a Multimetric Index for biological condition of aquatic ecosystems: experiences from the European AQEM and STAR projects and related initiatives. Hydrobiologia, 566(1), 311-324.

Herrmann, J. (2012). Chemical and biological benefits in a stormwater wetland in Kalmar, SE Sweden. Limnologica-Ecology and Management of Inland Waters, 42(4), 299-309.

Hill, L. (2004). Elands catchment comprehensive reserve determination study, Mpumalanga Province, ecological classification and ecological water requirements (quantity) workshop report. Report No. ENV-PC, 19, 1-98.

Holyoak, M., Leibold, M. A., Mouquet, N., Holt, R. D. y Hoopes, M. (2005). A framework for large scale community ecology. Metacommunities: spatial dynamics and ecological communities. The University of Chicago Press, Chicago, 1-31.

Horne, F.E., C. Dufilho, G. Polla, P. Schmid Y A. Bruce. (2004). El agua. Metodologías para el estudio y manejo sustentable de mallines. Parte I. Actas del Primer Taller sobre Mallines Patagónicos, Esquel, Chubut, Argentina. 12 pp.

Hornung, J. P. y Rice, C. L. (2003). Odonata and wetland quality in southern Alberta, Canada: a preliminary study. Odonatologica, 32(2), 119-129.

Hornung, J. P. y Foote, A. L. (2006). Aquatic invertebrate responses to fish presence and vegetation complexity in western boreal wetlands, with implications for waterbird productivity. Wetlands,26(1), 1-12.

Iriondo, M. (1989). Quaternary lakes of Argentina.Palaeogeography, palaeoclimatology, palaeoecology,70(1), 81-88.

Jackson, R. D., Allen-Diaz, B., Oates, L. G. y Tate, K. W. (2006). Spring-water nitrate increased with removal of livestock grazing in a California oak savanna. Ecosystems, 9(2), 254-267.

Jara, F. G., Perotti, M. G. y Diéguez, M. C. (2012). Distribution of backswimmers in shallow ponds of Patagonia and their predatory role on a common tadpole-copepod assemblage. New Zealand Journal of Marine and Freshwater Research, 46(4), 459-473. 
Jara, F. G., Úbeda, C. A. y Perotti, M. G. (2013). Predatory insects in lentic freshwater habitats from northwest Patagonia: richness and phenology.Journal of Natural History, 47(43-44), $2749-2768$.

Jarosiewicz, A., Ficek, D. y Zapadka, T. (2011). Eutrophication parameters and Carlson-type trophic state indices in selected Pomeranian lakes.Limnological Review, 11(1), 15-23.

Jeffries, M. (1988). Measuring Tailing's element of chance in pond populations. Freshwater Biology,20 (3), 383-393.

Jingfeng, H., Hongyu, L., Hebing, H. y Jing, A. (2011). Assessment of Urban Wetland Ecological Security at Differing Scales [J]. Journal of Nanjing Normal University (Natural Science Edition), 1, 026.

Johnson, P. T., Hoverman, J. T., McKenzie, V. J., Blaustein, A. R. y Richgels, K. L. (2013). Urbanization and wetland communities: applying metacommunity theory to understand the local and landscape effects. Journal of Applied Ecology, 50(1), 34-42.

Jones, J. I., Murphy, J. F., Collins, A. L., Sear, D. A., Naden, P. S. y Armitage, P. D. (2012). The impact of fine sediment on macroinvertebrates. River Research and Applications, 28(8), 1055-1071.

Jurado, G. B., Johnson, J., Feeley, H., Harrington, R. y Kelly-Quinn, M. (2010). The potential of integrated constructed wetlands (ICWs) to enhance macroinvertebrate diversity in agricultural landscapes. Wetlands, 30(3), 393-404.

Kadoya, T., Akasaka, M., Aoki, T. y Takamura, N. (2011). A proposal of framework to obtain an integrated biodiversity indicator for agricultural ponds incorporating the simultaneous effects of multiple pressures. Ecological Indicators, 11(5), 1396-1402.

Kagalou, I. I., Kosiori, A. y Leonardos, I. D. (2010). Assessing the zooplankton community and environmental factors in a Mediterranean wetland.Environmental monitoring and assessment, 170 (1-4), 445-455.

Kashian, D. R. y Burton, T. M. (2000). A comparison of macroinvertebrates of two Great Lakes coastal wetlands: testing potential metrics for an index of ecological integrity. Journal of Great Lakes Research, 26(4), 460-481.

King, R. S., Nunnery, K. T. y Richardson, C. J. (2000). Macroinvertebrate assemblage response to highway crossings in forested wetlands: implications for biological assessment. Wetlands Ecology and Management, 8(4), 243-256. 
King, R. S. y Richardson, C. J. (2002). Evaluating subsampling approaches and macroinvertebrate taxonomic resolution for wetland bioassessment. Journal of the North American Benthological Society,21(1), 150-171.

Klemm, D. J., Blocksom, K. A., Fulk, F. A., Herlihy, A. T., Hughes, R. M., Kaufmann, P. R. y Davis, W. S. (2003). Development and evaluation of a macroinvertebrate biotic integrity index (MBII) for regionally assessing Mid-Atlantic Highlands streams. Environmental Management, 31(5).

Klemmer, A. J., Wissinger, S. A., Greig, H. S. y Ostrofsky, M. L. (2012). Nonlinear effects of consumer density on multiple ecosystem processes.Journal of Animal Ecology, 81(4), 770780.

Kneitel, J. M. (2014). Inundation timing, more than duration, affects the community structure of California vernal pool mesocosms. Hydrobiologia,732(1), 71-83.

Kolka, R. K. y Thompson, J. A. (2006). Wetland geomorphology, soils, and formative processes. Ecology of Freshwater and Estuarine Wetlands, 7-42.

Kratzer, E. B. y Batzer, D. P. (2007). Spatial and temporal variation in aquatic macroinvertebrates in the Okefenokee Swamp, Georgia, USA. Wetlands,27(1), 127-140.

Kreutzweiser, D. P., Capell, S. S. y Good, K. P. (2005). Effects of fine sediment inputs from a logging road on stream insect communities: a large-scale experimental approach in a Canadian headwater stream. Aquatic Ecology, 39(1), 55-66.

Kutschker, A. M., Epele, L. B. y Miserendino, M. L. (2014). Aquatic plant composition and environmental relationships in grazed Northwest Patagonian wetlands, Argentina. Ecological Engineering, 64, 37-48.

Lacoul, P. y Freedman, B. (2006). Environmental influences on aquatic plants in freshwater ecosystems. Environmental Reviews, 14(2), 89-136.

Lee Foote, A. y Rice Hornung, C. L. (2005). Odonates as biological indicators of grazing effects on Canadian prairie wetlands. Ecological Entomology, 30(3), 273-283.

Lee, S. Y., Dunn, R. J. K., Young, R. A., Connolly, R. M., Dale, P. E. R., Dehayr, R. y Welsh, D. T. (2006). Impact of urbanization on coastal wetland structure and function. Austral Ecology, 31(2), 149-163. 
Leeper, D. A. y Taylor, B. E. (1998). Abundance, biomass and production of aquatic invertebrates in Rainbow Bay, a temporary wetland in South Carolina, USA. Archiv für Hydrobiologie, 143(3), 335-362.

Leibold, M. A., Holyoak, M., Mouquet, N., Amarasekare, P., Chase, J. M., Hoopes, M. F. y Loreau, M. (2004). The metacommunity concept: a framework for multi-scale community ecology. Ecology letters, 7(7), 601-613.

Leps, J. y Smilauer, P. (2003). Multivariate analysis of ecological data using CANOCO. Cambridge university press.

Lewis, W. M. y Wurtsbaugh, W. A. (2008). Control of lacustrine phytoplankton by nutrients: erosion of the phosphorus paradigm. International Review of Hydrobiology, 93(4-5), 446465.

Libonatti, M. L., Michat, M. C. y Torres, P. L. M. (2011). Key to the subfamilies, tribes and genera of adult Dytiscidae of Argentina (Coleoptera: Adephaga). Revista de la Sociedad Entomológica Argentina 70(3-4): 317-336

López, C., Gaitán, J. J., Ayesa, J., Siffredi, G. y Bran, D. (2005). Evaluación y clasificación de valles y mallines sudoeste de Río Negro. Area de Recursos Naturales Relevamiento integrado. INTA EEA Bariloche Comunicación Técnica, 97, 1-27.

Lopez, R. D., Lyon, J. G., Lyon, L. K. y Lopez, D. K. (2013). Wetland landscape characterization: practical tools, methods, and approaches for landscape ecology. CRC Press.

Lopretto, E.C. y Tell, G. (ed.). (1995). Ecosistemas de aguas continentales: Metodologías para su estudio. Ediciones Sur, La Plata.

Lougheed, V. L., Crosbie, B. y Chow-Fraser, P. (2001). Primary determinants of macrophyte community structure in 62 marshes across the Great Lakes basin: latitude, land use, and water quality effects. Canadian Journal of Fisheries and Aquatic Sciences, 58(8), 16031612.

Ludwig, J. A. y Reynolds, J. F. (1988). Statistical ecology: a primer in methods and computing (Vol. 1). John Wiley \& Sons.

Lukács, B. A., Dévai, G. y Tóthmérész, B. (2009). Aquatic macrophytes as bioindicators of water chemistry in nutrient rich backwaters along the Upper-Tisza river (in Hungary). Phytocoenologia,39(3), 287-293. 
Lunde, K. B. y Resh, V. H. (2012). Development and validation of a macroinvertebrate index of biotic integrity (IBI) for assessing urban impacts to Northern California freshwater wetlands. Environmental monitoring and assessment, 184(6), 3653-3674.

Macchi, P. A. (2008). Degradación de la calidad del agua del arroyo Durán. En: Libro de resúmenes de las I Jornadas de Ciencias Naturales en la Patagonia. Biodiversidad y Conservación. Esquel, Chubut.

Macchi, P. A. y Dufilho, C. (2008). Variación en la composición y organización funcional de macroinvertebrados bentónicos en una cuenca Patagónica. In: Libro de resúmenes: IV Congreso Argentino de Limnología (p. 78). Bariloche. Río Negro.

Macchi, P. A., Klaich, M. y Loewy M. (2012). Impacto de plaguicidas en ensambles de macroinvertebrados en el Alto Valle del Río Negro y Neuquén. En: Libro de resúmenes del V Congreso Argentino de Limnología. Santa Fé.

Macedo, D. R., Hughes, R. M., Ferreira, W. R., Firmiano, K. R., Silva, D. R., Ligeiro, R. y Callisto, M. (2016). Development of a benthic macroinvertebrate multimetric index (MMI) for Neotropical Savanna headwater streams. Ecological Indicators, 64, 132-141.

Mackereth, F. J. H., Heron, J. y Talling, J. F. (1978). Water analysis: some revised methods for limnologists. (scientific publication 36) Freshwater Biological Association. Cumbria and Dorset, England.

Magurran, A. E. (1988). Why diversity?. InEcological diversity and its measurement (pp. 1-5). Springer Netherlands.

Maltchik, L., Rolon, A. S. y Stenert, C. (2010). Aquatic macrophyte and macroinvertebrate diversity and conservation in wetlands of the Sinos River basin. Brazilian Journal of Biology, 70 (4), 1179-1184.

Malvárez, A. I. y Bó, R. F. (2004). Documentos del curso taller "Bases ecológicas para la clasificación e inventario de humedales en Argentina" (Vol. 30). Buenos Aires.

Marcolín, A., Durañona, G., Ortiz, R., Sourrouille, E., Latur, M. y Larrama, G. (1978). Caracterización de Mallines en un área del sudoeste de la Provincia de Río Negro. VIII Reunión Argentina de la Ciencia del Suelo.

Mazzoni, E. y Vázquez, M. (2004). Ecosistemas de mallines y paisajes de la Patagonia Austral (Provincia de Santa Cruz). INTA.63 pp. 
Mazzoni, E., y Rabassa, J. (2013). Types and internal hydro-geomorphologic variability of mallines (wet-meadows) of Patagonia: Emphasis on volcanic plateaus. Journal of South American Earth Sciences,46, 170-182.

McParland, C. E. y Paszkowski, C. A. (2006). Effects of small-bodied fish on invertebrate prey and foraging patterns of waterbirds in Aspen Parkland wetlands. Hydrobiologia, 567(1), 4355.

Menetrey, N., Sager, L., Oertli, B. y Lachavanne, J. B. (2005). Looking for metrics to assess the trophic state of ponds. Macroinvertebrates and amphibians.Aquatic Conservation: Marine and Freshwater Ecosystems, 15(6), 653-664.

Menu-Marque, S. y Balseiro, E. (2000). Boeckella antiqua n. sp. (Copepoda, Calanoida, Centropagidae) from Patagonia. Hydrobiologia, 429(1-3),1-7.

Mercado, M. (2004). Macroinvertebrados de turberas australes (Tierra del Fuego). Los Turbales de la Patagonia, bases para su inventario y la conservación de su biodiversidad. Fundación Humedales. Wetlands International, Buenos Aires, 119-126.

Mereta, S. T., Boets, P., De Meester, L. y Goethals, P. L. (2013). Development of a multimetric index based on benthic macroinvertebrates for the assessment of natural wetlands in Southwest Ethiopia. Ecological Indicators, 29, 510-521.

Merritt, R. W. y Lawson, D. L. (1979). Leaf litter processing in floodplain and stream communities.General technical report WO-US Department of Agriculture, Forest Service.

Merritt, R. W. y Cummins, K. W. (1996). Trophic relations of macroinvertebrates. Methods in Stream Ecology. Academic Press, San Diego, 453-474.

Michat, M. C. y Archangelsky, M. (2007). Descriptions of larvae of Desmopachria Babington (Coleoptera: Dytiscidae: Hydroporinae): the D. vicina Sharp species group. The Coleopterists Bulletin,61(2), 264-276.

Michat, M. C., Archangelsky, M. y Bachmann, A. O. (2008). Generic keys for the identification of larval Dytiscidae from Argentina (Coleoptera: Adephaga).Rev. Soc. Entomol. Argent, 67(3-4), 17-36.

Mischler, J. A., Taylor, P. G. y Townsend, A. R. (2014). Nitrogen limitation of pond ecosystems on the plains of eastern Colorado. PloS one, 9(5), e95757.

Miserendino, M. L. (2001). Length-mass relationships for macroinvertebrates in freshwater environments of Patagonia (Argentina). Ecología Austral, 11(1), 3-8. 
Macchi, Pablo. 2017. Macroinvertebrados acuáticos como indicadores ecológicos de cambios en el uso del suelo en mallines del sudoeste de la Provincia de Río Negro (Dra. María Laura Miserendino - Dra. Nora Gómez)

Miserendino, M. L. y Pizzolon, L. A. (2004). Interactive effects of basin features and land-use change on macroinvertebrate communities of headwater streams in the Patagonian Andes. River Research and Application, 20, 967-983

Miserendino, M. L. (2005). Interacciones bosque río implicaciones para los ecosistemas acuáticos. Patagonia Forestal, XI (4), 14-17.

Miserendino, M. L. (2007). Macroinvertebrate functional organization and water quality in a large arid river from Patagonia (Argentina). In Annales de Limnologie-International Journal of Limnology (Vol. 43, No. 3, pp. 133-145). EDP Sciences.

Miserendino, M. L. (2009). Effects of flow regulation, basin characteristics and land-use on macroinvertebrate communities in a large arid patagonian river. Biodiversity \& Conservation, 8(7), 1921-1943

Miserendino, M. L. y Brand, C. (2009). Environmental effects of urbanization on streams and rivers in Patagonia (Argentina): the use of macroinvertebrates in monitoring. Advances in Environmental Research, 6, 183-220.

Miserendino, M. L. y Epele, L. (2009). Estudios biológicos de los mallines del noroeste del Chubut. Carpeta Técnica, Medio Ambiente 12. EEA INTA Esquel.

Miserendino, M. L. y Masi, C. (2010). The effects of land use on environmental features and functional organization of macroinvertebrate communities in Patagonian low order streams. Ecological indicators, 10, 311-319.

Miserendino, M. L., Casaux, R., Archangelsky, M., Di Prinzio, C. Y., Brand, C. y Kutschker, A. M. (2011). Assessing land-use effects on water quality, in-stream habitat, riparian ecosystems and biodiversity in Patagonian northwest streams. Science of the Total Environment, 409(3), 612-624.

Mitsch, W. J. y Gosselink, J. G. (2007). Wetlands. Hoboken. ed: John Wiley \& Sons, Inc.

Miyasaka, H., Genkai-Kato, M., Miyake, Y., Kishi, D., Katano, I., Doi, H. y Kuhara, N. (2008). Relationships between length and weight of freshwater macroinvertebrates in Japan. Limnology,9(1), 75-80.

Mlambo, M. (2009). Biodiversity patterns of wetland macroinvertebrate assemblages in the South-Western Cape, South Africa (Doctoral dissertation, University of Cape Town). 
Mlambo, M. C., Bird, M. S., Reed, C. C. y Day, J. A. (2011). Diversity patterns of temporary wetland macroinvertebrate assemblages in the south-western Cape, South Africa. African Journal of Aquatic Science, 36(3), 299-308.

Mokany, K., Ash, J. y Roxburgh, S. (2008). Functional identity is more important than diversity in influencing ecosystem processes in a temperate native grassland. Journal of Ecology, 96(5), 884-893.

Montalto, L. y Marchese, M. (2005). Cyst formation in Tubificidae (Naidinae) and Opistocystidae (Annelida, Oligochaeta) as an adaptive strategy for drought tolerance in fluvial wetlands of the Paraná River, Argentina. Wetlands, 25(2), 488-494.

Moreno, C. E. y Moreno, C. E. (2001). Manual de métodos para medir la biodiversidad (No. Sirsi ¡9789688345436). Universidad Veracruzana.

Morris, D. P. y Lewis, W. M. (1988). Phytoplankton nutrient limitation in Colorado mountain lakes.Freshwater Biology, 20(3), 315-327.

Movia, C. P., Ower, G. y Perez, C. (1982). Estudio de la vegetación natural del Neuquén. Relevamiento. I. Ed. Ministerio de Economía y Hacienda. Subsecretaria de Recursos Naturales. Neuquén.

Movia, C. (1984). Tipología de mallines. En: Rabassa, J. y A. Brandani; Capua, O. y Ottonello, E. Curso de campo de sistemas ecogeomorfológicos: Guía excursiones. Dpto. de Posgrado. Universidad Nacional del Comahue. Neuquén.

Moya, N., Tomanova, S. y Oberdorff, T. (2007). Initial development of a multi-metric index based on aquatic macroinvertebrates to assess streams condition in the Upper IsiboroSécure Basin, Bolivian Amazon. Hydrobiologia, 589(1), 107-116.

MPCA (Minnesota Pollution and Control Agency). (2007). Macroinvertebrate community sampling protocol for depressional wetland monitoring sites. Biological Monitoring Program. Standard operating procedures. Minnesota, USA: MPCA.

Mukherjee, D. P. (2011). Stress of urban pollution on largest natural wetland ecosystem in East Kolkata-causes, consequences and improvement. Archives of Applied Science Research, 3(6), 443-461.

Muller-Dombois, D. y Ellenberg, H. (1974). Aims and methods of vegetation ecology. John Willey and Sons. Inc., New York. 
Macchi, Pablo. 2017. Macroinvertebrados acuáticos como indicadores ecológicos de cambios en el uso del suelo en mallines del sudoeste de la Provincia de Río Negro (Dra. María Laura Miserendino - Dra. Nora Gómez)

Muñoz, E. y Garay, A. (1985). Caracterización climática de la Provincia de Río Negro. INTA Estación Experimental. Región Agropecuaria de San Carlos de Bariloche, Argentina.

Murkin, E. J., Murkin, H. R. y Titman, R. D. (1992). Nektonic invertebrate abundance and distribution at the emergent vegetation-open water interface in the Delta Marsh, Manitoba, Canada. Wetlands, 12(1), 45-52.

Muzón, J. (2002). Estado de conocimiento y conservación de insectos acuáticos en la Patagonia extra - andina continental. En: Resúmenes V Congreso Argentino de Entomología, Buenos Aires.

Muzón, J. y Von Ellenrieder, N. (1997). Description of the last larval instar of Sympetrum villosum Ris (Odonata Libellulidae). Neotropica, 43, 43-46.

Muzón, J., Spinelli, G. R., Pessacq, P., Von Ellenrieder, N., Estevez, A. L., Marino, P. I. y Mazzucconi, S. (2005). Insectos acuáticos de la meseta del Somuncurá, Patagonia, Argentina. Inventario preliminar. Revista de la Sociedad Entomológica Argentina, 64(3-4), 47-68.

Muzón, J., Spinelli, G. R., Rossi, G. C., Marino, P. I., Díaz, F. y Melo, M. C. (2010). Nuevas citas de insectos acuáticos para la Meseta de Somuncurá, Patagonia, Argentina. Revista de la Sociedad Entomológica Argentina, 69(1-2), 111-116.

Muzon, J., Pessacq, P. y Lozano, F. (2014). The Odonata (Insecta) of Patagonia: A synopsis of their current status with illustrated keys for their identification. Zootaxa, 3784(4), 346-388.

NRC (National Research Council) (1995) Wetlands: Characteristics and Boundaries. Washington, DC, USA: National Academy Press.

Neiff, J.J., Casco S.L. y Arias J.C. (2004). Glosario de humedales de Iberoamérica. En Neiff J.J. (ed.), Humedales de Iberoamérica. CYTED, Subprograma XVII - Red Iberoamericana de Humedales. Cuba. ISBN: 959-270-036-2. 336-380 pp.

Neiff, J. J., Casco, S. L., Cózar, A., de Neiff, A. P. y Ubeda, B. (2011). Vegetation diversity in a large Neotropical wetland during two different climatic scenarios. Biodiversity and Conservation, 20(9), 2007-2025.

Nicolet, P., Biggs, J., Fox, G., Hodson, M. J., Reynolds, C., Whitfield, M. y Williams, P. (2004). The wetland plant and macroinvertebrate assemblages of temporary ponds in England and Wales. Biological Conservation, 120(2), 261-278. 
Macchi, Pablo. 2017. Macroinvertebrados acuáticos como indicadores ecológicos de cambios en el uso del suelo en mallines del sudoeste de la Provincia de Río Negro (Dra. María Laura Miserendino - Dra. Nora Gómez)

Niemi, G. J. y McDonald, M. E. (2004). Application of ecological indicators. Annual Review of Ecology, Evolution, and Systematics, 89-111.

Nilsson, A. N. (1986). Community structure in the Dytiscidae (Coleoptera) of a northern Swedish seasonal pond. In Annales Zoologici Fennici (pp. 39-47). Finnish Academy of Sciences.

Ocon, C. S. y Rodrigues Capítulo, A. (2012). Assessment of water quality in temperate-plain streams (Argentina, South America) using a multiple approach. Ecología Austral, 22, 81-91.

Oertli, B., Biggs, J., Cereghino, R., Grillas, P., Joly, P. y Lachavanne, J. B. (2005). Conservation and monitoring of pond biodiversity: introduction. Aquatic Conservation: Marine and Freshwater Ecosystems,15 (6), 535-540.

Oertli, B. (2008). The use of dragonflies in the assessment and monitoring of aquatic habitats. In: Córdoba-Aguilar, A. Dragonflies and damselflies: Model organisms for ecological and evolutionary research (pp.79-95) Oxford University Press.

Oliva A., Fernández, L.A., Bachmann, A.O. (2002). Sinopsis de los Hydrophiloidea acuáticos de la Argentina (Insecta, Coleoptera). Monografías de Museo Argentino de Ciencias Naturales 2: 1-67.

Ortega, M., Velasco, J., Millán, A. y Guerrero, C. (2004). An ecological integrity index for littoral wetlands in agricultural catchments of semiarid Mediterranean regions. Environmental Management,33(3), 412-430.

Osborne, L. R. (2012). Phosphorus Immobilization of Lead in Wetland Soils of the Coeur D'Alene River Basin, Idaho.

Paggi, A. C. y Rodrigues Capítulo, A. (2003). Chironomid composition from drift and bottom samples in a regulated north-Patagonian river (Rio Limay, Argentina). Internationale Vereinigung fur Theoretische und Angewandte Limnologie Verhandlungen, 28(3), 12291235.

Paniagua, C. D., Zamudio, R. F., Florencio, M., Murillo, P. G., Rodríguez, C. G., Portheault, A. y Siljestrom, P. (2010). Temporay ponds from Doñana National Park: a system of natural habitats for the preservation of aquatic flora and fauna. Limnetica,29(1), 41-58.

Paruelo, J. M., Jobbágy, E. G. y Sala, O. E. (1998a). Biozones of patagonia (Argentina). Ecología Austral, 8(2), 145-153. 
Paruelo, J. M., Beltran, A., Jobbagy, E., Sala, O. E. y Golluscio, R. A. (1998b). The climate of Patagonia: general patterns and controls on biotic. Ecol Austral,8, 85-101.

Paruelo, J. M., Golluscio, R. A., Jobbágy, E. G., Canevari, M. y Aguiar, M. R. (2005). Situación ambiental en la estepa patagónica. La situación ambiental argentina, 302-320.

Paton, P. W. y Crouch, W. B. (2002). Using the Phenology of Pond-Breeding Amphibians to Develop Conservation Strategies. Conservation Biology,16(1), 194-204.

Pellerin, B. A., Wollheim, W. M., Hopkinson, C. S., McDowell, W. H., Williams, M. R., Vorosmarty, C. J. y Daley, M. L. (2004). Role of wetlands and developed land use on dissolved organic nitrogen concentrations and DON/TDN in northeastern US rivers and streams. Limnology and Oceanography, 49(4), 910-918.

Peña, O. R. y de Ferreras, A. M. C. (2012). Estado de degradación en mallines localizados en el Centro Oeste de la Provincia de Neuquén (Argentina). Revista Geográfica de América Central, 2(49), 157-173.

Pereyra, F. X. (2007). Geomorfología urbana de San Carlos de Bariloche y su influencia en los peligros naturales, Río Negro. Revista de la Asociación Geológica Argentina, 62(2), 309-320.

Perkin, E. K., Hölker, F., Richardson, J. S., Sadler, J. P., Wolter, C. y Tockner, K. (2011). The influence of artificial light on stream and riparian ecosystems: questions, challenges, and perspectives. Ecosphere, 2(11), 1-16.

Perotti, M.G., Diéguez M.C., Jara F. y Pérez P. (2004). Consideraciones sobre el efecto de las variables del clima y las interacciones biológicas sobre las comunidades acuáticas de humedales patagónicos. Taller los mallines en la Patagonia. Esquel: INTA.

Perotti, M. G., Diéguez, M. C. y Jara, F. G. (2005). Estado del conocimiento de humedales del norte patagónico (Argentina): aspectos relevantes e importancia para la conservación de la biodiversidad regional. Revista chilena de historia natural, 78(4), 723-737.

Persson, J., Somes, N. L. G. y Wong, T. H. F. (1999). Hydraulics efficiency of constructed wetlands and ponds. Water science and technology, 40(3), 291-300.

Pessacq, P. (2009). Estado de conocimiento del orden Ephemeroptera en la Patagonia. Rev. Soc. Entomol. Argent, 68(1-2), 155-161.

Pessacq, P., Epele, L. B. y Rogers, D. C. (2011). A new species of Lynceus (Crustacea: Branchiopoda: Laevicaudata) from Patagonia, with comments on laevicaudatan systematics. Zootaxa, 3043, 25-32. 
Picazo, F., Bilton, D. T., Moreno, J. L., Sánchez-Fernández, D. y Millan, A. (2012). Water beetle biodiversity in Mediterranean standing waters: assemblage composition, environmental drivers and nestedness patterns. Insect Conservation and Diversity, 5(2), 146-158.

Pinto-Coelho, R., Pinel-Alloul, B., Méthot, G. y Havens, K. E. (2005). Crustacean zooplankton in lakes and reservoirs of temperate and tropical regions: variation with trophic status. Canadian Journal of Fisheries and Aquatic Sciences, 62(2), 348-361.

Poi de Neiff, A. S. y Casco, S. L. (2003). Biological agents that accelerate winter decay of Eichhornia crassipes Mart. Solms. in northeastern Argentina.Ecología e manejo de macrófitas aquáticas. Maringá. Brasil, 127-144.

Poi de Neiff, A., Neiff, J. J. y Casco, S. L. (2006). Leaf litter decomposition in three wetland types of the Paraná River floodplain. Wetlands, 26(2), 558-566.

Polla, G. y Horne, F. (1999). Dinámica del agua en mallines de Patagonia. Análisis de la dinámica freática a partir de un balance hídrico. Revista extraordinaria de resúmenes. Chillán. Agrociencia III Congreso Chileno de Ingeniería Agrícola. I Congreso Americano de Educación en Ingenieria Agricola.

Poulton, B. C., Graham, J. L., Rasmussen, T. J. y Stone, M. L. (2015). Responses of Macroinvertebrate Community Metrics to a Wastewater Discharge in the Upper Blue River of Kansas and Missouri, USA.Journal of Water Resource and Protection, 7(15), 1195.

Prat, N., Ríos, B., Acosta, R. y Rieradevall, M. (2009). Los macroinvertebrados como indicadores de calidad de las aguas. Macroinvertebrados bentónicos sudamericanos. Sistemática y biología, 631-654.

Quintana, X. D., Cañedo-Argüelles, M., Nebra, A., Gascón, S., Rieradevall, M., Caiola, N. y Boix, D. (2015). New tools to analyse the ecological status of Mediterranean wetlands and shallow lakes. InExperiences from Surface Water Quality Monitoring(pp. 171-199). Springer International Publishing.

Rabassa, J. y Brandani, A. (1983). Guía de excursiones Curso de Campo en sistemas ecogeomorfológicos. Universidad Nacional del Comahue. Informe de tirada limitada, 132 $\mathrm{pp}$

Raffaele, E. (1999). Mallines: aspectos generales y problemas particulares. Topicos sobre humedales subtropicales y templados de Sudamerica. Oficina Regional de Ciencia y Tecnologia de la UNESCO para America Latina y el Caribe. ORCYT, Montevideo, Uruguay, 27-33. 
Ramírez, C., San Martín, C., San Martín, J., Armestó, J. J., Villagrán, C. y Kalin Arroyo, M. (1996). Estructura florística de los bosques pantanosos de Chile sur-central. En: J.J. Armesto, C. Villagrán y M.K. Arroyo (eds.) Ecología de los bosques nativos de Chile, Editorial Universitaria. Santiago, Chile.

Ravera, O. (2001). Monitoring of the aquatic environment by species accumulator of pollutants: a review. Journal of Limnology, 60(1s), 63-78.

Reckendorfer, W., Keckeis, H., Winkler, G. y Schiemer, F. (1996). Water level fluctuations as a major determinant of chironomid community structure in the inshore zone of a large temperate river. Archiv für Hydrobiologie Supplementband, 115, 3-9.

Reddy, K. R., y De Laune, R. D. (2008).Biogeochemistry of wetlands: science and applications. CRC press. New York. 806 pp.

Resh, V. H., Norris, R. H. y Barbour, M. T. (1995). Design and implementation of rapid assessment approaches for water resource monitoring using benthic macroinvertebrates. Australian Journal of Ecology, 20(1), 108-121.

Resh, V. H. (2008). Which group is best? Attributes of different biological assemblages used in freshwater biomonitoring programs. Environmental Monitoring and Assessment, 138 (1-3), 131-138.

Rivera-Usme, J. J., Pinilla, G. A., Rangel-Churio, J. O., Castro, M. I. y Camacho-Pinzón, D. L. (2015). Biomass of macroinvertebrates and physicochemical characteristics of water in an Andean urban wetland of Colombia. Brazilian Journal of Biology, 75(1), 180-190.

Robson, B. J. y Clay, C. J. (2005). Local and regional macroinvertebrate diversity in the wetlands of a cleared agricultural landscape in south-western Victoria, Australia. Aquatic Conservation: Marine and Freshwater Ecosystems, 15(4), 403-414.

Rodrígues-Capítulo, A. (1992). Los Odonata de la República Argentina (Insecta). Fauna de agua dulce de la República Argentina 34(1): 1-91.

Rodrigues-Capítulo, A., Muñoz, I. Bonada, N., Gaudes, A. y Tomanova, S. (2009). La biota de los ríos: los invertebrados. In: Elosegui, A. y Sabater, S. (Eds.). Conceptos y técnicas en ecología. Fundación BB VA.Bilbao.

Roig, F. A. (1998). La Vegetación de la Patagonia, en M. N. Correa (ed.), Flora Patagónica, INTA. 8 (1): 48-166. 
Macchi, Pablo. 2017. Macroinvertebrados acuáticos como indicadores ecológicos de cambios en el uso del suelo en mallines del sudoeste de la Provincia de Río Negro (Dra. María Laura Miserendino - Dra. Nora Gómez)

Rolon, A. S., Homem, H. F. y Maltchik, L. (2010). Aquatic macrophytes in natural and managed wetlands of Rio Grande do Sul State, Southern Brazil. Acta Limnologica Brasiliensia, 22(2), 133-146.

Rosenfeld, J. S. (2002). Functional redundancy in ecology and conservation. Oikos, 98(1), 156162.

Ruhí, A., Herrmann, J., Gascón, S., Sala, J., Geijer, J. y Boix, D. (2011). Change in biological traits and community structure of macroinvertebrates through primary succession in a manmade Swedish wetland.

Ruhí, A., Fairchild, G. W., Spieles, D. J., Becerra-Jurado, G. y Moreno-Mateos, D. (2016). Invertebrates in Created and Restored Wetlands. InInvertebrates in Freshwater Wetlands (pp. 525-564). Springer International Publishing.

Rybczyk, J. M., Day, J. W. y Conner, W. H. (2002). The impact of wastewater effluent on accretion and decomposition in a subsiding forested wetland.Wetlands, 22(1), 18-32.

Sahlén, G. y Ekestubbe, K. (2001). Identification of dragonflies (Odonata) as indicators of general species richness in boreal forest lakes. Biodiversity \& Conservation, 10(5), 673-690.

Sahuquillo, M., Miracle, M. R., Morata, S. M. y Vicente, E. (2012). Nutrient dynamics in water and sediment of Mediterranean ponds across a wide hydroperiod gradient. LimnologicaEcology and Management of Inland Waters, 42(4), 282-290.

Sakamoto, M. (1966). Primary production by phytoplankton community in some Japanese lakes and its dependence on lake depth. Arch. Hydrobiol.,62, 1-28.

San Martín, C. y Alvarez, M. (2009). Floristic composition of anthropogenic seasonal wetlands in the coastal mountain range of Cautin, Chile. Agro sur, 37(1), 9-25.

Sánchez-Carrillo, S., Angeler, D. G., Álvarez-Cobelas, M. y Sánchez-Andrés, R. (2010). Freshwater wetland eutrophication. In: Ansari, A. A., Gill, S. S., Lanza, G. R. y Rast, W. (Eds.). Eutrophication: causes, consequences and control (pp. 195-210). Springer Netherlands.

Santos, C. D., Miranda, A. C., Granadeiro, J. P., Lourenço, P. M., Saraiva, S. y Palmeirim, J. M. (2010). Effects of artificial illumination on the nocturnal foraging of waders. Acta Oecologica, 36(2), 166-172.

Saunders, D. L., Meeuwig, J. J. y Vincent, A. C. J. (2002). Freshwater protected areas: strategies for conservation. Conservation Biology, 16(1), 30-41. 
Sayer, C. D., Davidson, T. A. y Jones, J. I. (2010). Seasonal dynamics of macrophytes and phytoplankton in shallow lakes: a eutrophication-driven pathway from plants to plankton?. Freshwater Biology, 55(3), 500-513.

Scheibler, E. E. y Ciocco, N. F. (2011). Distribution of macroinvertebrate assemblages along a saline wetland in harsh environmental conditions from Central-West Argentina. Limnologica-Ecology and Management of Inland Waters, 41(1), 37-47.

Schindler, D. W., Hecky, R. E., Findlay, D. L., Stainton, M. P., Parker, B. R., Paterson, M. J. y Kasian, S. E. M. (2008). Eutrophication of lakes cannot be controlled by reducing nitrogen input: results of a 37-year whole-ecosystem experiment. Proceedings of the National Academy of Sciences, 105(32), 11254-11258.

Schneider, D. W. y Frost, T. M. (1996). Habitat duration and community structure in temporary ponds. Journal of the North American Benthological Society, 64-86.

Schneider, S. C., Lawniczak, A. E., Picińska-Faltynowicz, J. Y Szoszkiewicz, K. (2012). Do macrophytes, diatoms and non-diatom benthic algae give redundant information? Results from a case study in Poland.Limnologica-Ecology and Management of Inland Waters, 42(3), 204-211.

Scrimgeour, G. J. y Kendall, S. (2002). Consequences of livestock grazing on water quality and benthic algal biomass in a Canadian natural grassland plateau. Environmental Management, 29(6), 824-844.

Sculthorpe, C. D. (1967). The Biology of Aquatic Vascular Plants. 610 S. London: Edward Arnold Ltd.

Segnini, S. (2003). El uso de los macroinvertebrados bentónicos como indicadores de la condición ecológica de los cuerpos de agua corriente. Ecotropicos, 16(2), 45-63.

Semeniuk, C. A. y Semeniuk, V. (1995). A geomorphic approach to global classification for inland wetlands. Vegetatio, 118(1-2), 103-124.

Sharitz, R. R. y Batzer, D. P. (1999). An introduction to freshwater wetlands in North America and their invertebrates. Invertebrates in freshwater wetlands of North America: ecology and management, DP Batzer, RB Rader y SA Wissinger (eds.). Willey, New York, 1-21.

Sharitz, R. R. y Pennings, S. C. (2006). Development of wetland plant communities. Ecology of Freshwater and Estuarine Wetlands, 177-241. 
Sharma, R. C. y Rawat, J. S. (2009). Monitoring of aquatic macroinvertebrates as bioindicator for assessing the health of wetlands: A case study in the Central Himalayas, India. Ecological Indicators, 9(1), 118-128.

Sigee, D. C. (2005). Freshwater Microbiology: Biodiversity and Dynamic Interactions of Microorganisms in the Aquatic Environment. John Wiley \& Sons, Ltd.

Silla, A. J. (2005). Effect of Cattle Grazing on Benthic Macroinvertebrate Communities in the Kalgan River System, south-west Western Australia. BSc Honours Thesis, University of Western Australia.

Silver, C. A. y Vamosi, S. M. (2012). Macroinvertebrate community composition of temporary prairie wetlands: a preliminary test of the effect of rotational grazing. Wetlands, 32(1), 185-197.

Silver, C. A., Vamosi, S. M. y Bayley, S. E. (2012). Temporary and permanent wetland macroinvertebrate communities: Phylogenetic structure through time. Acta oecologica, 39, $1-10$.

Sim, L. L., Davis, J. A., Strehlow, K., McGuire, M., Trayler, K. M., Wild, S. y O'Connor, J. (2013). The influence of changing hydroregime on the invertebrate communities of temporary seasonal wetlands. Freshwater Science, 32(1), 327-342.

Smith, G. R., Vaala, D. A. y Dingfelder, H. A. (2003). Distribution and abundance of macroinvertebrates within two temporary ponds. Hydrobiologia, 497(1-3), 161-167.

Smith, L. M. (2012). Drivers of Wetland Zooplankton Community Structure in a Rangeland Landscape of the Southern Interior of British Columbia (Doctoral dissertation, Thompson Rivers University).

Smith, V. H., Joye, S. B. y Howarth, R. W. (2006). Eutrophication of freshwater and marine ecosystems. Limnology and Oceanography, 51(1part2), 351-355.

Søndergaard, M., Kristensen P. y Jeppesen, J. (1992). Phosphorus release from resuspended sediment in the shallow and wind exposed Lake Arres $\varnothing$, Denmark. Hydrobiologia 228: 9199.

Sokal, R.R. y Rohlf F.J. (1995). Biometry. 3rd edition. W.H. Freeman and Company: New York.

Spencer, M., Blaustein, L., Schwartz, S. S. y Cohen, J. E. (1999). Species richness and the proportion of predatory animal species in temporary freshwater pools: relationships with habitat size and permanence. Ecology Letters (United Kingdom). 
Spieles, D. J. y Mitsch, W. J. (2000). Macroinvertebrate community structure in high-and lownutrient constructed wetlands. Wetlands, 20(4), 716-729.

Stagliano, D. M., Benke, A. C. y Anderson, D. H. (1998). Emergence of aquatic insects from 2 habitats in a small wetland of the southeastern USA: temporal patterns of numbers and biomass. Journal of the North American Benthological Society, 37-53.

Steinman, A. D. y Rosen, B. H. (2000). Lotic-lentic linkages associated with Lake Okeechobee, Florida. Journal of the North American Benthological Society, 19(4), 733-741.

Steinman, A. D., Conklin, J., Bohlen, P. J. y Uzarski, D. G. (2003). Influence of cattle grazing and pasture land use on macroinvertebrate communities in freshwater wetlands. Wetlands, 23(4), 877-889.

Stevenson, R. J., Bothwell, M. L., Lowe, R. L. y Thorp, J. H. (1996). Algal ecology: Freshwater benthic ecosystem. Academic press.

Stewart, T. W. y Downing, J. A. (2008). Macroinvertebrate communities and environmental conditions in recently constructed wetlands. Wetlands, 28(1), 141-150.

Stoddard, J. L., Herlihy, A. T., Peck, D. V., Hughes, R. M., Whittier, T. R. y Tarquinio, E. (2008). A process for creating multimetric indices for large-scale aquatic surveys. Journal of the North American Benthological Society, 27(4), 878-891.

Stuijfzand, S. C., Poort, L., Greve, G. D., van der Geest, H. G. y Kraak, M. H. (2000). Variables determining the impact of diazinon on aquatic insects: taxon, developmental stage, and exposure time. Environmental toxicology and chemistry, 19(3), 582-587.

Summerville, K. S. y Crist, T. O. (2004). Contrasting effects of habitat quantity and quality on moth communities in fragmented landscapes. Ecography, 27(1), 3-12.

Sundaravadivel, M. y Vigneswaran, S. (2001). Constructed wetlands for wastewater treatment. Critical Reviews in Environmental Science and Technology, 31(4), 351-409.

Suren, A. y Sorrell, B. (2010). Aquatic invertebrate communities of lowland wetlands in New Zealand: characterising spatial, temporal and geographic distribution patterns. Science for Conservation, (305).

Tall, L., Méthot, G., Armellin, A. y Pinel-Alloul, B. (2008). Bioassessment of benthic macroinvertebrates in wetland habitats of Lake Saint-Pierre (St. Lawrence River). Journal of Great Lakes Research, 34(4), 599-614. 
Tangen, B. A., Butler, M. G. y Ell, M. J. (2003). Weak correspondence between macroinvertebrate assemblages and land use in prairie pothole region wetlands, USA. Wetlands, 23(1), 104-115.

Tarr, T. L., Baber, M. J. y Babbitt, K. J. (2005). Macroinvertebrate community structure across a wetland hydroperiod gradient in southern New Hampshire, USA. Wetlands Ecology and Management, 13(3), 321-334.

ter Braak, C.J.F. (1986). Canonical correspondence analysis: a new eigenvector technique for multivariate direct gradient analysis. Ecology 67: 1167-1179.

ter Braak, C. J. F. y Smilauer, P. (1998). CANOCO Reference manual and User's guide to Canoco for Windows: software for Canonical Community Ordination (version 4). - Microcomputer power, Ithaca, NY.

ter Braak, C. J. F., y Smilauer, P. (1999). CANOCO for Windows (version 4.02) a FORTRAN program for canonical community ordination. Centre for biometry, Wageningen, The Netherlands.

Tibúrcio, V. G., Arrieira, R. L., Schwind, L. T. F., Bonecker, C. C. y Lansac-Tôha, F. A. (2015). Effects of nutrients increase on the copepod community of a reservoir using cages. Acta Limnologica Brasiliensia, 27(3), 265-274.

Trochine, C., Balseiro, E. G. y Modenutti, B. E. (2008). Zooplankton of fishless ponds of northern Patagonia: insights into predation effects of Mesostoma ehrenbergii. International Review of Hydrobiology, 93(3), 312-327.

Trochine, C., Modenutti, B. E. y Balseiro, E. G. (2009). Chemical signals and habitat selection by three zooplankters in Andean Patagonian ponds. Freshwater Biology, 54(3), 480-494.

U.S. EPA (2002) Methods for Evaluating Wetland Condition: Developing an Invertebrate Index of Biological Integrity for Wetlands. Office of Water, U.S. Environmental Protection Agency, Washington, DC. EPA-822-R-02-019.

Urban, M. C. (2004). Disturbance heterogeneity determines freshwater metacommunity structure.Ecology, 85(11), 2971-2978.

Urrutia, J., Rivera R., Hauenstein, E. y De los Ríos, P. (2014) Modelos nulos para explicar asociaciones de macrófitas en ambientes lénticos de la región de La Araucanía, Chile. Revista Internacional de Botánica Experimental 81: 7-13 
Macchi, Pablo. 2017. Macroinvertebrados acuáticos como indicadores ecológicos de cambios en el uso del suelo en mallines del sudoeste de la Provincia de Río Negro (Dra. María Laura Miserendino - Dra. Nora Gómez)

Usseglio-Polatera, P. (1994). Theoretical habitat templets, species traits, and species richness: aquatic insects in the Upper Rhône River and its floodplain. Freshwater Biology, 31(3), 417437.

Utrilla, V., Ferrante, D., Peri, P.L. Kofalt, J.C. y Humano, G. (2008). Plan de Investigación (INTAUNPA): Efecto de la dinámica hídrica edáfica y ambiental sobre la productividad y calidad forrajera de mallines en la Patagonia Austral. Informe Técnico Final. E.E.A. INTA Santa Cruz

Utrilla, V. R., Andrade, M., Billoni, S., Peri, P. L. y Rogel, V. (2013). Monitoreo de indicadores de degradación en Mallines del sur de Santa Cruz.EEA, INTA Santa Cruz, Informe Técnico.

van der Valk, A. (2012). The biology of freshwater wetlands. Oxford University Press.

van Egeren, S. J., Dodson, S. I., Torke, B. y Maxted, J. T. (2011). The relative significance of environmental and anthropogenic factors affecting zooplankton community structure in Southeast Wisconsin Till Plain lakes. Hydrobiologia, 668(1), 137-146.

Vanschoenwinkel, B., Buschke, F. y Brendonck, L. (2013). Disturbance regime alters the impact of dispersal on alpha and beta diversity in a natural metacommunity. Ecology, 94(11), 2547-2557.

Verhoeven, J. T., Arheimer, B., Yin, C. y Hefting, M. M. (2006). Regional and global concerns over wetlands and water quality. Trends in ecology \& evolution,21(2), 96-103.

Vidovic, M. M., Rodic, M. N., Vidovic, M. U., Trajkovic, I. S. y Jovanic, S. Z. (2015). Assessment of the Trophic Status by Monitoring of Reservoir's Water Quality. Journal of Water Resource and Protection, 7(1), 1.

Villagrán-Mella, R., Aguayo, M., Parra, L. E. y González, A. (2006). Relación entre características del hábitat y estructura del ensamble de insectos en humedales palustres urbanos del centro-sur de Chile. Revista chilena de historia natural, 79(2), 195-211.

Vollenweider, R. A. (1968). The scientific basis of lake and stream eutrophication, with particular reference to phosphorus and nitrogen as eutrophication factors. Organisation for Economic Cooperation and Development, Paris, 159.

Walker, B. H. (1992). Biodiversity and ecological redundancy. Conservation biology, 6 (1), 1823.

Waterkeyn, A., Grillas, P., De Roeck, E. R., Boven, L. y Brendonck, L. (2009). Assemblage structure and dynamics of large branchiopods in Mediterranean temporary wetlands: patterns and processes. Freshwater Biology, 54(6), 1256-1270. 
Macchi, Pablo. 2017. Macroinvertebrados acuáticos como indicadores ecológicos de cambios en el uso del suelo en mallines del sudoeste de la Provincia de Río Negro (Dra. María Laura Miserendino - Dra. Nora Gómez)

Welborn, G. A., Skelly, D. K. y Werner, E. E. (1996). Mechanisms creating community structure across a freshwater habitat gradient. Annual review of ecology and systematics, 337-363.

Wetzel, R. G. y Likens, G. E. (1991). Limnological Analyses. Springer New York

Whittier, T. R., Hughes, R. M., Stoddard, J. L., Lomnicky, G. A., Peck, D. V. y Herlihy, A. T. (2007). A structured approach for developing indices of biotic integrity: three examples from streams and rivers in the western USA. Transactions of the American Fisheries Society, 136(3), 718-735.

Wiederholm, T. (1989). Chironomidae of the Holarctic region. Keys and diagnoses. Part 3. Adult males. Entomologica Scandinavica, Supplement (34).

Wiggins, G. B., Mackay, R. J. y Smith, I. M. (1980). Evolutionary and ecological strategies of animals in annual temporary pools. Archiv für Hydrobiologie supplement, 58(97), 206.

Wilcox, D. A., Meeker, J. E., Hudson, P. L., Armitage, B. J., Black, M. G. Uzarski, D. G. (2002). Hydrologic variability and the application of index of biotic integrity metrics to wetlands: a Great Lakes evaluation. Wetlands, 22 (3), 588-615.

Williams, D. D. (1996). Environmental constraints in temporary fresh waters and their consequences for the insect fauna. Journal of the North American Benthological Society, 634-650.

Williams, D. D. (2006). The biology of temporary waters. Oxford University Press.

Williams, P., Whitfield, M., Biggs, J., Bray, S., Fox, G., Nicolet, P. y Sear, D. (2004). Comparative biodiversity of rivers, streams, ditches and ponds in an agricultural landscape in Southern England. Biological conservation, 115(2), 329-341.

Wissinger, S. A. (1999). Ecology of wetland invertebrates: synthesis and applications for conservation and management. Invertebrates in freshwater wetlands of North America: ecology and management, 1043-1086.

Wissinger, S. A., Oertli, B. y Rosset, V. (2016). Invertebrate Communities of Alpine Ponds. In Invertebrates in Freshwater Wetlands (pp. 55-103). Springer International Publishing.

Wright, A. B. y Smock, L. A. (2001). Macroinvertebrate community structure and production in a low-gradient stream in an undisturbed watershed. Archiv für Hydrobiologie, 152(2), 297313.

Wright, A. L., Reddy, K. R. y Corstanje, R. (2009). Patterns of heterotrophic microbial activity in eutrophic and oligotrophic peatlands. european journal of soil biology, 45(2), 131-137. 
Macchi, Pablo. 2017. Macroinvertebrados acuáticos como indicadores ecológicos de cambios en el uso del suelo en mallines del sudoeste de la Provincia de Río Negro (Dra. María Laura Miserendino - Dra. Nora Gómez)

Wrubleski, D. A. y Ross, L. C. (2011). Aquatic invertebrates of prairie wetlands: community composition, ecological roles, and impacts of agriculture. Arthropods of Canadian Grasslands: Inhabitants of a Changing Landscape. (Ed. KD Floate) 91-116.

Wygodzinsky, P. W. y Coscarón, S. (1989). Revision of the black fly genus Gigantodax (Diptera, Simuliidae). Bulletin of the American Museum of Natural History (USA).

Yimer, H. D. y Mengistou, S. (2010). Water quality parameters and macroinvertebrates index of biotic integrity of the Jimma wetlands, Southwestern Ethiopia. Journal of Wetlands Ecology, 3, 79-99.

Zedler, J. B. y Kercher, S. (2005). Wetland resources: status, trends, ecosystem services, and restorability. Annu. Rev. Environ. Resour.30, 39-74.

Zelnik, I., Potisek, M. y Gaberscik, A. (2012). Environmental conditions and macrophytes of karst ponds. Polish Journal of Environmental Studies, 21(6), 1911-1920.

Zilli, F. L., Montalto, L. y Marchese, M. R. (2008). Benthic invertebrate assemblages and functional feeding groups in the Paraná River floodplain (Argentina). Limnologica-Ecology and Management of Inland Waters, 38(2), 159-171.

Zilli, F. L. y Marchese, M. R. (2011). Patterns in macroinvertebrate assemblages at different spatial scales. Implications of hydrological connectivity in a large floodplain river. Hydrobiologia, 663(1), 245-257.

Zimmer, K. D., Hanson, M. A. y Wrubleski, D. A. (2016). Invertebrates in Permanent Wetlands (Long-Hydroperiod Marshes and Shallow Lakes). In Invertebrates in Freshwater Wetlands (pp. 251-286). Springer International Publishing.

Zimmer, K. D., Hanson, M. A., Butler, M. G. y Duffy, W. G. (2001). Size distribution of aquatic invertebrates in two prairie wetlands, with and without fish, with implications for community production. Freshwater Biology, 46(10), 1373-1386.

Zuloaga, F. O., Morrone, O. y Belgrano, M. (2008). Catálogo de las plantas vasculares del Cono Sur. Vol. 1, Pteridophyta, Gymnospermae y Monocotyledonae. Monogr. Syst. Bot. Missouri Bot. Gard, 107. 